\title{
Rob "Fresh I.E." Wilson: A Socio-analysis of Musical Self-Transformation
}

\author{
by
}

Aaron J. Klassen

A thesis submitted to the Faculty of Graduate and Postdoctoral Affairs in partial fulfillment of the requirements for the degree of

Doctor of Philosophy

in

Sociology

Carleton University

Ottawa, Ontario

(C) 2018

Aaron J. Klassen 


\begin{abstract}
Music is a self-transformative process, practice and ethic. The co-mediation of music and the self represents an assemblage of distinct yet simultaneously occurring parts where contradictions can exist alongside their more pragmatic uses. In this dissertation, I note such an assemblage in the case of Rob "Fresh I.E." Wilson. Rob's case provides a striking example of musical self-transformation in that his biography follows a trajectory from abusive conditions in Winnipeg's infamous North End during the 1970s, and a life centered around drugs and pimping in the 1990s, to its lyrical renunciation according to his newfound beliefs as he converted his hip-hop to Christianity and joined the ranks of Grammy nominees in 2003 and 2005. Yet music was not all good for Rob. Despite fame and influence, by the end of the decade, he was overwhelmed by the demands of a grueling tour schedule and the pressure to remain relevant. His rising self-doubt pushed him to suicidal ideation. And yet, despite successfully restructuring his musical practice, now independent of the music industry, Rob's Christian-themed hip-hop still situates him between the rock of the institutional church and the hard place of having to constantly build a following. The constantly evolving nature of the contemporary Christian music industry and hip-hop's unique conditions in Canada, combined with the church's refusal to accept hip-hop as a legitimate mode of worship and Rob's refusal to leave, creates a distinct set of challenges.
\end{abstract}

In this dissertation, I use ethnographic research methods to explore the ways in which Rob negotiates such challenges. I employ biographical methods to trace his present practice to the conditions of his formative and educational years. Not to take my case at his word only, I use historical methods to trace the trans-national links between 
Rob and hip-hop as it has become institutionalized, and before that, to its roots in African American religious musical practices since modern slavery. Finally, I use critical social theory to assess the significance of Rob's musical self-practice to himself and his scene, within the whole of the cultural realm. 


\section{Acknowledgements}

It gives me great pleasure to thank a number of folks, here, that I consider to be instrumental — indeed, irreplaceable — to my producing this dissertation. There was a certain harmony that I enjoyed while working under the tutelage of the following committee members at Carleton: Primarily, Bruce Curtis, I appreciated so much, your professional, consistent, extensive, and precise attention to my sociological practice throughout my time in Ottawa, as in the doctoral seminar and a reading group or two, and while I was in the field. Thank you for your mentorship, truly - you were the steady rhythm that kept me going. John Shepherd, you introduced me to ways of thinking about music that I never imagined were possible; and then you showed me how importantsignificant, really — music is to our selves by refusing to allow me to separate the two. Thank you for making music more musical for me - you were the timbre. And, as though you meant to honour music itself (but not "it" self), Jesse Stewart, you challenged me to write to a richer, more nuanced standard. Sincerely, thanks for calling when I needed a boost - you were the ghost note and the equalizer.

Filling out this performance, I also wish to thank my examiners, Paul Théberge and Will Straw, for your most excellent comments and questions, and your time. Also, thanks to the grad administrators at Carleton, Paula Whissel and Darlene Moss. Special thanks to the best cohort I could have asked for-we miss you Blake. And finally, I wish to thank my wife, Amy, for your support that was, and remains, infinitely beyond quantifiable - truly yours, my dear. 


\section{Table of Contents}

Abstract $\quad$ ii

Acknowledgements $\quad$ iv

Table of Contents $\quad$ V

Appendices $\quad$ vii

\section{Chapters:}

1.

Introducing the case of Rob "Fresh I.E." Wilson and the problem of musical selftransformation

Introduction

Background of the problem: A biographical and ethnographic revelation

The aim and significance of this dissertation with key terms

Summary and chapter outline

2.

Music and the Ethics of Self-Transformation: Conceptualizing the Musical Self

The problem of "music" and the "self"

Toward an ethic of musical self-transformation

Methodological considerations

3.

Historicizing the Musical Self and the Ethic of Musical Self-Transformation: An historical sketch of African American religious musical practice, from the underground of modern slavery to its standardized representation in the contemporary Christian music industry

Introduction

1750-1865: Modern slavery, the body, spirituality and the Afrological musical self

1865-1900: Minstrelsy, Emancipation, Jubilee Spirituals and the rise of the American culture industry

The rise of American popular culture and the institutionalization of the "Gospel Blues" from 1900 to the Great Depression, with a "musical self" comparison of Arizona Dranes and Thomas Andrew Dorsey 
Gospel's Post-Depression "Golden Age," "Sister" Rosetta Tharpe, and the complexity of "crossing over"

From Civil Rights to Post-industrialization: The emergence of Soul as commodified struggle and the struggle for musical hegemony

The organization of Contemporary Christian Music, Contemporary-urban Black Gospel, and the case of Kirk Franklin

Conclusion

4.

Hip-hop, Religion, and the Contemporary Christian Music Industry: The mediating roots of Christian-themed hip-hop

Introduction

A Social history of the Bronx and the conditions giving rise to Hip-hop

Hip-hop and spirituality: The cultural improvisation of Afrika Bambaataa

The competition for and classification of hip-hop sound: From DJ Herc's sonic

improvisation to the commodification of the "authentic street"

The tenuous, institutional mediation of Hip-hop and Christianity

A literature review of hip-hop and spirituality: A bridge to the biographical and ethnographic study of holy hip-hop artists

Conclusion

5.

\section{Rob "Fresh I.E." Wilson: A socio-analysis of musical self-transformation}

Introduction

Colonial history and trauma trails in the racially segregated space of Winnipeg's North End: Conditioning Rob Wilson (1972-87)

Winnipeg's Hip-hop house party scene: Educating "Freshie" (1988-97)

Musical self-transformation Part I: Re-Moralizing "Fresh I.E." (1998-2009)

Musical self-transformation Part II: A change in scene (2010 - present)

Appendix: Contradictions of collective interest in musical self-transformation)

Conclusion: The precariousness of musical self-transformation

6.

\section{Conclusion: De-marginalizing the Musical Self}

Dissertation findings

Recommendations for future research

Why the musical self matters: Personal opinion, accepted limitations, and an answer

Bibliography 


\section{Appendices}

Contradictions of collective interest in musical self-transformation

Interview Guide 


\section{Chapter One}

\section{Introducing the case of Rob "Fresh I.E." Wilson and the problem of musical self- transformation}

It is for freedom that Christ has set us free. Stand firm, then, and do not let yourselves be burdened again by a yoke of slavery. (Galatians 5:1)

\section{1 - Introduction}

In this dissertation I seek to understand and explain musical self-transformation specific to the case of Rob "Fresh I.E." Wilson. As opposed to a strict topic, my research question is drawn from what the cultural studies methodologist Ann Gray calls, "lived problems" (2003: 60-5). My interest in musically lived problems stem, in part from my own musical practice, including several years spent performing as a semi-professional musician during my twenties and the struggles that I encountered having to do with my own life trajectory and various institutional structures. I am interested in live public music making, recording-studio based production, and the politics of such performances, altogether linking the musical self to historical practices and processes while also making up transformative change. Arguably, musical practices are formative, operating as processes through which the modern self is subjectivated, mediated by context, albeit in ways which afford self-transformation vis-à-vis its basis as a "technology of articulation." As this entails a combination of self-problematization and strategy, self-transformation is at the same time a modern ethos. The combination of my experiences as a musician and now my interests as a musical sociologist leads me to consider the embodiment of musical self-transformation as represented in a specific musician's story. Rob “Fresh I.E." Wilson's life experiences and on-going practice provides access to the ways in which the sounds of "music" mediate his self and ethic of self-transformation. Though 
varying in significance, the consistent presence of music throughout life, ties that life through immediate experiences to historical processes and institutions, necessitating my conceptual development of the "musical self." The musical self allows for a richer understanding and explanation of music not only as contributing to self-transformation, but indeed, as self-transformation. Here, Wilson's musical self-practice provides insight into how music contributes to self-transformation as self-transformation.

\section{2 - Background of the problem: A biographical and ethnographic revelation}

Rob "Fresh I.E." Wilson ${ }^{1}$ was raised during the early 1970s in Winnipeg's first public housing projects in the infamous North End. It was here that he experienced racism, domestic violence, drug and sexual abuse early on. During his itinerant young adult years, he became entangled with criminal behavior involving drug and alcohol abuse, gang violence, and pimping. A near fatal car crash in 1997 led to charges that were stayed on condition that he "invests in his music." The following year, Rob returned to Winnipeg's poverty stricken inner city where he began working at a Christian outreach called the Children's Mission. Then, incidentally, after happening across a blind man in the street, Rob converted to Christianity, his epiphany being that he himself was wandering through life without a vision. At this time, he also met his wife, journalist and present Grand Chief MKO (Manitoba Keewatinowi Okimakinak), Sheila North. With her investment, Rob recorded his first tape of Christian-themed hip-hop in 1999. Counter to mainstream gangsta rap at the time, Rob's lyrics were critical of gang violence, drug and alcohol abuse, and misogyny. His musical self-practice was broadly transformed when his next two self-produced albums, Red Letterz (2003) and Truth is Fallin' in Than

\footnotetext{
${ }^{1}$ I will be using Wilson's names interchangeably as they relate to the various periods of his musical career, including his production and performance as an artist. For example, before becoming a Christian he went
} 
Streetz (2005) were nominated for Grammy awards. Following his nominations, The National Academy of Recording Arts and Sciences (NARAS; today, The Recording Academy) amended the category for which Rob was nominated ("Best Rock Gospel Album") to include, "Best Rock or Rap Gospel Album." By the mid-2000s, Rob's musical practice appeared to be unencumbered, affecting real change through the sounds of his beats and his "message of hope." Such change extended throughout his various audiences, including minority youth participants in his music-discipleship program, EDIFY, and those making up his invited tours to First Nations and Inuit communities affected by mental illness, manifest in drug and alcohol abuse, and suicide. Rob was one of the few confronting, with music no less, the traumatic effects of Canada's postcolonial history, effects which Senator Murray Sinclair (former Justice, and chair of the Truth and Reconciliation Commission), has called a "crisis of youth" (CBC 2015).

However, sketching a case of musical self-transformation demands reflexivity in its theorization and method of research. About ten months into field research with Rob, the collection of my thoughts around music and self-transformation was suddenly challenged; unprovoked, Rob confessed that he had contemplated suicide, just five years earlier, in 2010. Such contemplation led to him literally taking steps toward its attempt along the banks of the Red River near the historic Forks - La Forche - in his hometown of Winnipeg. What struck me about his statement was not so much the act of suicide, although I consider life precious, but what it meant for this dissertation. Rob's contemplation of suicide revealed both a limitation in the way in which I had been conceiving of music and self-transformation, and contradictions in Rob's musical practice that now necessitated attention. 
A commonly held perspective in the field of music sociology—one which I initially shared — is that which views music as a freely wielded resource and, by extension, a boundlessly positive or good force (Prior 2011; Hesmondhalgh 2008). For instance, Tia De Nora understands music as a "technology of the self," or, as she states, "a cultural resource that actors may mobilize for their on-going work of self-construction and the emotional, memory and biographical work such a project entails" (1999: 32). As a resource, such an unencumbered prosthesis offers certain "affordances" in the way of aesthetic ordering, controlling emotions and affecting moods as a management device irreducible to non-musical elements. De Nora draws on Gibson's notion (1966) in her understanding of how music works: "objects 'afford' actors certain things; a ball, for example, affords rolling, bouncing and kicking in a way that a cube of the same size, texture and weight would not" (2000: 39). The major advantage to her approach is that in focusing on the "musical event" (2003: 49) in which "music" takes on significance for the individual, she is able to bypass the question of music's meaningfulness, the “immanence-arbitrary” debate (Shepherd and Devine 2015: 10), without sacrificing music's significance to both the individual and the context in which its significance circulates. As opposed to investing "meaning" in either the "immanence" of a song's composition, on the one hand, or the arbitrary discourse around its experience, on the other hand, De Nora notes the ways in which music "mediates" the self. However, in considering musical consumption practices among adults, her approach tends to underestimate music's complexity in both consumption and music making, including its potential to reproduce social inequalities even when used to overcome them. 
Arguably, music ought to be reconsidered as self-transformation, taking into account both biographical and institutional aspects heretofore underestimated in music scholarship. This demands, first, consideration of the way in which music mediates the self, that being in its appeal through the body and emotions as a medium in sound. Shepherd and Wicke call this the level of music's primary signification in that its sounds do not signify denotatively as in language, but neither are they free of affect. As such, there is a direct correlation between sound and its perception in the body, which only takes on meaning as "music" at its fleeting moment. The authors call this the "semiological moment" in which its sounds become inextricably one with the self(1997: 153-68). As it enters the world of signification, "music" thus entails a secondary mode of signification. The semiological moment alone provides the "technology of articulation" for which we can conceive of the self's musical mediation and by extension, musical affordances. It is the concrete aspect of the self as musical that makes Wilson's contemplation of suicide so significant; somehow, contradictions in his musical selfpractice became so overwhelming as to lead him to look for an escape through selfdestruction. However, equally important to remember, De Nora's musical "affordances," though guiding, shaping, and facilitating, are not determining (Shepherd 2016: 6). Rob's contemplation of suicide is also wrapped up in its symbolism. Nonetheless, music has power in the sense that it is intimately wrapped up with the self: "It can speak directly, concretely and with precision to the states of awareness which constitute our subjectivity, our very being" (Shepherd and Wicke 1997: 215-16). For this reason, it becomes necessary to consider the conditions of Rob's musical self, both biographically, in order to trace the ways in which he came to perceive music as something worth appreciating, 
part of the schema of dispositions which Bourdieu calls the habitus (1993: 64), and institutionally, in this case the space of possibles making up his field of practice, Christian-themed hip-hop, in order to reveal the sources of the contradictions contributing to his self-transformative ethic. Both biography and institutional analysis demand historical consideration.

Music in Wilson's case was not so freely wielded nor is he singularly a consumer, as De Nora's approach would suggest. Rather, it became apparent through his confession of suicidal thoughts that, despite the apparently positive effects of his musically related accomplishments, Rob's musical-self is a complex process and practice wrapped up both in his biographical past and the nature of the professional field in which he performs. The hip-hop and religious studies scholar, Monica Miller, defines "complex subjectivity" as "the externalizations of practices [that] offer a window beyond subjective quests for meaning, to consider complex dimensions of social reproduction, inherited externalized dispositions, and lived reality" (2013: 116-17). Miller's concept raises critical questions: What were the conditions of Rob's musical self-formation and how can we tie that complex subjectivity to his transformations? While music can be a cultural resource within the micro-sociological realm of everyday life and in relation to the symbolism and relations making up one's biography—Rob's being the object of this dissertation—-there are aspects of music's modern subjectivity that demand a broader analytical scope. Such scope needs to allow us to account for musical self-transformation as it is "mediated" by wider processes. The cultural anthropologist and sociologist of music Georgina Born conceives of musical practice along the topologically themed analytic, "four planes of musical sociality" (2012: 202-11). Such planes include not only the realm of its 
immediate experience, the "musical event" described above, but also, the musical mediation of specific communities or "scenes" with which the self forms "affective alliances" (Straw 1991), providing a basis for "techniques of imagination" through which one can claim membership (Born 2000: 37). Such techniques relate to aspects of selfidentification with race, class, and gender, and significantly for our explanation of Rob's case, of the institutions making up the culture industry. Rob's case, moreover, demands consideration of his musical mediation by way of the institutional church and the ethical system that makes up his religious beliefs as they merge with his musical self-practice in specific ways that alternately work to constrain or encourage self-transformation. This matter of "the musical self," not a relation between two separate entities but as a matter of self-transformative ethics linking that selfsame self to the conditions of possibility obtaining in the wider social realm, is taken up in chapter two.

Specifically, the notion that music is freely wielded, thus boundlessly positive (good) in active self-identity construction, evinces a perspective of the self that is too narrow in scope, focused as it is on the immediate experience of consumptive habits. Yet while more critical approaches do in fact consider wider influences related to music's historical trajectories and modes of production having to do with institutional structures (Lott 1993; Born and Hesmondhalgh 2000; Born 1995; 2012: 202-11), the constitution of music's practice as a matter inextricable from the self and biography is often underestimated. Music sociology and the broader social sciences stand to benefit from the additional consideration of the ways in which music's immediate experience also serves to subjectivate social inequalities while also reproducing such inequalities through their embedding in the self. By "subjectivate," I mean the ways in which the self 
experiences subjectivity, internalizing the social conditions of its mediation and according to available means of interpretation or knowledge. Foucault's analytical philosophy of "self-care" practice, including the genealogy of its development since antiquity, frames our concern with subjectivation as a means of self-discipline, and with the potential for reproducing social inequality $(1985: 27 ; 1986: 37-68 ; 1988: 16-49)$. By extension, musical self-practice is conditioned by social inequality, including its emotional corollaries. At the same time, musical self-practice is a matter of problematizing and, in turn, responding to such experiences, informing an ethic that in Rob "Fresh I.E." Wilson's case is wrapped up with historically rooted themes of selftransformation and the history of hip-hop. As such, Rob "objectivates" his musical selfpractice, translating its experience into a workable symbolic form or resource, the meaning of which is not self-evident but relates to the "space of possibles" and positions making up a field (Bourdieu 2004: 94-114). ${ }^{2}$ Arguably, as a strategy of response to the complex subjectivity of biography and the present challenges of everyday life, including his participation in making music, Rob used hip-hop to transform his conditions. In considering Rob's musical self-practice, the research in this dissertation aims to fill the gaps in music sociology around biography and the reproduction of social inequalities as they stem from musical-institutional organization.

\section{3 - The aim and significance of this dissertation, with key terms}

To answer the question of musical self-transformation in Rob's case, it is necessary to consider the history of African-American religious musical practice and the emergence of Christian hip-hop, in addition to his biography and the lived problems of his present musical self-practice, including at home, in the studio, and on tour, and with his

\footnotetext{
${ }^{2}$ I discuss Bourdieu's concepts further below and in chapter two.
} 
collaborators, peers, and audiences. As such, qualitative research methods are employed here. In chapter three, historical analysis allow for insight into the ways in which musical self-practice was affected by the massive social inequality imposed on AfricanAmericans by their European and colonial captors during modern slavery, and how such practices became institutionalized through "singing schools" with the conversion of American slaves and the establishment of the African-American church, its mainline and Pentecostal branches. Such methods allow us to understand and explain the structuring structures of the institutional black and white churches as they affected various forms of religious musical practices, such as Black Gospel, up to the emergence of Christianthemed hip-hop in the 1990s. Not to limit our consideration to genre, comparative biographical analysis reveals the ways in which historical processes subjectivate individual figures such as Thomas A. Dorsey, "Sister" Rosetta Tharpe, and Kirk Franklin, who at the same time use their musical self-practices to challenge existing musical categories and boundaries through self-work.

In terms of Rob's musical self-practice, historical and biographical methods allow us to trace the conditions of possibility offered to him across his life cycle, from his formative to educational, to professional years in Winnipeg, Canada. Interviews, for instance, provide insight into Rob's personal experience of self-transformation, pointing to significant or formative "musical events" such as favourite songs or dances and the specificities of their experience for Rob. In addition, focus-group interviews, for instance with his peers, help to reveal variations in the themes and struggles around Rob's biography, suggesting reasons why his musical self-practice emerged to take on the specificities that it did. Interviews with peers and former collaborators also provide 
insight into the conditions around Rob's sudden transformation, for instance around his Grammy nominations and how such changes worked to affect his musical practice, whether disciplining his musical practice into "Christian hip-hop" or alternately, liberating him from his past self. By tracing significant experiences in his past, biographical methods suggest explanations for his present strategies as he encounters challenges in everyday life, for instance having to do with self-doubt. Methods of ethnography or field research allow us to trace the sources of such challenges not only in Winnipeg but also to the various places in which he performs. Here, multiple poles of tension, for instance, between the changing culture industries, a general reluctance of the church to accept Christian hip-hop, and Rob's career interests, are characterized by precariousness. Such precarity both conditions his own self-transformation and that of his audience, promoting an ethic of self-transformation. The purpose of this dissertation is to trace the specificities of Rob's musical self-practice, including the ways in which it is mediated by and mediates transformative change. Arguably, as the theory of musical self-transformation is intimately wrapped up with its method of analysis, the research design is discussed in latter half of chapter two.

The significance of this study is in understanding and explaining musical selftransformation, how it conditions the musical self and how that self affects change. In the post-colonial context of Canada's Residential Schools, Rob's musical practice—and, reflexively, my own as collaborator-holds enormous potential for reconciliation, and for stemming the aforementioned, "crisis of youth," affecting peoples indigenous to Canada. Transformative musical self-practice holds the potential for rectifying generations of colonially-related abuse and otherwise, and as an aspect of the self that is often 
underestimated compared to more common—and commonly patronizing —redress practices that reduce reconciliation to fiscal terms alone; however, musical self-practices must be checked by history and ethics. Over the course of researching this dissertation, for instance, the Truth and Reconciliation Commission (TRC) summary findings were released (June 2015), revealing the disastrous consequences of the Residential Schools in which Indigenous and Inuit children were forcibly removed from their families in order to "take the Indian out of the child." The collective result of such experiences, arguably, constitute what the cultural sociologists, Jeffery Alexander and Ron Eyerman have called, "cultural trauma": "Cultural trauma occurs when members of a collectivity feel they have been subjected to a horrendous event that leaves indelible marks upon their group consciousness, making their memories forever and changing their future identity in fundamental and irrevocable ways" (Alexander 2004: 1). The TRC summary findings would suggest that, despite exceptions, the Residential Schools affected such trauma. ${ }^{3}$ For our purposes, Eyerman (2002; with McCormick 2006: 6-7) argues that cultural trauma is refracted in and through music, affecting collective cognitive alignment, and by extension, the recruitment of participants into social movements (Eyerman and Jamison 1998). ${ }^{4}$ Rob's heritage and upbringing in Winnipeg's North End uniquely positions him as a mediator to the city's population of roughly 65,000 Aboriginal people in addition to the province's total population of 195,900 (NHS 2011). In addition to the sounds of his musical practice, Rob's self-transformation makes up a compelling narrative that he

\footnotetext{
${ }^{3}$ Relatedly, local Manitoba-based scholars are beginning to attribute "social problems," such as the organization of "Native gangs" in the 1990s, to the "trauma trails of colonialism" (Cormack et al. 2013). The authors expand on Alexander and Eyerman's concept with their empirical study, for instance, attributing the emergence of gangs to the effect of forced resettlement following major Provincial government-led hydro projects in the 1950s and 1960s.

${ }^{4}$ Eyerman insists that the blues affected such alignment that then fed into the Civil Rights movement.
} 
presents as the focal point of his performances. However, while his story is "hopeful" and he is indeed invited to share his "testimony" as part of his performances across North America, most troublingly, Rob's tours are limited in affecting real lasting or material change. This dissertation offers insight into this contradiction between Rob's ethic of self-transformation and his partial success in achieving it through his musical practice, allowing us to trace and name its sources and pose explanations and possible solutions toward reconciliation.

The primary research question guiding this dissertation asks, how does music contribute to self-transformation? However, as will become clear in the second chapter, music is arguably wrapped up with the self through the mediation of its sounds with the emotions and other aspects of the embodied self. The mutual accommodation of the sounds of music with the self across the life cycle precludes their separation as variables. Thus, the "musical self" presents a more accurate notion of how music "contributes" to self-transformation because it reminds that we are musical beings, mediated by sound in context and sonically mediating the contexts in which we find ourselves. As such, the "assemblage" of mediations making up Rob's musical self is traced here through biographical, ethnographic, and historical methods. Significant mediations ethnographically traced here include the local urban Winnipeg Christian hip-hop "scene" in which he produces and performs his music and runs his youth music mentorship program, EDIFY, and the First Nations reserves that he tours. Semi-structured interviews and participant-observations have been recorded and categorized according to theme. Biographical mediations are traced to collaborators and peers who at one time or another obtained influence in his musical practice. For instance, semi-structured phone 
interviews with peers from Rob's first major transformation reveal a profile of the local Winnipeg Christian music scene in the early 2000s. And historical mediations are traced to the general organization of the culture industry of contemporary Christian music and the history of African-American religious musical practices. Such methods reveal common themes in circulation leading up to the time of Rob's formative and educational musical experiences.

The overall theoretical framework upon which this dissertation is based is interdisciplinary, analytical, and critical. That framework draws on the strengths of the music and cultural theory of Shepherd and Wicke, the music sociology of De Nora and cultural anthropology of Born, along with the analytic philosophy of Foucault's late career, Miller's religious studies perspective, and Bourdieu's critical social theory. Such theorists' work is assessed and synthesized in chapter two, and the latter half of chapter four. For instance, one way of accounting for the musical mediation of the self across the life cycle is to consider that self as conditioned by the possibilities that make up the distinct spatio-temporal realms of the formative, educational, and professional years. In his "sketch of self-analysis," Pierre Bourdieu conceives of each these realms as a "space of possibles" (1993: 64) at once generated in the relationship between the dispositions making up a "habitus" and the positions making up a field, while at the same time generating that selfsame habitus-field relationship (2004: 94-114; 2008). The advantage to his theory is in collapsing subject-object relations otherwise difficult to reconcile in recent music sociology, for instance, between musical aesthetics and objects, thus allowing us to explain the "schemes of perception and appreciation which constitute a habitus." As Bourdieu continues, "These schemes, which reproduce in their own logic the 
fundamental divisions of the field of positions - 'pure art'/'commercial art'... are one of the mediations through which dispositions are adjusted to positions" (1993: 64). In turn, Bourdieu's concepts allow us to sketch the ways in which sound is perceived and appreciated specific to a field of agents, in this case, specific to Rob's formative, educational, and professional years. Bourdieu calls this process of categorizing or objectifying one's subjective experiences for one's purposes, albeit as a strategy in relation to a field, "objectivation" (2004: 94-114). Critically, it is in this relation to his fields of practice that Rob's musical self can be seen to take on a strategic character, as opposed to existing as a rule, sui generis.

While Bourdieu's approach helpfully allows for a critical assessment of musical self-practice in relation to a field, it falters in terms of explaining how agents perform work on the boundaries of that field and various overlapping fields at that. Here, various complementary theories are used. For instance, Lamont and Molnár's "boundary work" allows us to theorize the ways in which their conception affects Rob's musical practice, namely as more than just inclusionary and exclusionary (2002). Rather, there is a dialectical relation between their symbolic, thus cognitive functioning and empirical grounding. For instance, in his discussion of "authenticity work," Peterson (2006) traces the ways in which popular musicians, critics and fans claim authenticity to a specific form or genre, effectively objectifying both the music as works and its performers as geniuses. In this dissertation, the ways in which Rob conducts boundary work relates to genre, race, gender, spirituality, and ethnicity.

Foucault's late career concern with self-transformation also complements Bourdieu's social theory in that it allows us to understand and explain musical practice as 
a technique of self-care or "technology of the self." As discussed above, and further in chapter two, to avoid De Nora's formulation of music as boundlessly positive and freely wielded, Foucault's technologies are considered as exercised in concert with each other, not as singular domains. Such framing allows us to envisage musical self-practice as characterized by struggle due to relations of power and dominance. Expanding on Born's concepts of "planes of musical sociality" and "musical mediation" (2012: 202-11), it then becomes possible to trace the empirical grounding of such struggle in the relations between Rob's self and his selfsame biography, his formative musical experiences, his "techniques of the musical imaginary" (Born 2000: 37-47) that allow him to claim membership with various musical genres and sociological communities, his interrelations with the culture industry and the Christian church. Changes in such musical planes, for instance as they mediate Rob's case outside his control, help to explain his selftransformation as not just freely self-determined but as characterizing existential and market-based precariousness that affects his "complex subjectivity," thus imbuing his musical practice with emotional stakes in addition to economic stakes. Music and the emotions are both aspects generally underestimated in Bourdieu and Foucault's research agendas. Finally, interjecting musical self-transformation into Foucault's concern with the "ethics of self-care as a practice of freedom" (1991: 1-20) suggests that musical selfpractice is an ethical practice of problematization and response with consequences for the contemporary self and others (Koopman 2013: 182-216). However, keeping with Bourdieu's habitus-field relation, the ethic of self-transformation is not freely enacted but is itself a modern ethical practice in that it is conditioned by precariousness while at the same time holding symbolic currency that is exchanged in the realm of practice with the 
potential for conditioning further change. In other words, Rob's musical self is transformed by virtue of the fact of its mediation with various planes of sociality, while also transforming those mediations through his own ethic of self-transformation. Rob's musical self-practice as mediated by biographically rooted experiences and everyday life challenges is diagnosed in chapter five.

This dissertation is neither a comprehensive history of African-American religious musical practices nor a complete assessment of Christian hip-hop. However, Wilson's "acoustemology" or "sonic way of knowing and being in the world" (Feld and Brenneis 2004), links him to such trajectories. For instance, having spent time in the recording studio with Rob over the course of this dissertation research, it was interesting to observe the ways in which he digitally integrated sounds transnationally in to his musical selfpractice, thus linking him to a wider cultural history and present set of industry practices than might otherwise be observed on first impression. Common lyrical themes of "redemption," "transformation," and "purpose" situate him firmly in the contemporary Christian music industry and broader Christian moral system. However, "sacred-secular" boundaries affect an interesting set of challenges and opportunities for Rob. Distinct from "crossover" artists in the past, who risked tainting their "moral career" by deliberately leaving the Christian church of their upbringing to perform in the popular realm, Rob neither was raised in the church nor does he desire to take his musical practice into that secular realm, with exceptions being theme songs written for the Winnipeg Blue Bomber football club and the CFL (Canadian Football League). This relation to the sacred-secular divide is a unique character of Christian-themed or Holy hip-hop (Zanfagna 2015; Gault 2013). Unlike "crossover" artists whose musical self-practice, for 
instance, mediated the Civil Rights movement in the 1960s as "soul," affecting farreaching change in the manner of bringing social justice to the segregated American South, Christian hip-hoppers since the 1990s have sought to marry hip-hop sounds with Christian "redemption" in order to bring hope and change to urban centers hollowed out by the effects of globalization and post-industrialization. In many ways, Rob's independent or "indie" musical self-practice, as a deliberate rejection of the mainstream culture industry, at once is a strategy of connecting his music with those disaffected by such global forces, while also portending a claim of "street cred" or "authenticity" to hiphop culture. Authentic or not, the grounding of Rob's indie practice in Winnipeg is also underscored by his fear of flying, adding another level of complexity to our understanding and explanation of transnational flows of African-American religious musical practice and Christian hip-hop. While the background of such tensions and themes are taken up in chapter three, their institutionalization is discussed in chapter four.

\section{4 - Summary and chapter outline}

Music and self-transformation are introduced in the case of Rob "Fresh I.E." Wilson. Rob is not just a Christian hip-hopper but a musical self whose present practice is influenced by a number of variables including formative and educational sonic experiences rooted in his complex subjectivity and symbolically traded as the narrative making up his biography. The conditions of Rob's formative musical experiences were, distinctly, often conditioned by precariousness. However, many of Rob's formative musical experiences also afforded him with a means of self-ordering or discipline that allowed him to overcome such precariousness and which remain foundational in his present ethic of self-transformation. At the same time, Rob's present musical self- 
practice is influenced by the state of his art including the organization of institutions with which he contends, namely the contemporary Christian music industry and the Protestant church. Changes in the former, and rigidity in the latter, generally speaking, also characterize his musical practice with precariousness, thus contributing to his selftransformation as an ethos.

In the following chapter, "the musical self" is conceived in order to account for the ethic of self-transformation as a culmination of forces stemming from existential and market-based precariousness rooted in the complex subjectivity of one's biography and present conditions of practice. Music, it will be argued, is indelibly one with the self and thus with transformation. More than a simple commodity for consumption, music is a vital aspect of the self as a complex subjectivity and strategy of self-transformation. Through its mediations, the musical self affects transformative change indeed; however, as a bulwark against precariousness, the musical self appears to offer stability in the present and throughout life. Thus, musical self-transformation is finally problematized as an ethic. The intimate relationship between our theorization of the musical self and our method of tracing its various modes of practice for Rob's case, namely biographical, ethnographic and historical, is taken up in the latter third of chapter two.

In chapter three, the roots of Rob's present musical self-practice are traced to the history of African-American religious musical practices. Various modes of such practices and their transformations are traced here, including the introduction of social inequalities having to do with difference such as race, gender, class, and religion. Building on George Lewis' "Afrological perspective" the African American experience is musically mediated by such complex subjectivities, at once allowing for Africanisms to 
be retained in the New World, thus self-sustaining in the face of inequality, while also affording musically self-transformative practices and related strategies such as “improvisation" (1996). The effects of various technological mediations are also traced here, including the introduction of singing schools, songbooks and, later, electronic and digital recording devices, along with institutional structures having to do with the emergence of distinct musical categories. For instance, black universities encouraged Spirituals while the black church allowed for black gospel. The set of relations obtaining between the rise of the black church and its varying theological emphases relative to both mainline Christianity and systemic racism, along with the rise of the popular culture industry, complicates our understanding of traditional dichotomies such as "sacredsecular," "resistance-accommodation" and "liberation-prosperity." Key musical figures in this history and their self-transformational strategies, such as "crossing over" are compared in order to explain the complexities of such dichotomies. Comparatively, with the organization of the Christian music industry as a Christian-themed alternative to the secular counter-culture of the 1960s, contemporary Christian musical careers, including urban contemporary gospel, have become sustainable without "crossing over." However, such careers impose certain limiting factors on the musical self-practices of its artists.

Chapter four consists of an historical sketch of hip-hop and its mediation with the contemporary Christian music industry in the 1990s, forming Christian hip-hop. Postindustrialization in the 1970s led to the hollowing out of the American urban core and fracturing of African-American communities along class lines. Those economically and politically destitute, left behind in the relatively isolated Bronx, for instance, combined with newly immigrated Caribbean peoples in block parties making up the musical self- 
practices and ethics of self-transformation called hip-hop. While early progenitors infused spirituality into their practice, beginning in the mid-1980s, various hip-hoppers introduced Christian themes. However, despite being supported by the contemporary Christian music industry and related yet independent institutional means, the relationship between Christian hip-hoppers and the church is more tenuous. In the latter third of chapter four, this relationship is theorized according to the emergent literature.

Finally, Rob's musical self-practice is assessed in chapter five. The roots of the self-transformative techniques and strategies of his current practice are traced back to his formative years in Winnipeg's North End in which his musical self was co-mediated by his discovery of his favourite songs along with the trauma of various personal experiences of racism, difference, and physical and sexual abuse. His education into Winnipeg's first hip-hop scene reveals the ways in which he came to appreciate the various schemes of hip-hop, including the symbolism making up male posturing and the politics of dance and strategic collaborations. Rob's sudden self-transformation to Christian-themed hip-hop is problematized through interviews with peers and historical analysis of newspapers in order to provide a picture of the field in the early 2000s. Finally, his gradual self-transformation since contemplating suicide in 2010 is explained by his interest in self-preservation, in turn, influencing his present ethic of selftransformation. Interestingly, while working to transform his self through music making, his ethic has the effect of retaining the traumatic events of his formative years, at once giving a sense of consistency to his self while also making him susceptible to self-doubt. The imposition of the institutional church's reluctance to legitimize hip-hop as a valid form of worship and the changing nature of the music industry serves to exacerbate that 
doubt. Yet his own commitment to the potential of self-transformation for positive change, including according to the example of Jesus Christ, appears to drive him to work with other similarly affected minority youth, both in Winnipeg through his EDIFY mentorship program and on First Nation reserves and Inuit communities.

This dissertation concludes in chapter six. Four dissertation findings are discussed, including first the revelation that music is self-transformation. Second, that music's mediation with the self across the life cycle necessitates the concept "the musical self." Third, that Rob's main musical self-transformative technique involves "reclaiming" his past through its musical mediation with his complex subjectivity, "projecting" that self through the sounds of his present musical practice, and "proclaiming" his transformed self through his present lyrics. Fourth, musical self-transformation is found to be not only a practice, but also a modern ethic based in its mediation with existential and market-based precariousness, and its common use to problematize and respond to such conditions. Recommendations for future research include consideration of other critical musical biographies, other models of musical youth mentorship, and music's function as a matter of "collective interest." Also, Rob's case raises the question of why music and why now, demanding that we expand consideration of the historical emergence of the modern musical self beyond Western culture, and reflexively, to its variant among academics today. Finally, the musical self is discussed as a matter of interpersonal music making, emphasizing the significance of its potential as a collective transformative power. 


\section{Chapter Two}

\section{Music and the Ethics of Self-Transformation: Conceptualizing the Musical Self}

\section{1 - The problem of "music" and the "self"}

How does music contribute to self-transformation? Music is self-transformation. Music is a complex process and an ongoing practice wrapped up in being. Rather, entwined with the self, its formation and transformation across time and space, music is an inextricable aspect of the self. Although certain characteristics of their mutual mediation lend themselves to regularity, unity, and control, neither music nor the self is consistent across time and space. Thus, explaining music's contribution to self-transformation requires an understanding of the way in which it mediates the self. Like a language, music is significant to the listener, performer, and arguably, the unengaged musical self alike. Music presents certain properties that afford the self certain modes of being in the world, affecting mood and entraining certain movements such as those making up dance. However, music is more than an exclusive matter of self-mediation. Musical experiences are often shared, not only presently, but also across time and within groups. Such temporal and collective aspects of musical mediation force us to reconsider hard and fast distinctions between musical production and consumption, for instance, and draw our attention to the wider realms of musical scenes, cultural imaginaries, and their institutional organization. All of these forces factor in to the formation and transformation of the musical self throughout life.

"The musical self" is introduced in this chapter in order to draw attention to music's inextricable mediation within the self, which doubles as a technology of that self's articulation and transformation. In this way, I assess existing musical and critical 
scholarship, that is, assess and propose various arguments in order to fill out a broad and rich scope of music and self-transformation. As music is so intimately tied up with the self, so too, the theory proposed in this dissertation is taken as tied up with the research methods, specifically, biographical, ethnographic and historical. This chapter concludes with such consideration.

In the case of Rob "Fresh I.E." Wilson, there is a dual set of tensions that characterize his musical self-practice. On the one hand, there is a tension between his own self-doubt, which it is found to have roots in his formative years, and with music's potential to mitigate that sense of crisis by providing meaning or significance by way of resolution. On the other hand, his musical self-practice reveals a tension between the precariousness of the field in which he practices - precarious by virtue of the changing nature of the musical selves that make up that field - and the status that his recognition affords him in that field. In such a context of negotiation between the complexity of his formative experiences and the precariousness of the contemporary Christian music industry, Wilson deploys strategies, including musical, that combine to form an ethic of self-transformation. The more apposite question for consideration then becomes: how is the musical self mediated, and relatedly, how might we specify that mediation?

Music defies definition; at least as far as definitions tend to reduce otherwise complex subjective processes to the established conventions of language, thus distancing them, for instance, from processes of co-mediation with the body and the emotions. As the sounds of music are tied up with those aspects of the self having to do with the body and emotions, among complex subjective processes having to do with race, class, gender, and religion, they are inextricable from the self. According to Shepherd and Devine, the 
academic study of music until recently has been characterized by opposing views between, on the one hand, those who attribute its significance to its "immanence" in the specific melodic, harmonic and rhythmic organization of its sounds (particularly in notated form) and, on the other hand, those who deny music the capacity for meaning, except as it is "arbitrarily" assigned by agents in a specific set of social relations in which “music" circulates (2015: 10; see also Shepherd and Wicke 1997: 7). Music scholars typically hold the former view with an interest in the social while the latter is typically held by social scientists with an interest in music. Neither has been able to produce adequate analyses in the minds of the other. Concerning the debate, the authors state:

On the one hand, music scholars make connections between music conventions and social structures/mores in ways that do not stand up to the empirical demands of sociology. Sociologists, on the other hand, describe the processes by which a musical work comes to be and the conditions in which it is used but fail to account for the specificity of the music itself. The challenge, in others words, has been to develop a sociology of music that is also a sociology of music. (Shepherd and Devine 2015: 10; "the challenge..." is paraphrased from Dahlhaus 1983: 139)

From either side of the debate the key problem has been to explain how music articulates social significance without reducing music through that explanation to the condition of an 'empty signifier.' To take this route is to reduce music to the condition of language. Shepherd and Wicke have argued, for instance, that such a condition of "Difference in language is based on a principle of repulsion which results in the order of relations obtaining between elements of signification deploying components of meaning in an exclusive, consistent and, as a consequence, 'immanent' association with sounds recognized as discrete" (1997: 162). Such a condition is distinct from music as a medium in sound, as they continue: "Difference in music is based on a principle of attraction which results in the order of relations obtaining between similar and different elements of 
signification deploying components of meaning throughout concatenations of sounds recognized as discrete in a manner which has the potential to become infinitely complex" (Shepherd and Wicke 1997: 162). As Shepherd has said, "The idea that the characteristics of sound in music play little role in the construction of meaning appears curious to musicians who have experienced reactions both favourable and otherwise to their performances" (2016: 3). The immanence-arbitrariness debate reveals its limitations, then, when we consider the sounds of "music" and the emotions of the embodied self as mediating factors in the construction of music's meaningfulness.

Shepherd and Wicke offer a possible solution to the immanence-arbitrariness debate in their conceptualization of music's semiological moment, the moment when the sounds of music enter and mediate the self in such a way as to be undeniably one aspect of subjectivity (1997: 153-68). Key to their theorization is a distinction between "music" and its sounds as they enter and mediate the body and constitute forms of affective awareness. As Shepherd states:

However, because there is one word, 'music,' there can exist a tendency to conflate the sounds of music with music itself as if they constitute one undifferentiated phenomenon. This tendency implicitly posits music as external to human agency in the creation of musical experience and results in a line of thinking which approaches the issue of musical significance as one requiring an understanding of how music and individual subjects interact. (2016: 9)

Without the distinction between "music" and the mediating role of the sounds of music in constituting the self and others, Rob "Fresh I.E." Wilson's case of self-transformation could only be explained superficially. As we shall see, such superficial explanations are multiple in music sociology, for instance, reducing self-transformation to singular processes such as consumption, or practices of "genius," thus rendering music as functionally teleological. Such an approach fails to explain the ways in which the songs' 
specific characteristics mediated Rob's self, not to mention the context in which those influential songs originated. Relatedly, such an approach precludes accounting for the strategies that Rob employs in production, including from dance to lyrical execution, relative to a specific field of performers, as he perceives them.

According to Shepherd, "music" functions through its semiological moment: the sounds of music penetrate the self, inextricably serving to constitute that self (2016). He uses the term "technology of articulation. . to capture the notion that the sounds of music act as a direct and concrete material lever on the body" (Shepherd 2016: 9; see also, with Wicke 1997: 117-24). As part of their broader project to present a comprehensive theory of music's signification, Shepherd states, "This theorization rests on an understanding of how sounds which are perceived as individual musical events and which underwrite each semiological moment virtually interpenetrate one another to give rise to musical experiences through what we have termed a 'sonic saddle' (159-68) that surrounds, envelopes and enters us" (2016: 9). The specific organization of sounds that make up the "sonic saddle" mediate the self in such a way as to be powerfully and complexly affective, with varying degrees of significance. In being distinct from language, the sounds of music's capacity to be affectively powerful at the level of primary signification can only be read as non-denotative. In contradistinction to the potential of music's sounds to instigate connotative meanings at the level of secondary signification, the capacity of the sounds of music to act non-denotatively at a primary level of signification through music's semiological moment is grounded in a material and concrete technology of articulation that creates at various levels of signification multifarious conditions of possibility displaying considerable imaginative potential. Such potential allows the self 
to be linked to the cultural realm and sociological phenomena, categorized after the fact as class, gender, race and religion through affective affinities (Straw 1991; Born 2012: 202-11) - I will return to this below. As Born and Hesmondhalgh state of "techniques of the musical imaginary," "It is precisely music's extraordinary powers of imaginary evocation of identity and of cross-cultural and intersubjective empathy that render it a primary means of both marking and transforming individual and collective identities." They continue, "Music's hyperconnotative character, its intense cognitive, cultural, and emotional associations, and its abstraction, are perhaps what give it a unique role in the imaginary constitution of cross-cultural and intersubjective desire, of exotic/erotic charge for the other culture or music in social fantasy" (2000: 32). A possible combination of Shepherd and Wicke's characterization of "music" as acting through a material and concrete technology of articulation whereby the self is sonically mediated through a semiological moment distinctive to music with Born and Hesmondhalgh's elaboration of music's hyperconnotative character as it mediates intersubjectively and cross-culturally may serve to solidify a theorization of the intrasubjective materialization of the musical self. Questions may remain regarding the conceptualization of the character and interaction of various levels of "musical" signification with respect to the work of the two pairs of scholars. The resolution of such questions does not however appear to impede the potential for the establishment of a broad theorization of the intrasubjective materialization of the musical self as just indicated. The resolution of such questions is also beyond the scope of this dissertation. This having been said, Born and Hesmondhalgh's sensitivity to music's potential to reproduce cultural inequalities through "techniques of the musical imaginary" fits with the ethnographic revelations of 
this dissertation as described in the introductory chapter: the contradiction of Rob's contemplation of suicide despite his numerous accolades and seemingly unrestrained power to create his music at will. Having argued for music's distinctive capacity to signify through a material and concrete technology of articulation and, through that, to be indelibly involved in the mediation, articulation and constitution of the self, it remains to problematize and further examine the character of that mediation and articulation as it occurs through the body and somatic awareness as well as outside the body as the self interacts with and contributes to the cultural realm. For that, it is necessary to turn to the development of the concept of "mediation" through music.

Antoine Hennion, Tia De Nora and Georgina Born have offered a possible route to the resolution of the immanence-arbitrariness debate with their respective theories of musical "mediation." Hennion, whose work stretches back to the 1980s, insists on tracing music's "mediation" of subject-object relations between music lover and musical sound in the co-production of taste. Tastes are taken as constructed through a range of selfadministered practices and techniques. He states:

Mediations are neither mere carriers of the work nor substitutes that dissolve its reality; they are the art itself, as is particularly obvious in the case of music: when the performer places a score on his music stand, he plays that music, to be sure, but music is just as much the very fact of playing; mediations in music have a pragmatic status - they are the art that they reveal, and cannot be distinguished from the appreciation they generate. Mediations can therefore serve as a base for a positive analysis of tastes, and not for the deconstruction of these tastes. (Hennion 2012: 196)

In his analyses of jazz, rock, and rap, for instance, Hennion notes the role of reproductive technologies in mediating their historical emergence in ways that are distinct from that which produced the canon of classical music. In the case of rap, accessible recording and playback technologies allowed hip-hoppers to deny the stage, so venerated in the classical 
arts, and connect with the "street," including its people and politics, and through dance. However, while his use of "mediation" broadens the scope of music's analysis beyond art's objects and aesthetic experience, valuably adding insight into the technological mediation of self-transformation, Hennion's work underestimates the complex subjectivity of biography, including the ways in which musical self mediation allows for the recreation of social inequalities through their embedding in the self as suggested by music's “technology of articulation." Indeed, in his haste to embrace apparently new tastes as evidence of positive (good) agency, Hennion tends to overlook music's capacity to reproduce social inequality. Thus the character of music's mediation with the self demands further understanding.

Perhaps more than anyone else, Tia De Nora has expanded the sociology of music into the realm of music's mediation with the self through consideration of aspects of the body and emotions and in the context of everyday life (2000). Notably, she explores music not just as an external presence but as a constitutive agent that serves to mediate the self in specific ways. This leads her to insist on ethnographic methods, which adds a valuable empirical dimension to her research. As Shepherd reads her approach, "This marriage of theory and the empirical in De Nora's work precludes the often unspoken assumption that meanings are simply projected onto music by individuals: 'while music's semiotic force can be seen to be constructed in and through listener appropriations, a focus on how people interact with music should also be concerned with... the role music's specific properties may play in this construction process"” (De Nora 2000: 24, in Shepherd 2016: 5-6). The key here is to recognize music's articulation of the self as not just a one time semiological moment but also as that articulation "affords" particular 
emotional states and modes of cognitive ordering, which guide, shape and facilitate action, yet without determining it (De Nora 2003: 45-51). Such an understanding of musical self mediation, as the basis for a "technology of articulation" grounded in the body, arguably, exists as a potential resource for future reference and action. Music, as it comes to be recognized by the individual as a resource for agency thus comes to play a vital role in the construction, maintenance and negotiation of identity, or the presentation of self.

Music affords through its appeal through the body. As Shepherd states, "In theorizing the body, De Nora shifts the focus away from "what the body "is" (and what can be done "to" it), to a focus on what the body may become as it is situated within different contexts and from within different terms of reference"' (De Nora 2000: 75, in Shepherd 2016: 6). Music's mediation of the body helps to overcome the immanencearbitrary debate by suggesting how music "gets into" the body, for instance, giving rise to "entrainment" through musical properties such as rhythm, melody, and harmony. The concept of entrainment is helpful in understanding music's mediation of effects, as in the ordering, regulation and control of the body. Dance exemplifies a more complex mode of entrainment that links music to specific forms of behaviour: "dance and more mundane and subconscious forms of choreography are media for the autodidactic accumulation of self and gender awareness" (De Nora 2000: 78). As discussed in chapter five, the sounds of music contributed to the entrainment of Wilson's musical self early on.

A valuable contribution of De Nora's theory-method is her concept of the “musical event" (2003: 49; see figure 2.1). Like Shepherd and Wicke's "sonic saddle," the semiological moment in which the self comes to intermingle indelibly with the sounds 
of music in order to provide a technology of articulation, De Nora's musical event reveals "how the music is, or comes to be, meaningful to the actors who engage with it, including such matters as whether the relevant actors notice it (as in the case of background music in public places)" (2003: 49). In terms of noticing music, De Nora draws on Stockfelt's modes of listening (1997), in which the actor's engagement with music is differentiated according to context and the presence of others. ${ }^{5}$ The musical event reveals the elements mediating the semiological moment, and the character of that moment as a process, as opposed to a causal relationship. Significantly, her concept allows us to see how the sounds of music mediate the self in a biographical sense. Because an individual who comes to that moment with certain biographical features experiences the sounds of music in a certain context, that event holds the potential to either reproduce or alter that self through its mediation of the emotions and the body, and by extension, the cognitive realm. De Nora's musical event allows us to trace what music comes to afford, if anything, through that event. Importantly, her "musical event" allows us to conceptualize the specific ways in which music contributes to Wilson's transformation, including consideration of the context in which he experiences the sounds of music through his emotions and body, and to some extent, the ways in which those sounds gain significance, as in his biographical narrative. Finally, in linking music's mediation of the self to the cognitive realm, De Nora offers an understanding of the ways in which music affords individuals control over their selves, for instance in relation to their own biography and to aspects of everyday life.

\footnotetext{
${ }^{5}$ This is as opposed to Adorno's singular and non-dynamic conception of the listener. Lacking empirical research, his figure of the listener becomes stripped of agency versus the overbearing dominance of the culture industry and the standardization of cultural (and musical) production (cf. 2001: 29-60). Indeed, De Nora's After Adorno (2003) is both a critique of Adorno's lack of empiricism and a rigorous development of his concern with music's mediation of consciousness.
} 
TIME 1 - Before the Event (all prior history as meaningful to A. Actor(s))

\section{Preconditions}

Conventions, biographical associations, previous programming practices

TIME 2 - During the Event (the event may be of any duration, seconds to years)

2. Features of the Event

A Actor(s) Who is engaging with music? (e.g., analyst, audience, listener, performer, composer, programmer)

B Music What music, and with what significance as imputed by Actor(s)?

C Act of Engagement with music What is being done? (e.g., individual act of listening, responding to music, performing, composing)

D Local conditions of C. (e.g., how actor came to engage with music in this way, at this time (i.e., at Time 2 - During the Event))

E Environment In what setting does engagement with music take place? (material cultural features, interpretive frames provided on site (e.g., programme notes, comments of other listeners))

\section{TIME 3 - After the Event}

3. Outcome Has engagement with music afforded anything? What if anything was changed or achieved or made possible by this engagement? And has this process altered any aspect of item 1 above?

- Fig. 2.1. The "musical event" and its conditions. (De Nora 2003: 49)

While De Nora's sociology of music has offered inroads into the understanding of music's mediation of the self, including affording a resource for self-making, her work has also become the subject of criticism on two counts. First, her perspective supports an overly positive estimation of music's role in active self-making (that it is universally and consistently good) while neglecting its contradictory role in the reproduction, for instance, of social inequalities (Hesmondhalgh 2008; Prior 2011). And second, her analysis is limited to the micro-sociological realm (Shepherd and Devine 2015; Born 2005; 2012). In the former, David Hesmondhalgh points to a problematic conception of the self in De Nora's work that fails to account for the historical rise of active selfmaking as an individualized enterprise unique to late-modernity. Hesmondhalgh traces this historical shift to the late 1960s when, under pressure from social and artistic critiques, capitalist institutions accommodated demands for autonomy in working life, as opposed to providing job security. Drawing on Boltanski and Chiapello, Hesmondhalgh 
states, "The result is a society based on a "connexionist" model where the self is an individual enterprise, and where transitory relationships and commitments are considered more legitimate than stable ones because rapidly changing one's connections can supposedly lead to personal growth and greater self-realization" (2008: 334). While he does not disagree that music can present certain affordances, in the connexionist society, where bonds between people are shorter and more fragile, digitally mediated for instance, emotions are also wielded like weapons in a battle for status. Considering music's comediation with the self, sounds and emotions, active self-making then becomes a dangerous game. For instance, Hesmondhalgh draws, on the one hand, on Axel Honneth, who claims that the appropriation of emotions by powerful institutional interests leads to a rise in levels of depression (clinical and culturally), while on the other, Boltanski and Chiapello "place greater stress on anxiety and anomie [societal dis-integration], citing statistics on the rising numbers of suicides" (2008: 334). Either way, his critique demands that we consider musical affordance not only positively and the musical self as mediating a broader historical and contextual realm than the musical event entails.

Georgina Born's conception of musical mediation elaborates a theoretically sophisticated and methodologically practical means of reconnecting the micro-sociology of music's mediation of the self in everyday life to the macro-sociology of musical scenes and global culture industries, while at the same time providing a—now, necessarycritical perspective. First, she proposes a way through the immanence-arbitrary debate by providing a "composite conception of the cultural object/process, which is at once both a sociological and an aesthetic conception and which engenders combined sociologicalaesthetic critique" (1993: 224). Like Hennion and De Nora, she draws on the critical and 
original theorist of musical mediation, Theodor W. Adorno. However distinctly, Born turns Adorno's critical theory back on the objects that he otherwise underestimates: first, the mediation of autonomous music by its commodification within the culture industry; and second, his self, including both academically and musically. Valuably, Born adds a reflexive dimension to our consideration of musical self-practice. Reflexivity allows her to maintain Adorno's concern with music's mediation of consciousness and institutions, yet without underestimating her own role in interpreting and formulating its critique.

To Born, Adorno views music as both a process and as a work whose modern mediation produces the "torn halves of an integral freedom" (Adorno et al. 2007: 133). ${ }^{6}$ Quoting Jarvis and De Nora, Born states, "In this way Adorno conceived the subjectobject dialectic as a dual movement: in terms of the composer's agency in reworking musical materials (that is, 'everything which confronts [composers], everything about which they have to decide'); and in terms of the 'human made quality of musical discourse and the ways in which musical material [is] pre-formed by history"' (2005:12; her quotes). She continues, "Thus, in his study of Schoenberg, the subject-object dialectic appears in the guise of a compositional process in which classical and prior musical techniques and norms are absorbed and then determinately negated, yielding a 'dialectical... relationship between tradition and the new' through 'relentless subjectification"' (ibid; Born's quotes). However, while Adorno is right to identify a relationship mediating music's experience by the culture industry, in the case of Schoenberg, he fails to subject the composer to the same critical perspective, instead

\footnotetext{
${ }^{6}$ The quote is taken from Adorno's letter to colleague Walter Benjamin, written in March 1936, a short critique of the latter's important "The Work of Art in the Age of Enlightenment" (1968).
} 
insisting on a transcendent negation apparently located in Schoenberg's "genius," genius which transcends its sociological base.

To Born, Adorno's weakness is his ontological inconsistency. Specifically, she states, "Focused on the interaction between the composer's subjectivity and musical text, it provides only a weak theorization of the relations between autonomous music and broader socio-historical processes, in which the social appears primarily in its metabolization in musical form" (Born 2005: 12). Indeed, these relations, far from being "between" music and social processes, are a matter of mediation of "the several dimensions in which music's existence is permeated by commodification - whether musical form, performance mode, filmic exposure, radio play, production or reception" (Born 2005: 13). She continues, "In this way it points to a constellatory conception of music's multiple mediations, understood now in the non-dialectical sense of the assemblage - of music's multiple forms of existence" (ibid). The major advantage to Born's reworking of musical mediation is the multiplicative way in which it exists, including in contradictory ways. Drawing on Deleuze's concept, "assemblage," music's multiple mediations are envisaged as a particular combination, whether in terms of sonic, discursive, visual, artefactual, technological, social, and temporal. Born thus extends musical consideration into the subjective realm of imagination, as in Benedict's "imagined communities" (cf. 2006; See also Born and Hesmondhalgh 2000: 37-47 on "techniques of the musical imaginary"), and into the realm of institutions (cf. Born 1995). Born's mediation theory and concept of assemblage opens up for consideration of music's mediation with the self as an historical construct, an approach taken up here, albeit with some qualifications, in the first half of chapter three. Historically, music 
mediates specific sets of discursive knowledge or representations, particularly as the sounds of music are translated from the realm of primary significance within the self into their secondary significance as "music." To Born, such translation affects music's very ontology in that, for instance, the "musical work" has become wrapped up with the Weberian thesis of rationalization and the autonomization of art. She states, "Among these changes were the rise of the romantic principle that musical invention depended on the self-expression of the individual composer-genius, who must refuse to follow established rules or submit to external controls; and the arrival of a 'work-based practice' centred on the belief that musical works were perfectly formed, finished and untouchable,' and transcended any particular performance" (Born 2005: 8). Thus, Rob "Fresh I.E." Wilson can be seen critically as a case of subjectivation, his subjectivity being mediated not only by the semiological moments of aesthetic experience that provide a technology for their articulation, but the ordering of that experience according to the romantic principle of self-expression. Such a process of articulation worked to bring his musical self practice under the public scope and rhetoric of ethical systems, for instance, having to do with "authenticity." However, in distinguishing between modes of signification (primary and secondary), we can recognize "authenticity" as a social construct, a system that reflects back on Rob, influencing his musical self-practice in certain ways. I will discuss the cultural influences of such representations on self-

\footnotetext{
${ }^{7}$ I discuss "authenticity" further in chapters three and four, particularly as it coincides with hip-hop's emergence in the "streets" of the Bronx. Peterson (2006) identifies six distinct types of authenticity, including "authenticity to genre" and "authenticity to self," the latter of which I have in mind here. Charles Taylor defines such authenticity as a specifically modern ethic and a moral ideal with corresponding practices called "self-determining freedom" (1991: 26-7). This ethic emerged as a Romanticist response to earlier forms of individualism such as Descartes' disengaged rationality and an atomism that rejected ties of community. I discuss "authentic" hip-hop in chapter four.
} 
transformative practices below while elaborating on the broader historical roots of such practices in chapters three and four.

Finally, Born's analytic finds its fullest conception in her topologically themed, "four planes of musical mediation" (2011; and 2012: 202-11). Here she builds on Will Straw's influential theory of musical "scenes" and the constitutive formation of "affective alliances" therein (1991). "Scenes" demarcate an important development in the sociology of music as it expands, for instance, on De Nora's "musical event," to include the comediation of multiple identities by sound and emotions in a specific scene. Compared to the cultural theory of youth "subculture," for instance, scenes denotes a less homogenous and static, more fluid assemblage of cultural mediations. In such a conception, scenes are free to emerge with locally specific characteristics, revealing "music's" variable significance to a group of individuals, whose membership in the scene is free to wax and wane according to any number of variables. Born lends nuance to Straw's scenes by reading into them four planes of musical mediation (2012: 202-11). She distinguishes the immediate experience of performance practice, including the "micro" realm of the dance floor as the first plane of co-mediation. Secondly, the public realm invoked by "affective alliances" mutually mediates that experience. It is in such intimate experiences that music catalyzes imagined communities and vice versa, that "imagined communities imbue the socialities of performance with collective emotion" (2012: 203). Third, musical scenes link selves to wider identity formations marking social differences such as those having to do with class, gender, race, and religion. Finally, Born links musical scenes to the wider macro-sociological realm of institutions which variously influence the ways in which music is produced and consumed by scenes and which are also influenced 
by emerging aspects of scenes. Altogether, her four planes of musical sociality draw attention to the mediations of the musical subject-object and how changes in the assemblage of those mediations might contribute to self-transformation. However, despite offering significant advantages to our explanation and criticism of music's mediation of the self, Born's analytic tends to underestimate the ways in which music varies in significance to the individual across the life cycle, namely, in terms of biography and an ethics of self-transformation.

To this point, I have discussed recent theorizations of music's significance as they open up possibilities for understanding and explaining the musical selftransformation of Rob "Fresh I.E." Wilson. I began with Shepherd and Wicke's conception of music's semiological moment as that in which the sounds of music and the self become inextricably one at the level of primary signification. The semiological moment allows us to recognize that musical self-transformation is not reducible to a causal relationship between separate variables, "music" - now understood as a system of secondary signification - and the self. Rather, following Hennion and De Nora, music and the self are mediated in a multiply variable practice, in terms of sound's appeal through the body, its giving rise to the channeling of emotions, formation of attachments, and entrainment of the body, including movements amounting to dance. This mediatory understanding necessitates a move from separate modes of theory and method, to their collapse into a theory-method. With ethnography, a valuable method of analyzing everyday life, mediation scholars allow us to expand on Shepherd and Wicke's work to consider the material environment as they also mediate the semiological moment vis-àvis the musical event, scene, and to a degree, planes of sociality. However, De Nora's 
theory-method of musical practice as affording a "technology of the self" is problematic for understanding and explaining Rob's case, mainly as it provides a limited explanatory function related to his personal transformation and production practice as a professional hip-hop artist. Born's work draws our attention beyond the immediate context of the musical event, providing a valuably critical perspective of musical production practice. Rather, the materiality of musical mediation provides a basis for techniques of imagination, including self-identification with scenes, collectivities, along with their respective histories. Born's use of the term assemblage also allows for the recognition and criticism of present contradictions, contradictions that have to do with the particular organization of institutions as structuring forces that enable music's production and consumption. Altogether, the theories presented so far inform a valuable framework that allow us to conceive of the ways in which music mediates the self vis-à-vis the conditions of its experience. However, despite De Nora's suggestion that musical practice affords a "technology of the self," she remains uncritical of its conditioning. Moreover, despite Born's consideration of music's mediation of institutions and imaginative techniques of the self, she does not explore the changing nature of those mediations across the life cycle or biography of that self, namely, the way in which the self variously practices its mediation as consumer and producer. Such conditions demand the elaboration of a new concept called "the musical self," that accounts for the self"s co-mediation not only with music but also the self's reflexive practice across its own biography, making up an ethic of self-transformation. In the next section, the strengths of musical mediation theories are linked to Michel Foucault's late-career analytics of self-transformation, Monica Miller's development of "complex subjectivity," and Pierre Bourdieu's critical social theory. 


\section{2 - Toward an ethic of musical self-transformation}

Working with the theories discussed above building on Born's topologically themed model, musical mediation within the self occurs across four planes that are irreducible to each other $(2011 ; 2012: 202-11)$. In the semiological moment of music's immediate experience, sounds appeal through the body and emotions in such a way that they become inextricably one, significantly providing a material base for their articulation. As that formative experience is also mediated with contextual aspects, it makes up a musical event or scene in which affective alliances are made replete with exclusive boundaries that work to demarcate membership. As an imaginative technique, musical mediation creates the basis that allows one to articulate their identification with certain aspects associated with scenes and their members, for instance, aspects having to do with social categories such as class, race, gender, and religion. At the same time, music's experience vis-à-vis its institutional production and (sometimes) transnational distribution mediates the other planes to form a specific condition or as we shall see, structuring structure. With these four planes in mind, it can be surmised then, that self-transformation occurs with the spatial and temporal differentiation of musical mediation across and between each plane. ${ }^{8}$ However, additional factors remain to be problematized, including the biographical distinction of the formative, educational, and professional years and how experiences during these periods condition current modes of musical self-practice. Moreover, self-transformation is a concept that not only helps to explain the experiences and strategies behind musical self-practice, but as a symbolically traded concept, "self-

\footnotetext{
${ }^{8}$ The most comprehensive example where Born explores the spatial and temporal differentiation of her four planes is her critical analysis of IRCAM, Boulez, and the institutionalization of the musical avant-garde (1995). However, her analysis is not exclusively focused on self-transformation, particularly as she does not take Boulez as her object; rather, she considers him to be just one aspect of the aesthetic discourse involved in the wider negotiation of contradictions making up IRCAM and the musical avant-garde.
} 
transformation" is itself variable in conditioning its self-practice; at any given time, it holds culturally specific meaning, for instance as innovative, creative, and progressive, and is therefore tied to the circulation of power. As such, self-transformation is arguably not just a set of techniques making up a practice, but also an ethic that has the effect of ordering such transformative techniques.

As mentioned at the beginning of this chapter, Wilson's musical self-practice is affected by a dual set of tensions that contribute to his ethic of self-transformation. These tensions are rooted in his formative years in which he experienced self-doubt and his current practice in which that doubt is triggered by his sense of being challenged to maintain relevance by a constantly changing hip-hop market, and the Christian church's qualified acceptance of that form of worship (e.g. Christian themed). It remains for us to problematize, then, the roots of the ethic of self-transformation in the changing notion and practice of the self, and the particular form of its present practice.

According to José Silva, self-transformation is understood metaphorically and can be distinguished according to type (2010: 28-32). Self-transformation can happen through a change of emotions, of perception, and of function, for instance, as it is observed through behavior and bodily skills. It can also happen as a result of an expansion of consciousness, where one feels in touch with a larger consciousness or spiritual reality. Transformation can be sudden, as in the experience of a peak state or mystical experience, or the gradual result of a steady spiritual practice. Drawing on Metzer (1998), Silva lists twelve universal principles that are found across East-West mythical and spiritual systems of transformation and Western psychotherapeutic techniques. These principles are described in the following metaphors: awakening from 
the dream of reality, uncovering veils of illusion, movement from captivity to liberation, purification by inner fire, movement from fragmentation to wholeness, reconciling with an inner enemy, on dying and being reborn, movement from darkness to light, journey to a place of vision and power, and returning to the source (Silva 2010: 21-30). The metaphor of self-transformation that most relates to Wilson's case is the sudden experience of dying and being reborn, which addresses a complete transformation of the psyche where one experiences the death of identity and the emergence of a new sense of self. This metaphor is exemplified by Christ's resurrection. The multiple types of transformation are distinguished according to the kinds of change they are associated with. For instance, whereas transcendence involves rising above, to transform is to perform inner alchemy. And where translation is viewed as a superficial lateral shift, transformation is a radical vertical transcending of self. While transformation can be seen as relatively irreversible (Braud in Silva 2010: 32), often cited as demarcating a liminal shift (Szakolczai 2000), Silva insists on "transformative change," as it encompasses an ongoing process as opposed to completed action. However, Silva uses a strictly psychospiritual framework to understand music "as a vehicle" of selftransformation in the reception of Brazilian singer Rita Lee's musical practice. Although he rightly notes that music's "power to affect us depends on how deeply we listen to it and how much we involve ourselves in this process, by surrendering to physical sensations and emotional responses and by letting imagination flow," he tends to underestimate institutional influences involved in transformative change along with their culturally specific meaning (2010: 33). In other words, the metaphors of self- 
transformation listed here, including the Christian example of dying and being reborn, have roots in the history of world civilizations.

According to Shulman and Stroumsa, self-transformation is wrapped up both with the history of concepts of the "self" and "transformation" and with the varying influence of culture and religion found across all major civilizations of the world (2002). Curiously, all civilizations, cultures and religions are characterized by notions of selftransformation, "distinguishing 'self' from 'soul' (which usually does not require or allow transformation) and from the confused list of related metapsychological concepts such as 'persona,' 'ego,' and 'subject”' (Shulman and Stroumsa 2002: 4). The major period in which self-transformation occurred on a global scale, drawing on Karl Jaspers, is called the Achsenzeit (other historical sociologists such as Arpad Szakolczai refer to this period as the Axial Age (2000)), beginning around 1000 BCE. For our purposes, the distinct model of self-transformation embodied by the case of Rob "Fresh I.E." Wilson is that of the soul in need of salvation or conversion, elaborated by Augustine following Constantine's adoption of Christianity as the state religion in the fourth century CE. Notably, in elaborating their analytic, Shulman and Stroumsa describe transformation as not a random or chaotic act but rather as a ritualized practice that involves directionality, integration, and voicing, including musical. Such characteristics vary in ways specific to the religion and culture in which transformation circulates. The authors stress a systems approach to understanding transformation in order to account for its culturally specific conception and practice. ${ }^{9}$ Self-transformation thus becomes an "evident channel for precisely such necessary attempts within culture to integrate and continually reorganize

\footnotetext{
${ }^{9}$ According to Shulman and Stroumsa, it is hard to distinguish between culture and religion up until Alexander's conquests in the fourth century BCE, which necessitated techniques of conversion, thus separating religion from ethnos (2002).
} 
disparate components of experience and vision" (Shulman and Stroumsa 2002: 10). Methodologically, the authors suggest that despite its limitation of translating selftransformation to language, valuably, autobiography offers a means of understanding and explaining self-transformation by focusing on a transforming subject whose presence throughout such change is consistent, providing insight into the sequence of her or his own change, with some degree of accuracy and with some degree of persuasiveness.

Applying Shulman and Stroumsa's analytic to our case, Rob "Fresh I.E." Wilson's self-transformation is seen to embody a sudden conversion followed by gradual change. The former transformation involves movement along a vertical axis toward selfapotheosis that renders his former self, or specifically, his former ethos, not only obsolete but sinful. The latter transformation involves a horizontal metamorphosis observed in the shift in his presentation from masculine prowess based on womanizing to patriarchal youth mentor and pastor. Yet his former self is not entirely discarded. Following Shulman and Stroumsa, there is a splitting that occurs in Wilson's transformation into "selves"; some defined by values and corresponding behaviours are rendered "bad," while others are rendered "good." Yet, his transformation is largely determined by context and the social regulation of techniques of differentiation specific to that context, relative to its scale. Thus, in the contemporary context, Rob's conversion and ensuing transformative practice fits with broad themes, such as "healing" and "liberation" and their motivating logics rooted in his biography. Specifically, his transformation works to integrate his former self in certain ways with the representations that dominate his context. Hence, voicing his transformation then works to reassemble his split self in certain ways that cohere around healing and liberation. In chapter five, I discuss how 
such voicing creates problems and solutions for Rob, depending on context; for instance, Rob transformed his stage persona from "Freshie," as it is associated with masculine prowess and sex appeal, to "Fresh I.E.," as it denotes his status relative to the divine, "fresh in eternity," and by extension, his adoption of Christian morals, including sexual purity. Finally, space for transformation is found to be firmly present in Rob's self, including the demarcation of inner and outer realms suitable for change. Shulman and Stroumsa argue that "An expansive 'self' opens further under the impact of regulated transformation, which tends to enhance its internal resonances and (especially) dissonances, to intensify or accelerate movement, to extend or knead the boundaries of identity and experience, looping and twisting these boundaries through one another without discarding earlier personae" (2002: 13-14). While the authors helpfully trace its history and open up new ways of conceiving of self-transformation, including gesturing toward a critical explanation of its representation and regulation, it remains for us to link its history to the contemporary context in order to trace variations of such influences. For that, I turn to the work of Michel Foucault.

In the period roughly from 1977 until the time of his death in 1984, Michel Foucault developed a research agenda that explored the care of the self, its history and governance as a set of transforming and transformative practices and ethics. In taking sexuality as his object, for instance, he discovered normative affects specific to and stemming from its form of knowledge "not in terms of repression or law, but in terms of power" (1978: 92). In the following often-cited passage, Foucault spells out the ways in which forms of knowledge, like that around sex, circulate power in such a way as to affect its very practice and social reproduction: 
...power must be understood in the first instance as the multiplicity of force relations immanent in the sphere in which they operate and which constitute their own organization; as the process which, through ceaseless struggles and confrontations, transforms, strengthens, or reverses them... and, lastly, as the strategies in which they take effect, whose general design or institutional crystallization is embodied in the state apparatuses, in the formulation of the law, in the various social hegemonies" (1978: 92-3).

Foucault's concern with power draws our attention to the ways in which knowledge about the self and self-practices contributes to the transformation of those selfsame practices and thus, concepts of the self. Not just a coercive external force, such knowledges are internalized, contributing to the governing of the self by the self through "care of the self" practices related to the "cultivation of the self" (Foucault 1986: 37-68). For instance, in terms of sexuality, Foucault notes an intimate relation between knowledge of the self and self-governance that developed in the first century CE of the ancient Greco-Roman world: “...this added emphasis on sexual austerity in moral reflection takes the form, not of a tightening of the code that defined prohibited acts, but of an intensification of the relation to oneself by which one constituted oneself as the object of one's acts" (1986: 41). In other words, bringing one's behavior into line with one's beliefs, and by extension with those beliefs shared by others within the sphere in which one practices those beliefs, required increased attention to oneself. Constituting oneself as the object of one's acts in order to transform oneself into an ethical subject, for instance, is what Foucault calls a "mode of subjection" or subjectivation (1985: 27). I will return to this mode below. Notably, even after the rise and fall of the Christian church as the central institution of morality in Western nations, the dominant modes of the care of the self and others as self-cultivation remain intact today, albeit propagated by a wide variety of expert knowledges, including science and medicine, education, and psychology. 
Arguably, Foucault's concern with self-knowledge (toward the governance of self-practice and its normalization) can be extended to musical self-practice; the historical transformation of self-care was also a transformative technology that individuals practiced upon their selves. We have already noted Tia De Nora's use of his concept, "technologies of the self," as it applies in the context of everyday life: "I have tried to show how actors engage in aesthetic reflexive activities of music consumption so as to produce themselves as types of actors imbued with specific feeling forms, attributes and identity characteristics, and as objects of knowledge to themselves and to others. In this respect I think it is fair to suggest that music is clearly an available technology of the self" (De Nora 1999: 53). To the consumer, the sounds of music as they mediate the self exist as a resource in a broader "toolkit" constituting a "cultural repertoire" that can be drawn upon to control emotions and affect moods. However, the problematic ontic here is De Nora's explicit focus on musical consumption and her underestimation of both the biographical roots influencing that practice, and the institutional means by which music comes to that self. As a result, she neglects to employ Foucault's concept in concert with the other technologies that he spells out and in the spirit of his wider concern with the ethics of self-care as a practice of freedom. ${ }^{10} \mathrm{He}$ defines the four technologies, "each a matrix of practical reason" as follows:

(1) technologies of production, which permit us to produce, transform, or manipulate things; (2) technologies of sign systems, which permit us to use signs, meanings, symbols, or signification; (3) technologies of power, which determine the conduct of individuals and submit them to certain ends of domination, an objectivizing of the subject; (4) technologies of the self, which permit individuals to effect by their own means of with the help of others a certain number of operations on their own bodies and souls, thoughts, conduct, and way of being, so

\footnotetext{
${ }^{10}$ For a critique of "Gestural Referencing and Conceptual Misappropriation," see Curtis' article (2015). Strikingly, Curtis highlights not only De Nora's limited discussion of Foucault's "Technologies of the Self" in her article by the same name, she fails to reference his work in the bibliography.
} 
as to transform themselves in order to attain a certain state of happiness, purity, wisdom, perfection, or immortality. (Foucault 1988: 18)

Notably Foucault reasserts that these technologies are inseparable from each other while also being characterized by dominance, two qualities that De Nora tends to neglect in her concern with consumption and present challenges. For our purposes, Foucault's analytic highlights both the conditions of the experience of musical self-practice and the subjectivation of the self as characterized by struggle and reflexivity. The technologies of the self are a means of problematizing one's biography and present concerns and transforming one's self practice as a means of response "in order to attain a certain state of happiness, purity, wisdom, perfection, or immortality" (1988: 18). So, on the one hand, I take up Foucault's concern with the geneaological development of self-practice as a technology of the subjectivation of the self, particularly, the supplanting of the "knowing self" in principle over and above the care of self in practice. This concern draws our attention to the ways in which Rob's self may have been dominated through his formative experiences combining to fill out a complex subjectivity. On the other hand, Foucault's analytic provides a conceptual strategy for understanding and explaining Rob's musical self-practice as a strategically employed technology of production in the face of dominating forces.

There are several criticisms, in addition to inspirations, taken from Foucault's work that demands our attention before I synthesize them with musical self-practice. Perhaps most significant, stemming from Nancy Fraser and other feminists, is his "lack of an adequate normative perspective"; she reads his early career perspective as nihilistic, for instance, as he relativizes madness through his criticism of prisons (in Koopman 2013: 211). Indeed, even in his late career "Morality and the Practice of the Self," 
Foucault traces the geneaology of the forms and transformations of "morality" in order to reveal not only external legal bases delimiting modern sexual practices, but also the ways in which those practices have come to be adopted through the self-formation of the "ethical subject" (1985: 25-32). In discerning variations in "moral codes" and "ethics" ("forms of moral subjectivation" and of the practices of self that are meant to ensure it) since ancient and pagan Greco-Roman times, Foucault appears to question the legitimacy of modern moral codes and ethics.

However, before disqualifying Foucault's project, the philosopher Colin Koopman argues for its enrichment starting from Fraser's critique. Distinctly, Koopman recognizes an "ethic of problem and response" or a "responsive ethics" in Foucault's late work. Such ethics are distinct from a principled conception of what "must be right in a given situation but rather a melioristic conception of how to respond to the specific problematic situation in which we find ourselves" (Koopman 2013: 183). Koopman reads Foucault's logic of thought and practice as proceeding through the categories of the problematic and the responsive, rather than through such categories as position and negation. ${ }^{11}$ Rather, he insists that Foucault's concern lies with modern ethics as tending toward one of two purified forms, either as disciplinary power, especially when exercised in disregard for its "corollary forms of freedom," or oppositely, liberationist forms of freedom that disregard the powers circulating through it. In focusing on Foucault's orientation to self-transformation as a process, Koopman emphasizes that the advantage to "philosophical work on ethics consists not in the pronouncement of verdicts (the claim of commitment), but in clarifying and conceptualizing extant possibilities for ethical living in the present (the work of orientation)." He continues, "Commitments as such are

\footnotetext{
${ }^{11}$ Following Born, I have already critiqued Adorno's concept of negation.
} 
often tightly bound to the contexts in which they do their work. Orientations, by contrast, are usable across a remarkable variety of contexts" (Koopman 2013: 189). Koopman's interpretation of Foucault's ethics offers several advantages.

Two essential ideas that emerge from Koopman's development of an ethics of self-transformation that I wish to draw on is first, "the idea that transformativity suggests that ethics is primarily about process and modification;" and second, "the idea of reflexivity central to a self-transformative ethical orientation helps bring into focus the object of modification or transformation on Foucault's ethics" (2013: 198). For our purposes, it is important to consider self-transformation not only as a present practice, but also as an ethic of problematization and response. Such "responsive ethics" offers the advantage of explaining Rob "Fresh I.E." Wilson's musical self practice as combining with his moral and ethical system, yet without committing to a moral code as though it is set. As such, Rob's self-transformations, both sudden and gradual, reveal a more fluid system of morals, as they are drawn upon to problematize and respond to situational challenges, than much sociology of religion allows for (cf. Weber's insightful yet static profiles of religious classes 1993: 95-117). At the same time, Koopman's ethics of selftransformation allow us to trace the ways in which Rob comes to embody certain contradictions between the moral codes of the institutional church and Christian music industry and the everyday life challenges that he, his peers and audiences face. Here, music does not contribute to self-transformation; rather, as a stake in the field of Christian hip-hop, Rob's "authenticity" demands constant self-evaluation and musical selftransformation. Such ethics fits with recent scholarship in African-American religious studies and hip-hop studies. 
The African-American religious studies scholar, Monica Miller offers insight into the distinction of the religious self, including reflexively, her own perspective. Miller's academic program begins with a criticism of Anthony Pinn's concept “complex subjectivity." Pinn views complex subjectivity as the experience of "terror and fixity," for instance making up African-American history. However, Miller is critical that he privileges "experience" (religious, affective dimensions, and emotions) as "meaningful" in and of itself, as beginning in the interior realm of subjectivity. As such, he underestimates the multiple forces mediating those experiences and the economics of their symbolism. Instead, Miller proposes, practically, "a turn towards evaluating religious uses in Hip-Hop culture as effects of larger social, political, cultural, and economic processes, rather than the culmination of a shared uncaused underlying essence" (2013: 109). Her concept allows us to parse out the ways in which subjectivity becomes wrapped up in the reproduction of social inequality, including dimensions of race and poverty. Miller then draws on Bourdieu's analytic of, "habitus-field" in order to explain music's circulation of power once it enters the symbolic realm. Miller states:

...exploring religious uses cannot only be figured as a pure intentional "response" to terror and fixity, but rather, as products of durable inequalities tethered to structuring structures. The latter figures religious uses not as the solution, but also part of the reproduction and inheritances of inequality itself. Thus, the externalizations of practices offer a window beyond subjective quests for meaning, to consider complex dimensions of social reproduction, inherited externalized dispositions, and lived reality. (2013: 116-17)

For our purposes, Miller's complex subjectivity allows for the consideration of Rob's musical self-practice as indeed characterized by tension between the two poles of terror and fixity. However, such states are not given but wrapped up in the specific contexts of their experience and representation in the symbolic realm. In other words, Rob's 
formative experience of racism and rejection is wrapped up in a set of emotions and the context of the Gilbert Park public housing in Winnipeg's North End during the late 1970s, as they make up his biographical narrative and strategies of self-transformation. Complex subjectivity and its characterization by terror and fixity—in Rob's case precarity and self-doubt - help to explain both the presence of contradictions in hip-hop and religious practice and also their mediatory role in the reproduction of social inequalities. In the latter section of chapter four, I review hip-hop studies and AfricanAmerican religious studies in order to better understand and explain Rob's musical mediation with the complex subjectivity of his biography, hip-hop, Christian hip-hop, and the institutional church.

Significantly, Bourdieu's critical social theory provides the final framing mechanism for understanding and explaining the musical self across the life cycle in three dimensions. First, as the analysis of the significance and immediacy of musical experience has been extended to the consideration of its mediation with the planes of the social and the ethics of self-transformation, it remains for us to link such dispositions and interests to their reproductive principle and logic, namely, as they are tied to and bounded by their participation in a field. Bourdieu's durable analytic, "habitus-field," is helpful here as it precludes the kind of subjectivism suggested by philosophical concepts of pure "intentionality" and "individualism" or "autonomy" by collapsing the subject and object together into practice (1977). Instead, one's participation in cultural production, for instance, enables the development of a "feel for the game" and the structuring structure of dispositions or habitus that makes up that feel, generated by one's interest in competing for the stakes in that field, including the definition of those stakes (1993: 61-73). Rather 
than economically determined - a common critique of his work (for a summary cf. Prior 2011) - Bourdieu underlines the simultaneously structured and structuring relationship of the "field-habitus" nexus, conditioned by possibilities available, thus, although tending toward social reproduction, also holding a generative capacity (1990: 10-17). For our purposes, Bourdieu's critical theory allows us to relate Rob "Fresh I.E." Wilson's musical self-practice to a field, specifically, those spaces of possibles with which Rob's habitus was mediated during the various periods of that practice. This is the second dimension of his critical theory to be adapted to this dissertation and which helps to explain musical self-practice. Late in his career, Bourdieu produced a "sketch for self-analysis" (2004; 2008) in which he traces the distinct temporalities of self-practice having to do with the formative years, formal education, and participation in a professional field. Such periods allow us to consider musical self-practice as both formative, in providing a base that is inextricable from the self and its mediation with the context of its experience, and as transformative, in its strategic representation in the symbolic realm and mediation with the public and institutions. Bourdieu's sketch for self-analysis provides the framework for linking Rob's musical self-practice to the field of his formative years, including the significance of adopting his favourite songs and learning to perform for an audience by dancing in the Gilbert Park project, and to his educational years in which he adopted the meanings and significances circulating around hip-hop in the mid to late 1980s, and his professional practice in Christian themed hip-hop beginning in the early 2000s. By extension, I link Rob's practice to the history of African American religious musical practice in chapter three and the historical emergence of Christian hip-hop in chapter four. Relatedly, Bourdieu conceives of the symbolic realm as characterized by the same 
interests and strategies of competition and exchange as in the economic realm of capital. Thus we can conceive of the symbolism of dance moves or masculine posturing as technologies of articulation that variously carry symbolic currency that can be exchanged for hard currency.

Finally, Bourdieu's discussion of "reflexivity" is helpful not only in drawing our attention to the ways in which our object performs self-care and boundary work, but significantly, in attempting to remove hidden assumptions on my behalf and attending carefully to how my own presuppositions, stances, and conceptual and moral/political choices shape the research object $(1991 ; 2004)$. As Curtis states, "the aptitude here is that of being adept at putting our beliefs on hold and making them an object of scrutiny, in order to see how our analysis could be different if we came at it with a different ensemble. It is a stance of sceptical distancing of oneself from oneself' (2017; see also 2014).

Music has been transformative for me. Similar to Wilson, I experienced a gradual formation of attachments or favourite songs that fed into my own musical education, albeit as a drummer, and semi-professional practice in a number of "indie" touring and recording bands during the 2000s. The sudden transformation of my semi-professional musical self-practice, while boosting my self-confidence and broadening my worldview, was not bad, although unsustainable in the long run. My political orientation toward more avant-garde and counter-cultural forms of "operatic indie-jazz" and Rock, both being unpopular in the fields in which I was performing at the time, proved to be constraining factors in my musical practice. Such musical involvement informs my concern with the institutional mediations of the musical self. However, I also quit 
performing professionally because of my moral commitment to supporting my family's financial and spiritual wellbeing. Perhaps it is the combination of that moral commitment with my fond musical memories that has contributed to my finding myself in the course of writing this dissertation, propping up music as a boundlessly positive resource for selftransformation. Rob's contemplation of suicide, in addition to the "crisis of youth" on Canada's First Nations reserves (see chapter five), shocked me and in some ways influenced my initially uncritical "apologetics" for musical practice. It was hard for me to see suicide as anything but bad, and Rob's "message of hope" minimized any misdoings on our part. However, with some distancing, I hope to have achieved a more critical interpretation and explanation of music's contribution to Rob's selftransformation, attributing to its manifest practice the combination of sometimes contradictory forces between his biography and professional field of practice. I relegate the apologetics to those more articulately adept.

In this section, self-transformation was problematized according to the concepts "self" and "transformation," revealing a complex subjectivity and historically specific ethic. More than a simple function of narrative and self-construction, Shulman and Stroumsa trace how the self is wrapped up with complex processes of transformation, including differential shifts in the meaning of transformation across religions, cultures, and history (2002). While Foucault's analytic approach helps to reveal the practices of self-care, by extension music as a "technology of the self," it is critical to remember that the techne or self-administered application of such practices are not wielded as though free from influences of domination, including the self acting upon the self, despite appearances that suggest otherwise. At the same time, the capacity to transform oneself 
is itself an ethical practice with alternatively self-disciplinary-liberating potential. Selftransformation is an ethic specific to modern subjectivity and culture, at once raising the stakes of self-care practices and of musical mediation. Miller's "complex subjectivity" reminds of the scope of processes and practices of subjectivation, extending consideration beyond the self to its mediation by institutional organizations, including the church and music industry. Finally, Bourdieu's critical theory adds normative weight to this dissertation by allowing us to frame the ethic of self-transformation according to the conditions of Rob “Fresh I.E.” Wilson's musical self-practice, including his relation to the church and music industry, and reflexively, my collaborative work with him, its interpretation, and explanation.

\section{3 - Methodological considerations}

- (Auto) Ethnography (April 2014-May 2016) - Participating observer; Insider-Outsider; Journal; Field Notes; Discourse analysis

- Historical analysis - Primary; Secondary; Comparative

- Interviews (n. 20) - Open ended; semi-structured

- Reflexivity

- Audio-visual analysis

What is the specificity of musical self-transformation? The overall approach taken here is critical in that I take my own position as wrapped up with and implicated through the politics of my case, Rob "Fresh I.E." Wilson (Denzin and Lincoln 2008: 1-20). Hence the production and interpretation of research material is neither neutral nor objective. At the same time, the approach taken is also qualitative in that I refuse to take my work with Wilson at face value but as wrapped up and implicated with otherwise taken for granted forces related to his subjectivity and professional practice, forces that I problematize systematically (Snape and Spencer 2003: 1-23). Rather, in answering the question above, I combine three primary methods, biography, ethnography and historical analysis, 
keeping in mind and practice a reflexive method in the vein of Pierre Bourdieu and Arpad Szakolczai. Advantageous for this project, these authors reject as arbitrary, divisions between subject/object, including that of my own relation with my case. Following from Gadamer and linking to Bourdieu, Curtis argues, "The researcher's 'horizon of interpretation' will have consequences for the research object," thus demanding, "a specific form of 'epistemological vigilance': to be attentive to and to be cognizant of the ways in which the practices of, procedures, and projects of knowledge-production have a formative influence on objects of knowledge - and on the politics in which they are embedded" (2014: 48). Such reflexivity is congruous with recent Critical Indigenous scholars (cf. Denzin and Lincoln 2008: 1-20) who insist on grounding research methodologies in an "oppositional consciousness that resists neocolonizing postmodern formations. These pedagogies fold theory, epistemological methodology and praxis into strategies of resistance unique to each indigenous community" (Denzin and Lincoln 2008: 10). Finally, the combination of multiple qualitative research methods in this dissertation is called, "triangulation," and is advantageous in that it offers a potentially fuller understanding of the research object than if just one method was used (Ravelli and Webber 2016: 110).

The form of ethnography that I employed allowed me to get a sense of the breadth and depth of Wilson's musical practice, extending my consideration of hip-hop beyond typical genre-related representations having to do with musical form and content, including here, male posturing, sex and materialism, while also allowing insight into the temporal variations of the habitus or musical self that my case embodies. According to David Grazian, ethnography is literally the art of writing about people; while traditional 
sociological ethnographies, he states, "have referred specifically to the task of the participant observer who 'gathers data by participating in the daily life of the group or organization he studies'... in recent years the term has been appropriated by researchers who employ a broader range of qualitative methodologies, such as open-ended interviewing and biographical narrative collection" (Grazian 2004: 197; he quotes Howard Becker from 1958). Indeed, open-ended interviews allowed me access to Rob's biographical narrative, including stories linking his self and music throughout his life and his vision going forward. However, interested as I am in recognizing the significance of music in relation to his biography, it is important to consider the ways in which I categorize elements making up that narrative. At the simplest level, I categorized his narrative according to temporal divisions of Rob's formative and educational years (Bourdieu 2004: 88-94; 2007) and according to the spaces whereby he experienced new forms of subjectivity. Moreover reflexively, such categories are not self-evident but wrapped up in the historically and spatially contingent discourses which Rob, other subjects, and I employ.

With his 'reflexive historical sociological method,' Szakolzcai distinguishes forms of subjectivity according to knowledge, thought, and the closing of space and regularizing of time (1998: 216). Notably, he argues that such forms become distinctly significant in the historical anthropology of the individual agent when their subjectivity becomes spatio-temporally distinguished - no longer the same as they were. Borrowed from the anthropologist, Victor Turner, he terms such transitions "liminal." Not to negate the dialogical quality of the subject's agency, Szakolczai conceives for instance, of liminal "reading experiences," as "technologies of the self" (Foucault 1988: 16-49) in 
which the self's outlook or perspective coalesces around points of insight or epiphanies. Incorporating a sonic historical anthropology into my ethnography, I add to liminal reading experiences, Feld's “acoustemology:" one's sonic way of knowing and being in the world (Feld and Brenneis 2004). In Wilson's case, Prince's “Free," Michael Jackson's Thriller, and 2Pac's "So Many Tears," were sonic epiphanies that contributed to the linking his subjectivity to the space in which those experiences were perceived. Such experiences are linked to the creation of the place, as opposed to space, of Winnipeg's North End, and, relatedly, his sense of injustice due to his then familial relations. However, keeping in mind Shepherd and Wicke's distinction between primary and secondary signification (1997: 103), sonic experience is a complex process; given its non-denotative character at the level of perception, sound is not always liminal and not always positive or good. As roots in his past, Rob's sonic experiences are also discursively rendered, wrapped up in the history of the space in which he was conditioned as a child and its relation to his current practice.

By extension, Rob's musical self experiences are linked to the history of African American religious musical practices, discussed in chapter three. Historical research in music sociology lends the advantage, for instance, of guarding against taking musical categories such as "genre" or its related content as given (De Nora 2004). Themes of "salvation" and "deliverance," making up Wilson's lyrical practice, for instance, do not simply emerge without basis in a historical trajectory. Such a trajectory is traced first, from Rob's formative years in Winnipeg to the Bronx, and the birth of hip-hop in the mid-1970s. Indeed, the historical similarities between hip-hop's emergence in Winnipeg and the Bronx are comparable, particularly as each respective scene was geographically 
isolated from the greater metropolitan area, effectively structuring "difference" into each scene, by the CPR yards in the former, and the cross-Bronx Expressway in the latter. Second, the thematic and aesthetic content of Rob's musical self-practice is traced to the institutional organization of Christian-themed hip-hop (chapter four) and AfricanAmerican religious musical practices (chapter three). Such historical trajectories help to explain the contradictions around Rob's musical practice having to do with his felt need to remain relevant, bringing him into contact and conflict with the institutional church and contemporary Christian music field, on the one hand, and the various audiences to whom he performs, including controversially, First Nations reserves and Inuit communities.

Ethnography and interview methods are susceptible to a considerable amount of bias if left unchecked, both in terms of my case's discretion in interviews and my own biases as researcher. In terms of researcher bias, I certainly do not support Becker's use of the term, "data" in the quote above, as it makes claims to objectivity and positivism. Rather, following Gray's Cultural Studies model of ethnography, the result of this biographical, ethnographic and historical work amounts to "research material" in an interdisciplinary framework (Gray 2003: 79-80). ${ }^{12}$ As opposed to data, research material reveals the ways in which procurement and presentation processes are implicated by the researcher's intentions and preconceptions. Secondary historical methods give context to Rob's formative years while also guarding against subject and researcher biases. For instance, the historical background to Rob's formative years in "Gig Town" (pronounced

\footnotetext{
${ }^{12}$ Gray is concerned with anthropological approaches that tend toward essentialism, formulating its object as such through uncritical ethnographic methods. Such uncritical methods tend to frame its object as exotic, constructing notions of "authenticity" and exacerbating social inequality through the creation of difference. Sociological studies that support notions of a unitary society have tended to support normative ideals leading to consensus or compromise while overlooking qualitative differences between and within subjects.
} 
"jig town"), are framed by the history of public housing in the North End and across Canada. According to Bourdieu, accounting for conditions of possibility gives an idea of how an agent's habitus is conditioned - alternately constrained and liberated - by the specificity of its conditions (1993: 64). Laslett conceives of biography as a means of probing links between agency and social structure (1991: 511-38). Of Abrams' term, "structuring" - and noting its similarity with Bourdieu's problem of objectivation - she states: "history and society are made by constant and more or less purposeful individual action and that individual action, however purposeful, is made by history and society" (1991: 516). Indeed, Rob's formative years were conditioned by the racialized and postcolonial space of Winnipeg's North End, including his internalization of social uncertainty due to parental absence. Such conditions led directly to his education, formal and informal.

In considering his educational years, interviews and historical research were extended beyond Rob to include his peers. This strategy not only helped to triangulate Rob's biographical narrative, it also revealed the specificity of his hip-hop (Born and Hesmondhalgh 2000: 2) in its transnational-local articulation (Shepherd 1993; Hall 1996: 1-17). While the history of hip-hop has been well documented, in contrast, Winnipeg's first hip-hop scene is not. However, primary historical research reveals, here, the scene's publicity in the Winnipeg Free Press, rendered as a racialized subculture, subordinate to the city's dominant Rock scene. Moreover, the "focus group" interviews conducted with Rob and his peers from the late-1980s and 1990s, "Papa" Ev, Deval "DJD" Dryden, and Les, reveal a fascinating dynamic within the boundaries of the scene, in the co-mediation of each artist's musical self, namely their "distinction" (Bourdieu 1984). Rob's sense of 
difference contributed to a complex strategy to claim authenticity in order to overcome that difference, forming affective alliances with key players at the local level, and attachments with influential hip-hop artists at the transnational level with whom he "learned about [his] culture" (Interview 2015).

As a further layer, De Nora's historiography of musical subjectivity (2004: 21121) is helpful in relating the representation of Rob's musical self to the nineteenth century Romanticist principle of the artist "genius" or "hero." Indeed the particularity of the artist as genius-and as masculine-prototypical of Beethoven persists in Rob's case and in comparable figures such as 2Pac and Kirk Franklin before him. However, significantly, in tracing the musico-racial subjectivation (Radano 2012) of agents in the African diaspora back to the trade ships of modern slavery (Epstein 1977: 9), a racial dimension is added to De Nora's method, here. Moreover, in relation to the dominant forms of Rock in the ' 80 s, and contemporary Christian music, Rob is also something of an anti-hero. His status is evident in the racially minoritized background of his peers and audiences, past and present. The present mode of his anti-hero status is discussed below. Finally, comparative historical methods render Rob's ethic of self-transformation a variable, including the way in which he narrates his biography as a demise and redemption, falling into pimping and violence before subsequently transforming into a Christian hip-hopper. According to Bourdieu, the agent's professional practice relates both to the state of the field having its own history and the internalized strategies employed therein as stemming from the agent's formative and educational years (2004; 2007). However, Rob's transformation is problematic for Bourdieu's model of practice, as it "tends toward reproduction" (1977: 189), particularly in that his education, as it relates to his current 
practice, was informal, altogether eschewing linearity. Rather, it was necessary to combine various qualitative methods in order to explore his transformation. Using primary historical methods, at least twenty newspaper interviews from the period of Rob's Grammy nominations were analyzed and coded according to his discussing his transformation from violent drug running pimp to running youth programs at inner city Missions and churches. Here, it was necessary to trace Rob's transformation to the realignment of his moral system with Christianity, in which his musical self practice mediates that system lyrically, including the reclamation of his past, while also projecting his transformed self into the future. Significantly, in decentering Rob's self according to Born's four planes of musical mediation $(2011 ; 2012)$, his transformation is traced in terms of the temporal-spaces of his immediate experience, membership in local scene and imagined community, and cultural industry. Lyrical content was analyzed in order to understand the self-transformative aspect of the musical self. The discourse around his transformation at once relates to the primary significance of Wilson's musical experience, while as a "technology of articulation," also revealing the ways in which its symbolic content circulates in the public realm. For example, interviews with his wife, Sheila, suggest both Rob's early ambivalence about Christian rapping and her vouching for his talent; "I could tell he was good" does not necessarily denote a strictly lyrical evaluation. Finally, linking Rob's musical habitus to the early scene, I not only traced the effect of the Grammy nomination in establishing his Christian hip-hop status at the institutional level, but I also linked him to peers in the local contemporary Christian music scene. Again, it is shown through semi-structured interviews (See Appended interview guide) with such peers, Jon Loeppky, Jon Buller, and Adrian Bradford, that institutional- 
organizational aspects of the field mediated Rob's musical practice, both affording certain advantages such as establishing esteem around him (Heinich 2009: 85-107) while in turn subjecting him to certain expectations related to the reproduction of those expectations.

In considering Rob's current musical practice, it was found to be necessary to employ the ethnographic methods of participant-observation and interviews, including of his musicians, peers and audience members, while adding auto-ethnography and audiovisual analysis as they offer critical reflexive insight. Auto-ethnography is an important method of understanding and explaining musical subjectivity as it provides insight into the relation between the participant observer and, in this case, my own discursive rendering of my musical experience. At the same time, auto-ethnography raises the importance of reflexivity in considering the ways in which musical subjectivity is rendered (Grazain 2004; Kumanyika and Elavsky 2013). For instance, throughout my performances with Rob at Tha City at the YFC "youth excellence center" in downtown Winnipeg, and on his tours to First Nations reserves, I recorded my observations and experiences in a journal for future reference. While auto-ethnography is rightly criticized for presenting a biased account, I also used a remotely controlled audio-visual recorder for the purpose of critical interpretation and explanation. Controlling the camera from my iPhone for instance allowed me to record myself leading the band, while using the stock camera on my phone offered the benefit of adding a further layer of research material. It perhaps goes without saying that the accessibility of iPhones offer incredible research potential for capturing aspects of everyday life. However, the amount of effort required to set up the remote recorder, time the recording appropriately, safely transfer 
recordings to separate disc, then setup and publish those recordings on a third party site such as YouTube, was simply prohibitive for this dissertation. In the interest of time, I elected to prioritize posting videos of Rob's Collide (2015) CD release party. Posting videos on third party websites offers the advantage of triangulating my own descriptions of those events with those comments volunteered by the public, in turn allowing the reader to evaluate my interpretation and explanation of those musical events. Such sites, in hosting observers' comments, suggest the significance of musical events, providing insight into the "meaning" of Rob's musical self practice. Unfortunately, in this case, such posts failed to attract significant opinions, likely due to several factors, including a lack of exposure, a lack of willing contributors, and relatedly, a lack of time between my posting the videos, and drafting this paper. Rather, the more significant discoveries that I made in this dissertation stem from the trust building face-to-face interactions that I had with my case and agents in his scene.

According to Tomaselli et al., in that this case study overlaps with the place of my roots in Winnipeg, it places me within the category, "Native Ethnographer" (2008: 34772). ${ }^{13}$ Considering the ways in which my religious beliefs and musical competence do indeed overlap with my case, I am also an "insider-outsider." Faulkner and Becker discuss several (dis-) advantages to "studying something you are a part of" with which I concur (2008). For instance, familiarity with my case and the urban space in which he practices allowed me to immerse myself in Rob's scene and spend less time and effort, for instance, acquiring instruments and the wherewithal to play them or understanding the ins and outs of Christianity as it is practiced by my case in his scene. Instead I was able

\footnotetext{
${ }^{13}$ Considering my own racialization, distinct in certain ways as it is from Rob, I am not for instance an, 'Indigenous ethnographer:' someone who identifies as indigenous to the land of their ancestors, and of which they study (Tomaselli et al. 2008).
} 
to balance fieldwork with the domestic responsibilities that I felt important to maintain, like taking a month away from my case with the arrival of my second son. Such work included inserting myself in the scene, getting to know and form "affective alliances" (cf. Straw 1991; Born 2012, discussed above) with my case, peers and fans; capturing images and taking notes of my observations, mainly digitally on my iPhone; and reflexively, considering related implications for following up. Significantly, my previous experience leading contemporary Christian worship, among other musical practices, enabled me to assume that role at Tha City, and with some competence, from ordering set lists, coordinating practices and providing instruments in order to fill out a band-like formation, to giving rides to band mates.

Notably, collaboration allowed me to nurture trust with Rob, his peers and the youth in attendance, leading to one of the most significant discoveries of the project: the musical mediation of Rob's contemplation of suicide as internalized uncertainty or precariousness. Until the revelation of his contemplation of suicide, my first musical point of contact with Rob was in April 2014, when I flew to Winnipeg to play drums for his Red Letterz 13 DVD release party at the West End Cultural Center. ${ }^{14}$ The show and DVD were meant to celebrate the tenth anniversary of Rob's first Grammy nomination. However, roughly ten months later, while driving him home on a blustery Wednesday night after Tha City, Rob disclosed his contemplation of suicide in 2010. With this new information, I uncovered a contradiction that compelled me to reconsider my tack, including addressing Rob by his given name as opposed to stage name, "Fresh I.E.," and

\footnotetext{
${ }^{14}$ As I discuss in the ethnography section of chapter five, my collaborative work with Rob for this dissertation is preceded by a tour we shared ten years earlier.
} 
my argument, that music is a boundlessly good force ${ }^{15}$ But neither is music a purely negative force. Rather, Rob's case suggests that his musical self practice is characterized by precariousness, both internal and external, and variably across the life cycle. This is a subtle distinction from Bourdieu's argument that fields are characterized by struggle. Instead, in accounting for Rob's self-work as it coalesced around his transformations, such a transformative ethic is explained as less a matter of claiming a position against others, though such an interest applies to an extent here, than as opposing life threatening forces, in a general sense, such as doubt. For example, the critical success of his album, Collide (2015), as an exercise in collaborative bridge building between hip-hop, country, Contemporary Christian Music, dance, and Rock, performers and styles, disguises the paralyzing wave of writer's block due to self-doubt with which Rob wrestled in fall 2014, self-doubt that he only disclosed to me six months later, in April 2015. If not for the mutual trust built between us in those first few months together, this complex subjectivity of Rob's musical mediation might have been underestimated, if at all noticed.

Finally, immersion in Wilson's scene allowed me to grasp the significance of his practice to his peers and fans, adding a final, albeit limited, layer of accountability to the inherent bias in his biographical narrative. As mentioned above, stemming from my insider-outsider status and background with Rob, trust allowed for semi-structured interviews at will. Yet most interviews were left until the end of my time in the field given the new knowledge of his suicide contemplation, which effectively broke the frame of analysis (Goffman 1986; cf. chapter ten). Such revelation precipitated a transition

\footnotetext{
${ }^{15}$ Including addressing Rob by his given name as opposed to his stage name as it suddenly seemed more respectful. Relatedly, I recall Rob sentimentally describing a recent banquet in which his assigned seat was labeled with his given name, the first time this had occurred. His delight suggests that he appreciated the gesture at that time.
} 
from a "sinner-to-saint" interpretive model to one in which Rob's musical self-practice is gauged according to his Grammy nominations and suicide contemplation. ${ }^{16}$ As such, I interviewed roughly twenty peers and fans involved in his practice from 2010 to the present. Eighty percent of interviewees hail from minority backgrounds, including selfidentified American Indian, African, African-American, Middle-Eastern including Lebanese, South East Asian including Filipino, and Eastern European. Ages ranged from eight to forty-something. Most came from single-parent homes, living in public housing and low rent dwellings. While all interviewees were Christian, most were new-converts or second generation. Semi-structured interviews with peers (See Appendix) consistently touched on identity-related issues, from gendered themes of beauty and sexual purity, to community-based themes of alienation, belonging and purpose, to religious themes of sanctification, faith or trust in God, joy, and forgiveness of sins. Materialism is generally shunned, but the identity and organizational support lent by Rob's "greatness" is unquestionable. Both peers and fans, all identifying as minoritized, esteemed the combination of Rob's fame with his faith in Christ. As a method of problematizing his relationship with his peers and fans, it was necessary to discursively analyze Rob's websites, and attended the first public "info night" of his EDIFY program. While the former is limited in suggesting his intentionality only, the latter provides insight into the ways in which young people (roughly twelve) invested themselves in the scene and music. Dialogically, the info night also revealed Rob's justifications for mentoring youth, including organizing the program to benefit less fortunate youth for whom learning to write, perform, and record music are otherwise impossible. Beyond his peers

\footnotetext{
${ }^{16}$ The curiosity of Rob's consistent Grammy nominations referencing ten years on suddenly made sense in light of his suicide attempt, not only as an economic interest in selling merchandise but as a bulwark against self-doubt.
} 
and fans, the limited number of organizers that I interviewed who invited Rob to perform, for instance at YFC and First Nations reserves, including during "Addictions Awareness Week" at Fisher River Cree Nation, espouse Rob for inverting themes of violence in his music and testimony. As such, Rob is an anti-hero. However, as his self-transformation was the focus of this project, peers and fans predominantly inform my interrogation of his scene; only about six interviews were conducted with institutional level organizers and personal funders. Nonetheless, interviews with fans and peers are not insignificant; they articulate the ways in which Rob's hip-hop practice is received and becomes meaningful to his peers and fans in specific places, notably, giving a voice to the otherwise voiceless (Denzin and Lincoln 2008: 1-20).

In this chapter, I have argued that music is self-transformation, that selftransformation is an ethic, and that the qualitative research methods of biography, ethnography and history, are necessary for the adequate interpretation and explanation of Rob “Fresh I.E." Wilson's musical self-practice. As a centripetal force throughout life, musical mediation supports the notion of the musical self. However, that self is not consistent. Rather, the distinction between its primary and secondary mode of signification reveals that musical self practice mediates the public realm in which symbolism is circulated. As a public articulation, "music" invites normative forces to affect the self. The specificity of such normative forces as they relate to Rob's musical self mediation remain to be traced. In the following chapter, the roots of Christian hiphop will be traced to African diaspora religious musical practices and modern slavery. It is in such a context that specific musical selves became subjectivated in particular ways that distinguished their musical practices, and in turn, became a condition of possibility 
for future musical practice. The mediatory assemblage of musical experience and imaginary techniques can thus be read to inform musical self-interests and strategies, from existential survival to market-based innovations. The specificity of such musical mediations will be traced across the historical trajectory of the classification of categories related to both genre, from Spirituals to Urban Contemporary Gospel, and to the biographies of significant figures in the history of African-American religious musical practices. Such biographical specificity will inform our ensuing analysis of Christian hiphop and the case of Rob "Fresh I.E." Wilson. 


\section{Chapter Three}

\section{Historicizing the Musical Self and the Ethic of Musical Self-Transformation: An historical sketch of African American religious musical practice, from the underground of modern slavery to its standardized representation in the contemporary Christian music industry}

\section{1 - Introduction}

The mediation of Rob “Fresh I.E.” Wilson's musical self-practice with Christian hip-hop, its sounds, lyrical themes, and institutional organization, and with the ethic of selftransformation, is also a link to the history of hip-hop and African American religious musical practice. While I take up the history and organization of Christian hip-hop in Chapter Four, I take up its broader history here.

Music, as a self-practice and transformative ethic that mediates social inequalities, and which is characterized by precariousness, has its institutional roots in modern slavery, the Black church, and the American culture industry. The organization of such institutions have variously contributed to the structuring of social inequalities having to do with race, class, gender, religion, and sexuality, while their historical establishment continues to reproduce such inequalities which, in turn, condition the musical self today. The musical self and ethic of self-transformation is also wrapped up in its symbolic exchange. With the creation of a distinct public realm of expressive culture (Neal 1999), representations of black culture and music gain currency and work to differentiate musical selves through their circulation of power, including modes of dominance and resistance (Gray 2005). Throughout the history of African American musical practices, such modes are recognizable not only according to themes of "liberation" and "freedom," but also as variable forms of resistance, accommodation, or lateral movement, as in posturing and dance, and as related ethical strategies having to do, for instance, with 
"authenticity" and "street cred." The circulation of such representations, themes and strategies, effectively distinguishes musical selves and practices, contributing to the designation of "imagined communities" (Anderson 2006: 9), to which new recruits claim membership through "techniques of the musical imaginary" (Born and Hesmondhalgh 2000: 37-47; on musical recruitment into social movements, see also Eyerman and Jamison 1999). At the same time, music mediates the conditions of its immediate experience or "musical events" (De Nora 2003: 49), and the formation of "affective alliances" making up a "scene" (Straw 1991). Such experiences are variably formative, educational, professionalizing, and transformative, in their mediation of musical selftransformation throughout life (Bourdieu 2004: 94-114). Altogether, the assemblage of musical mediations making up the history of African American musical self-practices are sketched, here, especially as they relate to the case of Rob "Fresh I.E." Wilson.

\subsection{1 - 1750-1865: Modern slavery, the body, spirituality and the Afrological} musical self

Musical categories or genres are modernist concepts consisting of the objectivation of an otherwise complex subjectivity making up musical self-practice. In tracing their roots, here, we can understand and explain both the conditions of their experience or the subjectivation of the musical self, and the objectivation of such experiences by musical selves for themselves. At the same time, these are the roots of the ethic of musical selftransformation.

According to the historian Robert Darden (2004), it is unknown when exactly the musical expressive culture that was to be called the Spiritual emerged. Yet clues are found both in the social conditions of its practice and the slave's sonic way of knowing 
and being in the world or "acoustemology" (Feld and Brenneis 2004). However, access to such acoustemology during this period is limited to third party observations recorded in newspaper advertisements and journals, which otherwise confirm that slaves were viewed as sub-human, thus explaining the absence of first-person accounts. That having been said, various scholars insist that slaves from Africa would not have objectified "music" or "musical experience" apart from being; rather, music was performed as a function of tribal rites of passage, such as going to war or courtship (Bohlman 1999; Small 2000). ${ }^{17}$ Nonetheless, in the encounter with Europeans on the ships of the infamous "middle passage" that brought slaves to the New World, a "new [musical] subjectivity" emerged (Szakolczai 2000: 207). In turn, historicizing this subjectivity not only reveals its conditioning, but also allows us to understand and explain how the ethic of self-transformation emerged. In the following description, recorded between 1780 and 1787 by the slave ship surgeon, Alexander Falconbridge, such musical selftransformation is depicted:

Exercise being deemed necessary for the preservation of their health, they [slaves onboard ship] are sometimes obliged to dance, when the weather will permit their coming on deck. If they go about it reluctantly, or do not move with agility, they are flogged; a person standing by them all the time with a cat-o'-nine-tails in his hands for that purpose. Their musick [sic], upon these occasions, consists of a drum, sometimes with only one head; and when that is worn out, they do not scruple to make use of the bottom of one of the tubs [in which their food is served].... The poor wretches are frequently compelled to sing also; but when they do so, their songs are generally, as may naturally be expected, melancholy lamentations of their exile from their native country. (Epstein 1977: 9)

\footnotetext{
${ }^{17}$ Bohlman, for instance, distinguishes "four ontologies of music," one of which compares with Small's concept of "musicking," which focuses on musical performativity as a constitutional aspect of the self. For our purposes, however, the musical self allows for historical and biographical ebbs and flows in the self's objectification of its own musical self-practice. Feld's "acoustemology" fits more consistently with the concept of the musical self.
} 
Falconbridge's journal entry signals a monumental shift not only as a moment of provenance in the history of African American musical practice, but also in the modern emergence of the musical self. It suggests a transformation of the musical self through the objectification of its relation to itself, thus allowing for transformative self-work.

Several factors conditioned musical self-practice and the ethic of transformation during the period of modern slavery in the New World. Historically, the growing importance of expert opinion in the eighteenth century is reflected in Falconbridge's assessment, at once suggesting that "music" is a thing and that "it" is good for selfpreservation, a technology for entraining bodies (while also underlining the power differential inherent in the relationship between the surgeon and his subjects). Arguably, slaves, too, would have recognized music making's power to sustain for themselves. However, economically objectified by their captors as bodies, now, slaves were subjected to the most horrific conditions of inequality. During the pre-emancipation period in North America, such conditions included an enforced system of legal chattel slavery that established laws, attitudes, and practices, often paternalistic, hateful and condescending, which in turn inculcated in slaves and their descendants a certain cultural disposition. By extension, Ron Eyerman argues for instance, that the shared experience of slavery affected a common disposition across the collectivity of the African diaspora, ${ }^{18}$ constitutes "cultural trauma" (2001). According to Amiri Baraka (1963: 1-10), it took just two generations of slaves having children on American plantations for Africa to be

\footnotetext{
${ }^{18}$ Neal argues that while the term diaspora is typically linked to disparate conditions among global Jews and more recently linked to the global dispersion of African peoples, black migration patterns in the twentieth century represent the development and construction of an African-American diaspora (1999: 12).

I maintain that the combination of oppressive social conditions, including forced migration, and the standardized labour of cotton and sugar harvesting in the South and small industry farming and trades in the North during the pre-Emancipation period, also contributed to the emergence of the African-American diaspora.
} 
forgotten. The nature of trading effectively separated slaves from each other in the New World, rendering their languages obsolete and contributing to cultural amnesia. But the temporary loss of spoken language does not necessarily indicate dialogically free relationships, including in musical expressive culture. Almost at once, the Afrological perspective, including the spiritual belief that life intertwined with the supernatural, combined with the Eurological perspective vis-à-vis the African practice of adopting the gods of one's captors. The outlawing of familial relationships and the reservation of copulation for purposes of breeding only, further conditioned such a shift. ${ }^{19}$ Ironically, such conditions also increased the chances for equality between men and women slaves, at least in terms of limiting the diffusion of patriarchy across relationships and vaulting women to a prominent place among the African diaspora. These conditions affected the disposition brought to musical practices.

A difficulty with historical research is to problematize a practice that appears to be specific to a group of people without essentializing those people through the specificity of the problem. George Lewis (1996) and others (cf. Bohlman 2012; Gilroy 1993; Born and Hesmondhalgh 2000; Born 2011) avoid such a difficulty by taking music making, along with its related discursive codifications and representations and related social categories of class, gender, and race, as historically emergent and wrapped up in relations of power. By focusing on music making, as opposed to "music," such authors frame an ontology of music that fits with our notion of musical self-practice as selftransformation discussed in the previous chapter. For our purposes, Lewis introduces the "Afrologic perspective" to elucidate a set of musical sensibilities specific to African

\footnotetext{
${ }^{19}$ Forced breeding increased, particularly, after the criminalization of international slave trading in 1808 (Davis 1998; Wald 2007).
} 
American musicians. ${ }^{20}$ However, key to his definition of "Afrologic" is its counter relation with a dominant "Eurological" perspective, highlighting the way in which social inequality was, at the time, refracted through musical practice. Like Afrological musical sensibilities, Eurological musical sensibilities are rooted in a history whose specificity is themed and discursively circulated, in this case according to universalisms and the technique of compositional notation. By extension, the Afrologic perspective allows us to understand and explain historical musical-self transformation, for instance, in the first encounters in the New World, from the slave ships of the middle passage already mentioned, through to the major concentrations of African religious musical sensibilities represented by spirituals, Jubilee Spirituals, Gospel hymns, and urban contemporary gospel, in order to uncover instances of music's contribution to transforming cultural inequalities, including in the very agents performing such change.

One of the roots of the Afrological perspective that was both sustained and sustaining throughout the African diaspora in the pre-Emancipation period is the seamless combination of spirituality with a particular worldview stemming from tribal tradition (Davis 1998; Neal 1999; Darden 2004; Moore 2002). Before slavery, music played a key role in ceremonial ritual and thus the social reproduction of tribes. Although it is important to note its couching in Western musicological terms, Darden references

\footnotetext{
${ }^{20}$ Lewis considers African American musical practices after 1950. In the post-war era, composerperformers such as Charlie Parker, Thelonius Monk, and Dizzy Gillespie practiced a form whose sonic assemblage came to be codified by themes of freedom, spontaneity, and personal expression as it entered the discursive realm of critics and fans alike. Uniquely, these composers designated significant aspects of their songs as performer-supplied, as opposed to composer-specified. In this case the style (as opposed to notated form) was called bebop (arguably a subheading to jazz), and the practice, rooted in African traditions, was called improvisation. The juxtaposition of Afro- and Eurological musical perspectives, both mediated by the organization of institutional networks making up their separate but related scenes or "art worlds," then, worked alternately, to retrench or disrupt cultural inequalities. The emergence of improvisation in the 1950s and 1960s, then, allows us to understand and explain the Afrological musicoaesthetic sensitivity as a transformative strategy specific to an historical time and space.
} 
Scottish physician, Mungo Park, whose 1795 exploration of the Niger and Gambia rivers and its peoples includes the observation of consistently occurring elements: alternation of verse and chorus, a preponderance of rhythm, the use of short musical phrases, a call-andresponse format (antiphony), lyrics with secondary meanings, and a joy of improvisation (2004: 16). Referencing John Lovell Jr., Darden significantly notes that such music making is also characterized by a vigor that is not limited to sacred-secular distinctions. Indeed, prior to its institutionalization, all aspects of slave life were refracted through musical self-practice (Davis 1998; Baraka 1963). While it may sound clichéd, the conditions of slave life were extremely constricting for slaves, limited to the watchful eye of their owners and the ways in which life was ordered on the plantation; however, the sustaining of such a life, deplorable as it was, was also a function of Afrological musical self-practice that in turn opened slaves to the European derived logic of their owners, and relatedly, proselytization.

Beginning in the mid-eighteenth century in the Mainland colonies, Christianity spread via revivals such as the "Great Awakening" and the evangelism of traveling ministers. At the time, evangelizing slaves was hardly considered valuable, many slave owners themselves not being Christian, while many believers felt such bondage justified based on the myth that Africans were descendants of the biblical figure, Ham, the wicked, thus cursed, son of Noah. However, in 1706, the influential Bostonian Puritan preacher Cotton Mather advanced both spiritual and pragmatic arguments for the "Negro Christianized" through baptism: "the Christian has a moral responsibility for the souls of those in danger, and the Christianized servant is more profitable to his master" (Darden 2004). Concerned that they would lose their slaves, masters allowed baptism on 
condition of a massive indenture, the imposition of Mather's "responsibility" for the black soul as "the white man's burden." In this new subjectivity, slaves were racialized, the basis of their socially denigrating experience being the idea that identity was rooted in the colour of their skin. Nevertheless, the ethnomusicologist Radano argues, "the musical possessions of slaves remained only partially obtainable by whites even though they could otherwise claim ownership of the bodies of the slaves themselves. For in music, slaves had discovered a generative basis of culture whose life-affirming power stood repeatedly in contradiction to the life-denying assertion that blacks were nothing more than property" (2012: 237-8). Evangelized into the Christian church, slave musical selfpractice was transformed. For instance, Southern revival meetings provided one of few public sites where slaves accompanied their owners (Darden 2004: 48-69), exposing slaves to Protestant worship ritual and music, which was in turn widely adopted along with Christianity.

Christianization played an influential role in shaping the public space of dance and musical practice. As Sunday Sabbaths were observed, slaves were allowed to gather away from their owners, as in New Orleans at Place Congo, where crowds would form circles - an early form of the cipher - around musicians and dancers, playing well into evening (Epstein 1977: 84, 90-98, 133-35). On the one hand, as they integrated newly arrived slaves from Africa and the West Indies, such gatherings worked to preserve certain Africanisms in the New World, while on the other hand, such forms were refracted through the Christian liturgical calendar; for instance, the feast of Pentecost Pinkster among Dutch colonists and Whitsunday among Anglicans. Although recorded as early as 1667 , the historian Southern recounts a vivid description from eighteenth 
century Albany, in which slave and free men and women formed a perimeter around the town square, leaving a space for partners to dance with the rhythm of the eel-drums:

Briskly twirled the lads and lasses over the well trampled greensward; loud and more quickly swelled the sounds of music to the ear, as the excited movements increased in energy and action; rapid and furious became their motions... and still the dance went on with all its accustomed energy and might for several days. (Dr. James Eights of Albany, in Southern 1971: 50-53)

Such public spaces conditioned African rites economically and spiritually, according to both the workweek and now, the Christian calendar too. ${ }^{21}$ The sharpening contrast between sacred and secular that came with Christian revivals, contributed to the retreat of dance to the private sphere, as in the Southern "brush arbour."

The roots of Old-line (Anglican-Episcopalian, Methodist-United, Presbyterian, Puritan, and Reform) Church worship practice are found in the encounter between the Afrological and Eurological perspective, the formal establishment of singing schools, and later, the publication of hymn books. According to Cusic, singing schools began around 1717 in Boston, with the intention of re-establishing musical literacy among increasingly diverse congregations (2012: 66). Moreover, "music directors" were designated to take over from ministers the role of leading worship. In the South, singing masters were contracted on plantations for a week at a time, hired to teach songs and notational rudiments, often completing lessons with a weekend performance. Such lessons were particularly appealing among youth, slave and free. In 1739, Isaac Watts' Hymns and Spiritual Songs was published in the U.S., printed in part by Benjamin Franklin in Philadelphia and in part by his partner James Parker in New York, while the binding was

\footnotetext{
${ }^{21}$ The case of New Orleans was distinguished by French and Spanish colonial rule up to the Louisiana Purchase in 1803, including for instance Catholic funeral rites, plaçage, and influxes of gens de couleurs following the eighteenth century Haitian revolt. Specific to the crescent city, all this contributed to the practice of jass and later jazz, which became popularized in Chicago and Harlem during the Great Migration at the turn of the twentieth century.
} 
completed in Boston. It was the first publication as such to be shared among colonies. At the time, Watts' hymns were distinct in that his lyrics reflected a personalized devotion to the Lord, relevant to the growing Independence movement. In comparison, the Puritan approach to worship rigidly required fidelity to the scriptural Psalms and barred instrumental accompaniment. Watts' hymns became a favourite among slaves, manumitted, and freedmen in the Northern black church. Cusic mentions William Billings as among the earliest singing masters established in the North; "not a great singer" but possessed by a "vast amount of self-confidence." Billings is also considered the first major composer in America, publishing his New England Psalm Singer in 1770 and establishing a "Sacred Singing School" in Stoughton, Massachusetts, in 1774. The formal organization of such leadership and schools extended the structural makeup of the Church into the everyday lives of its congregations, creating a space in which musicosocial ordering could occur and establishing a consumer-performer base for the publication of song sheets and hymnals. Indeed, such schools and publications would receive a further boost after Independence through the push to establish an American (non-British) culture industry, and after the Civil War, through the founding of black universities and university choirs.

\subsection{2 - 1865-1900: Minstrelsy, Emancipation, Jubilee Spirituals and the rise of} the American culture industry

Drawing on James C. Scott, Mark Anthony Neal attributes the survival of the African American diaspora in the face of dehumanizing oppression during slavery, to the technique of "hidden transcripts," and the strategy of creating covert or safe spaces in which slaves could attain a sense of collectivity, like the "brush arbor" (1999: 2). Hidden 
transcripts constitute sonic "signifyin(g)" ${ }^{, 22}$ practices that convey two meanings. On the surface, slavers interpreted musical expressive culture simply as utilitarian "work songs," religious "spirituals," or worse, as bestial noises. However, the double entendre of such signifyin $(\mathrm{g})$ also reveals codified meanings, as in the songs that disguised directions north to Canada and freedom.

With the succession of the American Revolution, the Civil War, and Reconstruction, Afrological signify(n) musical practices moved from the private space of the brush arbor to the public sphere of the stage, sacred and secular, yet with unique distinctions. The designation of such spaces contributed to the social construction of public performance places and a co-dependence between institutionalized American popular culture and black popular culture (Neal 1999; Negus 2004). Covert safe spaces did not disappear; rather, the Black Church and black schools, for instance, became spaces where former slaves could practice democracy relatively free from persecution, albeit according to hierarchized Christian patriarchal structures. According to Tracy (2002), Reconstruction brought hope to newly liberated slaves or "freedmen," manifest in freedom of movement, the opening of black patronized banks and schools, and most significantly, enfranchisement. However, with the withdrawal of Northern troops from the South, resentment toward former slaves entered the discourse of the public sphere, while also manifesting itself in exploitative working conditions and widespread lynching. The depression of 1873, and in 1883, the Supreme Court's repeal of the Civil Rights Act (1875), exacerbated the issue, precipitating Jim Crow segregation. Lack of education and

\footnotetext{
${ }^{22}$ Henry Louis Gates Jr. traces the provenance of "signifyin'(g)," a device for playing with rhetorical difference common in Afrological expressive culture, to the mythical, Esu-Elegbara, or signifying monkey representing the devil (1988: 44-88). I will elaborate on the sacred-secular aspect of the Afrological perspective below.
} 
health care left many unemployed, including the blind. In some ways, former slaves became worse off with the failure of Reconstruction than in the previous period.

However, the Emancipation Proclamation allowed the conditions for the development of black public life and a philosophy of that life vis-à-vis the Black Church and Black Southern schools (Neal 1999: 3-9). In turn, the emergence of Black public spheres contributed to the division of Afrological musical self-practices into private and public, secular and sacred modes and their representations. ${ }^{23}$ In terms of its division, the Christianized Spiritual became distinguished through its codification of Christian ethics and themed by a hopeful hereafter while often adopting Eurological compositional form. In contrast, the secular blues came to express the desperate conditions of the present codified in secular terms and sonically supported by a transposable 12-bar format (cf. Oliver 1986; Baraka 1963; Moore 2002). ${ }^{24}$ Here, the blues became the express politic of the individual as a derivative of a collectivity, as opposed to a universalistic projection of the collective as an aggregate of individuals. According to Harris (1992), Reconstruction opened the South to investment. This included attempts by Northern churches to outdo each other in the race to construct new schools and universities. Although often no more than glorified high schools, by 1870, there were more Negro universities in the American South than those for whites. According to Darden (2004), Fisk University based in

\footnotetext{
${ }^{23}$ Although during slavery, the distinction between work songs and spirituals denotes a secular-sacred divide, Afrological tradition would suggest that both modes remained firmly spiritual. However, this ontological divide would appear to emerge in parallel with the conditions that made assimilation a viable option or not, for instance, exacerbated with citizenship and the rise of the Black Church.

${ }^{24}$ Notably, the sacred-secular divide was not always cut and dried as many performers straddled both realms, helping to define the fields through opposition. For instance, "guitar evangelists" such as Blind Willie Johnson embodied the itinerant blues singer yet performed to and about Christ; and Washington Philips, who recorded with a dulcimer-like instrument, took an ecumenical stance, critical of the abuse of power in the institutionalized church in songs like "Denomination Blues," which despite its namesake, expanded definitions based on the 12-bar format. I will discuss the perceived - and often exploited transgression of the "crossover" artist musician further below, as it gained currency after the Great Depression. For now it is important to note the elaboration of the sacred-secular boundary after Emancipation, particularly as its demarcation affected African-American musical practice.
} 
Nashville, Tennessee, was started in 1866 by the American Missionary Association

(Albany, NY), along with six other colleges and schools of theology across the South.

Fisk soon found itself running a deficit. In response, First Sgt. George Leonard White, a Union veteran, agreed to develop a choir called the Fisk University Jubilee Singers. He toured the Singers first across the state to Memphis, later to major Northern cities, including New York, and in 1873, to the UK, to perform before Queen Victoria in London. Distinctly, the Jubilee Singers worked to popularize the Spiritual by marrying its Afrological roots (in antiphony and rhythm) with the Eurological compositional form, while it became justified structurally through critical acclaim and popular support in the Urban North, even earning enough funds to expand building construction at Fisk. ${ }^{25}$

However, it was the Jubilee's distinction from yet another secular form during this period that worked to objectivate the expressive culture of the Spiritual.

According to Darden (2004), the term "minstrelsy" first appeared in 1842 to describe various forms of popular blackface entertainment. However, as early as the late eighteenth century, groups of white men began painting their faces black with burnt cork and staging concerts where they would perform "authentic" African-American songs from the South. ${ }^{26}$ Although Darden conservatively insists that Northern organizers, performers, and audiences were sympathetic to African-Americans (perhaps initially), by the 1810 s, representations of minstrelsy were undeniably and pejoratively racist: the world that it (re)-presented, was one of codified and caricatured plantations, cities,

\footnotetext{
${ }^{25}$ Minstrelsy is another form that in a way preserved the spiritual; however, despite providing employment and exposure, for instance being performed and broadcast as late as the 1970s in Britain (Christina Baade 2014), I will not be discussing its influence on the development of gospel music here.

${ }^{26}$ While I have discussed it in chapter two and will be discussing it further in chapter four, suffice it to say that the concept of "authenticity" and its use denotes a multifarious and highly charged social construction that has at its root, the capitalization of difference. The era from Independence to Reconstruction is no exception to this rule and its related strategies; in fact, it is arguably the era during which authenticity became a foundational aspect of American popular culture.
} 
Negroes, Irishmen, and Germans. ${ }^{27}$ Either way, musical appropriations during this period and represented by the field of minstrelsy denote a complex admixture polarized by race.

Significant for this project, minstrelsy performances became sites in which former slaves could subvert racism through transgressive techniques of humour and music. For example, Darden quotes African-American historian Alain Locke: "We might say that Negro musical comedy made its way luring its audience with comedy farce and then ambushing and conquering them with music" (2004: 125). Even before AfricanAmerican dissenter W.E.B. Du Bois endorsed the apparently benign, subversive technique, Black Folk used musical practices to claim the humanity that their oppressors so adamantly refused, even if it meant the apparent compromise of assimilating white appropriations of their own representation. In the end, such transformative techniques signaled emergent critiques of Romanticist and Modernist extremes wrapped up in the question of essentialism or "authenticity;" given its sociality, music is not reducible to race, while race is not an essence prior to its sociality, respectively. After the 1870s, minstrelsy enthusiasts contended with the rising popularity of the Jubilee, incorporating Spirituals into performances and thus underlining the distinction between "authentic" and "fake." Darden insists that such changes reveal the beginnings of a black collective consciousness. The objectivization of musical subjectivity also indicates a step toward music's objectification apart from its mediation of the self.

\footnotetext{
${ }^{27}$ Darden explains that by the Reconstruction period, minstrelsy had already become America's first successful cultural export to continental Europe and the UK, attributing its pervasiveness to the class culture of audiences from the era, that being the predominantly poor, white, and illiterate (2004). Also, limited mobility meant that minstrelsy was the first exposure that such audiences had to the world outside their immediate community. Summarily, he insists that minstrelsy provided a means whereby former slaves could find work when otherwise unemployable, becoming self-sufficient and supporting relatives through school and old age.
} 
In sum, the distinction between Afrological sacred and secular musical selfpractice in the United States was underscored in the period from Independence to Reconstruction by changes in citizenship and its subsequent retraction under Jim Crow in the South, the expansion of education and the popularization of the Jubilee Spiritual, and the emergent culture industry and the popularity of Minstrelsy. And yet, the most significant objectivating influence upon African-American musical subjectivity came from within the Black Church vis-à-vis its institutionalization.

\subsection{3 - The rise of American popular culture and the institutionalization of the "Gospel Blues" from 1900 to the Great Depression, with a "musical self" comparison of Arizona Dranes and Thomas Andrew Dorsey}

From the 1880 s to the 1920 s, major social changes swept across the U.S. that encouraged the rise of American popular culture as global popular culture, in conjunction with changes in Afrological musical practices and the makeup of the institutionalized AfricanAmerican Church. In the main, such changes are attributable to the migration of former slaves and their descendants from Southern states to the urban North and the expansion of mass media, its reproduction technologies of print and electric recordings combined with the organized dissemination of various representations. The gospel historian Don Cusic (2012) insists that after the end of the Civil War, former slaves were in conflict with their past, determined to distance themselves from slavery through education, upward mobility, and self-sufficiency, essentially assimilating to dominant middle class ideals. Yet with the gradual erosion and failure of Reconstruction, such aspirations would be seriously constrained by political, socioeconomic and climatic conditions. At the time, Southern blacks lived in abject poverty, and if employed, worked in serf-like conditions; 
Darden (2004) places unemployment as high as 75 percent in regions across the South. The 1896 Plessy v. Ferguson Supreme Court decision effectively decimated civil rights, including endorsing separate but equal spaces, coerced disenfranchisement at the polls, and instituted Jim Crow laws. From 1860 to the beginning of the twentieth century, the African-American population in the U.S. doubled to about nine million, eight million of which lived in the South, the majority living in rural settings. Quoting the historian Leon Litwack, Darden describes a depraved condition between 1890 and 1917 in the South in which "two or three" African Americans were "hanged, burned at the stake, or quietly murdered every week" (2004: 132). According to Baraka (1963), the failure of Reconstruction and rise of Jim Crow stripped African-Americans of any sense of citizenship, differentiating "them" from the dominant culture of the American South in particular, and whites in general. Even after their return from service in the Great War in the Red Summer of 1919, black soldiers were met with violent racism and lynching (Wald 2007: 11). However, industrialization in the North coupled with a labour shortage brought about by constricted immigration due to the First World War, provided the condition for the Great Migration that brought an estimated five million former slaves and their descendants to major urban centers including Chicago, Detroit, Philadelphia, Washington, Richmond, Cleveland, and New York in the North, and also to coastal cities such as Los Angeles and Oakland, and ship building centers such as Norfolk. Such were the conditions that influenced the forms and content of Afrological expressive culture to come.

The Great Migration represents a new public articulation of cultural and material forces that were acting upon and through Southern exiles attempting to escape the legacy 
of slavery and presently desperate circumstances through the acquisition of selfdetermination through industrialized labour (Neal 1999). Mark Anthony Neal argues that migration facilitated the development of the Black Public Sphere in the urban North, both of which highlight the diasporic nature of the African-American community: "within this context, the concept of 'movement' emerges as a primary trope of African-American political and cultural expression in the twentieth century" (1999: 12). Quoting Cornel West, Neal insists that the major themes of twentieth century black life are "neither integration nor separation but rather migration and emigration" (1999: 12-13). However, migration and its signification in black cultural expression should be treated as symptomatic of the impetus to sever ties with slavery and the South and create community elsewhere. The Northern urban black church thus surged in attendance and in its public presence, yet ironically, with the effect of reproducing traditions established in the South. In the covert space of the slave church, slaves mitigated the tyranny of their owners with a sense of collectivity, both through participating in various roles and practices such as pastor, deacon, and singer, and also through the symbolism of exodus represented in ancient Israel's Egyptian captivity, trials in the wilderness, and redemption represented in the Promised Land. With the Great Migration, the now institutionalized Church was again seen as a sort of refuge in the midst of change - a means whereby African-Americans could acculturate. Distinctly, even as African-American public leaders such as Booker T. Washington and W.E.B. Du Bois were emerging, the Black Church already debated the two leaders' respective frameworks, divided according to two distinct lines: full integration with the mainstream white culture and the assimilation of its value system, including the more pragmatic strategy of acquiring labour ready skills; and 
arguably, to a lesser extent, separation through political dissent and collectivized critical consciousness. ${ }^{28}$ Established by the end of the eighteenth century, mainline Methodist, Baptist, and to a lesser extent, Catholic, churches in the North, typically aligned with the first perspective and practice; and Holiness and Pentecostal Churches, which emerged in the South at the turn of the twentieth century before spreading quickly throughout the country, provide the other.

In terms of the religious field, the St. Thomas African Church of Philadelphia, dedicated in 1794, was the first independent African-American church in North America (Darden 2004: 37). One hundred years later, 5.2 million blacks claimed church membership, 60 percent of whom were Baptist, and the African Methodist Episcopalian (AME) a distant second (Harris 1992: 75). Here Methodist founder John Wesley's mantra derived from Matthew 5:48, ${ }^{29}$ justification through sanctification, became adopted by the emerging Sanctified movement. Darden states that mainline churches did not always take kindly to what was perceived as a debased rural lifestyle, and hollering "amen" and "hallelujah" in church. Such Sanctified churches had worked to assimilate white middle class respectability and a well-established infrastructure, often seen as one and the same. For instance, according to Thomas Andrew Dorsey's biographer Michael Harris (1992), Chicago's Olivet Baptist church grew such that from 1882, it established from its house meeting groups at least nine churches, each of which numbered by the middle 1920s no fewer than 500 members, and as a group made up the major religious

\footnotetext{
${ }^{28}$ I say to a lesser extent not to diminish the prominent place of the New Negro Movement in the African diaspora and American popular culture from about 1918 until the 1930s, represented for instance in the public emergence of Black literary arts and the "Harlem Renaissance;" rather, while the movement arguably reached its zenith from about 1924-1929, the Great Depression effectively devastated its production and consumptive bases, compared to the Black Church which continued its influence up until its waning in the post-industrial 1970s.

29 "Be ye therefore perfect, even as your father which is in heaven is perfect."
} 
body in black Chicago. Similar schisms grew the AME churches as well. Harris states that the first opera to be sung by African-Americans in Chicago was performed in December 1921 by the Bethel AME Church choir, with orchestral support by members of the Chicago symphony. Once its leaders recognized that the reputation of their church hinged on musical performance, the old-line black church modeled itself institutionally and musically after European derived churches, opposing indigenous traditions through the adjudication of formal choirs and orchestras according to the dictates of formally educated and highly paid musical directors.

While the mainline church would provide the infrastructural foundation for Black Gospel, the Holiness Pentecostal movement would vitalize its heart and soul. Following an unorganized revival first in 1901 in Topeka, Kansas (Charles Parham) and a second in 1906 at the Azusa St. Mission in Los Angeles, the Pentecostal movement influenced an approach to Christian worship inspired by the Acts 2 account in that believers experience God's presence through his Holy Spirit, manifested in gifts such as glossolalia, or speaking in tongues, and prophecy. The Holy Spirit would often overwhelm or possess the worshippers and lay them out on the floor, hence attracting the derogatory term, "holy rollers." Initially, led by African-American minister William J. Seymour, the Azusa St. revival transcended a variety of social boundaries, including ethnicity, and spread to attendees who came from around the globe (Sumrall 1995). According to Corcoran (2012), Charles H. Mason was one of the only converts at Azusa whose church was legally incorporated as the Church of God in Christ (COGIC). Mason ordained over 300 ministers at Azusa St. before bringing the movement back to his church in Lexington, 
Mississippi, and shortly thereafter to what would become the seat of the COGIC church in Memphis (Boyer 1995; Darden 2004; Cusic 2012).

The appeal of the Pentecostal movement lay in a vibrant spiritual abandon to God in which material reality is infused with the spiritual, manifest in dance and congregational musical expression and similar to Afrological perspectives long practiced in Southern states (Corcoran 2012; Oliver 1986). Musical performances accompanied by instruments played a key role in mediating this experience, arguably adding another layer of expression to worship in the urban storefront churches of the period. In addition to weekly meetings, C.H. Mason and his bishops maintained an annual Azusa-like Convocation of ten days in which COGIC leaders would keep the Holy Spirit fire alive. By 1925, into the thick of this movement entered a young black woman, a blind pianist called Arizona Dranes. ${ }^{30}$ In the liner notes to her remastered compendium of songs, Corcoran (2012) writes that Dranes significantly influenced the emergent Afrological musical expression that was to be called Black Gospel by making the piano and a particular rhythmical style of performance the focal point, thus structuring agent of worship.

In terms of her musical self, Dranes' formative and educational years overlapped in a Texas, state legislated (1887) school for the "educable blind and deaf" (Corcoran 2012). She studied octaves and vocal tone production by the age of eight and sonatas by Mozart, Beethoven and Liszt by age ten. Her formal education prepared her for a career in music. According to a 1921 city of Sherman Texas directory, when she would have been 32 , her occupation is listed as an actress where she most likely practiced barrelhouse

\footnotetext{
${ }^{30}$ In this hyperlink to Youtube audio video recording of "It's All Right Now," (1926) Arizona Dranes' distinct piano playing style, including 1651 opening progression, barrelhouse style, and articulate singing are apparent.
} 
and ragtime musical styles. Darden describes the appeal of the black theater at the turn of the century, as it shifted from minstrelsy to vaudeville; with high rates of unemployment already for the able-bodied and skilled, many, including women and the blind, had little option but to turn to the theater for work. Baraka (1963) states that by the 1920s, the New Negro Theater operated as a site in which blacks could resist the oppressive regime of middle class ideals, setting a precedent that would be followed by successive Afrological forms such as the blues, jazz, swing, bebop, and freeform. I would argue that figures such as Dranes infused gospel with a particular Afrologic perspective that recalled African tranditionalisms relative to mainstream and middle class values modeled in the old-line church. In any case, Dranes' recorded performances are characterized by ragtime and barrelhouse on three separate recordings that she made, first with Okeh records in Chicago, 17 June 1926, then after Okeh was bought by Columbia, 15 November 1926 and 3 July 1928. It is interesting to note that if not for recordings, we might not know of the ways in which Dranes infused gospel worship with such styles. Improvisation likely would have dominated her playing and notation would have been negligible. Corcoran states that the secular styles of playing would not have been openly accepted in the COGIC at the time, yet her emotional singing as recorded embodies the evangelical fervour espoused by the Pentecostalist preachers with whom she traveled and performed. Endorsements for Dranes came from Mason in Memphis, Emmet Morey Page in Dallas, R.F. Williams of Cleveland. Moreover, Dranes' ability to combine several styles in an emotional and relevant fashion appealed to a growing urban population that perhaps remembered such expressive practices with fondness from their upbringing in the South (cf. Baraka 1963; Kot 2014), in turn operating to propagate the 
Black Church as support to the Pentecostal movement and as a challenge to the musical programming of the mainline church to update its sound. Before died of complications related to a stroke and dementia, the challenge of Dranes' piano playing style was taken up by among others, the father of the Gospel Blues.

According to the sociological biographer Michael Harris (1992), in 1907, by the time Thomas Andrew Dorsey turned eight years old, he had experienced a set of tensions that combined with his education so as to inform his professional musical practice. Having been raised in rural Villa Rica, Georgia, where his itinerant preacher father taught him the Afrological practice of moaning, and pious mother along with blues guitarplaying and bootlegging uncle Phil taught him the shape note or sacred harp tradition, Dorsey's musical self engendered an emotionality linked to an appreciation for performance synched with notation. However, despite practicing his musical self practice at rent parties under the tutelage of a theater pianist, his lowdown rural blues performance style was deemed simplistic in the hierarchized musical scene of Atlanta. Even after joining the Great Migration in 1916, South Side Chicago with its nascent blues and jazz scenes offered few alternatives; Dorsey was relegated to the lower ranks of the respective scenes, limited to late night brothels. Here, the demand to entertain both proprietors and their patrons provoked depression and a nervous breakdown, sending him back to Atlanta in 1920 for rehabilitation. Although the details of his breakdown are not forthcoming, Dorsey's determination to return to and compete in the Chicago scene led to transformative experiences in his relation to both sacred and secular musical practices.

By the 1920s, the Protestant old-line churches of Chicago were the most attended and most influential of African-American organizations in the U.S. According to Harris, 
the black church served as an "institutional means of social control and as an avenue of assimilating non-Afro-American values," evident in, "priestly," preaching and formal musical practice (1992: 103-116). As orchestra-accompanied choirs became more popular, such integrationist churches competed for formally trained music directors, luring them with high salaries and artistic freedom, organizing monthly musicales where they could showcase their cultural capital. However, to the Southern Baptists and the Pentecostals alike - Dorsey included - the structure of the Northern churches quelled "indigenous music practices, like congregational singing, hand-clapping, foot-patting, and other demonstrative behavior" (Harris 1992: 106). Soon though, their increasing numbers by way of the Great Migration lowered the reformatory flash point, while Dorsey's particular practice helped to spark it.

Following his first major bout with depression and return to Chicago, Dorsey attended the National Baptist Convention in 1921, then the largest African-American organization in the U.S. Here, Dorsey became impressed with "Professor" W.M. Nix, whose performance of “I Do, Don't You," doubled as promotion of the seminal hymnal, Gospel Pearls, of which he was an editor. Significantly, Harris argues that stylistic elements in Nix' performance, including ornamentation and tempo, were recognized by Dorsey as derivative of moaning: "Given the despair, grief, and loneliness Dorsey projected through his blues, he had to be aware that Nix's singing conveyed feeling of the same order and that the similar elements of both lowdown blues and the Nix styles provided for an expression of feelings not unrelated to one another" (1992: 74). Dorsey's conceptual rendering of music not just as sounds but as feeling meant that he was open to 
incorporating otherwise derided blues notes into gospel music, blurring the sacred-secular divide, and eventually, influencing worship as it was then practiced in the church:

Blues is as important to a person feeling bad as "Nearer My God to Thee." I'm not talking about popularity; I'm talking about inside the individual. This moan gets into a person where there is some secret down there that they didn't bring out. See this stuff to come out is in you. When you cry out, that is something down there that should have come out a long time ago. Whether its blues or gospel, there is a vehicle that comes along maybe to take it away or push it away. A man or a woman singing the blues in the church will cry out, "Holy, holy, holy." (Dorsey in Harris 1992: 99)

Although after his NBC experience, Dorsey found recognition with the publication of his "If I Don't Get There" in the second edition of GP (September 1921), the market for his compositions was unsustainable compared to the fields of secular blues and jazz. Here Dorsey capitalized on the growing popularity of the classic blues scene, particularly following the success of Mamie Smith's "Crazy Blues" (1920), and the musical labour shortage created by the exodus of elite performers from the South Side to Harlem. Significantly, from 1924 on, Dorsey developed a then distinct talent for arranging blues with enough structure that bands and singers could together follow chord changes, for instance, yet without restricting its embellishment, as in improvisatory trills and moaning, that both stemmed from the Afrological tradition and garnered the appreciation of paying fans. Free from the assimilationist church, Dorsey in his two-year stint with "Ma" Rainey soothed the lowdown blues. ${ }^{31}$ Yet, he blurred the boundaries again after making musical sense out of the combinations of a two-year debilitating round of depression and the death of a friend ("If You See My Saviour, Tell Him that you Saw

\footnotetext{
31 "Georgia Tom" Dorsey found huge success again after writing and performing with "Tampa Red" Whittaker as The Hokum Boys, particularly with the raunchy, "Tight Like That" (1928). Although perhaps exemplary of a transgressive performance relative to the Black Church, both the ambivalence of his relationship to the church and my focus on musical self-transformation, deems this aspect of his career less significant.
} 
Me" (1927)), and the deaths of his own wife and infant son due to complications with childbirth ("Take My Hand, Precious Lord" (1933)). This latter example is perhaps the most significant example of music's contribution to self-transformation in Dorsey's life, particularly as he altered his sonic delivery from stating in a more reverent style, "Blessed Lord," to proclaiming in the more devoted and personal style, "Precious Lord." Harris states of his writing process, 'Up until 'Precious Lord' 'hooked' Dorsey that night, his gospel blues consisted of lowdown blues 'twists' and 'turns,' but without their verbal 'prick,' their articulation of sorrow." He continues, "With 'Take my Hand, Precious Lord,' Dorsey allowed himself to wail, to get 'lowdown,' to purge - rather than just soothe - his grief" (1992: 239). Like no song before it, "Precious Lord" melded the sorrow songs, spirituals, jubilee, and camp-meeting songs into the intimate wail of the blues" (2004: 171), changing the focus from formal performance to personalized yet congregational songs. Equally, the rhythm was distinct from the otherworldly focused and therefore blindly happy spiritual (e.g. "Oh When the Saints"), in that it heavily accented the beat, so as to invite physical and emotional engagement or dance. Moreover, with the successful reception of "Precious Lord..." at the 1931 NBC, Dorsey devoted his craft and future practice to the Lord, thus supporting the establishment of the sacred music field (although not limited to that field alone), underscored both by Sallie Martin's contribution of organizational skills and by burgeoning urban congregations. Alogether, a national network of churches was established whereby his published "Dorseys" could be showcased along with his choruses, culminating in the establishment of the annual National Convention of Gospel Choirs and Choruses (NCGCC). Here, singers such as 
Martin herself and Mahalia Jackson, the "Queen of Gospel," contributed to the establishment of the golden age of gospel, from 1945 to the $1960 \mathrm{~s} .{ }^{32}$

Cusic (2002) insists that Thomas Andrew Dorsey is a key figure in the establishment of the Afrological religious musical sensibility called Black Gospel, its writing and publishing, because of several traits, including personality, as composer, publisher, performer, teacher, choir director and organizer, as well as music director. And yet, we have seen the ways in which Dorsey objectivated three influential experiences that led to specific forms of thought and knowledge relative to the foundations of the field of gospel in the midst of major institutional and migratory forces. Compared to Arizona Dranes whose performances, though inspiring, were viewed within the Pentecostal Church as simply complementary, Dorsey's spatial-temporal position relative to the increasingly prominent old-line strain of the urban Black Church would help to influence the careers of several gospel performers. Many such performers engendered alternately "prodigal son" or "sinner-to-saint" trajectories, ending up committed to the Lord and thus the Church. However, the rise of the American popular culture industry with the expansion of radio during the Second World War and TV in the 1950s provided the means for such performers to maintain a foothold in both sacred and secular fields. In the next section I will be sketching the conditions that gave rise to the Afrological musicalself practices often called, $R \& B$ and Soul, before analyzing the moral career of the “crossover artist" exemplified by Sister Rosetta Tharpe.

\subsection{4 - Gospel's Post-Depression "Golden Age," "Sister" Rosetta Tharpe, and} the complexity of "crossing over"

\footnotetext{
${ }^{32}$ Dorsey’s songs, "Take my Hand" along with "Let there be Peace in the Valley," written just before Hitler invaded Poland in 1939, sold over one million copies each for Red Foley and Elvis Presley respectively in the 1950s, two artists whose influence would also span sacred and secular fields (Darden 2004: 170-71).
} 
According to Mark Anthony Neal, in 1940, African-Americans in Northern U.S. cities such as Harlem emerged from the Depression "ravaged by economic neglect, structural erosion, and the spawning grounds of an angry and frustrated constituency" manifest in the first commodity riots to occur in the U.S., including two in 1943 in Detroit and Harlem (1999: 19-23). The source of that frustration was the paradox of poor living conditions and high unemployment, in what was for many meant to be the promised land of the North. Complicating the conditions was the rising population of African-American children, the first to be born in the urban North after the Great Migration. According to Neal, at the start of the Great Depression, more than seventy-five thousand black children under the age of fifteen lived in New York, "some forty-seven thousand in Manhattan alone." On their conditions, he continues, "Yet, while the city sought nearly \$121 million in federal funds for new school buildings, only $\$ 400,000$ was earmarked for schools in which blacks made up the majority of students... The number of black youngsters arraigned in Children's Court, which had nearly tripled in the decade before, more than doubled again afterwards. In 1938, black youngsters represented a fourth of all cases" (Neal 1999: 20). During the Harlem Renaissance of the 1920s, African-American cultural expression typically privileged a male liberal bourgeois perspective, engendered by mainline black churches and cultural progenitors such as Langston Hughes, Duke Ellington, and James Weldon Johnson. However, while Harlem's status as the cultural capital of the black public sphere was sustained through the Depression, the emergent youth who came of age in the 1940s maintained a more militant attitude, directly influencing the rise of the Civil Rights Movement in the mid-1950s and 1960s. While a rise in occurrence of youth crime and the aforementioned riots was indeed problematic, 
political organization by activists and groups such as the NAACP often worked to extend rights to African-Americans, including at the threat of A. Philip Randolph and Walter White's March on Washington, Franklin Roosevelt's signing of Executive Order \#8802 in June 1941, guaranteeing fair employment practice in defense industries and government. The Second World War, with its related expansion of industry production, contributed to the growth of the middle-class and in turn, consumption. Increased income and spending combined with new mass media technologies such as the transistor radio, for instance, (circumventing the familial surveillance of listening practices allowing racerelated boundary crossing) and recorded music as a cheaper alternative to live performance both on air and in concert, to create what Neal calls a "tumultuous marriage between black cultural production and mass consumerism - one in which black agency is largely subsumed by market interests." He continues, "Thus black musical artists were not fully integrated into the marketplace, and increasingly white artists appropriated black musical styles, in effect blocking black advancement within consumer culture, except in the role of mass consumers" (1999: 17). Coming out of the Depression and through the Second World War then, despite the growth of informal African-American "chitlin' circuit" venues, such as coffee shops and "juke joints," the black church remained the primary sphere in which leaders and congregants addressed social needs, political ideas and cultural expressions.

In terms of African-American religious musical practice, the establishment of black gospel as the dominant form characterizes the period from the Depression to the Civil Rights Era. The gospel historian Horace Boyer calls this period, The Golden Age of Gospel (1995). Arguably, the conditions described above contributed to an insular 
network of churches that in turn supported what I call a lineage of "artist-performers" with distinct career trajectories, many of whom began in the church performing with Dorsey in the 1930s, including Mahalia Jackson, the Martins, and Marion Williams. In their refusal to perform in certain venues because of the association with secularity, these artists worked to define the sacred-secular divide during an otherwise mass-mediated era. As such boundaries were established, their transgression, or "crossing over," would often become increasingly polarizing, such that a figure with the status of Dorsey in the 1940s could not maintain significant influence in both sacred and secular fields, simultaneously. At the same time, the secular market and American popular culture was poised to receive religious artists and their vigor, particularly as events leading up to the Civil Rights movement responded well to celebrity and lay-activists (Kot 2014). The growing youth segment of middle-class white Americans was increasingly exposed to Afrological perspectives and their gospel derived performances, through the expansion of independent black radio programming and also through performers who were obviously indebted to such perspectives, such as Chet Baker in the 1930s, Red Foley in the 1940s, and Elvis Presley in the 1950s.

If Thomas Andrew Dorsey's musical self-articulation in the black church during the Depression contributed to the establishment of boundaries that consisted in institutionalized black gospel, "Sister" Rosetta Tharpe consistently blurred those boundaries during her professional career from the 1940s on. According to her biographer, Gayle Wald (2007:1-14), Rosa was born in 1915 on Tillman Cooperwood Farm outside of Cotton Plant Arkansas, to Katie Harper (later, "Mother Bell" Nubin), and Willis Atkins. Her formative years were directly influenced by her parents' interest in 
African indigenous expressions preserved in the Pentecostal movement. However, her father's direct influence ended when Katie moved Rosa to Chicago, before the age of six, to join the Pentecostal movement. The largest church to organize in the movement was the Church of God in Christ (COGIC), led by Charles H. Mason, headquartered in Memphis. Wald suggests that while Katie may have left Arkansas because of the church's condemnation of the conception of children out of wedlock, her move was also affirmed by the promotion of women to dignified roles such as missionary and honorific titles, "Mother" or "Sister," also unique to COGIC. Empowered through the doctrine of Sanctification (set apart from the world) and the baptism of the Holy Ghost (selfsufficient through God's calling) taught at Robart's Temple in Chicago, Sister Rosetta accompanied Ma Bell on evangelistic tours and crusades across the Midwest and East coast throughout the 1920s.

The education of Sister Rosetta Tharpe's musical self in the Pentecostal movement can be explained using the framework of Du Bois' analysis of the paradoxical state of "double-consciousness," her identity being affirmed internally to a historically emergent field (African-American) yet also being discriminated against because of her lack of power within a more dominant field (mainstream American) ${ }^{33}$ However, where Du Bois focuses exclusively on racial difference, the specificity of Tharpe's religious belief system distinguishes her further. For Pentecostals, certain lifestyle behaviours were condemned, including "the lust of the flesh," lasciviousness, envy, murder, drunkenness, and other immoralities listed in the Pauline passage (Galatians 5:16-21).

\footnotetext{
${ }^{33}$ The Holiness/Sanctified movement emerged already in the mid to late nineteenth century, particularly in the Methodist and Baptist churches, drawing teaching from the John 17:15-19 passage. The Pentecostal movement adds the baptism of "the Holy Spirit and fire" with evidence of tongues that the apostles are described to have experienced, in Acts 2:4. The modern manifestation of this experience drew the derisive, "holy rollers."
} 
Such "walking in the Spirit" distinguished sanctified adherents from both the secular "world" in everyday life and from old-line Christians in musical expressive culture (2007: 22). For instance, as discussed above regarding Arizona Dranes, Pentecostals embraced instrumental accompaniment where the old-line church did not, even incorporating secular sounds in worship. Interestingly, in the relationship between secular musical sensibilities and sacred worship practices exists a circuit of social reproduction; arguably, the emotionality of secular musical forms such as the blues fit with the expressive worship practice of Pentecostals, which often returns to the secular realm with the same vigour. Indeed, Tharpe's absorption of the emotionality characteristic of Pentecostal worship contributed in part to her success in the secular field.

In 1938, Sister Rosetta Tharpe left her husband preacher Tommy Tharpe and her regular worship practice at the COGIC Temple in Miami for the Cotton Club in New York. To that point, "crossing over" had rarely caused moral panic among Christians, nor was the sacred-secular boundary as established as it was then. True, others already blended secular and sacred sounds in the 1920s, such as Blind Willie Johnson who sang gospel infused lyrics accompanying himself with slide guitar in a blues style, while others such as Blind Joe Taggart were already hiding their secular lyrics behind pseudonyms, including Blind Joe Amos (Walton 2010). However, by the 1940s, two opposing forces seem to have affected Tharpe's case. First the field specific strategies of Dorsey's musical practice, including copyrighting publications, the organization of annual choir conventions, and the pool of talented performers available to showcase his music, worked to insulate the sacred scene from secular appropriation. For example, after Tharpe 
seemingly appeared out of nowhere at the Cotton Club, she recorded, in late-1938, four singles for Decca, including "Rock Me." ${ }^{34}$ In this tune, she alters Dorsey’s lyric about a parent-Deity"s care, by introducing the "w" into "swinging" and rolling her "r" (e.g. "rrrrr-Rock Me"), opening up for secular interpretation, sexual innuendo. ${ }^{35}$ To the church, such secular incorporation constituted a grave transgression, drawing the fire of Dorsey himself in a Chicago Defender article published in 1941: "I have written more than three hundred gospel songs and spirituals. I do not object to them being used on the air, but they must not be desecrated or used for dance purposes" (Wald 2007: 47). Due to the rise of the gospel blues and wholesome stars such as Mahalia Jackson and the black church as a space set apart from secular popular culture, Tharpe's performances and, as Wald argues, her lack of "a viable 'crossover' narrative” (2007: 35), apparently doomed her to languish in obscurity.

After the sacred-secular distinction, the second force to detract from Sister Rosetta Tharpe's success “crossing over" is her gender and that through the mediation of her guitar. Generally, female musical selves, to that point, were celebrated for their voice, sensual or otherwise, while instrumental mediation was, for the most part, limited to supporting roles played on the keyboard, as in the piano in Arizona Dranes' case and organ in Dorsey's mother's case. Tharpe's prowess on the guitar, though selftransformative, at the time, in increasing her space of possibles, was otherwise seen as a

\footnotetext{
${ }^{34}$ In this hyperlink to Youtube video, Sister Rosetta Tharpe is heard performing "Rock Me" backed by Lucky Millinder's orchestra (1941). "Rock Me" begins with her solo guitar over the melody so as to mimic speech. Her lyrics express her devotion to her loving Lord yet with sensuality in the rolled "rrr" of "Rock." ${ }^{35}$ Tharpe's own sexuality is manifold in her three marriages, including the public spectacle of her third to Russell Morrison at Griffith Stadium in Washington, D.C., July 3, 1951. Newspaper ads for the event read: "Wedding bells ring out for... Sister Rosetta Tharpe. Witness the most elaborate wedding ever staged! Everybody is welcome! Plus world's greatest spiritual concert!" (Wald 2007: 116). Moreover, her bisexuality, taboo at the time, is manifest in her relationship with collaborator and touring partner, Marie Knight.
} 
threat to male performers. Biographically, since instrumental accompaniment was celebrated in the Pentecostal movement as an extension of the Holy Spirit within, live performance became the main testing ground for authenticity. At first, likely due to the dynamics of unamplified space, Tharpe developed a dexterous and rhythmic approach to the acoustic National Resonator guitar, making it "talk" (Wald 2007: 151-5, 174). After 1947, live and on recordings such as "That's All" she used various electric Gibson guitars to amplify her musical self-expression. Moreover, she mastered her performances according to a verse-chorus-bridge (guitar solo) structure more common to the then unpopular blues, yet significantly foreshadowing the guitar hero trope that would define Rock. However, ahead of her time, Sister Rosetta fell prey to gender norms widely held in the socially conservative 1950s and 1960s. Tharpe's peer Inez Andrews recalls the view that she was considered a threat to the scene: "we used to stand up and watch her from the sideline, at the time we were doing a lot of traveling with the Soul Stirrers and the Caravans.... And Sam Cooke used to tease all of the guitar players, and say, 'Man, I wouldn't let a woman outplay me!'” (Wald 2007: 153). Wald suggests that Tharpe would on the one hand, ignore gender norms in her musical practice, while on the other hand, exaggerate the inequality, claiming for instance that she was "not bad for a woman." Nonetheless, by embodying a bawdy yet large and in charge attitude, Tharpe challenged gender norms and helped to define the "bad girl" artist, inspiring subsequent performers such as Etta James, and significantly, in the 1960s, folk and blues revivalists in the UK that encouraged the rise of rock'n'roll.

In sum, Horace Boyer suggests that Sister Rosetta Tharpe "insisted upon a sound and lifestyle of ambiguity" (2007: 216). However, hindsight and Boyer's view from 
inside Gospel's golden age, perhaps, skew his assessment. Rather, “crossover" artists like Tharpe did not begin to experience professional career-sustaining success until gospel's golden age began to fade, coterminous with the emerging Civil Rights movement and the rise of Soul, as I discuss in the next section. Otherwise, she did not have had a successful example to follow, from which she could have learned to deal with various challenges. As Wald insists, gender norms in the conservative post-war period rendered Tharpe's "crossing over" to the secular popular realm the exception. Relatedly, the colour of her skin also precluded her from enjoying success in the white dominated and culturally dominant pop realm. Nonetheless, despite her apparent lack of success, Sister Rosetta Tharpe in fact brought vigour to the popular realm, inspiring the "bad girl" singer and contributing to the folk and blues revival in the UK that gave rise to rock'n'roll. Her apparent apolitical stance notwithstanding, I would suggest that the musical self-transformation behind Tharpe's "crossing over" contributed to the rise of black nationalism and the Civil Rights Movement by inspiring others not to be beholden to gender norms, nor to be afraid of racism, nor to shirk from engaging the world outside the church. Soon enough, such gains became inextricable from the expanding AfricanAmerican middle class in the postwar period and by extension the increasing autonomy of black popular culture relative to the mainstream. Into this space would emerge gospelinfluenced musical sensibilities that were to be called, R\&B and Soul.

\subsection{5 - From Civil Rights to Post-industrialization: The emergence of Soul as} commodified struggle and the struggle for musical hegemony

While African-American religious musical self-practice and the emergence of the ethic of self-transformation have been the subjects of this chapter, I have been at pains to sketch 
its history not as a totality, nor its agents as homogeneous, as designations such as "black" and "gospel" imply. As discussed in chapter two, music is self-transformation, the mediated planes of its practice being moving targets across the life cycle, and the dimensions of their objectivity being wrapped up as much in processes of objectivization (e.g. people making sense of themselves for themselves) (Bourdieu 1977; 2004) as they are in their public representation (e.g. the optics or politics of sound) (Neal 1999; Hall 2004; Gray 2005). Such moving targets in the post-war period, mass-mediating Afrological musical self-practice, including the rise of the Civil Rights movement in response to the structured racial inequality of Jim Crow, and changes due to processes of post-industrialization at the behest of neoliberalism. However, as Herman Gray points out, integrationalist representations of African-American cultural practices, for instance, in the mass media and TV slowly gave way to self-determined, resistance practices, strategies, tactics, and moves (2005). To Gray, conventional assumptions about recognition and representation as a means to membership in American democracy came into question here, in turn changing the political stakes of musical self-transformation. In this period, African-American religious musical self-practices fed into two trajectories: one stemming from the black church (Soul) and the other remaining within the church (Black Gospel), though fragmenting in traditional and urban contemporary forms in the 1970s with changing social conditions.

According to Mark Anthony Neal, the political and musical terrain for AfricanAmericans in the U.S. began to change after the Brown v. Board of Education of Topeka, Kansas, judgment, in 1954, which desegregated schools by granting the right to education to all Americans regardless of race (1999: 28-36). Such policy change, along with the 
Montgomery bus boycott, unsettled the Jim Crow South by rallying blacks. This had the circuitous effect of supporting the emergence of black leaders such as Martin Luther King whose representation in the media served to lend coherence to the Civil Rights movement, and in turn, to rally the support of the growing Southern black middle-class, the black church, and white sympathizers in the North. With such support, King led several non-violent protests against legal segregation and constraints on voting rights and social mobility until his assassination at the Lorraine Hotel in Memphis, on April 4, 1968. However, conditions in Northern and Midwest cities were somewhat distinct from the South, including strains related to rising unemployment due to the largest influx of Southern migrants yet, and relatedly, police brutality and housing discrimination. Black people across the U.S. were growing dissatisfied with such conditions, including the political impotence of consumerism. Instead, with the leadership of King in the mid1950s, African American communities rallied for Civil Rights.

Neal argues that Afrological musical expression in the Civil Rights era became a means of anti-capitalist resistance through the rejection of consumerism, and began to center around political themes and goals of social justice (1999: 25-34). Performers soon emerged whose musical selves embodied, expressed, and engendered the struggle of their social conditions. By the 1950s, after the Afrological musical expression jazz had been wholly separated from its organic roots in working-class black life through its fetishization, appropriation and commodification by the American mainstream, AfricanAmerican musicians who practiced in the covert safe spaces of the chitlin' circuit, coffee bars, and the black church, transformed their selves through the development of new Afrological musical forms. Rhythm \& Blues or R\&B embodied and came to represent 
the political and economic struggle felt by many urban African-Americans after the Depression, a reality heretofore ignored - at least lyrically - by crossover artists like Sister Rosetta Tharpe and Louis Jordan, due to the sacred-secular boundary upheld by the church, between the transcendent realm of the sacred and the material reality of the secular. ${ }^{36}$ Yet in marrying the sounds of the church with the political concerns of bebop's working class, the Afrological perspective of Soul emerged.

In a fascinating discussion, Neal attributes Soul's significance to its roots in the African-American experience in which planters obliterated slaves' sense of privacy, and pain overwhelmed their ability to objectivate their existential condition (1999: 38-39). Yet in their loss of private space and being overwhelmed by pain, slaves redefined their subjectivity within the aural parameters of polytonality. However, Neal makes the important distinction that antebellum era polytonal expression rooted such liberatory power in the motion and musicality of the African voice. Drawing on Elaine Scarry's elaboration of the body in pain, Neal explains that as pain overwhelms the self, it obscures the objective faculties, destroying language. In turn, Neal quotes Scarry, "when physical pain is transformed into an objectified state, it (or at least some of its aversiveness) is eliminated." She continues, "A great deal, then is at stake in the attempt to invent linguistic structures that will reach and accommodate this area of experience normally so inaccessible to language" (Neal 1999: 39). By extension, Soul singers in the 1960s gave public expression to the desperate social conditions that characterized their own formative years, yet like the slaves before them, in a way that was acceptable, even pleasurable both to the African-American community and American mainstream.

\footnotetext{
${ }^{36}$ For instance, the emergent sounds of bebop and its improvisatory practice are widely considered a rejection of both the Eurological compositional perspective and commodity fetishism represented in swing and jazz (Gray 2005: 52-76; Neal 1999: 29-36)
} 
The way in which R\&B and bebop set the stage for Soul begins with Ray Charles, a jazz pianist from Seattle, who swapped secular lyrics with Dorsey-influenced gospel blues. In December 1954, Charles released "I Gotta Woman" on Atlantic Records, to popular and critical acclaim, namely because of the organic way in which he combined the musical sensibility of his gospel style piano playing with the raw emotion of his vocal delivery of a transgressive topic. The association of sexual virility and masculine prowess with the black body in popular cultural expression is traced back to slavery (cf. Lott 1993). A notable singer inspired by Charles included former Highway QC and Soul Stirrer gospel quartet member, Sam Cooke, from Chicago. ${ }^{37}$ Cooke's smooth voice, sex appeal, and political sensitivity embodied in "You Send Me" (1957), his first single to receive wide popular-secular attention, helped him find success in both sacred and secular audiences. Significantly, although his initial crossover status was categorized as R\&B, his smooth and sexy aesthetic was too distinct to last as such. Moreover, demographic changes in (white) American popular culture, specifically the emergence of "youth" as a category between adolescence and adulthood and leisure activities mediated by cars, radios, and independent record labels and radio stations, allowed for Cooke to gain wide exposure to the formerly untapped white youth market. While Elvis crossed over in 1955, a white man performing R\&B (emergent rock'n'roll), Cooke crossed over in 1957, a black man performing non-R\&B (emergent Soul). However, the recognition of the massive white audience arguably did more to expand the conditions of possibility for black performers in the church than it did for white performers. Such change became

\footnotetext{
${ }^{37}$ In this hyperlink to Youtube video, Sam Cooke is seen and heard performing "You send Me" on the Ed Sullivan show (1957). One of the first crossover artists from gospel to the popular mainstream, Cooke's music played a vital role in establishing soul. Like gospel, "You Send Me" combines lyrically expressed abandon, here to his lover. Also, harmonized singers as in barbershop quartets back him.
} 
politically contentious, including Cooke's brief proprietary venture as the first AfricanAmerican to own a record label promoting African-Americans, ending in the speculative circumstances of his untimely death in 1964 at age 33. Nonetheless, Cooke's influence on emergent Soul was indelible.

It was not uncommon for black gospel and Soul musicians in the 1960s to straddle the sacred-secular boundary and with greater ease than previous crossover artists like Sister Rosetta Tharpe, due in part to factors of political solidarity then openly discussed in the church and represented in public behind leaders such as King. Mavis Staples was one such singer who shared the gospel scene with Sam Cooke as a youngster in Chicago before his crossing over and who straddled the sacred-secular divide throughout her career (Kot 2014). The Staple Singers were formed in the late 1940s in Chicago by Mavis' father, Roebuck "Pops" Staples, and achieved their widest recognition in the early 1970s. Having grown up learning the Delta blues Afrological sensibility in Mississippi during the interwar period, Pops distinctly accompanied himself with a tremolo soundeffected electric guitar described by Bob Dylan as sounding "mysterious" (Kot 2014). After marrying and moving to Chicago, Pops sang and recorded songs with his children, including sounds and styles ranging from what would be called gospel-folk to that of Soul. After signing to Stax records in the 1960s, the group developed a "funk" sound, writing politically inflected lyrics on songs like "Respect Yourself" (1971) while retaining a Christian influence on "I'll Take you There" (1972). Al Green is another notable variant on the crossover career who was influenced by Sam Cooke and who achieved popular success both as a Soul artist in the early 1970s and later as a gospel artist, crossing over several times after returning to the black church in 1976 as an 
ordained pastor of the Full Gospel Tabernacle in Memphis. Distinctly, Green popularized a style of falsetto singing that was inspired by Claude Jeter of the Swan Silvertones, one of the most popular gospel quartets of the postwar period.

However, to Mark Anthony Neal, Aretha Franklin and Marvin Gaye are the most notable crossover artists, whose most aesthetically consistent musical performances also represent the apex and demise of the Civil Rights era (1999: 57-61). Arguably, Booker T. Washington's “Atlanta compromise," and the dissident, W.E.B. Du Bois' call for political change represent two practical trajectories in the African-American experience still effective throughout the Civil Rights era and in Soul and gospel music. According to Neal, Martin Luther King represented the last vestige of Du Bois’ liberal bourgeois values in the black church before his death in 1968. Comparatively, militant leaders such as Malcolm X decried King's nonviolent method as politically ineffective. After the deaths of both King and X, organizations such as the Black Panthers emphasized political resistance as opposed to demanding Civil Rights. However, from 1967 to 1972, President Richard Nixon and FBI head, J. Edgar Hoover, repressed such resistance, often indirectly, as in the disproportionate drafting of young black men into the war effort in Southeast Asia, and also directly, through the FBI's counterintelligence program, COINTELPRO, which targeted King through phone-tapping, and Panther leaders, Mark Clark and Fred Hampton, ending in police raids and their respective deaths (Neal 1999: 57-61). Aretha's "Respect" not only came to represent the economic desperation that was hitting urban black families but more significantly, brought awareness to the gendered specificity to this plight. Largely considered a landmark for the feminist movement, her lyrical demand for reciprocity spanned domestic and political spheres 
alike. Sonically, Aretha's Atlantic recording, produced by Jerry Wexler, included instrumental sounds considered "raw" as the Muscle Shoals Rhythm Section from Alabama performed them. Yet her vocal expression drew on her formative years in her father's church in Detroit (Rev. C. L. Franklin) in which she regularly spent time listening to and practicing with leading gospel singers of the day such as Mahalia Jackson, Sam Cooke, and James Cleveland. However, despite Cooke and Aretha's popular success in popularizing the urban black condition, the African American community, arguably, lost much of its political momentum with the deaths of its prominent leaders between 1964 and 1971 and the state repression of its populist organization.

According to Neal, the Washingtonian trajectory in African-American cultural life serves to undermine political resistance through its commodification of vital cultural expressions and codes, thus rendering them irrelevant. To Neal, Washington's seductive appeal is in the control of resources through the self-determined individual, engendered during the Civil Rights era, for instance, in the huge success of Berry Gordy and his label, Motown Records (1999: 42-46). Modeled on the efficiency that he recognized while working in the Detroit automotive industry, Gordy streamlined Motown's musical production through the explicit employment of songwriters and studio performers and lifestyle marketing, epitomized in his label slogan: "The Sound of Young America." The paradox of Motown's appeal to upward mobility, represented, for instance, in the carefully choreographed moves and sequined dresses of Diana Ross and the Supremes and the Jackson 5, however, lay in its eschewing the politics of representation, effectively countering the ideals of the Civil Rights movement. Ironically, after the Detroit riots of 
1967 , like much of the "black flight" of the ensuing era to the suburbs, Gordy declared his intent to move Motown's base of operations from Detroit to Hollywood, completing the move the year after the "crown prince of soul," Marvin Gaye, released his What's going on (1971). Neal states, "The genius of Gaye's work is that by mimicking the diversity of communal voices, he popularized a dominant black social paradigm, precisely at the moment when communal relations within such a paradigm were increasingly fractured and disjointed." He continues, "Thus Gaye not only synthesized an era of black protest narratives but perhaps documented the era's passing, framing the African-American experience through the very prism of postmodernity that has come to define contemporary American culture and in effect produced an aural and commodified text that could be appropriated by later generations" (1999: 64). Neal suggests that Gaye's recording technique of overlapping three ranges of his own voice (falsetto, gospel shout, and smooth midrange), combined with apparent sounds of conversations mixed into the sonic background, at once suggests community, while also critiquing U.S. foreign policy and the breakdown of civil discourse that coincided with the deaths of black leaders. Gaye masterfully links this social change to the breaking down of the basic nuclear familial unit personally, by articulating his own struggles with drug addiction and depression following the death of performing partner, Tammi Terrell, and his conflict over his brother's participation in the Vietnam War. Of course Gaye's focus on basic familial relations as the source of civil relations reveals King's influence. However, with the ensuing albums, the movie soundtrack Trouble Man (1972), and studio recording Let's Get It On (1973), Gaye's critical commentary, like that of the leaderless post-Civil Rights era, phased into the simple affirmation of identity, 
masculinity, and sexuality. The expansion of mass media as here, into the bedroom, contributed to hypersexualized-Blaxploitational representations of black popular culture in the 1970 s.

\subsection{6 - The organization of Contemporary Christian Music, Contemporary-urban} Black Gospel, and the case of Kirk Franklin

While Neal may be right to criticize the role of the Washingtonian compromise and market capitalism in undermining the potential for racial equality in the post-Civil Rights era, he limits his analysis to the commodification of secular Soul musical sensibilities and its performers. I argue that Neal's critique should be extended to include terms of commodifying the sacred sounds of black gospel and its performers through the organization of independent record labels as part of the wider Contemporary Christian Music industry. And yet, I would like to complicate the argument, following Melinda Weekes (2005), by suggesting that the Christian music industry also serves a democratic function in maintaining links among African-Americans otherwise affected by changing social conditions in the 1970 s that otherwise divided the community along class lines.

The black church declined in the 1970s from its preeminent status in the AfricanAmerican community as spiritual and political convener for several reasons. The achievement of education and voting rights, following by the untimely deaths of black leaders had the effect of fragmenting political perspectives and goals. At the same time, internal division increased due to the combined effects of the growing middle class and related white and black flight to suburbia, along with the abandoning of the urban working class to post-industrial social dysfunction is urban city centres (Weekes 2005: 49-51). Mainline urban churches suffered major congregational losses as they struggled 
to maintain relevance in the face of rising poverty, crime, drug and sexual abuse, particularly as their coffers were often affected by the loss of their most generous members. In terms of worship, adolescent youth refused to identify with then conventional gospel blues. Still, the growing urban destitute population responded to James Cleveland's worship leadership, including his organization of the Gospel Music Workshop of America (GMWA). Compared to Dorsey's choir conventions, Cleveland invigorated African-American religious musical practice with a more driving feel, including the instrumental accompaniment of drums, electric guitars, and Hammond B-3 organ. While crossover musicians had already taken the B-3 out of the church and into jazz as early as 1955 , Billy Preston, for instance, contributed to its popularity through his collaborations with the Beatles in the 1960s. The Gospel Music Workshop, however, also marked the emergence of a schism between traditional and contemporary genres of Black Gospel. This division resulted from the shifting demographic makeup of the postwar U.S. and the marketing strategies of a growing white gospel genre.

The split between traditional and contemporary black gospel was augmented during the late 1960s by the growing Christian culture industry, which includes the organized work of publishing song sheets, the establishment and management of a network of recording studios, musicians and producers, much like the secular music industry, for the purpose of recording songs, and the promotion of those songs and musicians through networks of churches, their worship leaders, and congregants. According to the gospel historian Don Cusic (2002), by the Civil Rights era, the religious musical practice of the predominantly white Christian church was represented in three subgenres, including Southern gospel, for instance, in the form of quartets and family 
singers, Contemporary Christian Music (CCM), which tended to mimic the sounds of popular music, and "praise \& worship" or music specifically written for liturgical purposes and Sunday morning services. CCM has roots in the Jesus People movement of the 1960s (Cusic 2012: 279-386; Stowe 2011). Like the counter-cultural movement, Jesus People were comprised of young musicians and fans invigorated by rock'n'roll and at odds with paternalism and power politics, such as systemic racism and the Vietnam War. Yet, they were distinguished by their faith in a revolutionary Jesus, and counterpopular culture beliefs. ${ }^{38}$ Musician Larry Norman, the father of Christian Rock, led the charge. In 1967, he left his secular band, People!, first to write for theatre, but later to record and perform the first rock albums designated Christian: Upon this Rock (1970; Capitol) and Only Visiting this Planet (1972). Norman's lyrics are critical of drugs and free sex as the answer to social problems, while his sounds were then current, epitomized in his lyric: "Why should the devil have all the good music?" (Stowe 2011: 6-7).$^{39}$ From 1975-1980, Norman's Solid Rock record label was distributed by Word Records, originally a southern gospel publishing company established in 1951 in Waco, Texas. In 1966, Word started a subsidiary label called Light Records with Billy Graham composer Ralph Carmichael, also considered a progenitor of Christian music for his work in establishing Contemporary Christian Music. Carmichael's Light Records' acts included

\footnotetext{
${ }^{38}$ Cusic states: “The essence of early rock'n' roll was rebellion - children rebelling against the past, their parents, hypocrisy, dishonesty, and a pressure to conform to the mainstream. In its own way, gospel/Christian music is also a music of rebellion, but it is a rebellion against popular culture, a culture that markets sex, drugs and dysfunctional families as the norm. The messages of rock'n'roll - stay true to your own soul, don't cave in to pressure to conform, and stand up for your beliefs - are the messages of gospel and Christian music" (2012: viii).

${ }^{39}$ In fact, Norman misquotes Rowland Hill (preacher), of the non-denominational, Surrey Chapel, London, who stated, "The devil should not have all the best tunes" (Hart 1981: 169-70). However, despite referencing Hill's biographer, V.J. Charlesworth (1877), Hart dates the statement to 1844, eleven years after Hill's death. Nonetheless, Hill's intention was to challenge Christians to respond to an apparent dearth in praise and worship. In comparison, Norman, perhaps critically, was attempting to claim a market niche among young Christians that also desired a blend of secular Rock sounds with non-transgressive, pseudotheologically based lyrics.
} 
the Oral Roberts Singers, namesake of the televangelist pioneer from the 1950s, and Andrae Crouch, the African-American, Grammy winning composer who became popular in the 1970s for crossing over both genre-related boundaries by blending so-called "world music sounds" $" 40$ and racial and secular boundaries, even performing on Saturday Night Live. By the 1990s, the Christian music industry consisted of a network of independent labels, including black owned and operated subsidiaries, but the economic and popular success of affiliated performers and studio producers precipitated a series of acquisitions by major record labels (cf. Capitol CMG 2016). ${ }^{41}$ Such labels often include in-house production in black churches. However, due to their increased accessibility because of digital technologies and boundary crossing capacity, independent labels of a wide variety now tap into the same distribution networks as the major labels (Weekes 2005). ${ }^{42}$ Digital sourcing in the new millennium has contributed to an expansion of production, sustaining alternative markets of independent musicians and artists mediated by personal computers. Howard and Streck (1999) identify three distinctly evangelical approaches to religious musical production that makes up the ethic of contemporary Christian music. First, "separationalists" consider music a form of ministry for the exhortation of the already faithful. They appropriate the latest secular sounds and styles into their songs and

\footnotetext{
${ }^{40}$ The categorization and capitalization of "world music" is rightfully critiqued in cultural studies literature as an extension of developed world dominance over the global South (cf. Frith 1989).

${ }^{41}$ According to Cusic, by the 1990s, Evangelical Christians produced and consumed \$3 billion worth of Christian entertainment, records and books, annually organizing and attending outdoor festivals, and producing televangelist programming (2012: vii). Politically, the same Christian consumer base is credited for electing born-again President Jimmy Carter, before consolidating as the Religious Right behind President Ronald Reagan in 1980. The largest major label backing Christian music is Capitol Christian Music Group (Capitol CMG), distributed internationally by Universal Music Group, the second largest label in the world. Chairman and CEO, Lucian Grainge CBE oversees UMG interests in over sixty countries (universalmusic.com, consulted February 2017). Billboard 100 voted him most influential music industry figure in the world in 2013, '15, and '16. In 2012, David Cameron named him British Business Ambassador. He sits on boards at Dreamworks Animation, SKG Inc., and Northeastern University in Boston.

${ }^{42}$ For example, Arrow Records is based in Creflo Dollar's World Changers International church, Atlanta.
} 
performances, yet for the purpose of sonically contemporizing their scripturally orthodox lyrics. Second, "integrationalists" combine contemporary aesthetic sensibilities with universally themed lyrics, arguing that such a combination is conducive to evangelism. However, this approach is commonly criticized both from within the church for obfuscating theologically orthodox lyrics (considered selling out) and in the popular realm for being watered down. Last, "transformationalists" attempt to avoid such criticism by insisting that the totality of music production be considered politically and spiritually relevant based on artistic merit, sonically and lyrically.

Melinda Weekes (2005) argues that the way in which the contemporary gospel music industry has been established is a result of secularization and North American Christians' disillusionment with church leadership. She draws on the social theorist Mark Chaves who suggests that secularization be measured against the church's declining authority in terms of societal, organizational, and individual dimensions. Here the fragmentation of black leadership is seen to have contributed to a loss of societal influence, while denominational schisms have led to organizational secularization and individual disillusionment. While economic stratification certainly underlines the growing rifts dividing the African-American community and the variable influence of the gospel music industry in that division, Weekes suggests that gospel music also functions to re-unify that community. Gospel musical self-practice mediates an aesthetically structured sensibility whereby listeners can identify with a more or less unique culture, albeit one that denotes an "imagined community" (Anderson 2006: 9; also Born and Hesmondhalgh 2000: 37-47). Such musical mediation suggest a fascinating twist on Du Bois' concept of "double-consciousness;" whether through listening or music making, 
"techniques of the musical imaginary" allow Afrologic perspectives to be propagated in the face of potentially existentially threatening factors such as socio-economic background and regionally specific racism. In other words, such mediation has a sustaining effect through musical self-practice. At the same time, however, music mediates self-transformation, including strategies of adapting to, or anticipating, broader changes. In any case, Weekes insists that the church and its gospel leaders would do well to learn from their history that the process of creating new music through adopting and borrowing new sounds is beneficial to the African-American community as a function of its relevance. In other words, gospel tends to be invigorated by a combination of the orthodox gospel message, grounded in a vigorous scriptural hermeneutic, and the evangelical goal of appealing to possible disciples through that message along with pleasing sounds. I would also argue that "popular" music would also do well to note its relation to gospel, particularly to those artists who crossover and the ways in which their musical practice is adopted by the mainstream. In fact, I agree with Weekes, that the definition of popular has less to do with popularity than simply a manufactured borrowing from artists and their musical practice, including those from the AfricanAmerican community.

Various performers emerged in the late 1970s as gospel superstars, continuing the crossover career trajectory model, including, Andrae Crouch as mentioned above. In the mid-1970s, Crouch signed the Marvin Winans' vocal group, the Testamonial Singers later the Winans - from Detroit (Darden 2004: 298-301). The Winans are ten siblings who were each interested in writing and performing in a contemporary gospel style that included somewhat controversially popular influences, Gladys Knight and the Pips, the 
Jackson Five, and Marvin Gaye. The most successful group of Winans singers were BeBe (Benjamin) and Cece (Priscilla), who in 1981 first achieved wide recognition for their performances on Tammy Faye and Jim Bakker's Praise the Lord Club (PTL), a televangelistic program that was widely distributed across the U.S. and Canada on the Trinity Broadcasting Network (TBN). However, the duo left PTL before the program's demise at the exposure of Jim Bakker's sexual affair with Jessica Hahn, divorce, and subsequent incarceration for fraud. In 1985 Bebe and Cece were the first AfricanAmerican performers to sign with then influential Christian label, Sparrow Records. The siblings sold 300,000 copies of their first album Introducing Bebe \& Cece and won their first of several Grammys. However, despite the popular success of the Winans and the establishment of the contemporary Christian music industry in the 1980s, contemporary gospel represented middle-class Black American values and musical sensibilities. Moreover, an increasing segment of youth was growing up in the multi-cultural inner city, in a street culture characterized by drug and gang violence and more often with little exposure to African-American religious musical practices.

Compared to Dorsey's role in establishing sacred and secular boundaries and Tharpe's challenge to those boundaries along gender lines, Kirk Franklin's musical selfwork embodies a complexity of relations that contribute to the emergence of urban contemporary black gospel. Franklin was born January 26, 1970, in Fort Worth, Texas, to his fifteen-year-old mother and absentee father, before being given up for adoption at age four to his grandmother's sister Gertrude (Darden 2004: 316-20). Having stillbirthed a child over forty years earlier, fourth grade educated, sixty-four year old Gertrude and her husband Jack raised Franklin as an only child and according to strict 
Christian morals. In his reflexive life lessons book, The Blueprint, Franklin attributes to his formative years a sense of rejection by his parents and sexual abuse, whereby he developed a "broken self-image," objectifying women and driven to accomplishment for acceptance:

I was raised in the African-American church community where much of the culture was based not on what you know but on how you feel. Sex was a big part of our upbringing; from the church to the streets and back again. What we did in one affected what we did in the other. In the summers, we had no adult supervision; the lack of affirmation and love at home caused us to look for them in one another at very young ages. At six and seven years old, we were introduced to things that children should be protected from. And a lot of that introduction came from people we saw as protectors. There were a lot of men in the black church gospel community who would try to do things to the young boys in the church. They would approach some of the young boys, maybe touch a leg or try to hit on you, and as a little boy that's very scary (Franklin 2010: 64).

Despite Gertrude's efforts and his consistent church involvement, Franklin claims in a recent online radio interview that a lack of model behavior in his upbringing led him to objectify women, manifested in promiscuity from age eight, having an unplanned son with a girlfriend at age seventeen, and addiction to pornography into his thirties (2015: 6:00). Together with his wife Tammy, Franklin publicly confessed his addiction on Oprah in 2005. Franklin continues to present his views on sexual ethics and support of monogamy in conferences and publications, where he proclaims that Jesus' self-sacrifice redeems his "struggles" with sex, fear, anxiety, race, and masculinity and reorients him according to Christian ethics. ${ }^{43}$

In terms of education, Franklin's commitment to Christ and involvement in the church stem not only from his formative years with Gertrude, but also from an experience

\footnotetext{
${ }^{43}$ Jesus is purported as both God and man in Christianity; his redemption modeled in his practical teachings in the Matthew 5 "sermon on the mount," unjust crucifixion and miraculous resurrection. In the case of Kirk Franklin, Jesus is seen to redeem Franklin's "broken identity" by giving him another chance.
} 
at age fifteen when his homeboy was shot and killed in Fort Worth. As recent as the Breakfast Club interview (Nov 13, 2015), Franklin maintains:

When he got killed, that kind of shook my world because I know that my life was the one that was file [reprehensible]. So that summer is when I trusted Christ with my heart and really got serious. Something happened: I was fifteen, summertime, Texas, and I remember when it was time to go to the skating rink and light up, I knew something had changed. And then the songs started coming man; my pen started getting weighty and folk really started liking my songs. (2015: 3:30)

Franklin was taught the piano at an early age, the church and school being his main practice venues. He became a protégé of sorts under various musicians and choir directors, gospel producer Milton Biggham, not being the least (Darden 2004: 317). While Franklin began directing the choir at Mount Rose Baptist church at age eleven and Greater Stranger's Rest Baptist at age seventeen, it was while leading The Dallas/Fort Worth Mass Choir that he attracted Biggham's attention. A major break came in 1990 when Biggham offered Franklin and his choir an original song called, "Every Day with Jesus," which was performed at the Gospel Music Workshop of America that year in Washington, DC. ${ }^{44}$ While he claims that learning piano in the ' 80 s linked him to gospel (as opposed to hip-hop), Franklin maintains that he was raised on a variety of secular pop genres (2015). That variety, combined with his urban upbringing, contributed to his distinct yet relevant style of gospel.

In 1992, Franklin formed The Family, the first of several groups to record and perform his songs, signing to Vicki Lataillade's Los Angeles-based independent label, Gospo Centric. The Family's remixed and re-mastered album Why we Sing (1993) received widespread recognition, including crossing over to the Billboard Top 200 charts and top 10 on the R\&B charts, selling more than two million units and winning Stellar,

\footnotetext{
${ }^{44}$ In the 1970s, James Cleveland's "contemporary" GMWA overtook Dorsey's "traditional” NCGCC in popularity.
} 
Dove, and GMWA awards. Cusic attributes Franklin's success to organizational shifts in the 1990s, including the consolidation of Christian bookstores and labels through corporate acquisition and computer assisted point of sale (POS) tracking (2012: 381-5). ${ }^{45}$ At the end of the 1990s, Franklin's continued success allowed him to collaborate with secular stars as diverse as Whitney Houston, Cheryl "Salt” James, Mary J. Blige, Bono, and R. Kelly. Though not without controversy in Christian circles, such crossover collaborations aided in his aim, "to make God famous" (Franklin 2015: 36:25), and were justified once it was determined that said artists "shared the same heart" as Franklin (Darden 2004: 320). On this last point he remains somewhat vague, as he is on institutional aspects of religion. For instance, in discussing his latest album, Losing my Religion $(2015)^{46}$ he critiques religion that imposes rules without grace, and equally spirituality without social justice; instead, he insists on a relationship with Jesus as incarnating a balanced model of both (Franklin 2015: 22:00). Kirk Franklin's diversification in the last decade alone has contributed to a complex gospel field, including starting his own label, "Fo Yo Soul" distributed by RCA, endorsing "Kirk Franklin's House of Blues Gospel Brunch" with locations across the U.S., and hosting and co-executive producing BET's original gospel talent show, Sunday Best.

In sum, Kirk Franklin's musical self-transformation across his life cycle mediates institutional changes in the black church, the contemporary Christian music industry and the urban-contemporary black gospel scene, and the complex subjectivity of his biography. The rise of independent African American gospel labels such as Gospo

\footnotetext{
${ }^{45}$ Neilson began tracking album sales using Sound Scan software in 1991; labels and stores responded to sales by stocking related inventory, effectively blurring boundaries that had previously been associated with genre (i.e. race), and establishing "Christian" (pop) and "Gospel" (black) as veritable categories.

${ }^{46}$ Losing my Religion can be heard in this youtube.com playlist. In the first clip, "Losing my Religion," Franklin asserts his intention for the album, a cappella, presumably to emphasize its textuality.
} 
Centric, for instance, provided him with a sound financial base upon which to hone his professional craft while also promoting his musical self-practice across the U.S. Such exposure, both in terms of live performance and nationally distributed recordings, allowed Franklin to win the support of fans beyond urban core churches, including in a network of, significantly, more affluent suburban super churches and Christian colleges, where arguably, racial difference no longer precluded the white consumption of black gospel. Relatedly, a general relaxation around norms of sexuality, or secularization as Weekes argues above (2005), has allowed Franklin to contribute his own related ethics to the public media realm. On the one hand, such relaxed norms have afforded Franklin a virile presentation of his musical-self on stage, while on the other hand, he uses the media to both address his struggles with objectifying sex, and promote a sexual ethic, for instance with his wife, of mutual respect and monogamy. Compared to Sister Rosetta Tharpe, Franklin's musical self-practice and ethic of self-transformation is drastically different. After decades of "cross over" artists to which he can compare his self, Franklin negotiates the sacred-secular divide seemingly with ease. No doubt his label support and stable financial base aids in his career strategizing. Distinctly, however, Franklin's ethic of self-transformation does not involve a complete "crossing over" to the secular pop world as in Tharpe's case, or for that matter, Sam Cooke, Aretha Franklin, Marvin Gaye and others. Rather, the relaxed boundaries between the sacred and secular have allowed him, in contrast, to attract collaborators from the pop world, arguably endorsing his sound by adding secular cache, yet without compromising his Christian lyrics. Following Weekes' argument, general disillusionment with the church has contributed to the 
transformation of musical selves like Franklin into alternative leaders or "voices" in his field, a role that Franklin himself navigates, arguably, with enthusiasm.

\section{$3.3-$ Conclusion}

The details of African-American religious musical practices sketched here span the period from modern slavery until the present. In this period, the musical self emerged as an object upon which the self can work, and in a variety of ways and terms. For instance, African slaves and their descendants were seen to break from music as a function of tribal life, forced instead, to use music making in order to survive existential threats, as in disease and melancholy, and later, to adapt to market-related precariousness related to the loss of work. At the same time, African Americans were seen to develop an ethic of selftransformation in order to adapt to and anticipate social change itself. Music is selftransformation, and self-transformation is an historically evolving ethic that relates to the complex subjectivity of the musical self, and how that self problematizes and responds to its field of condition. Using the framework laid out in the previous chapter, musical mediations were mapped between the musical self and institutions, sociological concepts having to do with race, class, gender, and religion, musical expressive cultures or scenes, and musical experience itself, including across the biographies of key figures.

Arguably, the institutional framework within which gospel has come to be reproduced, was in place by the time Thomas Andrew Dorsey's Afrological musical-self practice lined up with his position in the field that was and remains the mainline church. Although it appears as though Dorsey played a singularly formative role in the historical emergence of the gospel blues and black gospel, this was not entirely the case. Rather, gospel's emergence was afforded by a combination of institutional effects due to 
copyright law, publishing, and choir associations and also geo-political causes such as the great migration due to employment and geographical elements. The rise of the urban middle class posed new challenges to assimilationists in the 1950s and following the Civil Rights movement. "Cross over" artists such as Sister Rosetta Tharpe, Sam Cooke, Aretha Franklin, and Marvin Gaye interjected the popular realm with emotionalPentecostal fervor, evocative rhythms, and both with religiously transgressive and politically progressive lyrics. Such musical self-practices transformed both biographically rooted struggle having to do with the complex subjectivity of racism and social inequality, and the organization of institutions through which racism was systemic. However, while many, black and white, benefitted from the undermining of Jim Crow through the expansion of education and voting rights, the resultant intra-racial division among blacks contributed to new everyday life challenges in the 1970s. Post-industrial processes exacerbated such conditions. The loss of key African American leaders in the late 1960s and early '70s, along with growing disillusionment with the black church, conditioned the emergence of new musical self-practices and their institutional mediation with the culture industries.

The organization of the contemporary Christian music industry in the 1970s along with post-industrial processes conditioned the emergence of musical practices and their categories called, urban-contemporary gospel, and key figures such as Kirk Franklin. Unlike previous “cross over" artists, Franklin represents a form of religious musical practice mediated by the organization of concerted interests making up a recording label. In this case, his label support is "independent" at the level of production yet globally networked in both the distribution of his recordings and the venues in which he performs. 
Such institutional mediation, along with processes of secularization in the contemporary church, affords Christian artists the potential to sustain professional careers without having to "cross over" to the more lucrative popular secular realm. Mediated by Christian morals, Franklin's musical self-practice emphasizes an ethic of selftransformation that is both sudden, as in his conversion following the death of a close friend, and gradual, as in the constant discipline of his sexuality vis-à-vis his lyrics and mass-mediated interviews. Perhaps contradictorily, the institutional mediation of his musical self-practice, by both the Christian music industry and the church, imposes demands on that practice that he frame his self in marketable and moral terms. In other words, while Franklin's musical-self practice affords the self-transformation of his biography, the ethic of that transformation is in turn influenced by its mediation by the church and its moral system, and the Christian music industry and its capitalist logic.

This chapter links the case of Rob "Fresh I.E." Wilson to African American religious musical practices, including the emergence of both the musical self and the ethic of self-transformation, of racialized and publically defined sacred-secular boundaries, and of comparative figures mediated by the historically emergent institutional church and the Christian music industry. In the next chapter, I trace the roots of hip-hop to the Bronx in the 1970s, while also tracing its mediations with CCM and the church beginning in the mid-1980s. As we shall see, the musical self-practice variously called, Christian hip-hop, Christian rap or Holy hip-hop, is also variously mediated on institutional, local scene, and subjective levels, and across the life cycle of its numerous musical selves. However, compared to gospel music makers, Christian hip-hoppers contend with a unique set of 
existential and market-related challenges rooted in the specific conditions of their biographies, local scene, and institutional musical mediation. 


\section{Chapter Four}

\section{Hip-hop, Religion, and the Contemporary Christian Music Industry: The mediating roots of Christian-themed hip-hop}

\section{1 - Introduction}

The gradual emergence of Christian-themed hip-hop (also called Christian hip-hop or CHH, holy hip-hop, Gospel rap, Christian rap and hip hope) in the mid-1980s and 1990s, and its more substantial iteration over the past fifteen years is rooted in the confluence of hip-hop, and the institutional organization of religion, including the Nation of Islam and the Christian church in the United States, and of the contemporary Christian music industry. Historical changes in each of these tributaries overlap with and influence one another. As such, this chapter is not meant to present a comprehensive history of "holy hip-hop;" rather, the ways in which holy hip-hop has emerged reveal a complicated set of forces and relationships among and between networks of people mediating its context (postindustrial urban America), culture (postcolonial African-American and Latin@), ${ }^{47}$ religiosity (Islam and Christianity and boundaries of sacred-secular), and practice (as opposed to their strictly public representation). Following recent scholarship in religious studies (Miller 2013; Johnson et al. 2013) and ethnomusicology (Zanfagna 2010; 2012; 2015), these mediations are traced in order to assess their functioning both as a product of wider forces and also as a strategic resource for its various musical selves. Leaving holy hip-hop as a complicated set of practices allows me to interrogate concepts of "religion" and "music" which are typically posed as homogeneous, through the decentering and

\footnotetext{
${ }^{47}$ I have adopted Khabeer's moniker, Latin@, as she uses it to designate the hip-hop inspired expressive culture of people of Latin origins living in the United States. This is as opposed to the formerly common slang, "brown," as in "black and brown" people. Although still used in hip-hop culture, "brown" is more confusing, here, as it carries different meanings outside of the U.S., for instance, "pardo," meaning "multiracial" in Portuguese, and which can be derogatory. Latin@ is also an efficient means of combining the gender specific designations of Latino and Latina without losing their specificity; both of which maintain a strong presence in American hip-hop culture, as Khabeer's work reveals (2016).
} 
denaturalizing of the sacred-secular binary in African-American religiosity, while also contemporizing and localizing black liberation theology and rethinking strategies and representations of resistance and accommodation in popular culture. The history of hiphop and its Christianization is directly linked to the case of Rob "Fresh I.E." Wilson. Specifically, while the sounds of hip-hop mediate the complex subjectivity of Rob's biography, its institutional organization mediates the musical self-practice and ethic of self-transformation making up his professional practice.

\section{2 - A Social history of the Bronx and the conditions giving rise to Hip-hop}

Various historians, sociologists, and cultural critics have described the conditions of the Bronx during hip-hop's period of emergence as characterized by social destruction and postindustrial decay (Toop 1984; Dyson 2004 [1989]; Rose 1994: 27-34; Keyes 2002: 39-66; Chang 2005: 7-88; Williams 2015). Such decline was wrapped up in various global and local forces having to do with political and economic restructuring, including the relocation of local industries to satellite municipalities, social welfare abandonment, and displacement due to "slum clearance" policies. As a result, rates of poverty and unemployment increased sharply, along with the manifestation of gang violence and drug abuse. In the 1970s, the Bronx lost 600,000 manufacturing jobs, amounting to forty percent of the sector. The average annual per capita income in the Bronx dropped to $\$ 2430$, roughly half of the city average and forty percent of the national average. The official youth unemployment rate, although documented at sixty percent, was likely closer to eighty percent. Encouraged through federally backed mortgage programs from the 1950s on, the Bronx lost over 750,000 predominantly white, skilled residents of Italian, German, Irish, and Jewish descent, to the suburbs in New Jersey, Queens, and 
Long Island (Keyes 2002: 46; Chang 2005: 13). The historian Michael Chang describes

the exacerbating effect of the cyclical housing economy as follows:

Apartment buildings passed into the hands of slumlords, who soon figured out that they could make more money by refusing to provide heat and water to the tenants, withholding property taxes from the city, and finally destroying the buildings for insurance money... Slumlords hired rent-a-thugs to burn the buildings down for as little as fifty dollars a job, collecting up to $\$ 150,000$ on insurance policies. Insurance companies profited from the arrangement by selling more policies... Groups of organized thieves, some of them strung out on heroin, plundered the burned buildings for valuable copper pipes, fixtures and hardware... In housing, the final stage in capitalism is arson. (2005: 13-14)

Confoundedly, in spite of high rates of arson, seven fire departments were removed from the Bronx after 1968, while during a mid-70s budget crisis, thousands more firefighters and marshals were laid off; between 1970 and 1975, 68,456 fires were set in the Bronx alone (Keyes 2002: 46). On one hot day in June 1975, forty fires were set in a three-hour period. By the end of the 1970 s, 43,000 housing units were lost.

The demise of the Bronx was born out of the vision for the city and the prescribed urban function that each borough was to serve: architect Louis Sullivan's famous mantra, "form follows function," was redefined on an immense urban scale. According to Chang, in 1929 the New York Regional Plan Association developed a master plan for the five boroughs that called for decentralized industrial and residential zoning while centering financial and political power in Manhattan (2005: 7-88; see also Lewis 1963: 147-9). The plan gained momentum after the Second World War under the direction of Robert Moses, "the most powerful modern urban builder of all time" (Chang 2005: 11). Of his "urban renewal" projects, significant for our purposes was the seven-mile, Cross Bronx Expressway linking New Jersey, north Harlem, the Bronx, and Queens. One of the "Heartbreak Highway's" corollaries was the displacement of tens of thousands of 
residents, many of whom were relocated to massive apartment complexes in the absence of affordable alternatives. Such apartment blocks were designed by Swiss architect Le Corbusier and were based on his "Radiant City/tower-in-a-park" model which included 1200 to over 1700 units. Displacement combined with low rental rates attracted migrants from across New York, along with émigrés from Caribbean nations, such as Jamaica, where post-independence employment was scarce. As a result, high concentrations of African American, Hispanic and Latin@ poor and working class, garnered the South Bronx the moniker, "Caribbean City."

In the years from 1968 to 1977, gang-related violence increased in the South Bronx. Over one hundred gangs were estimated to be running during this period, claiming membership of 11,000 , seventy percent of whom were Puerto Rican, although such statistics likely reflected policing tactics (Chang 2005: 50). Keyes recounts, "Numerous brutal gang encounters, particularly around intra-territorial rivalries and sexual assault of female victims by male gang members, were common headlines in local newspapers, as were rapes, murders, and, as one writer recalls, 'Unspeakable rites of passage"” (2002: 46). The gang presence spread in part because of a power vacuum left after the assassinations of black leaders such as Martin Luther King Jr., Malcolm X, and Bobby Hutton, along with the targeting of "Black Nationalist-Hate Groups" by the FBI, including the Nation of Islam and Black Panthers (Chang 2005: 45-8). ${ }^{48}$ Gangs provided recruits with security and an alternative sense of belonging to traditional systems such as the family and religion. Comparatively, Bronx youth gangs were less optimistic than the

\footnotetext{
${ }^{48}$ For instance, Tupac Shakur's mother Afeni was part of the Black Panthers, demanding full employment and decent housing of government before she was arrested as part of a group of New York based Panther leaders called the "New York 21." After her release, she raised her son alone, often jobless and sometimes homeless (Chang 2005: 46-7).
} 
doo-wop singing groups of the 1950s and the dancing groups of the mid-1960s (Chang 2005: 48-50). Although Chang insists that a lack of political radicalism in the Bronx gangs was a function of increasing secondary school dropout rates, his political scope seems to be limited to the democratic forum of civic council rooms. Rather, in their internal structure and inter-gang dealings, members and leaders were actually quite politically adept, demarcating territory and organizing major truces as in 1971 , following the fatal wounding of non-violent "Ghetto Boy," "Black Benji." Either way, the demise of the Bronx gangs followed the reemergence of gang wars, targeted surveillance through the formation of the Bronx Youth Task Force, and the introduction of heroin and other illicit drugs (Keyes 2002: 47). Moreover, after 1971, "Black Spade” warlord Afrika Bambaataa began focusing on organizing a "crew"49 of artistically creative members that retained characteristics of security, belonging, urgency, and competitiveness associated with youth gangs, yet without risking death or incarceration.

\section{3 - Hip-hop and spirituality: The cultural improvisation of Afrika Bambaataa}

Although he had heard DJ Starski circulating the phrase "hip-hop" in his dance parties, Afrika Bambaataa (Bam) is credited with linking the phrase to the scene, thus giving coherence to its elements (Keyes 2002: 49). Often called the "godfather of hip-hop," Bam grew up surrounded by the Bronx' gang scene, later becoming a member of the notorious Black Spades. However, when he recognized gang life as ending in selfdestruction, he began searching for a sustainable alternative. He found such an alternative in Zulu (1964), a film in which an African tribe by the same name wars against an indomitable British army. Bambaataa describes:

\footnotetext{
${ }^{49}$ Crews eventually distinguished hip-hop collectivities from gangs based on non-violent functioning.
} 
When the British thought they'd won the next thing you see is the whole mountain full with thousands of Zulus and the British knew they was gonna die then. But the Zulus chanted - praised them as warriors and let them live. So from there that's when I decided one of these days I hope to have a Zulu Nation too (Toop 1984: 57).

According to Keyes, Bam's main inspiration was to curtail gang violence through DJ, MC, break, and graffiti battles (2002: 47-49). Bam was concerned with building selfknowledge in the face of inequality, including regaining a sense of connection to space, hence, the "place" of the "streets." He states:

What got me excited first was when James Brown ${ }^{50}$ came out with 'Say it Loud, I'm Black and I'm Proud'. That's when we transcend from Negro to black. Negro to us was somebody who needed to grow into a knowledge of themselves. There was no land called negroland. Everybody in America - when they came here they knew where they was from. If you were Italian you called yourself ItalianAmerican, but the blacks didn't know which way they was going. They was brainwashed - all this stuff was put into our mentality. (Toop 1984: 58)

Indeed, having witnessed the accomplishments of the Black Panthers, and earlier, the Civil Rights and anti-war movements, Bam recognized the transformative potential of organized knowledge. Yet, whereas he saw Dr. King's contribution as important, Malcolm X's more aggressive approach was shown to be more appropriate to what Bam wanted to do in the Bronx. He called his approach, "edutainment": the targeted education of young people whose access to traditional values and sense of rootedness was displaced by unemployment, drugs, gang violence, and broken family relations, combined with "a mix of fun and socially conscious music and discourse" (Gosa 2015: 64). Bam used

\footnotetext{
${ }^{50}$ James Brown is in fact an influential figure in the history of hip-hop, however, more in terms of the sounds of the "drum breaks" of his songs than his presence as a music maker. I discuss the technique of sampling and Brown's beats below. For our purposes, while he was no longer an influential figure in the African-American collective consciousness by the late 1970s, his music was. Brown's biography, like many "cross over" artists, is rooted in the COGIC, as discussed in the previous chapter, thus explaining his highly emotive musical self-practice and distinctive performance technique of stressing the downbeat or "the one." His emphasis on repetitive rhythms and minimal variation in song structure, in addition to Bam's stated political inspiration, proved to be innovative for hip-hop. Thus, James Brown's beats mediated the transformation of pop culture, from the emergence of hip-hop musical selves to its institutionalization.
} 
dance tracks to bait partygoers and then played excerpts from speeches by Malcolm X, Martin Luther King Jr., and Louis Farrakhan mixed over top of the instrumental breaks. Visually, he and his Soul Sonic Force crew would use fashion to counter the symbolism associated with gang wear, dressing up as Kemetic pharaohs, indigenous Native Americans, or Afro-futuristic space aliens. Bambaataa states:

[L]ater when gangs was fading out I decided to get into the Nation of Islam. It put a big change on me. It got me to respect people even though they might not like us because we was Muslims. The Nation of Islam was doing things that America had been trying to do for a while - taking people from the streets like junkies and prostitutes and cleaning them up. Rehabilitating them like the jail wasn't doing. (Toop 1984: 59)

Clearly, it is the common experience of youth and urban decay in the 1970s to which leaders such as Bambaataa and institutions such as the NOI responded, organizing hiphop in order to transform, if not transcribe, that experience. But considering the historically influential presence of the Black Church, how is it that hip-hoppers first incorporated ideas from Islam, long before Christian themes?

Concurrent with the rise of hip-hop is the attrition of the Black Church in the urban core of American cities due to post-industrialization, and the increasing influence of the Black Nationalist movement and the separationist teachings of militant leaders such as Malcolm X and groups such as the Black Panthers. Here the respect for others that Bambaataa mentions is a key component not only in the Nation of Islam but also of the influential Nation of Gods and Earths (NGE) or Five Percent Nation, begun by onetime Malcolm X disciple Clarence 13X (Zanfagna 2015: 73-5). ${ }^{51}$ Five Percenters believe

\footnotetext{
${ }^{51}$ Five Percenters believe that ten percent of the world's people know the truth about existence, an elite group that controls eighty-five percent of the world through ignorance (Zanfagna 2015). However, the remaining five percent, also enlightened to the truth, determine to disseminate that knowledge justly. The distinguishing principle taught here stems from a rejection of a mystery god of the universe and his or her representatives on earth, and rather, belief in the self as god incarnated.
} 
that black Asiatic people were the original humans on earth, therefore the fathers (gods) and mothers (earths) of civilization. Clarence 13X outlined a "natural" way of living on earth through knowledge of a Supreme Alphabet and Supreme mathematics, infusing the development of wordplay and "flow" by MCs such as Rakim Allah and Nasir "Nas" bin Olu Dara Jones, but more importantly, one in which individuals are empowered to overcome the precarity of their circumstances through self-initiative. ${ }^{52}$ As such, Five Percenters deny that they follow a religion; rather, in that they already make up the deity, they espouse a way of living. Historically, the Nation of Islam way of living bespeaks a specific articulation relative to racial inequality vis-à-vis American mainstream culture, and the declining power of the urban black church in the 1970s. ${ }^{53}$

\section{4 - The competition for and classification of hip-hop sound: From DJ Herc's sonic improvisation to the commodification of the "authentic street"}

Afrika Bambaataa's identification and consolidation of hip-hop's four elements plus knowledge arguably marks the beginning of the objectivation of the Bronx' block party scene as "hip-hop." Today, hip-hop's most influential offspring is rap. Rap combines the DJ and MC elements of hip-hop in recorded form, including a specific aesthetic sensibility, and draws on the massively influential organizational structure of the American popular culture industry. Rap's sonic emergence arguably began with the distinct musical sensibilities practiced by DJ Kool Herc in concert and competition with his audiences and contemporaries (Williams 2015: 1; Chang 2005: 67). Like his father before him, Jamaican born Clive "Kool Herc" Campbell was a disc jockey who played

\footnotetext{
${ }^{52}$ For example, "What up G?" is a phrase that initially hailed the addressee as god, before being appropriated by gangsta rappers. Mathematically, "g" is also the seventh number of the alphabet, seven being the holiest of numbers.

${ }^{53}$ Zanfagna also notes the decline of Islam associated hip-hop artists particularly after 9/11, making room for the rise of Christian-themed hip-hop (2015).
} 
recorded songs over his PA to variously engaged audiences (Keyes 2002: 46). Such audiences assembled in apartment rec rooms and outdoor parks across the Bronx - away from gang violence in the clubs. Herc made two significant adaptations to the way in which songs were played that contributed to the distinction of hip-hop sound. First, he configured his PA so as to amplify his music louder and clearer than his competitors. ${ }^{54}$

On the one hand, such clarity relates to environmental constraints upon bass frequencies encountered by playing out-of-doors at parks and block parties. On the other hand, as DJs compensated by amplifying the bass, they improved the quality of experience and attracted fans. ${ }^{55}$ Herc's second major contribution is that he used his PA like an instrument by "looping the break." He had noticed that dancers anticipated and responded with enthusiasm to the rhythmic sections of songs when instruments would drop out, all except for drums. ${ }^{56}$ Taking note, he began isolating breaks by marking his records and then by looping a break between two of the same records on two turntables connected through a mixer, a technique he called "merry-go-round" (Chang 2005: 79). As noted above, dancers who used the breaks to boast became labeled, "b-boys" or break boys, integrating a form of dance into hip-hop culture.

\footnotetext{
${ }^{54}$ Sound studies scholars such as Sterne (2012) argue that much technological development from the late nineteenth to late twentieth centuries stems from a modernist emphasis upon fidelity. For instance, telephony, the technology that all sound reproduction relies upon, defines and is defined by the lowest degree of sonic legibility. For a fascinating study of the science of bass frequencies as entangled with religiosity among other relations of power, see Paul Jasen's Low End Theory (2016).

${ }^{55}$ Hip-hop historian Keyes traces the competitiveness of DJ battles to 1960s Kingston, where bass "riddims" gained symbolic capital in a struggle for distinction (2002). Musical competitions, of course, predate DJ battles even further as in, for instance, the piano "cutting contests" of the 1920s, and, arguably, the Pinkster dances of the early nineteenth centuries.

${ }^{56}$ Though since the fading of the Black Power movement James Brown had become unpopular in the discotheques, songs such as his "Funky Drummer" (1970) contained exactly the kind of drum break that Herc's audiences responded to. The more immigrant working class based, thus less assimilated, Bronx Latin@ and Black crowds, took to such sounds. "The Funky Drummer" has become one of the most sampled beats in hip-hop and popular music ever (Reiff 2015).
} 
Although Kool Herc may have been the first to loop sections of songs, Hansen is quick to critique the singular DJ archetype (2015: 42-55). In his history of turntablism, Hansen recounts a competitive character of the local market in the 1970s, in which the employment of specific techniques worked to distinguish DJs: from Herc's looping of breaks collected from obscure Latin-funk records; to Grandmaster Flash and Grandwizard Theodore's innovative "scratching," where sounds are manipulated by speeding up or slowing down a turntable so as to produce new sounds and rhythms; or to Afrika Bambaata's integration of synthesized sounds such as those developed by the German electronic group, Kraftwerk. Such techniques were part of a greater strategy that awarded DJs not only parties to play but which also inspired further technological development such as sampling. With sampling, sounds are digitally isolated from recordings, then patched together in a new audio collage. ${ }^{57}$ By the end of the 1980s, digitized sampling afforded a proliferation of new music ${ }^{58}$; however, copyright law and royalty costs caught up to sound producers, liberalizing distinct modes of self-creation, leasing, or buying beats. ${ }^{59}$

Dimitriadis notes a major cultural shift in the early 1980s, with the genre classification and commodification of "rap music" (2004: 421-35). Sylvia Robinson

\footnotetext{
${ }^{57}$ Modern turntablism, a term conceived in 1995 by DJ Babu to describe his performance, has moved from the manipulation of sound using analog devices such as records and turntables to computer-based analog and digital sampling devices to digital vinyl systems (DVS) (Hansen 2015). The latter form ironically abandons erodible analog equipment for non-vinyl CDs and laptops, while the site for research \& development now includes not only "the streets" but also scientific fairs and DJ competitions.

${ }^{58}$ Genre classifications attached to sounds that emerged in the wake of Herc, Grandmaster Flash, and Bambaata's innovations, albeit sometimes falling under the disco umbrella, include among others, electronic music, techno, drum ' $n$ ' bass, hardcore, trance, electronica, dance, house, synthpop, ambient, triphop, and indietronica.

${ }^{59}$ De La Soul is a notable example of a hip-hop group which in 1989 was sued by The Turtles over the sampled use of sounds in "Me Myself and I" taken from recorded single, "You Showed Me." "Selfcreation" denotes a mode of production in which the musical self creates sounds on her own, though mediated, without emulating pre-existing sounds to the point of copyright infringement.
} 
assembled the Sugarhill Gang and produced "Rapper's Delight"60 in October 1979, distributing its release on her indie label, Sugarhill Records. Nearly fifteen minutes long, the recording is based on a sample of Chic's "Good Times," a dance hit released earlier that same year. Importantly, "Rapper's Delight" transcribed the block party onto vinyl via studio production. Up to that point, hip-hoppers such as Chuck D of Public Enemy were not able to imagine that a gig which typically lasted all night could be recorded at all: "And the ironic twist is not how long that record was, but how short it was. I'm thinking, 'Man, they cut that shit down to fifteen minutes?' It was a miracle” (Chang 2005: 130). Like jazz after the $1920 \mathrm{~s},{ }^{61}$ recorded hip-hop enabled MCs and DJs a medium in which to hone their craft, building on one-liners with more information, more boasting, and smoothing out delivery or flow while also structuring songs by verse and theme. Dimitriadis likens these changes to a closing of rap's narrative, transitioning from face-to-face interaction in a live setting to an imagined community of studio artists and audiences. To complete the transformation, from 1983 on, Run DMC became the first crew to successfully bridge hip-hop with mainstream pop culture, combining their brand of lyricism with producer Rick Rubin's suggestion to incorporate rock licks, such as the looped guitar line taken from Aerosmith's "Walk this Way" (1986). The three minute and thirty-eight second single version of "Walk this Way" reached \#6 on the Billboard 100, while RunDMC's collaboration with Steven Tyler and Joe Perry became the first rap video to be played in heavy rotation on MTV. From 1988-95, MTV telecast the first show dedicated to playing rap videos, Yo! MTV Raps, bridging black urban and white

\footnotetext{
${ }^{60}$ In this hyperlink to youtube video, "Rapper's Delight" has been transcribed. I have chosen this example for the accessibility of lyrics.

${ }^{61}$ Hennion argues that recorded sound such as jazz enabled a wide array of musicians to hear, learn, and practice techniques at a quickened pace compared to unrecorded music and in one-on-one apprenticeship relationships (2012).
} 
suburban America. However, Dimitriadis concludes, Run DMC incidentally created what we call "Old School" by reducing hip-hop to an aesthetic comprised of aurality and vocal discourse, effectively drawing attention away from spatial aspects of scenes, contributing to the sequestering of other elements such as breaking and graffiti in formal organizations and competitions (2004: 435).

While recording in studios effectively reduced hip-hop culture to imagined communities, it also altered conceptions of "the street," contributing to the objectification and standardization of "authentic" hip-hop. Themes of the street and authenticity in hiphop have been discussed widely in the literature (cf. Dyson 2004; Gray 2005; Gault 2013). Significantly, the African-American religious studies scholar, Anthony Pinn problematizes hip-hop's relation to "the street" as part of his complex subjectivity (2003). Here, "the street" is a conceptual strategy that both resists the historical oppression that reduces black bodies to worthlessness and provides a means for reclaiming self-identity by rooting it in a specific territory or space. The cultural critic Herman Gray evokes the metaphor of motion and movement in the "street and road" in order to emphasize the verbal and transgressive aspects of the discourses and practices of a distinct musical perspective he calls the "jazz left" (2005: 53). Here musicians and promoters pursue active creations and interactions that evolve out of performance and work to challenge canonical musical traditions. Similarly, hip-hoppers apply a street sensibility to resist culture industry related forces of commodification that remove the artist from both their formative conditions and education into hip-hop. At the same time, following Negus' argument below, signifiers representing the street can also be manipulated in order to claim "authenticity," a term loaded with power as cultural capital. However, as discussed 
further below in the literature review of spirituality and hip-hop, authenticity in hip-hop (as opposed to elsewhere) makes plain its social construction (e.g. "fo' real") in order to expose its more malevolent uses. The first recording to achieve widespread recognition in which the streets is objectified is Grandmaster Flash and the Furious Five's, "The Message" (1983): ${ }^{62}$

Broken glass everywhere / People pissing on the stairs, you know they just don't care I can't take the smell, can't take the noise / Got no money to move out, I guess I got no choice / Rats in the front room, roaches in the back / Junkies in the alley with a baseball bat / I tried to get away but I couldn't get far / Cause a man with a tow truck repossessed my car / Don't push me 'cause I'm close to the edge I'm trying not to lose my head It's like a jungle sometimes It makes me wonder how I keep from going under

Distinctly, after "The Message," lyricists began presenting experiences stemming from deindustrialization in urban America complicated by heroin and crack cocaine abuse, unemployment, and a return of gang related violence, including an increase in gun related crimes such as the "drive by." At the same time, DJs sought harder, tougher sounds, meant to represent struggle. For instance, MC Rakim Allah rapped about his experience, albeit distinguished by his style of lyricism and soft-spoken delivery, dexterously weaving an expanded vocabulary over DJ Eric B.'s distinctly thick beats. ${ }^{63}$ Alternately, Queens crew Public Enemy defined east-coast, hardcore rap by combining the sound of "dark" and "heavy" beats, with Afrocentric lyrics, sampling imagery from the Civil Rights movement, black church preachers, and Black Panther militants, particularly on the recording, "Fight the Power," from the album, It Takes a Nation of

\footnotetext{
${ }^{62}$ In this hyperlink to youtube video, "The Message," sounds and lyrics are presented with images of New York City streets in the early 80s. Like Stevie Wonder's "Livin' for the City" (1973), "The Message" ends with a case of police racial profiling, albeit with the Furious Five themselves being mistakenly arrested instead of Wonder's fictitious protagonist. This subtle difference adds currency to the Furious Five's claim to authenticity (Peterson 2005).

${ }^{63}$ While spontaneous one-liners like "raise your hands in the air and wave them like you just don't care" drew from a tradition of improvisation common in the open narrative of party rap, Rakim's style was distinct in its complexity, denoting a more contemplated, thus composed approach. He is credited with influencing notable artists like NAS, Tupac, Jay-Z, and 50 cent.
} 
Millions to Hold us Back (1988). Dimitriadis describes the album: "structured as a 58minute self-contained radio broadcast, its individual songs linked together along conceptual lines... interspersed with portions of a UK concert, static, the sound of a radio dial turning, and bits and pieces of radio shows." He explains, "Communication itself became most important as Public Enemy envisioned an Afro-American community that could be linked together through postmodern media technology" (2004: 428).

The style that has come to define the streets more than any other is that called "reality," west-coast rap, or gangsta, claimed most prominently after 1986 by the Compton California crew N.W.A (Niggaz with Attitude). N.W.A DJ and producer Dr. Dre is the most prolific figure in gangsta. Distinctly, he slowed down then current uptempo beats, creating G-funk: mid-tempo, synthesized melodies, deep bass, live instrumentation, and minimalist sampling, especially of George Clinton's P-Funk. Lyrically, gangsta rappers present the social and industrial decline of West-coast urban centers, relatable to urban America in general. Themes include and often caricature institutional corruption, drug abuse, gang and gun-related violence, sex, misogyny, and homophobia. N.W.A album, Straight Outta Compton (1988), includes "F*** tha Police," a song that protests police brutality and racial profiling. Not only are the sounds consistent with the gangsta style but also in the video, the way in which Dr. Dre plays judge in the parodied prosecution of LAPD invokes the Carnival tradition of inverting social power structures (cf. Burke 1978). More than parody however, "F*** tha Police" garnered a cease and desist letter from the FBI and, while on tour, an ultimatum from Detroit city police, to drop the song from their set or face prosecution. Moreover, by the end of the Rodney King trial, a new street aesthetic became demarcated by the way in 
which "O.G.'s" (original gangsters) use recordings to "diss" each other and their record labels and to use "street cred" to claim authenticity.

Popular culture scholar Keith Negus is wary of the way in which contemporary critics polemicize the culture industry and consumers by essentializing hip-hop as an aesthetic form of African American expression while ignoring the codependency of their relations (2004: 525-540). ${ }^{64}$ Instead, he traces the historical relations between the music industry and the African American diaspora - both artists and audiences - noting an arbitrary widening of space between them that allows artists to maintain a "real" connection to the street. Ostensibly, contemporary hip-hop artists enjoy relative autonomy from the culture industry such as the artistic freedom to self-produce, maintaining a relationship to the street, and legitimating claims of authenticity or street cred. Negus is skeptical of such claims, however, pointing instead to a relationship between artists' career strategies and culture industry structure, called "portfolio management" (2004). ${ }^{65}$ This relation emerged in the "80s with the demise of R\&B due to industry representatives' "incestuous cross-pollination," or apathetic dependency on A\&R strategies of recruitment and promotion within established relationships (George 1989). Historian George states, "Because the big boys were asleep at the wheel, rap would spend most of its young life promoted and recorded by independent labels run by hustling entrepreneurs" (1989: 189). In the 2000s, artistic freedom obtains in an arms-

\footnotetext{
${ }^{64}$ Negus says such renderings emphasize hip-hop as resistant style created through the appropriation of technology and existing signs and symbols in a long diaspora tradition meant to support variously essentialist or anti-essentialist arguments (2004: 525).

${ }^{65}$ Negus defines portfolio management as the dividing of labels, genres and artists into strategic business units, making visible the performance, profile and financial contribution of each division (2004: 527). Such strategies thus are informed by distinctions say, between well-established "cash-cow" genres and unpredictable "wild cats," the latter of which distinguishes hip-hop artists as careers, from rock band units as stable and bound, thus less risky. More than commercial strategies, Negus emphasizes the value judgments and cultural beliefs behind decision-making, including the reorganization of labels after the 1960 s and '70s leading to the creation of black divisions.
} 
length relationship between labels and artists, where artists on the one hand appear to control their careers by limiting label involvement in studio production, while on the other hand, labels promote said artists through record distribution to the mainstream. Critically, Negus attributes the formation of this relation to a knowledge system as opposed to structural organization alone: "it is that these [relations] are operated according to a particular type of knowledge through which the world is imagined in a particular way, a knowledge that depends upon many systematic data-collecting techniques. At the same time, uncritically received cultural assumptions and commonsense ideas about the social location of rap are continually articulated to notions of the street" (2004: 537). Arguably, industries together with artists construct and impose certain knowledge systems upon consumers constituting a significant aspect of the liberal market and popular culture; however, in terms of "data-collecting techniques" that allow us to profile audiences, the recent emergence of self-identifying Christian consumers has become the bedrock of Contemporary Christian Music and Christian-themed hip-hop.

\section{5 - The tenuous, institutional mediation of Hip-hop and Christianity}

Christian-themed hip-hop (also called CHH, holy hip-hop, hip-hope, Gospel hip-hop and Christian hip-hop) renews an evangelistic practice first exercised in the singing schools of the eighteenth century colonies, and builds on the organization of both the black church and the contemporary Christian music industry. Infusing holy hip-hop's practice and organization is what Afrika Bambaataa calls hip-hop's fifth element, knowledge, which stems from two distinct streams: postmodern Islamic pastiche and black revolutionary Christianity. Knowledge is power in the sense that it consolidates information (objective and subjective), whether dance as hip-hop, or sounds as hip-hop. The consolidation of 
knowledge in hip-hop has occurred in three distinct sets of relationships: (1) in terms of leadership, as in pastor and musician; (2) related to institutional spirituality, such as the hierarchized structure of the Nation of Islam or the Christian church; and (3) collectively, including shifting norms related to the class background and migration of the African diaspora.

In Chapter Three, I introduced the organization of the contemporary Christian music industry $(\mathrm{CCM})$ that involves the coordination of a network of performers, managers, recording studios, and marketers, for the purpose of producing and distributing new music. By the 1990s, CCM consisted of independent Christian labels, but their economic and popular success precipitated a series of acquisitions by major record labels (cf. Capitol CMG 2016) ${ }^{66}$ Though in-house production in black churches may be operationally black, along with black gospel subdivisions and dedicated black labels, today, they tap the same distribution networks as the major labels, regardless of race (Weekes 2005). ${ }^{67}$ Digital sourcing in the new millennium has contributed to an expansion of production, sustaining independent holy hip-hop artists and fan culture, both mediated by personal computers.

Christian hip-hop is a contentious designation, synthesizing the street culture and liberation theology of Holy hip-hop (cf. Zanfagna 2010) with Christian rap, the less controversial, commodified and evangelical cousin. Howard and Streck's model (discussed in chapter three) would suggest that Christian hip-hop manifests a shift from separational to transformational musical sensibilities. The first Christian rap song distributed through the contemporary Christian music industry is Stephen Wiley's "Bible

\footnotetext{
${ }^{66}$ See the organization of contemporary Christian music, above.

${ }^{67}$ For example, Arrow Records is based in Creflo Dollar's World Changers International church, Atlanta.
} 
Break" (1985) ${ }^{68}$ Seen by many today as "soft," Wiley ties a benign rap beat to an equally benign lesson teaching the names of the books of the Bible. The reason for such sounds and lyrics — and also for its success — are likely explained by the intended audience, that being suburban children as opposed to, say, urban youth. The widely popular mainstream Christian hip-hop group DC Talk was formed in the late-1980s, while members, Toby McKeehan, Michael Tait, and Kevin Max Smith, attended Jerry Falwell's (Moral Majority) Liberty University (Gault 2013: 171-88). The three-piece group combined hiphop's sonic sensibilities with neo-conservative and Christian counter-cultural themes, exemplified in "Jesus Freak" (1995) a song that takes its name from the 1960s Christian counter-culture. To religion and hip-hop studies scholar Gault (2013: 171-88), however, despite DC Talk being racially integrated, its theology was overly spiritual and abstract, failing to make political and territorially specific links, so important in secular hip-hop. Comparatively, "prophetic" Christian hip-hop crews emerged to fill that gap, including SFC (Soldiers for Christ) and the Dynamic Twins who formed in Los Angeles in the early 1990s (Barnes 2008: 322-24; Zanfagna 2010). These crews sampled sounds that were similar to their secular counterparts yet boasted a "liberation theology." At the same time, Christian music labels expanded their A\&R rosters by signing more acts that presented a "'hood" aesthetic such as P.I.D (Preachers in Disguise) on KMG, GRITS on GoTee Records, T-Bone on MetroOne. These acts presented a separational theology, created for relating to (typically male) youth (Barnes 2008). ${ }^{69}$

\footnotetext{
${ }^{68}$ In this youtube.com clip, Stephen Wiley raps over the first CCM produced hip-hop song, "Bible Breaks," published by Brentwood Contemporary.

${ }^{69}$ Barnes' research is the first in fact to note the use of hip-hop in church, to link apparent social needs with Christian pragmatics (e.g. promoting monogamy through marriage counseling) finding a direct relationship between increases in church membership and hip-hop in worship.
} 
In the early 2000s, Christian hip-hop achieved its widest distribution and popular recognition yet, including its own Grammy category in 2006 and the various "sinner-tosaint" successes of Black Church produced artists such as Mase, infamously mentored by the prosperity doctrine preacher, Creflo Dollar. Like many Christian hip-hoppers, Mase achieved popular fame prior to his conversion, thus inverting the "crossover" narrative discussed in the previous chapter. And yet, Mase is the first such Christian hip-hopper to cross back into the secular realm, albeit with mixed response, after his transformation and mentorship with Dollar. I discuss Christian hip-hoppers' navigation of sacred-secular symbolic boundaries, or the "politics of conversion" (Zanfagna 2010: 26), in the literature review below. Tellingly, the establishment of Christian hip-hop as an economically viable musical self-practice has led to the emergence of professional careers and figures such as Lecrae Moore. However uniquely, Lecrae's wildly popular hip-hop engenders a transformational approach manifest in the relation between his popular recognition, not only with fans but also in his association with celebrities and athletes like the basketball player, Stephen Curry, along with his position in Christian hip-hop, including influencing Billboard's categorization policy. ${ }^{70}$ For instance, in "Good, Bad, and Ugly" (2014) ${ }^{71}$ Lecrae uses Christianity to refract his personal experiences and contemporary social issues of abortion and sexual abuse, challenging sacred-secular binaries and genre-related boundaries:

I remember back in the day / I was barely in the first grade Got teeth missing, watching Tom \& Jerry / Tryna go outside so I could play

\footnotetext{
${ }^{70}$ See Whitaker's article on Lecrae's rise in popularity (2014). Billboard changed its categorization policy after Lecrae's success, overtaking artists and songs listed in the broad Gospel category; unless songs contain gospel motifs and sounds, artists such as Lecrae are categorized under the Christian subgenre (Shellnut 2015).

${ }^{71}$ In this youtube.com lyric video, $\mathrm{CHH}$ artist Lecrae links his endorsement of a girlfriend's abortion to his own sexual abuse as a child. Now a Christian, he believes God's forgiveness empowers him to "to say no to all of his struggles," including presumably, lust.
} 
I was told to watch out for strangers / Keep my eyes peeled for danger Folks workin' late, I had a babysitter / I ain't 'bout to sit here and name her I was almost 8 , when she came in late / Woke me up with a game to play Did a few things that's hard to say / Told me to keep that secret safe How a young boy supposed to deal? / I'm tryna act like it ain't real Had my innocence just stripped from me / And I still don't know how to feel And I'm wondering how to address it / Can't tell my family, too messy So I just embrace it, it's hard to face it / I'm too ashamed to confess it So I kept it in and ain't speak / Didn't think, it hit me so deep So into it, I got promiscuous / And only God can help me get free But I've been forgiven, my Savior risen / I'm out the prison, I know that I got the power to say no to all of my struggles / God will control that Every time we slip and we fall / Gotta get back up and fight on We are not defined by our past / The future look bright, I see the light on

Summarily, the increase of a transformational interest in Christian hip-hop has rendered inconsequential the disputes over the status of holy hip-hop versus Christian rap. ${ }^{72}$

\section{6-A literature review of hip-hop and spirituality: A bridge to the biographical and ethnographic study of holy hip-hop artists}

The case for the academic scholarship of hip-hop is largely founded on Tricia Rose's seminal Black Noise: Rap music and black culture in contemporary America (1994). ${ }^{73}$

She argues that, more than a genre, hip-hop involves a musical expression mediated by the lived conditions of postindustrial urban America, from the aesthetic strategies of flow, layering and posturing, and the racial and sexual politics of its critics, performers and fans alike. Significant for our purposes, Rose leaves intact hip-hop's relationship with the African-American community and the wider American popular culture industry, so as to avoid either the reduction of its practice to a simple expression of inner city social

\footnotetext{
${ }^{72}$ This dispute has sharpened in recent years with the rise of CHH's popularity, but Howard and Streck's model makes it apparent that the stakes have more to do with the intentions of the artists and their perceived influence than with genre definitions. For an anti-hip-hop view, see C. Craige Lewis on his website: www.exministries.com.

${ }^{73}$ Rose's major publication is preceded by David Toop's ground breaking, The Rap Attack: American jive to American hip-hop (1984), in which the figure of the rapper is linked to African oral traditions of storytelling carried by bards and griots. Rose significantly extends her scope of analysis beyond hip-hop's recorded element and African-American history to include the influence of processes of postindustrialization and politics of everyday life and the street.
} 
conditions alone or the attribution of the behavior that makes up inner city conditions to "the music itself," thereby demonizing its artists. By the end of the 1990s, a viable academic sub discipline of Hip-hop Studies emerged in the United States, including numerous journals, academic courses, and conferences on hip-hop. Neal and Forman's That's the Joint!: The hip-hop studies reader (2004), is the first and most comprehensive archive of the field to that point, updated with a second edition published in 2011. Yet despite its multifarious discussions of hip-hop's history and culture, including the representative politics of authenticity, gender, and the culture industries, none of the contributors explicitly unpack hip-hop spirituality. Elsewhere, the sociologist Eric Michael Dyson has made a case for spirituality in hip-hop as early as 1987 with the publication of his original rendition of "The Culture of Hip-hop" in the progressive Christian opinion magazine, Christianity and Crisis, (Dyson 2004: 401) and with his pseudo-autobiographical publication, Between God and Gangsta Rap: Bearing witness to black culture (1997). Dyson is one of the few to draw attention to hip-hop's "deviant" underworld of crime, domestic violence and illicit drug use, as here, through both that of Tupac's "Black Jesuz" (a character based on Jesus Christ who wrestles with the contradiction of the black church that espouses liberation theology without addressing the materiality of such social ills) and Dyson's own lived experience growing up in Detroit. However, his primary response has been to frame such conditions "as a valuable resource for the church in terms of assessing the church's inadequacies and assets" (Zanfagna 2010: 42), yet without problematizing the nature of the relationship between hip-hop and the church. 
Religious hip-hop has only recently begun to receive sustained critical attention. Due to face value interpretations, hip-hop has rarely been problematized in terms of spirituality, and equally, though perhaps more interestingly, spirituality has rarely been problematized in terms of hip-hop. Anthony B. Pinn's Noise and Spirit: the religious and spiritual sensibilities of rap music (2003), is the first collection to assemble various African-American religious studies scholars in consideration of such links, albeit limited to rap music, effectively, and significantly for the field, underlining their mutuality. According to Andre Johnson, Pinn's publication is also important because its contributors expand the field beyond hip-hop and Christianity to note other religious discourses, such as links to Islam (2013: xii). Yet, Johnson's edited collection serves to expand our perspective on hip-hop and spirituality by assembling various scholars representing multiple disciplinary approaches. Significantly for this dissertation, the religious ethicist, James Perkinson, argues that despite its commercialization, hip-hop's efficacy remains in the non-discourse of its musicality from which he argues for an "ethics of the groan" (2013: 1-18). He describes the conditions in which such ethics emerge as follows:

Hip-hop emerged as a cultural codification of life engaged creatively in trying to survive such [postindustrial-ghettoized] devastation. It did so by letting the urban ecology inscribe its character in the psyches and the bodies of the individuals and communities 'imprisoned' there. From the point of view of virtue ethics - such a character-formation is quintessentially postmodern. Its narrative is fractured, not simply coherent... Its community is historically minority, now globally 'rainbow,' and culturally structured in a shared affinity for the capacity of percussion... to make decimation yield meaning... The energies unlocked are what Michel Foucault would call "subjugated knowledges"... The "virtues' wrought - in the process of releasing and amplifying the energy - are the "stylistic virtuosities" that Rose identifies as "flow," "layering" and "rupture." (Perkinson 2013: 13)

Although he does not define "virtue ethics," Perkinson's reference to Foucault's "subjugated knowledges" serves to underline his focus on the ways in which the self 
problematizes and responds to, perhaps resisting, situations as a means of effecting change.${ }^{74}$ For our purposes, his "ethics of the groan" supports our theory that music is self-transformation in its sonic mediation through the body, and our elaboration of Foucault's analytic as an ethic of self-transformation: ethical self-care as ethical change. Perkinson builds on Rose's concept of rupture as a virtue ethic specific to the inner city identity of its people and the process of its survival amidst existential threats, including death. Although, he notes, rupture does not fit the classic Christian virtues of humility and gentleness, feminist scholarship has forced us to consider the enslaved context of its practice: “where one's self is itself 'stolen property,' stealing corn from the master's stockpile for one's hungry child may be a demand of justice" (Jaggar in Perkinson 2013: 13). In the modern ghetto, he argues, hip-hoppers face the reality of death more readily than elsewhere. Such precariousness thus frames rhythmic modalities and improvisatory strategies, including transgressing boundaries to which the church is otherwise beholden. In this way, the ethics of the groan "gives bodily witness to the contradiction that human vitality is a compound quality of pain and pleasure, joy and anguish, life-locked-inmortal-combat-with-death" (Perkinson 2013: 16). Perkinson's "ethic of the groan" at once critiques Eurocentric and Enlightenment rooted boundaries around religious experience and draws attention to the fluidity between hip-hop and spirituality. Indeed, the explicit focus on "hip-hop," "religion," and "Christianity" as conceptual monoliths has recently come under fire, and for several reasons. The AfricanAmerican religious studies scholar Monica Miller has led this critique, for instance noting

\footnotetext{
${ }^{74}$ Foucault discusses the practice of "virtue ethics" during Greco-Roman times as having to do with selfproblematizing as a means of responding to one's subjugation or complex subjectivity, and the various sources of that subjectivity (1986: 25-32). Ethics are distinct from overriding moral beliefs, as he defines: "Ethos was the deportment and the way to behave. It was the subject's mode of being and a certain manner of acting visible to others" (1987: 6). The ethic of self-transformation is discussed further in chapter two.
} 
the discursive ways in which both academics such as Dyson, and empirically based national studies of youth such as the Manhattan Institute for Policy Research, deploy religiosity as a sanitizing construct, "a moral contraceptive, if you will, utilized as a strategy to cleanse the sins of delinquent (cultural) transgressions" (2013: 18). Miller argues that the discourse wielded in such approaches tends to pathologize youth because of its hardened categorization of "hip-hop" and "Christianity." Such generalizations, which she reflexively admits to having taken early in her own research, has at its root the search for meaning. The search for meaning is problematic for several reasons. First, Miller argues that as a trace, meaning is characterized by incessant deferral, thus making its search (as presence), elusive. She states, "In Derridean language, the quest for religion, the search for its kind and knowledge, is in and of itself an aporia: among the 'blind spots' of metaphysical argument." She continues, "signification and meaning are unstable, thus leaving us with nothing more than a glimpse and presence of undecidability. Above all, a crisis of meaning" (Miller 2013: 75). Second, meaning is elusive because of the agent-researcher's position relative to the question, whose position is induced by the very question of meaning - meaningful to whom? Miller's debt to postmodern theory is unquestionable; she combines Derrida's notion of play, Bourdieu's habitus-field analytic, and McCutcheon and Beckford's theory of social formation/ construction, in order to build on Anthony Pinn's theory of complex subjectivity, while appealing to the methods of discourse analysis.

Miller's elaboration of Pinn's complex subjectivity is an interesting development for theorizing hip-hop and religious studies. Significantly, she insists that complex subjectivity allows us to break from intellectual inheritances that ground meaning both in 
sui generis phenomenological experience and in historical tradition as fixed. For instance, Pinn makes such an appeal when he states all "historical expressions" of world religions are underscored by an "underlying impulse," the experience of complex subjectivity as the recognition of and response to the feeling for complex subjectivity (in Miller 2013: 101-2). To Pinn, complex subjectivity is rooted in a sense of "terror and fixity," thus giving rise to continual struggle for increased agency and liberation of one's own subjectivity. However, because he roots complex subjectivity in the emotional states of terror and fixity, Pinn's argument is circular. Rather, it would be more appropriate that such states be considered characterizing mechanisms, instead. Thus, for example, the experience of social injustice having to do with racism might be terrorizing, as in the case of lynching, but considering its historical context, such an experience is not singularly emotional. Where Miller disagrees with Pinn is in his privileging, thus interiorizing of religious "experience" (affective dimensions, emotions, etc.) as "meaningful," as beginning in subjectivity itself. Pinn's intellectual inheritance, she states, is indebted to Charles H. Long, William James, and Paul Tillich, the latter of whom frames religion as a discernable "orientation." This, however, is problematic, as she states:

McCutcheon says it best when he writes, "Simply put, I have no interest in what religion really is ... instead, my interest has everything to do with how (i.e., description) and why (i.e., explanation) human communities divide up, classify, and ontologize their ad hoc social worlds in particular ways." Persuaded by these suggestions, I propose a turn towards evaluating religious uses in Hip-Hop culture as effects of larger social, political, cultural, and economic processes, rather than the culmination of a shared uncaused underlying essence $(\rightarrow$ inner impulse $\rightarrow$ elemental feeling $\rightarrow$ religious manifestation). (Miller 2013: 109)

Simply, Miller borrows from McCutcheon, a concept of religion as socially constructed so as to allow her to parse out the ways in which its practice becomes wrapped up in the reproduction of social inequality, including dimensions of race and poverty. I would, 
however, argue that to simply dismiss religion as socially constructed is to risk throwing out the baby of its complex systems of justice, modeled, for instance, on self-sacrificial figures such as Jesus, and built on themes of forgiveness, redemption and reconciliation, with the bath water of its institutional organization. ${ }^{75}$ For our purposes, Miller advantageously borrows Bourdieu's analytic, habitus, in order to evaluate musical selfpractices such as hip-hop, as not only mediating emotions such as terror and fixity, but "as products of durable inequalities tethered to structuring structures." She continues, "Thus, the externalizations of practices offer a window beyond subjective quests for meaning, to consider complex dimensions of social reproduction, inherited externalized dispositions, and lived reality" (Miller 2013: 116-17). Significantly, Bourdieu's habitus precludes the kind of subjectivism suggested by pure "intentionality" and "consciousness" by linking the musical self to a field, or sets of overlapping fields. Miller's complex subjectivity, combined with our theory of music as self-transformation as discussed in chapter two, allows us to understand and explain everyday life challenges as stemming from biographically rooted experiences and institutional mediations characterized by tension between the two poles of terror and fixity. Such complex subjectivity and its characterization help to explain both the presence of contradictions in hip-hop and religious practice and also their role in contributing to the reproduction of social inequalities.

\footnotetext{
${ }^{75}$ Miller's general criticism compares to Marx', that religion is the opiate of the masses. As Angela Y. Davis responds, however, "Marx goes too far in the sense that he assumes a necessarily and exclusively ideological relationship between religious consciousness and material conditions, i.e., that religion is fundamentally false consciousness and that the 'self' or community it articulates is necessarily an illusion. Such an all-embracing conception of religion cannot account for its extrareligious dimensions. On the other hand, he does not go far enough when he dismisses the revolutionary potential of religious consciousness (1998: 362-3, n.18). As to its extrareligious dimension, Davis has in mind the musical self-practice of the blues, particularly, the great female blues singers of the 1920 s.
} 
Miller proceeds to consider the materiality of hip-hop in her analysis of the recent explosion of hip-hop artist, co-authored publications. Her analysis of KRS One's The Gospel of Hip-hop: The first instrument (2009) is instructive for this study. KRS One, born Lawrence "Kris" Parker (August 20, 1965), is a U.S. based rapper from the Bronx, who began performing with DJ Scott La Rock in the mid-1980s under the name, Boogie Down Productions, until La Rock was shot dead. KRS began recording under his own name in 1993 with Return of the Boom Bap, and has since become an anti-violence activist and advocate for hip-hop. His "Temple of Hip Hop" website for instance, though not updated for five years at the time of writing, promotes hip-hop culture under the moniker, Ministry-Archive-School-Society (MASS), and lists nine elements, adding beatboxin', street fashion, street language, street knowledge, and street entrepreneurialism to the original four. Significantly, in analyzing the discourse used in his 800 page Gospel of Hip-hop, including its fashioning as a King James Bible, Miller notes the ways in which KRS One, as "the teacha" reproduces traditional notions of religion and thereby promotes his self (2013: 58-59). Miller's critical analysis is significant in the sense that she does not take religion for granted, as though self-evident; rather, she accounts for the ways in which cultural practices, experiences, and language come to be regarded as religion. Her critique of KRS One is instructive in that it reminds of the various and variable weights and boundaries (as opposed to meanings) that circulate throughout popular culture, strategically wielded in this case in order to divinize the culture of hip-hop.

However, Miller's reliance on the method of discourse analysis tends to diminish the conditions of everyday life that give rise to cultural artifacts such as KRS One's Gospel of Hip-hop. While she does well to link the knowledge production of his Gospel 
to his employment of market strategies (and equally, public responses to his Gospel found on blogsites), she does not interrogate the "terror and fixity" characterizing KRS One's condition. From where did his interest in hip-hop and religion, in this case Christianity, come? Moreover, while she does well to problematize religion, Miller misses an opportunity to treat hip-hop to the same critique. Arguably, the musical selfpractice of hip-hop, as a "technology of articulation," reveals one of the ways in which notions of "religion" become grounded in the self and thereby articulated. Finally, while Miller argues that the conflation of sacred and secular, as in the case of KRS One, works to entrench traditional notions of religion by exaggerating its distinction, she does not consider the strategies unique to independent artists and their local scenes.

Recent ethnographic research on hip-hop culture and spirituality draws attention to everyday life challenges with which hip-hop artists, their local scenes and fans, contend and strategize. For instance, the anthropologist Su'ad Abdul Khabeer interrogates Muslim life in the United States as it contends with normative forces in popular culture along lines of race, religion, and gender, using hip-hop as a pragmatic strategy meant to resist racism, a strategy she calls Muslim Cool (2016). Khabeer picks up on Pinn and Miller's problematizing of hip-hop and religion in order to note the ways in which Islamic religious practices have affected the development of hip-hop ethics and activism. Such epistemological work, she argues, forms a loop that links young Muslims to Black culture, including hip-hop and Black Muslim leaders, including influential figures in the history of hip-hop, such as Malcolm X, Clarence 13, and the Five Percenters discussed above. Plugging into the "loop of Muslim Cool" allows young Muslims to anchor their identity in such traditions of faith and ethics of social justice in 
order to overcome challenges specific to the American experience, including normativity and racism. Especially since 9/11, American Muslims have faced increased pressure to assimilate to dominant (white) cultural norms, while also being segregated through difference. American Muslims are in fact segregated further along an indigenousimmigrant divide, determined by global region of origin, such as North Africa, the Middle East, and Southeast Asia, as well as the United States. Drawing on Grewal, Khabeer states, "claims of proximity are a powerful form of cultural capital for Muslims in the United States who are geographically distant from traditional centers of Islamic authority today (2016: 13). In the face of increasing racism, hip-hop has become a resource for American Muslims.

Khabeer's ethnography is based for the most part in Chicago, where it is estimated that over 400,000 Muslims live. For her research, she notably followed and interviewed men and women, adding an important gendered perspective that is often overlooked in the literature. American Muslim women adopt and adapt to AfricanAmerican and Latin@ cultural practices of hip-hop while also transcribing traditional Muslim practices into hip-hop, through the fashioning of Hijabs with "street-cred," creating the Hijab-lite and 'hoodjab. Drawing on African-American vernacular culture, the 'hoodjab references both the contemporary urban experience, specifically the ghetto culture of Chicago's lower class neighbourhoods shared with African-American, Southeast Asian, and Latin@ peoples. Khabeer problematizes the ‘hoodjab according to Stuart Hall's concept of Black popular culture as a "contradictory space" and "a site of strategic contestation," "in which Black expressive cultures are simultaneously embodiments of Blackness that emerge, not unproblematically, from within Black 
communities themselves, and reproductions of Blackness that are appropriated and/or commodified outside Black communities.” Khabeer adds John Jefferies’ discussion of "the city" as contested space to Hall's theory, stating, "Thus, the 'hood, hip-hop's remix of Black urban home spaces, is the locale of Black cool. At this site of contestation, complex Black meanings stand beside representations that rely on familiar myths that “make" Black people cool: deviance and primitivism" (2016: 119). This localized network of meaning or knowledge (as opposed to universalized meaningfulness) in relation to its contested representation, gives grounding to Miller's overly textual analysis discussed above. Khabeer's "Muslim cool" sheds light on the ways in which hip-hop style crosses racial and gendered boundaries by exposing the social construction of identity. Far from disempowering, in this case, the presentation of the Muslim self effectively resists racism in Chicago and the U.S.

Ethnographies of hip-hop and Christianity are few though gradually emerging. Erika Gault, for instance, conducted such research for her dissertation on Christian rappers in Buffalo (2013). She notes various interrelated changes in the early millennium that contributed to the creation of a new "religious network" conducive to Christian hiphop practices. Such changes include a reconfiguration of space, including the makeup of the cityscape, redefinition of "the church," the creation of "not-a-church" communities based, for instance, on gendered themes of masculinity (e.g. "men's groups") and femininity (e.g. "motherhood"), and the expansion of social media. Christian hip-hop, she notes, is themed by "narratives of escape," including escape from destructive behaviours such as gang violence, "finding one's identity through music," including converting to a Christian system of ethics and "authenticity." Indeed, underlying much of 
the performed lyrical content and informal discussion that she conducted with her interviewees is a concern with "authenticity." Gault does well to tussle with issues of essentialism in her discussion of the significance of authenticity for Christian rappers stating:

Their search for authenticity involves a continuous and intentional performance of real manhood, rooted in real geography, stylized by real talk/language. Speaking of "the real," it is an attempt for real identity. Returning to Pinn's notion of complex subjectivity, Gospel rappers are wrestling to rid themselves of the harshly prescribed identities of their historical past. As Charles Long notes, the black body has been rendered historically meaningless. The nature of black religious experience is to prescribe some meaning (fullness) out of meaninglessness. (2013: 212-13)

Gault's discussion of authenticity strikingly draws out a number of tensions, binaries, and contradictions that characterize Christian hip-hop. Such tensions center on identity and its resources or anchors in race (essentialism vs. social construction), gender (traditional modes vs. liberal), geography (urban vs. rural), and morality (the church vs. "the streets"). "The Search for Authenticity" has been thoroughly deconstructed in recent music and cultural studies (Turner 1976; Peterson 1999; 2005; Roy and Dowd 2010) but rarely in terms of race and spirituality as Gault does here. The Christian hip-hopper's concern with "the streets" and "keeping it real" is distinct in that it functions as a double critique: at once, against the destructive violence of "the street," including challenges of racism, drug abuse, and sexual objectifications of women, from which the subject emerges, and against the institutional church's inability to address those challenges despite preaching a "liberation theology." To be clear, "authenticity" is not some "thing," as the conception and practice of such a thing entails the same problems wrapped up with essentialism and absolutism. However, in blatantly weaving claims of authenticity into the hip-hop narrative, artists call to mind the moral basis that commercialism and indeed 
the church so often betray. In getting gangsta rappers and would be criminals off the street, such a strategy can be helpful. However, despite drawing attention to this important topic, Gault does not problematize the Christian hip-hopper's economic interests in their musical practice. This is surprising considering the challenge that their radical stance imposes on their ability to make ends meet.

The ethnomusicologist Christina Zanfagna conducted the first ethnography of holy hip-hop, documented in her PhD dissertation, Holy Hip-hop in the City of Angels: Music, urban space and the politics of conversion (2010). Like Gault, Zanfagna explores the realm of everyday life in order to note both the ways in which holy hip-hoppers are affected by their social conditions and how they use hip-hop and spirituality to strategize against those conditions. Notably, she foregrounds the examination of hip-hop subjectivities as opposed to identity politics that tend to suggest total control over selfidentity claims, "thus leaving out issues of power and the ways in which cultural relativism can sometimes lead to increased intolerance and discrimination" (2010:25). Drawing on Foucault's assertion that freedom is not practiced outside power or discipline, Zanfagna defines subjectivity as both the self-fashioning of identity claims and the interpellation of individuals as subjects. Significantly, her approach allows her to challenge binaries of sacred-secular, opposition-liberation, and resistanceaccommodation that heretofore have been the subject of much debate in religious studies, critical race theory, and cultural studies. As we shall see, her approach also complexifies the authenticity-commercialism binary. Here, holy hip-hoppers in Los Angeles are found to be caught in a triple bind: their infusion of hip-hop sounds makes them musical mavericks in the church; their moral, Christian-themed lyrics make them soft, corny 
Bible-thumpers in the streets; and their retention of hip-hop signifiers, including gangsta fashion style makes them juvenile delinquents to the state. Their "difference" in each respective field has the ambivalent effect of polarizing holy hip-hoppers as both urban saints and outcasts. In turn, Zanfagna notes a distinct subjectivity and related strategy that such rappers employ in response to their conditions.

In following holy hip-hoppers in their everyday life and musical practices, Zanfagna discovered a complex space of possibilities for religious transformation or healing making up a "politics of conversion." Zanfagna introduces this term as follows:

As a conceptual strategy for understanding the dynamics of power, agency, and practice in the cultural production of holy hip hop as well as the sometimes tentative, sometimes total transformations that holy hip hoppers participate in. These transformations take into account the temporal registers of both today and the Promised Land. Practices of conversion, whether they involve a spiritual change, a change from one viewpoint to another, a physical transformation, a change in function, or even just a turn of phrase, make possible moments, sites, and experiences of transition, rebirth, and changeover. The "political" character of such cultural practices is not reduced here to policies and institutions of the state but instead derives, as Jocelyne Guilbault states, "from being inextricably linked with processes of exclusion, marginalization, and representation." (2010: 26)

The "politics of conversion" offers the advantage of problematizing what can be a monumentally transformative event in one's life by exposing those dimensions that contribute to its significance. Following the discussion in chapter two, Zanfagna's research adds nuance to our conception of self-transformation as she differentiates between tentative and total forms. She terms additional articulations and manifestations of conversion, "biographies of conversion," "geographies of conversion," the "evangelical hustle," and "flippin the script(ure)."

The "evangelical hustle" is particularly interesting as it draws attention to the everyday practices and strategies of independent hip-hoppers who do not have the 
support of a major recording label or institutional church. Expanding Bourdieu's "forms of capital," Zanfagna conceives of "spiritual capital" among other forms of cultural and symbolic capitals, as infusing a complex, non-vertical, and non-linear economy among holy hip-hop networks or scenes. Here, hip-hop performances, live and recorded, are envisaged as part of a broader, eternal cosmology, mediating both the self and wider institutions, such as the church. She states, "Gospel rappers' everyday practices demonstrate the costs and benefits of bringing the church into certain cultural markets, while at the same time unveiling the ways the market has always already been part of the church" (Zanfagna 2012: 198). One of the ways in which the church and markets intermingle thus is found in the alternative value of hip-hop, including its various musical self-practices. Zanfagna traces several instances where holy hip-hoppers perform and distribute recorded performances for free, calling such counter-intuitive acts "leaps of faith." Such leaps are viewed as holding the potential for face-to-face encounters that are hopefully converted into economic capital and result in the conversion of souls. The performances of hip-hop subjectivities also act as claims of authenticity, suggesting that holy hip-hoppers are true disciples of Christ, real hip-hoppers, and still in touch with the streets. In sum, Zanfagna's critical ethnographic research of Christian hip-hop adds a valuable empirical dimension and critical perspective to our consideration of its musical self-practice.

\section{$4.7-$ Conclusion}

Christian-themed hip-hop, although only a recently emergent phenomenon, has roots in the social conditions of the Bronx and the organizational strategies of the American popular culture industry that include commodifying that experience. Distinctly, with the 
dividing of African American people along socio-economic lines due to processes of post-industrialization, along with the loss of leadership and disillusionment with the church in the 1970s, and with the addition of newly immigrant minority peoples predominantly of Caribbean descent, hip-hop became wrapped up with local challenges having to do with youth, unemployment, crime, drug abuse and gang violence, and spirituality as opposed to institutional religion. Such spirituality, like the innovative techniques of its founding figures and their complex subjectivities, "sampled" a variety of sources and took a variety of forms. For instance, in the attempt to self-transform in the face of such complex subjectivities, characterized by precariousness, emergent hiphoppers redefined "the street" for themselves, making various claims of "authenticity" through various musical self-practices such as battles and posturing. As they gained recognition, the symbolic currency of such self-transformative practices became exchanged for economic currency, Christian hip-hop being no different. Non-church networks or un-institutionalized spirituality, and the contemporary Christian music industry, mediate the conditions and strategies of hip-hop musical self-practices, including the ethic of self-transformation. Transformative techniques such as "the politics of conversion" and "the evangelical hustle" provide conceptual insight into these mediations. Contemporary Christian music is no less complicated a terrain for holy hiphoppers already practicing their craft in the precariousness of everyday life. Although the Christian music industry poses possibilities for market-based success, albeit limited to the established networks of churches and Christian colleges, it also holds the potential for career failure, hence our consideration of market-based precarity. 
In the next chapter, I will trace the mediation of Rob "Fresh I.E." Wilson's musical self-practice with Christian hip-hop, across his life and in the present. In many ways, the conditions of Wilson's formative years compare very much to those of DJs and MCs raised in the Bronx, including the way in which he was brought up in Winnipeg's first public housing in the North End, relatively isolated from the rest of the city. As we shall see, his minority background presented certain possibilities and limitations in terms of his musical education. However, his musical self-practice and ethic of selftransformation, along with a supportive cast of scenesters, afforded him the potential to convert to Christianity, to become a reputable Christian hip-hopper and gain wide recognition and influence. And yet, as we have seen with figures such as Kirk Franklin, in the previous chapter, Rob's musical self-transformation has been met with certain constraints from the Christian music industry and the institutional church. Relatedly, self-doubt, rooted in his biography, has also strained his musical self-practice and significant relationships, culminating in his contemplation of suicide. The apparent contradiction of this contemplation, along with other related constraints and contradictions is explored and discussed further in the next chapter. 


\section{Chapter Five}

\section{Rob “Fresh I.E." Wilson: A Socio-analysis of Musical Self-Transformation}

\section{1 - Introduction}

Having theorized music as self-transformation, tracing the roots of African-American religious musical self-practice along with the institutional organization of the black church and contemporary Christian music industry, and the rise of Christian-themed hiphop, it now remains to link such theoretical, historical and organizational processes to the case of Rob “Fresh I.E.” Wilson. In considering Wilson's musical self-practice across his life we can understand and explain the ways in which musical self-transformation has occurred for him, distinguishing the gradual transformations of his formative and educational years, and later, after the establishment of his professional practice as a "Christian hip-hop artist," from the sudden transformation following his conversion to Christianity and Grammy nominations. Such transformations can then be explained as having to do not only with his biology, for instance, but also with his various and varying musical mediations with immediate experience, the scene in which he apperceived and practiced that experience, his imagined membership in a wider community, musical, ethnic, religious, or otherwise, and with the institutions of the culture industry and the church. Such complex subjectivities make up and condition Rob’s musical self.

As flagged in the introductory chapter, Wilson's biography is not complete but on going. It is from the perspective of his present musical self-practice that we can recognize the influences on and of his ethic and practice of musical self-transformation, including the ways in which his sense of self fluctuates, along with changes in the institutions with which he is musically mediated. In this chapter, I highlight some of 
these practices, including his musical self-production techniques of "collaboration," and those that I argue to be the elements of his "politics of conversion" (discussed in the previous chapter; cf. Zanfagna 2010: 26), the techniques of "reclamation" and "projection." In the face of self-doubt and the constantly changing fields of popular and Christian music, Rob self-transforms his musical practice, on the one hand, by reclaiming his formative experiences, which works to revitalize his self as per the Christian narrative of "redemption." On the other hand, Rob reclaims the field-specific legitimacy of his Grammy recognition as a method of reasserting his present professional practice. With either practice of "reclamation," Rob renews his ethic of self-transformation and reconditions his musical self-practice.

Finally, this chapter includes an appended account and discussion of the ethical significance of Wilson's musical self-practice. Rob's present musical practice and ethic of self-transformation is not self-contained; rather, his music making practices bring him into contact with a variety of collaborators, peers, mentees, and audiences, including with Christian churches and Indigenous people, two sites in which contradictions emerge. In the former, despite inviting others like him into the fold, Rob faces pressure to adapt his practice to the normalized model, for instance, of Youth for Christ in Winnipeg's downtown core (winter 2015). In the latter, despite bringing hope to its people, Rob's performance strategy of touring First Nations reserves appears to offer little material transformation. Such contradictions will be traced here, before concluding with a discussion of his youth mentorship program as a possible alternative model of musical self-transformation. 


\section{2 - Colonial history and trauma trails in the racially segregated space of}

Winnipeg's North End: Conditioning Rob Wilson (1972-87)

There is a parallel between the Bronx and Winnipeg's North End. Following from Chang's history (2007), as elaborated in the previous chapter, hip-hop emerged in the Bronx because of, and in response to, a number of historical processes and musical selfpractices. Such processes included "white flight" and the eviction of middle class residents due to urban planning policy around the automobile, and industrial divestment from the urban city center. Relatedly, African Americans divided along class lines, leaving many impoverished and working class people in the city core while the educated middle class left for the suburbs, a racialized process called "black flight." Slum clearance policies led to the construction of massive public housing blocks in secluded areas, which, despite the intent to offer affordable housing to the disadvantaged, instead, effectively concentrated the city's most vulnerable people in spaces far removed from former supportive networks or communities. Such processes in turn lowered the flash point for a variety of criminal activities. Such was the setting for young people growing up in the Bronx in the mid-1970s, where "the street" was their sometimes playground, oftentimes battlefield. At the same time, immigration from newly independent Caribbean nations to the Bronx led to a distinct cultural and musical mix, whose coalescence with the borough's African-American people around "block parties" or "rent parties" gave rise to the musical self-practice called hip-hop. Distinctly, block parties became sites in which youth with little material wealth could not only raise funds to pay the rent, but also compete for bragging rites as MC's, DJ's, graffiti artists, or break-dancers. Such were the conditions and elements of hip-hop's emergence in the Bronx, New York. 
Similarly, Rob "Fresh I.E." Wilson's formative years were conditioned by the relative isolation and racialized space of Winnipeg's North End. The defining feature of the infamous neighbourhood is the C.P.R. (Canadian Pacific Railroad) tracks that angle northwest from Point Douglas, and past Keewatin-Burrows, where Wilson grew up in the city's first public housing. With the Red River to the east, the tracks create both a distinct urban-geographical zone immediately flanked by commercial shops and industrial warehouses, and a cultural divide, populated for the most part by working class people while middle class folks make up the south end.

Historically, the lives of people near the tracks became entangled with the varying forces of the political economy of the last century, contributing to a considerable concentration of poverty and racial inequality, and its associated problems with crime and racism. Winnipeg based sociologists and social workers, Comack et al., attribute the "racialized space" of the North End to the "trauma trails of colonialism" and an economic boom at the end of the nineteenth century that implicated immigrants predominantly from Eastern Europe (2013: 46). In the second half of the twentieth century, social and cultural changes due to migration to Winnipeg's North End paralleled those of the Bronx, including a massive exodus of skilled labourers along with their established social networks, replaced by a fresh influx of immigrants. Jim Silver (2006: 11), cites studies that show a 29 percent decline in the inner city population between 1941 and 1976, while the suburbs grew by 200 percent; and, from 1941 to 2001, while the population of the city grew from 300,000 to 674,000 , the inner city population declined from 153,700 to 93,800 or from 51.2 percent to 13.9 percent of Winnipeg's total population. To Silver, incoming immigrants' conditions of possibility were increasingly constricted in this period by 
neoliberal policy and global political-economic forces in the form of deindustrialization.

The loss of manufacturing jobs and the local transition to a service based economy in turn only increased demand for affordable housing in the North End, exacerbating poverty related problems. Facing civic opposition, the construction of public housing in the North End was finally justified using "urban renewal" rhetoric, code for "slum clearance." However, although Salter-Jarvis residents moved into better living conditions - if not into the 160 units of the Burrows-Keewatin project, then the area surrounding Salter-Jarvis - it soon became apparent that the projects were founded on an unsustainable model. The problem with slum clearance, mid-century, was a deterministic idea that bricks and mortar created either deviance or civil society when in fact broader global forces were affecting job prospects. Although residents were initially pleased to escape poor living conditions, budgetary cutbacks at the end of the " 60 s caused the Winnipeg housing authority to reconsider its policy. While demand remained high, existing residents were forced out once they crossed a certain income threshold, and tenants were profiled according to income and marital status, contributing to a concentration of low income, single parent tenants. By the late 1960s, although it was affordable, public housing in the North End was a site of unemployment, poverty, crime, illegal drugs, and prostitution, offering few options for mobility, fiscally, materially or psychologically.

Wilson's formative years, including his tumultuous relationship with his parents, dovetail with the all too common experiences of child sexual abuse and neglect that narrate the North End, its history and people. His father emigrated to the North End from a northern First Nations reserve long enough for Rob to be conceived, but not long 
enough for Rob to get to know him. It is likely that his father was part of a slow trickle of Aboriginal peoples that began migrating from reserves into the North End in the 1960s. ${ }^{76}$ His father may also have been traumatized by Canada's Residential School system in which children were forcibly abducted from their parents with the stated aim, "to take the Indian out of the child" (Truth and Reconciliation Commission summary findings, June 3, 2015). According to Comack et al. (2013: 41-44) hydro dam related evictions and the Residential Schools contribute to the "trauma trails of colonialism," including constraining those possibilities available to victims and their descendants by severing ties to traditional cultural practices, and increasing their vulnerability to modern forces of inequality characteristic of urban spaces, such as unemployment, poverty and racism. ${ }^{77}$ Either way, Rob did not have a relationship with his father, although they later met twice: the first time when Rob was about sixteen years old and he sought approval after winning a dance competition to appear on Star Search; and, a few years after that when Rob rejected his father's attempt to reestablish his position as patriarch of the family (interview May 31, 2016).

It is not fair to say that Wilson's identity was formed by his father's presence as much as his absence. He knew that he was different from his neighbours and classmates because they were not "brothers" like his cousins on his Mom's Trinidadian side; yet he wasn't black like his cousins either, as he reflectively states: "My hair was straight" (interview 2015). Rather, Rob's upbringing informed a 'triple consciousness' (to complicate Du Bois' concept of "double consciousness" (2009 [1903])) in the sense that

\footnotetext{
${ }^{76}$ Canadian Aboriginals typically self-identify according to three cultures: First Nations (North American Indian), Inuit, and Métis. According to the National Household Survey, Winnipeg has the highest per capita concentration of urban Aboriginals in Canada at over ten percent, totaling 78,420 (statcan.gc.ca 2011).

${ }^{77}$ Comack et al. focus on Manitoba gang members in their ethnography (2013).
} 
he could not identify with the white folk of Winnipeg's dominant culture in the 1970s' 80 s, neither could he fully identify with the African-Caribbean descendants with whom he was related and whom he gravitated toward, nor, lacking the option of knowing his paternal relatives, could he identify with his Aboriginal roots. As such, Rob's upbringing is racially tinged in a uniquely Canadian way, combining the multicultural character of the North End of the period, circumscribed by Eastern European institutions and increasingly entangled with First Nation and Caribbean immigrants. Moreover, Rob points to his father's rejection - his failure to recognize the talented young b-boy both on the VHS tape and in person as his son - as a source of his objectification of sex in order to fill his need for acceptance. To Rob, women became little more than objects of pleasure and control. Although he attended St. John's High School at 401 Church Ave., he soon dropped out because in his words, he was "too busy chasing booty" (interview May 31, 2016).

Rob's maternal grandparents immigrated to Winnipeg in the 1960s under circumstances of rising unemployment and crime common to recently independent Commonwealth nations, in this case, Trinidad and Tobago (Interview, May 31, 2016). ${ }^{78}$ When I asked Rob about growing up with his mother, he told me he only lived with her for one year - and a rough year at that. Although his Mom may have raised the infant Rob, it was his aunts who provided guardianship from age six on, initially moving him from Burrows-Keewatin to Halifax - also into public housing - before moving back in 1983 to 'Jig Town' - as it is affectionately known to locals, disdainfully to outsiders, for its high concentration of racial minorities, blacks and Aboriginals. This was the moment

\footnotetext{
${ }^{78}$ Chang's hip-hop history links Jamaican independence to Kool Herc's mother's immigration - and thus hip-hop - to the Bronx (2005)
} 
when he reconnected with his biological mother and experienced the sounds of music on

a whole new level. Disturbed by the sounds of her "being beat up" in the room next door, Rob escaped his situation through his headphones, and through a song called, "Free" (Prince 1983).

"Free" is the first transformative musical experience in Wilson's biography, initially opening a space and time of refuge from his sense of abandonment and powerlessness. So strong was the impression left on the young Rob, that the line "Free to go "most anywhere, anytime" later appeared on his 2002 album, 28:3, along with a strikingly similar melody. The "Fresh I.E." version of "Free" draws on Rob's existential struggle with racial "difference," and struggle with injustice, during his youth, while recasting it as Christian redemption. Below, Rob recollects the familial relations in which his sense of "difference" emerged:

RW: I grew up not having parents in my life, with my aunties and grandmother. So, there were a lot of hurts as a young person, especially as Christmas and the holidays came around, or birthdays when I'd see my cousins open up gifts. When my birthday came it was always that guilt gift that someone gave me just because they knew I didn't have any parents to buy me presents or even throw me a birthday party. So, by the time I got to six-seven, I understood already what that was; I could recognize the compassion that my aunties and my granny had for me... [but] I knew they couldn't give what I needed. So, them giving me that gift really hurt more because I would open that gift and then I would watch my cousins open up all the rest of their gifts. It was like, what's wrong with me, why can't I have what normal kids have? (Interview: Feb 12, 2015)

Wilson's experience of "difference" associated with his family in turn conditioned his

musical subjectivity, and later, his musical disposition:

RW: So, those kind of situations when I was younger... I would go down into my room, in the basement and put on, Prince, or put on some music, and it would take me away from that place [to] where I felt like, 'hey man, these guys understand me,' you know what I mean? Even though my family tried to understand it, I felt like they didn't. But, when I listened to this music it made me feel like somebody understood me. So, it made me really just gravitate to music... I got to a point where I would put down some cardboard in the middle of the projects and then put on my ghetto blaster and dance, in front of everybody. People would watch out their windows, and cheer for me, you know? So, music, as a kid, really helped me get away from that place of guilt or rejection, and gave me something to press towards. And, although I 
didn't play music [an instrument] at that time, it was just a part of me; [although] I was a little kid, I was an old soul that already understood the pain I was dealing with, just from listening to you know, Prince or Michael [Jackson]. (Interview: Feb 12, 2015)

It is fascinating to note Wilson's recognition of his own musical subjectivity despite not "playing music." This experience suggests the emergence of a sonically mediated relation to his self. Sounds, music and dance, became ways in which Rob could relate to his experiences, or to know his self - gnothi seauton (cf. Foucault 1988: 19). Below, Rob describes the first time in which he attempted to musically self-transform with "Free":

AK: Do you think it was the sounds or the lyrics? Or was it everything?

RW: I think it was just the voice... the words and the cry that I wanted to say at that time but I didn't have the words, it was like they were talking for me. Like Prince, he had a song called, Free. I used to listen to it and just cry in my room just because I felt that way; I just want to be free from all... you know, listening to my Mom being beat up, and I just wanted to be free, you know? And so, there was a lot of stuff man, but music was my safe place; it would be something that I would do where I would just sit there and listen to records. (Interview: Feb 12, 2015)

Interestingly, the sonic experiences that contributed to Wilson's transformation not only involved listening to favourites like "Free," but also the engaged practice of those sounds, "in the middle of the projects... in front of everybody," in this case dancing to Thriller, the biggest selling album of 1983. Rob's bodily engagement with the sounds of music is the second formative experience worth pointing out as it involves an embodied release from his sense of racial and familial "difference" that parallels the intellectual release involved with listening to "Free.",79 Music sociologist, Lisa McCormick (2006: 121-44) argues for the centrality of performance, including dance, to musicological study because of the uniqueness that its embodied presence entails. As such, performance is irreducible to consumption or production. Thus, dance worked to

\footnotetext{
${ }^{79}$ Arguably, dancing in this case is not so much a release as it is a heightening of presence in order to flush out a sense of injustice. It is easy to imagine the presence of Rob's dancing in the projects particularly as pleasurable, and on two levels: in terms of his self-perception; and, it terms of the public support garnered from his audience of neighbours.
} 
support the emergence of Rob's sense of his musical self by forging a complex subjective space for him. ${ }^{80}$ As a result, his self-in-formation afforded the twofold emergence of his musical disposition, and of his ethic of self-transformation. Summarily, Rob came to embody a self-sustaining musical self-practice in a condition characterized by precarity, mediated by his bodily engagement with popular songs and a local public.

\section{3 - Winnipeg's Hip-hop house party scene: Educating "Freshie” (1988-97)}

As it feeds into his professional practice, Wilson's educational years involve the boundary work of learning hip-hop, contributing race politics and a localized articulation of such politics to his music. While his formal education may have ended when he dropped out of High School, Rob's professional education was in Winnipeg's first hiphop house party "scene," 81 where Rob became "Freshie." According to the urban dictionary (urbandictionary.com, consulted February 2017), "Fresh" was a common term in New York's hip-hop scene in the 1980s, meaning "the leading edge of style." Certainly, "Freshie" endeavoured to embody that sense in the Winnipeg scene, not only in his fashion style, but also in his dance moves. And as a point of reference, "Freshie" directly imposed that esteem both as a standard to live up to, and as a form of cultural capital to exchange. At the time, Winnipeg was a Rock capital, although its national status was waning in comparison to Toronto. Local music historian John Einarson (2005)

\footnotetext{
${ }^{80}$ Embodiment draws attention to the relation between the perceptual and the symbolic realm of the self, characterizing as it is characterized by "intentionality," important for our consideration, as it is effectively a decentering aspect of the self. Merleau-Ponty phenomenologizes "operative intentionality" as a characterizing aspect of being in the world that is defined by the body's perception (2012: 440-2). Importantly, perception returns us to the realm of subjectivity, as characterizing the "this-thing" of ideas. "Intentionality" is applicable in this case as it allows us to trace the ways in which sound was and remains perceived by Rob in dance, and its role in contributing to his discovery of related senses of pleasure. Shepherd \& Wicke similarly ascribe this aspect of sonic subjectivity, the "sonic saddle;" presence framed by passing and anticipation (1997: 159-68).

${ }^{81}$ Critically, Straw's concept accounts for the more fluid coalescence of plural agents in sonically infused environments than more simplistic analyses of youth subcultures that tend to render scenes as static, forever subordinate, and youth as homogeneous (1991).
} 
notes the influence of the city's relative isolation from what he calls "cultural meccas"

(e.g. Toronto and New York City) upon musicians and their practice, which together with

long winters feed into a DIY (do-it-yourself) ethos and the creation of home-based music making spaces. ${ }^{82}$ Winnipeg's first hip-hop scene was certainly bound to the homes of its biggest fans. However, the scene existed unnoticed for several years, characterized by and characterizing participants' minority status compared to the dominant Rock culture, and contributing to the formation of a tightknit group of individuals who organized house parties, including DJ D, or Deval "Thunder" Dryden. Deval performed at "events" making up the scene in the mid-'80s. Below, he describes his getting to know Rob "Freshie" Wilson, and reveals individualizing forces suffused throughout the scene: DD: Just to give you a good picture of Fresh, 83 Fresh at this time was thirteen, 84 extremely slender <laughter> - you have no clue - and so was JJ [Rob's b-boy friend and dance partner]. Where we first met, it was a thing where they were coming to events that I was DJ-ing. ${ }^{85}$ Fresh and JJ wanted to dance at these events, like be

\footnotetext{
${ }^{82}$ Although Einarson does well to include in his history of Manitoba made music, lesser known Francophone and Aboriginal acts and venues that emerged in the ' 80 s, as well as urban artists, including Mood Ruff and Fresh I.E. who won recognition in the early 2000s, he fails to mention the existence of the small yet not insignificant hip-hop scene that began to take shape around 1986-' 87 . This oversight is likely due to his underestimation of the cultural hegemony of popular dance and Rock over such lesser-known forms, and relatedly, how such inequality contributed to the confinement of the hip-hop scene at first to house parties, socials, and boat cruises.

${ }^{83}$ Deval refers to Wilson by his current stage name, but in the " 80 s Rob was going by the name, "Freshie". ${ }^{84}$ Wilson would have turned fifteen in November of 1987, when Deval was DJing house parties.

${ }^{85}$ In the following, Deval elaborates on his musical self-practice of DJing. Interestingly, he attributes the successful establishment of the scene to its transition from house parties to clubs, made possible by a cultural and economic vacuum created by middle class Winnipeg cottage-goers. Though not unique to Winnipeg, he suggests that cottage going in this case took Rock fans away from clubs where Rock was performed, encouraging booking agents to consider alternative sources of entertainment such as hip-hop. At the same time, local hip-hop fans that largely remained in the city throughout the summer, enthusiastically responded to the venue change, thus securing the more sustainable infrastructure of Winnipeg's clubs. AK: And what were you doing as a DJ?

DD: I used to DJ the parties. Myself, a gentleman by the name of DJ Fresh, Jimmy Jay, LK Rock, and Grandmaster Funk, they were the ones who started the hip-hop movement in Winnipeg. They would throw these parties, they'd rent basement churches and they used to throw like shows. And these shows would only attract like urban - it was all hip-hop, there was no dance, it was strictly hip-hop and reggae from A to $Z$ - and these parties would be maxed out. When I say maxed out, I mean extremely maxed out. It got maxed out to the point where the clubs would come to these parties, especially on long-weekends; that's when we did most of them. The clubs were puzzled because, you know Winnipeg long-weekends, everybody leaves. But, when we throw a party on a long weekend, we'd be packed: a thousand people, five hundred people. It would always be sold out, 'cause it'd be the only place that you got to hear hip-hop. (Interview May 1, 2015)
} 
dancers, and then they joined a dance team. A gentleman by the name of Kanes Mecca... had a dance-rap troupe; he had Fresh, JJ, and another gentleman by the name of Patrick Villa, who was my best friend - he moved away to Vancouver - his brother [sic] Jasen Villa, Rob McLaren, and Bobby Cortez. The group was more of a, just of individuals...

Hip Hop at the time was extremely new; it wasn't being played in the clubs at all. We would throw parties at houses and everybody would just come to these parties to have fun, right across from, what's the school? Across the street we used to have a house [on] Alverstone, where we used to just, on a Friday night, clear out all the furniture and we would host a party; the place would just be packed Friday night. 86 And then we started to charge two-three dollars to get in. We used to do this all summer up until winter. (Interview May 1, 2015)

It is important to note from Deval's account the principal "mode of social reproduction" that characterizes the field in which "Freshie" was educated, that is, as it was defined by dimensions of economic and cultural capital, heavily if not entirely weighted toward the latter (Bourdieu 1998: 19-30). As such, the social space of the hip-hop house party was characterized by non-pecuniary, symbolic exchange. For instance, masculine posturing was the main currency traded at the early house parties, between an "extremely slender" Rob and the rest of the group "of individuals." In such a setting, Rob competed for the approval of his peers in part, in order to make up for his complex subjectivity, including his sense of inadequacy deriving from his upbringing, his feeling of rejection from his parents and relatedly, a sense that he lacked ties to a specific ethnicity. Indeed, the education of Freshie's musical self was more than a simple lesson in style; rather, it incorporated a complex process of boundary and self-work, an exchange trade of cultural capital of masculinity and race relations.

However, the sounds of the Winnipeg hip-hop scene also represent a locally specific articulation of a transnational musical negotiation, in this case between hip-hop

\footnotetext{
${ }^{86}$ When crosschecked with Google maps, the address that D mentions - 326 - was not found to exist. Alverstone spurs off of Burnell St. bending around St Josaphat Ukrainian Catholic church at 590 Alverstone. It is more likely that he means Daniel McIntyre Collegiate, a major West End Winnipeg High School north of the address he cites, than General Wolfe Middle/Junior High which is just south on Burnell.
} 
that was coming from New York, and the local politics of Winnipeg's minority AfroCaribbean community, mediated by mix-tapes, videos, and radio. Everton "Papa Ev" Hibbert is perhaps the most prominent rapper and performer of the local Winnipeg scene in the 1980s. ${ }^{87}$ In an interview at Wilson's studio with Ev, Deval, and Rob, I learned of the way in which New York recorded hip-hop first came to the Winnipeg scenesters, introducing politically conscious rap along with fresh sounds:

[Fresh enters the studio mimicking one of Ev's old songs].

RW: 'I'm jus, I'm jus, I'm jus! I'm jus too much for you to do it.'

Ev: How do you even remember that song man? <Laughter>

RW: This a pioneer right here bro... We [AK, DD, and RW] were going at it yesterday, just about all the history of what y'know, how hip-hop started here in Winnipeg. $Y^{\prime}$ know a lot of people forgot about it.

Ev: Oh ya, ya. Those were like really good days because... you got a lot of different stuff coming out of the States - it was changing; uh, Public Enemy (PE) - 'cause you got a lot of guys just doing like parties, party songs basically, feel good songs - not so much of the violence. They'll talk about, battling, but that's about it, just lyrics really. There was a big thing with Cool mo Dee and $<L L>L L$ Cool J. It was just going back and forth, and we were just like, waiting to get the next record, y'know just to hear how he was going to get him back. So this guy would win this battle. Next record comes out and [he] takes him down. And so, it was mostly like that. $\mathrm{PE}$ comes along and changes the game $<\mathrm{RW}$ : Change the game! $>$ In a way where here's something conscious that people are listening to, whether they believe it what he [Chuck D] was saying - or not, you had to pay attention. Y'know what I mean? <RW: Ya, PE was a movement man> And so, not only with the lyrics, but music. I mean, you never dreamt of doing those sounds that he put into hip-hop. I mean it was just like, 'Whoa what's this?! Can you dance to this? What's that sound?!' Just freak you right out. <Yeah yeah>

Notably, Ev and Wilson describe the changing state of the genre at the time that they were learning their craft in which politically conscious hip-hoppers slowly eschewed the posturing of "party rap." It is interesting to note from Ev's statement - and Rob's affirmation - that the competitive boasting, toasting and roasting conveyed lyrically

\footnotetext{
${ }^{87}$ Ev's crew, Hard Edge Posse, opened for the first major label hip-hop act to perform in Winnipeg, DJ Jazzy Jeff and the Fresh Prince, who played the Winnipeg Convention Centre Friday February 9, 1990. Ev was the first to tell mainstream media that the local hip-hop scene preceded the show by several years. (Ostick 1990).
} 
between recording artists, was also interpreted in the sounds of hip-hop. Such qualities

were and remain empowering, not only on the level of subjective perception, but also in their objectivation according to the market of symbolic exchange in the scene, and Rob's biography to that point. His dancing worked to intensify the scene, ascribing significance through the contribution of his personal experiences. Further, the vast geographical distance between Winnipeg and New York, mediated as it was by mix-tapes, videos, and radio, fed into a uniquely transnational negotiation and local articulation. Below, Ev and Rob elaborate on the specifics of that articulation:

RW: The difference between now and then, was then, we heard, we learned our culture from the cats in New York - and they would bring mix tapes out here, or some of our guys would go out there and bring stuff back - and we would learn culture from that. But, when we heard a new song, we couldn't just get it on YouTube or whatever. The DJ's spun tracks in the club or at a BBQ or whatever, and that's when we first heard it. It [became] huge [by virtue of the fact that] everybody hears it right? Because the community is small in Winnipeg - when there's a hip-hop function, everybody goes, whereas now, it's saturated with commercialism right?

Ev: Ya [then], you couldn't call the radio station and say, 'Play this track for me,' right? $<$ Mimics irritiated response> 'what are you talking about? We don't know what that is.' < Fresh: Yeah exactly. Yeah....> Or, you [couldn't] go to a record store and buy it... You [had to] go down there [to the U.S.] and get it... <Fresh: Exactly> We used to pick up a radio station from, Grand Forks [North Dakota] late at night, say between midnight and 6a.m.... <excited responses> <Fresh: And you hear all the stuff you never heard before. Ya, ya, ya... > Yeah! Tune into this little radio station, stuff goes in and out... 'What is?...' < feigns frustrated attempt to restore reception; laughter>

RW: And that was exciting bro. I was like, 'Yo!' Y'know, you're discovering a part of you that you know is a part of you that you're discovering, $y^{\prime} k$ now, like culture. Cause we never really had that... Urban music in Winnipeg at that time really helped us find out who we were. The community in itself, it was dope man.

AK: So what were some of those aspects of, 'who you were', maybe that you identify every time [you listen to hip-hop] and on various levels?

Ev: Well for me, I came from Jamaica when I was fifteen... I was into reggae music, and [although] there wasn't that much around me [with the exception of] Black-orama - It was a [three day reggae] festival they'd have every year <Fresh: Ya, that was a big one $>-$ I always had a sense of who I am so to speak. But here in Winnipeg, there weren't a lot of black people, and [of] the ones that were here, I knew all of them. <Fresh: Right> As young kids, [watching] TV... whether it'd be black-white... you [would distinguish], 'Well that's cool, I want to get into that'... I had some cats in my crew that were white. <Fresh: Angelo> Ya... My music producer at the time Tommy Gun - is this white guy, but he was musical. He was just so broad... If I wanted jazz tracks, he'd give me jazz tracks cause he plays any instrument you can 
imagine. Dude plays the harp! He plays, any instrument you can... he could have been anybody he wanted... Like, I think he went to a music school with Sarah Mc... What's that singer? <Fresh: McLaughlin> Ya! He went to a music school with her <Fresh: Crazy> So he could have done whatever he wanted to do.

RW: And it was crazy too 'cause back then, even white boys were rockin' African pendants <chuckles> y'know what I mean... you'd be seein' dudes walking around with high top fades that were hair sprayed <chuckles > so they were just so engulfed in the culture themselves man.

Ev: Ya, it was just we were all together <Fresh: Ya $>$... It wasn't really like I'm black, you're white, [rather] we just rock it. Cause we needed them to survive right? < Fresh: Yeah> We were just a little community. (Interview September 18, 2015)

The conversation above reveals important dynamics of hip-hop between the cultural politics around its production in New York and its reception and reproduction in Winnipeg, namely having to do with the local scene and its boundary work of which Ev and Rob were a part. For Ev, hip-hop and musical performance has more to do with distinguishing himself from his reggae roots through claims to innovation. Comparatively for Rob, there is an undergirding tension between his inner and outer selves that encompasses not only his professional development, but also his sense of self as a whole. As such, his education entails "authenticity work," both in terms of the musical category or genre, hip-hop, and of his self. ${ }^{88}$ Outwardly, the education of his performative identity is represented in his style of dress, masculine posturing, boasting and toasting, improvised in dance moves considered "authentic" to hip-hop - authentic hip-hop likely assumed these forms because the competitive conditions of hip-hop both in New York and Winnipeg necessitated an immediate communication of one's position in the scene. However, the inward work of finding out "who we were" appears to have had more significance for Freshie than for Papa Ev - Charles Taylor suggests that

\footnotetext{
${ }^{88}$ On the significance of authenticity to hip-hop by the late- '80s see Dyson (2004 [1989]: 401-10). Symbolic interactionist, Richard Peterson (2005), has broken "authenticity work" down into its constituent parts, including authenticity to self, style and genre. However, he conflates external symbolism with internally related issues such as personal struggle, discrimination and racism, effectively decoupling 'authenticity work' from the complex ways in which it is internalized by those agents for whom it matters.
} 
"authenticity to self" stems from the Romantic era in which the artist came to embody genius; a reaction to secularization and the cold calculating sciences of the Enlightenment (1991). But this is not to make a Romanticized essentialist case out of Rob. Rather, his interest in hip-hop as a source of self-identity conditioned his education, increasing its significance for him. The stakes were further raised by the technological mediation of the sonic and visual elements of the locally situated transnational scene at the end of the ' $80 \mathrm{~s}$. On one side of the "authenticity debate," recorded and distributed hip-hop was seen as democratizing, and highly celebrated as such among contributors, fans, and academics. However, on the other side, reproduction also raised the potential for artists and associated labels to reduce situated politics to their commercial value, drawing the ire of critics and fans around the question of "authenticity." For Freshie, wanting to belong but constantly reminded of his difference, combined with the predetermined stakes of hiphop and the authenticity debate, raised the spectre of insignificance. Simply consuming "hip-hop" was not enough; rather, for Rob to purge his self-doubts, he sought to engage his embodied self in multifarious ways, making hip-hop more than just a genre. ${ }^{89}$

The uncertainty of Wilson's cultural background emerged as a stake in his educational years, making it important for him to imagine and attain membership in and solidarity with a collectivity. ${ }^{90}$ The way in which Rob claimed membership in the early

\footnotetext{
${ }^{89}$ Due to the presence of his self-doubts of which I am extrapolating, it is possible that Freshie engaged sound on a similarly deep level to the way he engaged with sound as Rob, the child, discussed previously. However, in distinguishing Freshie from Rob, he assumed a certain mastery over his self apart from those doubts likely enabling the ever-present posturing and later chauvinism. While self-doubts may have been overcome for the time being through the personality splitting of such a "Jekyll and Hyde" persona, their relationship is tenuous throughout his life.

${ }^{90}$ As discussed in chapter three on African-American musical self-practice, W.E.B. Du Bois' concept of "double consciousness" (2009 [1903]) helps to explain the inner pole that pretensions Freshie's education. It follows that Rob's self-doubt is attributable to his situated sense of collective membership. Rob's racialized "double consciousness," then, adds nuance to Bourdieu's field-habitus relation in explaining the way in which Freshie was racialized through his education as a hip-hopper. Lewis' "Afrologic perspective"
} 
Winnipeg hip-hop scene reveals transformative techniques, including strategic

collaborations and endorsement. Initially, Rob struggled to gain membership with

Winnipeg's minority African community, compared to Ev who says he, "always had a

sense of who I am". ${ }^{91}$ In the following transcription, Deval describes the way in which

Freshie overcame local barriers, including attaining the endorsement of Jamaican-

Canadians who made up an alternative late-night reggae scene, and transitioned from b-

boy to MC:

DD: Now what happened was [Rob and JJ] started getting respect from the reggae community 'cause they were hanging out at the reggae parties... Like I said it was a very unique situation because Fresh was extremely skinny, JJ was tiny dude... and he was probably one of the first Natives to actually get accepted by the Black

community, those two... They were the first outsiders to really just get... After a while you go to [hip-hop] parties, [Mimics Freshie's endorsement] 'I love these guys; these guys are good yo; they're always at the late night; putting in the work.' [However, although] they started getting that respect, when it came to hip-hop parties there was still a problem 'cause the hip-hop guys didn't go to the reggae parties. Now, the reggae guys were tough guys - like I'm Jamaican but they were the tough guys; what happened was the reggae guys started to [demand]: 'Yo! Give them the mic!' They started to force that situation on the hip-hop guys, out of respect [for Freshie]. It would cause arguments, to the point of physical altercations. Not Fresh and them, but the reggae guys. 'Cause to them, JJ and Fresh were invading the hip-hop scene 'You gotta give them respect because they represent us, what we do at night time.' (May 1, 2015 Interview).

Deval's description reveals the presence of centripetal forces that at first prevented

Freshie's membership in the hip-hop scene. However, with the endorsement of members of the more established reggae scene, Freshie was able to claim legitimacy that he used to access the hip-hop scene, eventually enabling his transition into rapping.

Like many post-colonial cities at the time, Winnipeg's race lines were drawn and entrenched according to geo-political constructs such as the North End rail yards, long before Wilson's arrival. However, without diminishing the real injustices of racism, Rob

also introduced in chapter three, allows us to situate the coalescence of otherwise aesthetic and political techniques, as in "improvisation," in a locally specific collective of the African diaspora.

${ }^{91}$ Again, it is interesting to consider Ev's pursuit of hip-hop and jazz subsequent to reggae, as a claim of distinction from his upbringing, compared to Rob who was interested in the cultural politics of hip-hop. 
and Ev's conversation above reveals the mutual benefit of collaborative techniques employed in order to win respect and gain acceptance. As stated above, Ev downplays negative aspects of racial difference: "we needed them to survive." By the time he was interviewed by the Winnipeg Free Press in 1990, the scene had moved from house parties to local hotels and clubs. Ev insists, "There's no colour to it," noting that the audience makeup of rap contests at local club, The Limetree, is one quarter white. Nevertheless, the club's promoter Val Ramanand's comment on the question of hip-hop's status in the city, "That might be when rap came to white Winnipeg," suggests the opposite; the scene's delayed recognition in major media represents in part, racial inequality between scenes and cultures.

Finally, Winnipeg's nascent hip-hop scene became established much like that of the Bronx, after a sufficient cultural resource was built up among its founding DJs and fans, before transitioning into an organized network of clubs through which national and international troupes would later tour. It was in such a mode of reproduction that Freshie was educated, and in terms that mattered both to him and to those members making up the field in which he practiced. Eventually, as Deval describes, Freshie completed his transition to MC-ing after joining a hip-hop troupe in Winnipeg, traveling with them on just their second Western Canadian tour to Vancouver and back:

DD: [They returned] from Saskatoon - and as they were doing their dancing they now were starting to become more woman orientated guys - they started to get into the pimping, and get into the rough, the rough situation. They did it pretty strong; they did it for a while. (Interview May 1, 2015).

The tour allowed for Freshie's musical self-transformation as he and his b-boy partner JJ insisted on rapping, leveraged by the endorsement of Winnipeg's established Jamaican community. Indeed, had it not been for JJ, the minority community support and Rob's 
interest in the stakes presented by hip-hop at the time, he might not have been impelled to adopt the specificity of hip-hop's musical self-practice for his self. Yet his involvement with women, and drug use, soon overtook his interest in hip-hop. This was despite his successes in dancing and rapping for Canada's first female rapper, Michie Mee, for pioneer rapper Maestro Fresh Wes, and in a group called, Lotusland, with Moka Only and Prevail who later formed the acclaimed Vancouver crew, Swollen Members (Kives 2004). Rob explains that hip-hop simply became a hobby for him in the ' 90 s, while pimping became his main occupation.

5.4 - Musical self-transformation Part I: Re-Moralizing “Fresh I.E.” (19982009)

After "Free" and Thriller, Wilson's third, most significant musical experience is 2pac's "So Many Tears"92 (1995). Tellingly, the "gangsta" style of the song lyrically presents the same tough street life that Rob came to live in the ' 90 s, replete with a fatalist anticipation of early death. So how did he arrive at such a practice? In terms of his destructive "old self," to use a trope of self-transformation, Rob Wilson began pimping girls in 1989 when he was sixteen. ${ }^{93}$ This is also about the same time that he transitioned from b-boying to rapping. Retrospectively, Rob claims that rapping allowed him to express the struggles he experienced while growing up: "I would expose myself in my

\footnotetext{
${ }^{92}$ In this youtube.com video, Tupac exemplifies "gangsta" rap, including slow tempo and phat bass sound, and lyrically tough street imagery foregrounding gang violence, death and the afterlife.

${ }^{93}$ Following his Grammy nominations in 2003 and 2005, Rob was interviewed in local, mainstream, and Western Canadian newspapers, often asked to account for his success in terms of his background, and the musical category in which he received recognition. While it is curious that he was rarely asked to discuss the sounds of his music, nonetheless, his interviews constitute a discursive rendering of his musical selftransformation and transition from one field to another. Rob and his interviewers' focus on lyrics and invoked themes likely has more to do with the respective newspapers' aim of conveying the significance of Rob's success in both private and public terms, including escaping his formerly deviant lifestyle, and the Grammy nomination, respectively. However, the links between private and public are largely taken for granted. Moreover, Rob's desire at the time, to distinguish his new self from his old self demanded that he emphasize differences between the two selves, thus leading to explanations firmly set in the representative realm of Christian morals and symbolism.
} 
music. I would tell people how messed up I was, whether I was bragging or hurting. Music was my meeting place - my soul searching” (Williams, 2003). Elsewhere Rob states, "My parents were hustlers - so were my uncles" (Graham, Calgary Street Talk). Although he has provided limited detail of the business, Rob describes his life leading up to his conversion as "living fast," constantly moving between urban centers, including Vancouver, Toronto, Niagara Falls, Seattle, and Buffalo (interview April 23, 2015). However, in 1995, after witnessing a murder at a party in Toronto, sensing that, "death was right around the corner," he decided to leave "his girls," reconciling with and returning to live near his Mom, April Wilson, in Kenora, Ontario. Wilson helped her son get a job at Shooter's, a popular hotel bar in the lakeside town where she was a server. While initially taking a job as a waiter and DJ, Rob was promoted to doorman and bouncer "because they saw how I could fight." The scene was rife with racism, with alcohol-fuelled fights between whites and Natives on a nightly basis. One night in the bar next door to Shooter's, Rob became the target of racism when he was called a "nigger." Rob decided to "fist up" for his own dignity, but suddenly found himself up against an entire football team. A beer bottle cut to his eye nearly made him blind, and reconstructive surgery left him with a distinct facial scar. But Kenora was also a scene where men and women came to party; something "Freshie" already had a knack for inducing. Girls regularly propositioned the longhaired charismatic figure, as Rob recalls: "They would offer 'pink slips' for their truck if I would go home with them." As a bouncer, he became the sole proprietor of a bootlegging scheme, amassing a stock of beer and hard alcohol, and offering patrons access to his stash afterhours, at off sale prices. Alcohol contributed to his weight gain and masked a growing sense of depression; 
maniacally, the influence of alcohol also contributed to a near fatal car accident, with Rob at the wheel. Surviving with a fractured skull, and facing multiple criminal charges, he felt compelled to return to Winnipeg's North End to escape drinking, fighting and partying.

Rob's conversion, including of his musical self-practice and corresponding ethic of self-transformation, according to the model of Jesus Christ and Christian morals constitutes a sudden as opposed to gradual self-transformation. However, rather than autonomous, it is found that Rob's sudden self-transformation involves three significant relationships in addition to one epiphany that worked to affirm his commitment. Each of these relationships and the epiphany allowed Rob to reframe his self into a biographical narrative replete with old and new self"s, including the ethic of an "utter rejection of the world and the flesh." His sudden transformation thus distinguished a transformed self and a former self, which he could then objectivate in order to perform self-work, including subsequent gradual self-transformative work.

In the first significant relationship, upon returning to Winnipeg in 1998, Rob began attending the "Prayer Mobile Children's Mission," an inner city Christian program for young people (cf. Kives 2004; Western 2003; Krahn 2010; interview May 31, 2016). His childhood friend and hip-hop crew co-member, Greg "Hard Rock" Jarvis of Too Def Crew - whose Dad ran the mission - invited him. According to interviews, Rob did not convert prior to attending the mission. But the time spent with inner-city kids reminded him of his own troubled upbringing, while his old friend's model of self-sacrifice, 
including the unsung work of educating underprivileged youth, inspired Rob to redeem his own "brokenness" by encouraging kids through theirs. ${ }^{94}$

Shortly after joining the youth mission Rob had an epiphany that led to his conversion. Exactly one year after crashing his car outside Kenora, he encountered a blind man walking in the middle of Selkirk Ave. Having stopped his car at the side of the road, he called out to the blind man to follow his voice out of harm's way. Later that night when drawn to his apartment window by the waving flashlights of neighbourhood watch people, Rob discovered the same blind man sleeping on his front step. Sensing that his encounters with the blind man had more to do with divine providence than coincidence, Rob sought God for its meaning (Williams 2003; Lockhart 2004). This is when Rob has his epiphany: he realized metaphorically, that he was the blind man wandering haphazardly through the streets of life, and as such, his death was imminent. Indeed, he was facing charges for his accident and other crimes, including negligence and driving under the influence, of up to thirteen years. Either way, taking his encounter with the blind man as providential, Rob suddenly held his fate in his own hands. He decided to commit his life to Jesus.

To help put his commitment into practice, Rob's second major transformational relationship was his meeting Sheila North. While today she is the first female grand chief of Manitoba Keewatinowi Okimakinak (MKO), representing 30 First Nations across northern Manitoba and Saskatchewan, North-Wilson's origins are modest. She grew up in the isolated community of Bunibonibee Cree Nation (Oxford House, MB), in a

\footnotetext{
${ }^{94}$ Such sympathy remains a major influence on his mentorship practices today. When I asked Rob why he continues to work with youth and indigenous people, he simply responded, "Helping out comes out of helplessness" (Interview: May 31, 2016). Rob's Pentecostal doctrine, first learned at the Mission and incorporated into his hip-hop, is discussed below.
} 
Christian family (Interview July 6, 2015). After divorcing her first husband, she moved to Winnipeg to raise her two children and study journalism. According to her CTV bio page, North-Wilson worked first for the $\mathrm{CBC}$ as a journalist, then for $\mathrm{CTV}$ as "Chief Communications Officer for the Assembly of Manitoba Chiefs where her primary role was to work with First Nations leaders in Manitoba, building bridges of understanding between First Nations, non-First Nations people and the media" (CTV, 2013). Her other interests include raising awareness of Missing and Murdered Indigenous Women (MMIW). North-Wilson's account of her meeting Rob provides insight into the early stages of his sudden transformation, and her role in its process. Sheila North-Wilson met Rob in 1998 at Sagkeeng First Nation, 126 km northeast of Winnipeg (Adamana 2010).

She recounts:

SN: He [and fellow volunteers] were there because his pastor... from the kidschurch, [wanted] to get them out of the city to get some different scenery... on a day trip. And I went because my sister and my Dad forced me to go.... I was [otherwise] sitting at my place; I had crutches on - I just had surgery; I was newly separated; all that good stuff; I was really down and I didn't want anything to do with my family, sort of pulling away from everyone. (Interview July 6, 2015)

Key to Sheila North and Rob Wilson's first meeting was that it constituted a Christian event, and distinctly, that its function was informal rather than liturgical. As such, the event was congenial for the two interlocutors seeking distance from their respective past selves, yet full of potential for a transformative relationship. ${ }^{96}$ Tellingly, North-Wilson's

\footnotetext{
${ }^{95}$ At the time I interviewed Sheila North-Wilson, she had just that day covered Maria Mitousis' letter bomb story in which the Winnipeg divorce lawyer lost her hand as the target of a client's divorcée's retribution. More positively, North-Wilson was also about to announce her intention to run for the position of Grand Chief of MKO.

${ }^{96}$ As far as the music at the event, her Dad had Sheila North-Wilson and her sister's support on stage including a brief testimony of God's faithfulness through her surgery, and a song sung in Cree - although she does not remember its title (Interview July 6,2015). That same evening while Rob was outside having a cigarette, North-Wilson was visiting with the guys from the Mission when she asked if any of them rapped. Though they said "Freshie" did, bringing him inside, Rob played coy, reaching for a bologna sandwich instead. Nonetheless, North-Wilson and her sister were given the pastor's business card and were invited to join the group in their outreach at Main and Manitoba Ave. Then, just two weeks later while out to attend
} 
"Looking for new friends" provided impetus for escaping what had become everyday

routine. She describes a follow-up visit with Rob and some of his friends at his place,

accompanied by her sister, giving insight into his transformational status:

SN: At the time, he wasn't as I knew a Christian to be, going to church, reading the Bible, no smoking in the home, no alcohol, and all that stuff - when we went inside to visit, it was anything but that: <chuckles> Budweiser poster on the wall, and he was holding a cigarette, I think he was smoking a joint, I don't know - there was music and alcohol. My sister and I were not used to that, we kinda felt uncomfortable, and then we left. He tried to make us feel comfortable, showing us pictures and visiting; but it was getting kind of loud so we just left. Then my sister said, that one guy seems different; maybe we should invite him out for coffee, visit with him for a while. So she called him up and asked if he wanted to come for coffee. As he says, he didn't want to come because he was high and didn't know what to do, but he came with us anyway. My sister and him visited. I was sort of distant I guess, 'cause I was still in that mind space like, not liking anything about church at the time. (Interview July 6, 2015)

Interestingly, North-Wilson's description provides insight into the practice and process of "sanctification," not simplistically as an individual convert's adherence to Christian morals in an autonomous church ("somewhere out there"); but as "discipleship," a close partnership conducive to the identification of moral categories and their practice, where a less experienced disciple is potentially held accountable to a mentor considered an expert in her field. Having been raised in church, North-Wilson brought a set of categories and practices to their relationship that, together with Rob's commitment, became foundational both to their marriage ${ }^{97}$ and to his musical practice. ${ }^{98}$ When brought together, their shared interests melded into a mutually supportive vision; as Sheila states, "Meeting Rob caused

local multi-cultural event, Folklorama, North-Wilson and her sister recognized the Mission's distinctly painted bus. Led by her slightly more outgoing sister, the two women followed it, eventually joining Rob and his friends for a visit, just long enough for the guys to ask for their phone numbers. Finally, after responding to the guys' calls, North-Wilson and her sister joined them at Rob's apartment where she was given the impression that he was not the kind of Christian that she was used to. Perhaps used to modest Christian men, North-Wilson's description (see in text above) of Rob's apartment and lifestyle suggests that Rob had not committed to Sanctified modesty.

${ }^{97}$ Rob Wilson and Sheila North were wed in a Christian ceremony, December 17, 1999.

${ }^{98}$ I asked North-Wilson if Rob considered himself "saved" (converted) at the time. She says, "I think he said, that night [that] we met at Sagkeeng was when he first really decided to, or changed his life, ya."

(Interview July 6, 2016). 
me to reach out to God even more. We [became] stronger, started reading the Bible more, and started trying to follow the Bible's principles more. When you do that, life just gets better" (Lockhart 2004). ${ }^{99}$ Significantly, Rob and Sheila North-Wilson's cotransformative relationship also reveals a gendered aspect of musical practice and the ethic of self-transformation heretofore underestimated in the literature. Rob might not have held on to his self-transformation had it not been for his meeting and marrying Sheila, the accountability of their relationship raising the transformative stakes for both, while at the same time incentivizing their commitment to each other.

The third major set of relations making up Wilson's sudden self-transformation involves his musical self-practice. There are two aspects of this practice considered here, including music as it inspirits his self inwardly, such as the ways in which he relates to his own past, present and future, and, as it relates outwardly in performance. In defining the former, I draw on the music sociologist Simon Frith who underlines the inextricable link between music and identity through a benign pedagogical exercise, by recalling one's favourite song(s) only to arbitrarily denounce their validity and artificially create an offense (1996: 108-27). Through such denunciation, Frith's point is to reclaim the subject by revealing the depth and breadth to which sounds infuse and thus inspirit the individual. Relatedly, in order for me to probe Rob's musical self, I asked about his favourite songs and sounds, a few of which I have already discussed. However, whereas

\footnotetext{
${ }^{99}$ Retrospectively, North-Wilson explains the significance of their meeting as "redemptive": I think for him he was just surviving: he didn't have anything, he didn't really own much; he was living at a place where most people living there were down and out. He was at a place where he felt ready to move past what he knew and what he saw in life; and just happened to be listening to the call of higher purposes for his life; and he heard it and he answered it. I happened to be in the same headspace which coincided together [with him]; I guess that was part of God's plan cause I was not in a place where I was searching and neither was he, he says. But we met at a place and at a time where we both needed someone to come in and blow life into our existence. (Interview July 6 , 2015)
} 
Frith's device is rhetorical, Rob's conversion provides the empirically based, pedagogical moment. Ontologically, the rhetorical device inevitably leads to a simple biographical snapshot, and underlines a teleological and consumerist understanding of the musical self. ${ }^{100}$ By contrast, Rob's conversion involved the very real effect of bringing his entire self into question - at least as much was submitted to the lordship of Jesus, and including those influential sounds that constitute his biographical self - his complex subjectivity demands a more nuanced approach than mere consumer or producer renderings allow for.

Rather, the way in which Rob's sudden musical self-transformation is practiced concerns his temporal mediation with his own complex subjectivity: First, the sounds of his favourite songs provide a link to his formative self, in which he was among other things, physically and sexually abused, and the witness of injustices committed against his mother. Second, as he confronted his present self in and around 1998, the misogynistic, drug dealer and alcoholic whose demise began with his becoming a b-boy and rapper during his educational years, music gives Rob a sense of presence, to choose between reproducing his musical self or adapting it to new conditions. Not that presence is axiomatic; rather, his conversion rendered his old braggadocio self obsolete, epitomized in a statement by journalist, Bartley Kives, in Rob's first mainstream media interview following his first Grammy nomination: "He's like an upside down version of an urban music cliché - a former street thug who doesn't brag about his past, but celebrates his delivery from it instead" (2004). If left to presence alone, in a phenomenological sense, Rob's musical self would be overwhelmingly precarious. And

\footnotetext{
${ }^{100}$ In this consumerist regard, Frith's approach is consistent with other heirs to British Cultural Studies, from Hebdige (1979) to De Nora $(2000 ; 2003 ; 2014)$.
} 
indeed, at moments during his conversion this was the case, as Sheila North-Wilson

explains here:

AK: So what was it about the music that contributed to his transformation... why was it music, why wasn't it something else? Or was it something else?

SN: I think, from what I remember is that he already had the interest and the talent and the desire to do music; but he didn't necessarily have anyone believing in him, to tell him that he could actually do something with it. And when he had that, it sort of became the key that allowed him to open the door to music and pursue it confidently. Before that he was sort of unsure and struggling if he should do music. When I met him I didn't even think to second-guess whether he had talent or not, cause I did see the talent and I noticed his passion for it. When I saw that his desire was to buy beats one at a time so he could do his music, I asked him if he wanted to do music on a bigger level. He said, 'Well, I want to do an album.' So I called up a friend who had a recording studio... (Interview July 6, 2015)

North-Wilson's $\$ 600$ seed, a significant amount for the single parent mother, enabled

Rob to convert the cultural capital that was his acquired skillset, into cassette tape-

recorded format. Significantly, this exchange, combined with their committed

relationship, signaled the beginning of Rob's Christian musical practice, and his first stake in the field of Christian hip-hop. Sheila North-Wilson's investment gave Rob the confidence to suspend his past doubts and present fears, and confidently project his new beliefs rendered audible.

Second, Rob's outward oriented musical self-practice is no less important to his transformation; and importantly, nor does it simply follow lineally from his inward self, whether as expression or strategy. Notably, as Rob began writing and performing his musical self after his conversion, he became linked to a preexisting field whereby his practice was objectivated as "Christian hip-hop," and his presentation of self around "Fresh I.E." Such objectivation affected various results. To explain this aspect of his transformation, as discussed in chapter two, I draw on Georgina Born's elaboration of Straw's "music scenes" - Straw argues that scenes are formed in and through the 
formation of participants' "affective alliances" (1991). Born (2011; 2012: 202-11) isolates four levels making up those alliances in which the self and social intersect. These levels have to do with the musical self-mediation of one's immediate experience, of localized musical publics or scenes, imagined membership with extended publics invoked by social categories such as race, gender, and class, and finally, of the wider organization of institutions, including the Church and culture industry. Notably, as our analysis moves from the immediate practice realm of music making to its institutional conditions, specifically in the realm between genre and the music industry, objectivating and objectifying forces tend to increase. Not only is musical practice objectivated for one's self use, here, the music industry's objectification of musical categories for purposes of commodification have far reaching effects.

The first and most intimate realm of Rob's musical mediation has to do with his name, "Freshie;" with his conversion, all that was wrapped up in that moniker became tenuous. Yet paradoxically, he did not want to simply start over with an altogether different name at the risk of losing his fans and his connection to his old self. Alternatively, with "Fresh I.E.," meaning "fresh in eternity," he retained the personage of the visionary prophet - "Fresh" - while his nod to the afterlife - "I.E." - also effectively focused his vision, as a Christian hip-hop artist concerned with his relationship with God and also with the redemption of his "sin"101 through sanctification. Extending both in and out from his name, Rob's musical performances, and later interviews, became a technology of his transformed and transforming self; but not simplistically, as a freely discretionary consumer. Rather, his musical self-practice involved a structuring set of

\footnotetext{
101 "Sin" is defined as having "missed the mark," that being the standards for living dictated by God in the ancient Judaic law of the Torah.
} 
relations, including both his partnership with Sheila North, and his participation in the various permutations of the religious field beginning with the Children's Mission, Rob's possibilities were, and remain, somewhat limited, at various times and spaces constraining.

In terms of immediate experience, Rob's musical self-practice is objectified in studio recording and in public performance. At the time he recorded his first album, Resurrection (1999), on cassette tape, "Fresh I.E." was rapping at various inner-city youth missions with his beats played through a karaoke machine. ${ }^{102}$ Yet as a "worship leader" working in that field - using music not only as a technology of his new self, but also in order to achieve among other things, collective effervescence or group solidarity ${ }^{103}$ - he was not alone. Rob was referred to another worship leader called, Jon Loeppky, who outlines their meeting and collaboration below:

JL: I met Fresh through a friend of mine. I was involved in doing inner city worship and we were doing songs written by Delirious; 104 [a lot] of UK, Anglo Saxon, British invasion worship. And the inner city kids didn't relate to it. So, I started introducing drum loops - I didn't have a drummer, it was just me with a guitar - so, I brought my laptop and put drum loops on it, hip-hop beats, and we would kind of redo the songs with a hip-hop vibe to it. I've always enjoyed kind of funky music. And the guy who was heading up the evening said, you should meet this guy; he's a rap artist, and I think you guys would really hit it off... So Fresh shows up at my house - just over here on Cathedral - we had never met. And he comes into my office, and we just kinda picked up the guitar and started writing songs - we wrote two and a half songs in about three hours. And so we [thought], 'this is a lot of fun', so we did that again, and did that again, over the course of I think three or four times that we met together, just for a couple of hours. We [eventually wrote] ten songs, and [thought], 'we should record an album'. It really fast tracked from just kind of rejigging old worship tunes, to writing brand new original hip-hop stuff. It was a blend of pop music and hiphop. I call it 'hip pop': pop choruses and rap verses. So that's how I got into it, back in 2000, so about fifteen years ago. (Interview May 19, 2015)

\footnotetext{
${ }^{102}$ Historically, Pentecostalism has encouraged worship accompanied by instruments in a contemporary style (Giacomo 2009).

${ }^{103}$ Durkheim's term is used interchangeably with 'collective solidarity' in order to give some substance to its otherwise vague and often functionalist definition.

104 This hyperlink to the youtube.com hosted song, "I Found Jesus," provides an example of one of

Delirious' most popular songs from the late '90s.
} 
Notably, in that Rob and Jon's collaboration was mutually beneficial - "a lot of fun" - it enabled the coproduction of "brand new hip-hop stuff," including the album of songs, 28:3. The collaboration gives insight into Rob's musical self-transformation at that point, and on several levels. For one, 28:3 includes the aforementioned Prince-influenced track, "Free," in which Fresh lyrically links his transformation to his relationship with Jesus, and projects the redemption of social ills through that relationship. As the sounds of "Free" resemble one of Rob's most formative songs, there is a continuity that is maintained with his past, albeit mediated by the transformative lens of his new faith. Thus, during this period and specifically through his new songs, Rob reclaims not only his formerly violent self, but also his formatively abused self. By reclamation, I mean the narration of one's biography in such a way as to evaluate past behaviour against a newly adopted moral system. Such reclamation constitutes self-transformative work because the narrator and protagonist in the narration is the same individual. Yet framing that past according to one's commitment to a new moral system - or submission to God - makes reclamation an essential aspect of one's redemption. Arguably, such self-work in relation to Christ constitutes what theologians call, a "redemption of sin," including both Rob's sins committed against God and others, and those which he suffered. In turn, it would seem that retaining the sounds of Rob's youth in "Free" works to embed the early experiences of that self yet in relation to the lyrically "born again" self, altogether working to transform that self. Moreover, Rob's rebirth is neither autonomous nor is it confined to the virtual space of Jon's recording studio. Rather, his proclamation relates outward, and on two planes: for one, on a vertical axis to his God; and for another, horizontally, aimed at an imagined public of peers and fans. As such, Rob's 
collaboration with Jon suddenly made him accountable to an imagined community, to live up to the morals espoused in his lyrics thus insuring his transformation against recidivism. Relatedly, recording worked to bridge then established boundaries between pop and hip-hop at the level of genre - "hip pop." His performance style had a distinguishing effect, positioning him at the leading edge of the local scene and emerging field of Christian hip-hop.

Wilson's musical self was also mediated by his public or live performances. Live performances, typically, complement studio recordings as a promotional tool, in this case, establishing his notoriety among peers and expanding his fan base. The professionalism of Rob's live performances, as involving not only a staged presentation, amplification, even smoke, lights, and video accompaniment, but also the advanced coordination of booking, promoting and touring shows in succession, and among potentially receptive audiences, such as inner city halfway houses, youth events and conventions, churches and Christian colleges, and on and off reservations, was expedited in this period through his collaborations with established performers and record labels. For one, Rob teamed up with Juno-nominated "gospel” singer-songwriter, Jon Buller. In the late 1990s, Buller led worship at The Meeting Place, a contemporary Mennonite church planted ${ }^{105}$ in the downtown Broadway area on Smith St. Aiming to expand his worship beyond the liturgical precepts of a typical Sunday morning, Jon began composing and recording original worship music, touring other Christian venues, and on a monthly basis hosting evening concerts called "Hear the Music." When attendance outgrew The Meeting Place,

\footnotetext{
${ }^{105}$ I use the Christian colloquialism "plant" to refer to the way in which The Meeting Place was established as a church stemming from an earlier congregation that worshipped elsewhere in Winnipeg. "Plant" speaks less of a building than of a collective bound by a common mission infusing the church's organization.
} 
Jon moved the events to the historical venues The Walker Theatre, ${ }^{106}$ Rainbow Stage and Pantages Playhouse. The latter is where I first met and performed with "Fresh I.E." Following the recent disbanding of Buller's first worship team - essentially a contemporary pop-rock band in form and sound - Jon hired my three-piece indie band, Freeman, to form the core of his new backing group. Whether anticipated or not, the combination of new musicians precluded the simple reproduction of his former band, and signaled a local scene change. Buller describes the effect that performing with Fresh had on him and the scene:

JB: The connection with Fresh was originally through Jon Loeppky, a Southern Manitoban musician. Jon had been in a Christian rock band with a couple friends of mine. When that band disbanded, he did a collaboration with Fresh which at that time was pretty unique - like you're asking about what the scene was like, to say it that way, that was a pretty new idea; to combine rap with Christian music or pop music. I'm not sure that it was the first time that that'd ever been done, and now a days, the crossover of rap into pop and country and rock, it's been normalized, but back then it was pretty neat, a fresh idea. And so, when I heard that project I [thought] this is pretty cool, I loved it. I thought it was pretty exciting. So I invited Fresh and Jon to Hear the Music... Fresh came with Jon and just blew the house down. It was so neat with those guys, that we could do that and it was considered worship, but [also that] it was accessible to a mainstream audience, which is something that I always liked about Hear the Music, especially at the Burt or the Walker: that people could come that you wouldn't find attending a church but felt totally comfortable coming to rock out... Anyway that was the initial connection with Fresh, and working together went from there. (Interview January 8, 2016)

At once, in creating a space outside a typical church service, Buller's Hear the Music events attracted an ecumenical mix of Christians and non-Christians, enabling the field of Christian worship music to expand into a local non-institutionally affiliated scene. At the same time, Fresh and Jon Loeppky's "hip pop" mediated wider exposure, garnering music industry related support. Had it not been for the local Christian music scene, Rob might have felt compelled to leave Winnipeg and its otherwise non-existent Christian

\footnotetext{
${ }^{106}$ With funding for renovation from its namesake, The Walker is now called, Burton Cummings Theatre, or colloquially, The BCT.
} 
hip-hop scene for bigger markets south of the border, such as Atlanta and Los Angeles, especially after experiencing his most significant musical self-transformation.

The greatest force in the process of objectivating "Fresh I.E." and securing Wilson's self-transformation came with his Grammy nominations for Red Letterz (2003) and Truth is Fallin' in tha Streetz (2005). Fresh's nomination by The Recording Academy (formerly NARAS - the National Academy of Recording Arts and Sciences) is significant in that it is peer-based, representing the most influential positions in the realm of professional music production and distribution, ${ }^{107}$ and in that it links his musical selfpractice to powerful forces that contribute to the objectification of sound according to specific categories, or genres. For the $46^{\text {th }}$ and $48^{\text {th }}$ Grammys, Rob's albums fell into the category of "Best Rock Gospel," a categorization that was apparently determined not by form or style of sonic organization, but by Christian content, thus lyrically based. But this is not to say that the sounds he produced on these albums were not influential. On the contrary, Fresh's nominations represent the outward influence of his position in the field, upon the organization of that field as exemplified in the subsequent change in category in 2006, to "Best Rock or Rap Gospel Album." As such, Rob's musical self was instrumental in challenging existing boundaries and on a transnational scale. In fact, his first nomination was so significant that it was met with doubt, assuaged only by his second nomination, as Rob states in a related article: “This speaks to the (fact) it isn't a fluke, what's happening with this music" (Williams 2006). Fresh's claim to authenticity is further legitimated in the same article by his being listed alongside fellow nominees, now peers: U2, Gwen Stefani, Bruce Springsteen, 50 Cent, and Stevie Wonder. Further, Rob's musical self-transformation was supported not only by his transnational

${ }^{107}$ It is important to note that membership in the Recording Academy is paid. 
recognition, but also locally in terms of ensuing awards, such as the Junos and GMAs (Gospel Music Association of Canada and Covenant awards), and in terms of media coverage. Such gatekeeping established Rob's association with Christianity and hip-hop, at once empowering him to extend his influence through performance, both live and in studio, but also constraining him according to the limits of the nascent field of Christian hip-hop.

Critically, the mediation of Wilson's musical self-transformation with the Christian music industry, the church and his wife was not all good. With his peer endorsements, "Fresh I.E." became a hot commodity, attracting the attention of industry personnel in the shape of recording labels and booking agents. Indeed, such dealings were preceded by his distribution deal with Tom Bee, CEO of Albuquerque based, Sound of America Records (SOAR), whose membership in The Recording Academy enabled the Grammy nomination for Red Letterz. But the deal with SOAR was limited to distribution and that, in the United States where he was only mildly interested in touring. Rob soon cut deals with Marshall Zacharias of Avanté Records, an independent Christian label with recording studio, and Gilles Paquin of Paquin Entertainment, a reputable booking agency, both in Winnipeg. Before long, Rob's income increased as his schedule became dominated by the steady work of recording, including seven solo albums in six years, and collaborations with Jon Buller and Steve Bell; and touring, from remotely located churches, high schools and reservations, to high profile broadcasts, such as the CBC's Concert for Asia, an aid relief fundraiser for surviving victims of the December 26, 2005 tsunami that killed over 150,000 in South East Asia. However, despite further awards, media attention, and a growing fan base, Rob's subordination to Fresh I.E.'s busy 
schedule, combined with his time away from Sheila North-Wilson, began to erode the vital intimacy of their relationship. Compounding stresses included a "break \& enter" at Waves of Glory in February 2008, in which $\$ 30,000$ worth of Rob's production gear was stolen from the church basement studio, and an apprehension in June of the same year for suspected grand theft auto in which it is likely that he was subjected to racial profiling. By 2010, the objectivation of his musical self into "Fresh I.E." was overwhelming Wilson. He felt constrained by such forces related to institutional structures of the Christian music industry that now expected a certain mode of performance, stuck in a category that he helped to define. Paradoxically, the fulfillment of his musical selftransformation, from misogynistic gangsta rapper and pimp to "salvation" preaching Christian hip-hopper, ended with his contemplation of suicide. What went wrong?

\section{5 - Musical self-transformation Part II: A change in scene (2010 - present)}

In 2010, Rob Wilson decided to kill himself. Relations with his wife were breaking down along with his musical career. The more he poured into one, the more the other suffered. And both had become precarious. However, before he could attempt suicide, Rob was interrupted three times. First, by his teenage son returning home to their apartment, then located in downtown Winnipeg. The thought of his loved ones discovering his body, dead, with arms cut open and surrounded by lifeless blood contributed to a sense of responsibility to at least dispose of his body out of sight. Then, Rob felt drawn to the calm flow of the Red River, where he dipped his foot into the cold water at the Forks - la Forche - the infamous destination of so many unwanted bodies in this region of the country, especially missing and murdered Indigenous women. However, his comtemplation was interrupted a second time, by a Salisbury House server's call to 
police; and finally, by his desire to see his beloved Sheila North. Recalling that night to me, Rob insists that he was saved by divine providence again. Had he not demanded to speak with North-Wilson, Winnipeg Police protocol was to forward suicidal cases to psychological evaluation and possible ward time. Whatever the evaluation may have been Rob was sure that its public exposure would have severely undermined if not destroyed his musical career. And yet, reconciling with Sheila North-Wilson on that night saved Rob and transformed Fresh I.E.... again.

Arguably, Rob's musical practice since his suicide attempt in 2010 constitutes a gradual musical self-transformation in that his survival was defined by his objectivation of and thus distinction from his alter ego "Fresh I.E." through active self-work. ${ }^{108}$ As in his sudden transformation in 1998, such self-work involves the reclamation of his past musical self-practice, channeling associated relationships and accomplishments particularly his Grammy nominations - into new practices and proclamations. At the same time, Rob's post-suicide transformation is not nearly as scintillating as his conversion, because he retains many of the same musical self-practices, his faith in God and relationship with his wife, amounting to a period of subtle changes. Yet it is interesting to understand and explain the way in which Rob's musical self-transformative practice continues to play out using ethnographic or participatory-observation methods. ${ }^{109}$ My observations are elaborated on four levels in order to provide a detailed, explanatory perspective: first, according to my experiences gained through participation with Rob's sonic practices from April 23, 2014 - May 31, 2016; second, through interviews with Rob, his peers and fans; third, I make comparisons to his earlier transformation as

\footnotetext{
${ }^{108}$ The distinction between sudden and gradual self-transformation is discussed in chapter two.

${ }^{109}$ In fact, it was through my participatory-observation with Rob that I learned of his suicidal ideation.
} 
discussed above; and fourth, I note changes in his field of practice, Christian hip-hop. My two years spent with Rob are highlighted by questions and discoveries that were made as I went; questions and discoveries that affected my research plan. Accordingly, the following sketch does not present Rob's gradual self-transformative practice in chronological order.

On Wednesday, April 23, 2014, I flew to Winnipeg from Ottawa to join "Fresh" ${ }^{, 10}$ for his Red Letterz 13 DVD release party - my first "field work." I was excited about meeting again and playing some music, having spent the flight notating songs, beats and breaks - the planned set list. I remember finding Fresh's songs to be lyrically powerful, tempered by struggle that I assumed to be specific to his upbringing, yet redemptive; things with which I could somehow relate. But I also found themes in his lyrics efficacious because of a relevance to current political issues specific to the Canadian context; issues such as MMIW (missing and murdered Indigenous women) as in "Mothers and Daughters." 111 As opposed to the braggadocio that characterizes much gangsta rap, glorifying substance abuse, violence and misogyny, Fresh constructs his identity through scripture, especially through his glorification of Jesus Christ. Indeed in some senses his music is thematically heroic, as in his referencing of Hebrews 11, the "hall of faith" on "I Believe" 112 in which the faith of prominent Judeo-Christian figures is celebrated; and, symbolically violent insofar as he makes drugs, gang violence, rape,

\footnotetext{
${ }^{110}$ At the time, I was addressing Rob as "Fresh" as I myself had not yet learned to differentiate between his names.

${ }^{111}$ In this youtube.com video, Fresh, along with "Regular Robb" and "Promise" raises awareness around the issue of MMIW. As opposed to an upbeat hard hitting sound, the song features a sampled track with phased electric keys and vocal line apparently clipped from a retro soul song, and looped throughout.

${ }^{112}$ In this youtube.com video, Fresh, along with "Brutha War," declares his faith in Jesus.
} 
suicide, and other social ills, his enemy. But reflexively, as a fellow believer in Jesus Christ, I also identify with the idea that our greatest enemy is embodied in the figure of evil - whether Satan, the lust of the flesh, or worldly pride - the spiritual source of such social ills. Being interested in musical self-transformation, I find the combined infusion of spiritual and political content to increase the potential for mitigating precariousness through social change. That said, I am more often moved by the sounds of music first. In the case of Fresh's recordings, I am inspired by his ability to intensify his lyrical delivery through dynamic arrangement and hard hitting beats, although I am not so much a fan of the high pitched, quick rhythms of the high hat-like sounds.

After disembarking and a short wait in the cool prairie air outside, the stout yet engaging rapper arrived to welcome me with an arm lock and hug. I remember being a little intimidated upon climbing into Fresh's white extended cab pickup truck to join two other rappers who easily could have doubled as football players - Tony Coté and Teah "One8Tea" Bailey. We drove across town to an acquaintance's basement where I had scheduled an afternoon rehearsal. ${ }^{113}$ Having met with Fresh over the previous Christmas break when we relived some old memories of touring with Jon Buller, I trusted that I had nothing to worry about. And indeed, with City of Worship (2012) thumping in the background, the ride was spent crediting Buller for allowing us to cross paths, the professionalism that he taught us, and the doors of opportunity that opened for us thereafter. But all the reading in Race Critical Theory that I had been doing sensitized me to various inequalities between us along racial lines, suddenly made evident in the slurs that Fresh's crew hurled at one another in jest. When I became implicated in such jesting

\footnotetext{
${ }^{113}$ At the time, Rob's studio was set up in his apartment and he lacked access to a rehearsal space. My acquaintance, also being a musician and being away for the day, allowed us to use his basement studio with sound system and acoustic drums. We ran through the set list to backing tracks played through the system.
} 
- Troy "Scribe" Lydiate responding to a statement I made: "Why, 'cause I'm black?" 114 _

I quickly realized that such posturing disguised and supported a solidarity underpinned by hip-hop and eclipsed only by their individual and collective devotion to Jesus Christ; solidarity which I was limited in sharing with these members of the Kingdom Music Fellowship crew (KMF).

The best way to unpack Wilson's current practice is as a major mediating agent in a "scene" (Straw 1991). ${ }^{115}$ As I discovered over twenty-six months, his presence in the scene is rarely stable, phasing in and out according to a variety of factors, including the varying stability of other agents in the field. ${ }^{116}$ Many of those factors have to do with Rob's reclamation of his musical practice from the objectifying forces of genre and the culture industry. Altogether then, the local scene to which Rob is a major contributor can be sketched according to a chiastic intersection between three temporalities along an Xaxis, and three space-defining systems of logic or interest, along a Y-axis - the middle third temporal-spatial realms overlap (See Scene Diagram 1). The scene along the horizontal X-axis span: (i) past and present peers; and (ii) the future oriented realm of Fresh's audience, whether in the social media or live performance realms. The vertical Y-axis is characterized by space-related tensions: (a) musical self-practice, whether authentic hip-hop or innovative worship; and (b) Christianity, characterized by inward and outward forces. At the centre of the scene is Rob's orientated presence in tension between his vision for mentorship and apparent biographical needs, from the

\footnotetext{
${ }^{114}$ Later in the rehearsal, Troy "Scribe" joined the crew, and joined the jesting with ease. However, when I enquired of his familiarity with a certain gospel singer of whom Scribe reminded me, he deflected my question into a matter of race: "Why, 'cause I'm black?" While my intention may have been as a backhanded compliment of Scribe's talent, it was not to be had then and there.

${ }^{115}$ Critically, Straw's concept accounts for the more fluid coalescence of plural agents in sonically infused environments than more simplistic analyses of youth subcultures.

${ }^{116}$ Some of Rob's mentees returned to jail while others compromised their morals, putting their performances indefinitely on hold.
} 
institutionally linked EDIFY program in which his influence is perhaps highest, to the varying affiliations of the more independent KMF network, to the practically mundane.

- Scene Diagram 1

What sort of artist is "Fresh I.E."? Unlike a musical director or "worship leader" who may be contracted to organize and lead the musical component of Sunday morning services at a particular church, or at the other extreme, the Contemporary Christian musician or "gospel singer" whose recording and touring decouples them from regular participation in a local church, I discovered an independent professional practice with Rob. "Indie" emerged in North America and in earnest in the alternative 1990s distinguished by a D.I.Y. (do it yourself) attitude - adopted from punk - and supported at once by a network of agents, including musicians, labels, college radio, and record stores, as an alternative to the mainstream culture industry (Hibbett 2005; Newman 2009). At the same time, highly accessible recording and social media technologies, such as ProTools, myspace.com, youtube.com, and Facebook, mediate indie music. However, 
Rob's indie status is more than simply enabled by technological mediation. Rather, having learned about his contemplation of suicide, I realized that his aversion to labels, including having quit Avante Records and Paquin Entertainment to manage his own career, represents Rob's reclamation of formerly marketed aspects of his musical selfpractice. Moreover, his practice of Christianity distinguishes Rob's indie status, altogether making up the scene, its affective alliances and musical self-transformations. The first way in which Rob mediates his scene is through his peers, who act as a bulwark against objectifying forces through both centripetal and centrifugal counter forces. Past peers that remain influential on Rob and his field have already discussed, such as Jon Buller and Amanda Cook whose continued musical production tends to both endorse and pressure Rob to remain relevant (more on relevance below). In terms of present peers, relationships range between loose associations with the potential for collaboration, ${ }^{117}$ to collaborative partnerships where moral accountability seems to take precedence even over musical practice. Kingdom Music Fellowship is exemplary of the latter. Although KMF precedes his thoughts of suicide, Rob's participation in the group since then involves the strengthening of his musical self-practice and defense against objectifying market forces. There are roughly twelve artists associated with KMF, though they tend to come and go; ranging from budding stars to long time friends; from Refuge's age of sixteen to Rob's age of forty-four; most living in Winnipeg, with others

\footnotetext{
${ }^{117}$ During my time with Fresh, he occasionally met with potential collaborators, including MC Jin, a onetime world freestyle champion based in Queens, and Ryeon, a rapper associated with the International House of Prayer movement in Kansas City. In both cases, Jin and Ryeon's visits to Winnipeg included performances at the Manitoba youth detention centre (MYC), in which roughly sixty inmates participated in shows hosted in the centre's gym (I was not allowed to take notes while inside). Notably, the transformation of the mood of inmates from mildly mischievous to composed, was both palpable and commendable. After the MYC, Jin performed with Fresh at a local waterpark, while Ryeon joined Fresh and Scribe in studio to collaborate on songs for an anti-suicide EP tentatively called, ",".
} 
living across Canada. ${ }^{118}$ Not quite a label in the sense of managing their careers, KMF contributes a centripetal force to the scene through moral accountability, considered invaluable to the artists I met and interviewed. For instance, at the DVD release on 24 April, 2014, a slew of KMF artists coalesced on the West End Cultural Centre stage to showcase songs on the DVD itself, as in Tomislav's collaboration with Wilson on "Life;" $" 119$ but also to showcase singles of individual artists such as One8Tea and Refuge. While backstage with Refuge, One8Tea described his appreciation for the accountability that KMF provides, also shared by his wife:

Fresh and I were talking about me coming here for this show and [my wife] even said 'You gotta go man, you gotta go meet your brothers - you have to go!'... Even as we were making the decision to pursue this as a career... she [pressed], 'Do you even believe in this God that you talk about all the time? And I was like, 'Oh! Let's tie these shoes up and run!'... That's one of the things that was really important to me, that I was part of something that I knew [my] heart [was into]; we're all going the same way; it's not about any of us, individually, it's about an entire family. (Interview April 24, 2014)

Christian morals provide a common bond in the scene, for One8Tea, vital to his musical practice beyond mere artistry, extending to his extra musical “...family.” Such accountability constitutes an inner tension, a centripetal force that both defines membership and constrains members, whether in their presentation on stage or selfgovernance in private. ${ }^{120}$ For example, Rob would sometimes use driving time to call and encourage peers who were in jail. Or, on a late night ride home from a gig in Fisher River Cree Nation, Manitoba, KMF member, Scribe, criticized up and coming artist,

\footnotetext{
${ }^{118}$ Caleb "Braveheart" Hart of Tasman Jude, was in Australia at the time of writing.

${ }^{119}$ On Red Letterz 13, backup singers begin the performance with the chorus, repeating, "This is life" every two bars, while Tomislav and Fresh rap in between, "The struggle, the beauty in the rubble, the rose in the concrete, the humble -this is life; The pain, the love in the rain that builds characteristics -this is life; the frame, the fire in the name, virgin desires are the game -this is life; the Christ the way and the truth, comin' to a "hood near you -this is life" (2014). It is important to note that while the lyrics can be interpreted as descriptive, or reactionary, critically, they also work to reproduce the scene in an individualistic sense. ${ }^{120} \mathrm{Cf}$. Bourdieu on field defining inner tension and outer forces (2004: 47); on the presentation of self, see Goffman (1959); on self-governance, see Foucault (1991: 1-20).
} 
Ezekiel, for suggestively letting one arm fall between his legs while rapping. Scribe's critique stems from a Christian principle barring lust, sexual promiscuity and premarital sex. Indeed, sexual purity, namely monogamy, is also a common theme in Fresh's lyrics, both a subtext to his involvement with KMF and sanctification of his former pimp self. Significantly, in that the scene includes young up and coming artists such as Ezekiel and Refuge, such accountability contributes to the reproduction of the scene. Finally, peerassociation with Fresh and KMF underlines the importance of solidarity against the precariousness of the market. For example, Scribe has attributed his ability to get gigs to his endorsement via Fresh, while One8Tea attributes his "survival" as the only Christian hip-hop artist on the East coast (Moncton, NB) to his association with KMF. The network of peers provides a self- and career-sustaining function in increasing morale, morals and the potential for gigs.

Two musical self-transformational practices whereby Wilson's outward resistance against objectifying pressure having to do with genre and the culture industry occurs are in studio production and live performance. I participated in the process of studio production on the album, Collide: City of Worship 2 (2015), ${ }^{121}$ in order to observe Rob's proclamation technique. ${ }^{122}$ Outwardly, his studio production represents an "adaptation," as opposed to innovation, to the changing field. ${ }^{123}$ In this case, Rob's first adaptation was

\footnotetext{
${ }^{121}$ As the title suggests, this is not his first such album, having previously collaborated with various peers on the album, City of Worship (2012), such as singer-songwriter and multi-Juno award winner, Steve Bell, on "Everything we Need." In this youtube.com video, Rob and Steve collaborate to remake Gord Johnson's song. I did my best Steve impression, performing the song with Rob at Tha City over the winter of 2015. ${ }^{122}$ After the Red Letterz 13 DVD release party, having moved to Winnipeg during the summer of 2014, I met with Rob at his home studio to deliberate over how I might contribute to his practice. At that point, he was conceptualizing Collide: City of Worship 2 (2015), and in talks with Youth for Christ about moving his studio to the core area, and setting up the youth programs Tha City and EDIFY.

${ }^{123}$ As opposed to innovation, as it suggests something from nothing, adaptation draws attention to the relation between claims of authenticity and originality, advantageously allowing such logics to remain in tension so as to assess their effect as strategies relative to each other (cf. Bourdieu 1984: 119-164).
} 
his interest in bridging boundaries through the combination of his beats and raps, with artists representing genres as diverse as dance, country, and contemporary praise \& worship. ${ }^{124}$ The way in which such "bridging" occurs is through the technique called, "collaboration," already common by the early ' 90 s in pop music and contemporary Christian music alike, but less so in the combination of hip-hop with country and praise $\&$ worship (see examples below). In the hierarchy of genre where hip-hop still vies for legitimacy with more established forms such as country, Fresh's collaboration with Paul Brandt on the song, "Pilgrim," 125 constitutes a claim of originality, boosting the cultural capital embodied by each respective artist and thus the album. In an interview at the Collide release party, April 11, 2015, Rob stated that the boundary defying intention behind the album is meant as an outreach to artists of all associations and an incitement to Christians in general, to "prepare for God's holiness," taken from Revelation $19 .{ }^{126}$ Yet ironically, collaboration still serves to reproduce genre boundaries, thus constituting a claim of authenticity.

\footnotetext{
${ }^{124}$ Cf. Roy and Dowd (2010: 196-7) on "bridging."

${ }^{125}$ In this link to the audio only file on youtube.com, Brandt's country style vocals sing the chorus while Fresh raps the verses. Mix engineer Adrian Bradford, presently in Los Angeles, explains his approach to mixing the song at first, "with phat bass," as he had heard on a recent Rick Ross album (Interview January 8, 2016). Interestingly, while it initially won him the job of mixing Collide, the approach didn't work for "Pilgrim." Instead, following producer Jon Loeppky's suggestion, Bradford remixed the song with bass at a lower volume than guitars and vocals, like a country song (Interview May 19, 2015).

${ }^{126}$ In this youtube.com video covering the Collide CD release party April 11, 2015, Paul Brandt describes how he collaborated with Fresh, while Fresh describes his intention behind the album.
} 
- Fig 5.1. Drum parts for the Red Letterz 13 DVD release party (My notation 2014). A technique used to distinguish Collide is to incorporate seamless transitions between songs. Such transitions are innovative for hip-hop because of the way in which beats are typically programmed, using modern recording software whereby rhythms are designed by the bar, and repeated for the length of the song, and at a set tempo. For 
example, my self-transcribed notation for Rob's show at the West End cultural centre,

April 23, 2014, illustrates the repetitive character of hip-hop (See Figure 5.1). While

such repetition is often celebrated for articulating a militant feel (Dimitriadis 2004: 486),

there are no places for improvisation and dynamics are limited to cuts and breaks when

the drum rhythms either stop for a designated time, or continue unaccompanied in order

to emphasize that militant sense. To add dynamics to Collide, Rob reunited with Jon

Loeppky as producer and multi-instrumentalist in order to adapt chords and rhythms,

such as pads played on keyboards and guitars, in order to minimize the abruptness of key

and tempo changes, exaggerated by such style changes as seemingly opposite as hip-hop

and country, exemplified respectively on the songs, "No God Can Save Us (But You)"

(feat. Infinite Automatik) and "Pilgrim" (feat. Paul Brandt). ${ }^{127}$ In contrast, the abruptness

of the transition from country to dance is exaggerated by the sounds of violins and

playback tape skipping, for instance from "Pilgrim" to "Lift Your Name" (feat. Fraser

Campbell). Rob also reunited with mix engineer and former collaborator, Adrian

Bradford, who describes his job as tensioned by the technical reproduction of sound, and

subjective emotions:

$A B$ : The mix engineer kind of wears two different hats, like there's the technical way of thinking frequencies, compression, and all these different things, e.g. going into a computer and moving tiny pieces of audio around. But then a lot of it is this real visceral emotional kind of thing where you have your hands on the faders and you're playing the whole thing like an instrument. So the things that you do as a mixer all go to finding this emotion that exists in the song. I mean you can just go ahead and turn up all the tracks and lay it down and everything will be just static, and still feel the emotion of the musician and the song, but part of what we're doing when we're mixing is honing in on specific things; what does the listener need to be listening to at this section of the song? Or maybe when the first verse comes in, depending on the emotion of the song you want to strip out all these elements and really highlight the vocal. So you go through

\footnotetext{
${ }^{127}$ In these youtube.com videos, Fresh's collaborations are transitioned (toward the end of "No God can Save Us (But You)") by Jon Loeppky's production, including a spoken word section over guitar pads in which the producer himself references Biblical passages. The spoken word trope arises often throughout the album as though sustaining truths amidst the struggles that Fresh raps about.
} 
all the different elements in the song and try and heighten the emotional chaos that the listener... and you get that by just feeling that yourself. Once you're moving your head and having a kind of emotional connection to what's happening in the music, you know that the listener is going to feel [the same]. So you have to sort of forget all the nerdy stuff that you had just been doing up until that point and just kind of get lost in the music. All these little things that you do affect the listener on an emotional level even if it's not obvious specifically what is happening. (Interview January 8,2016 )

Adrian's attention to the musical mediation of the emotions reveals a direct focus on the semiological moment of the musical self. His manipulation of the sounds of music in mixing, differentiating between sounds and their corresponding feel, represents a musical self-transformative technique. At the same time, concentrating on his mixing technique of "just feeling that yourself" should not overshadow his mediation with and orientation to the music industry. Rather, Rob's collaboration with Adrian reveals a technique in which his post-suicidal gradual transformation is secured, working to appease his selfdoubt due to the complex subjectivity of his biography and changing state of the field.

Relating the sounds of Collide back to Rob's musical self-practice, I collaborated on a song for which he was learning to play chords on a keyboard. As he states in his biographical documentaries, Rob doesn't know how to play an instrument per se. However, for "Beautiful” (feat. Cynthia Hamar, Nadia Pries), he learned enough to record simple scratch pads for the verses and chorus. In the following journal entry, I describe the events of that collaboration:

Last Friday night, Fresh texted me to join him in the studio [at YFC downtown]: "Hey bro, you have time to come by the studio for some songwriting? ... Bring an acoustic. I have a beautiful worship song in me; I just can't find the chords on a piano." He was working on something that he thought l'd really like. He also asked me to bring coffee. I had had a short sleep the night before and was not exactly feeling up to it, but... I dragged myself out to the YFC building [anyway], picking up coffees along the way.

Upon arrival, Fresh excitedly explained that he had been learning chords on his keyboard, arranging them into the structure of a song that he had already recorded on his computer. He was particularly excited because it was the first time he had ever written a worship song himself. Typically, he would write and record beats, or drum and bass rhythms, then rap over top of them, before sending the tracks to another artist with whom he was collaborating. Alternatively, he would send off the beats with parts to be sung by the collaborator - an epic repeating chorus line for instance - to which Fresh would then 
write and record a rap. However, with this latest song, Fresh had an idea of a melody that he had recorded earlier on his mobile phone, and to which he was matching supporting chords. [As his worship leader for Tha City, the song followed a familiar structure and style to "The King is Among Us," a song by Elevation Worship that I had covered at his and Coté's suggestion. So when Fresh explained that he wanted to write a bridge with a long build as a foundation for a string section - both rarities for hip-hop - I recalled Elevation's style, simply suggesting that he invert the chords that he had been playing... After recording enough of the song that we could walk away and not forget our trajectory upon return, I gave Fresh a ride home.] (Dissertation Journal: January 9, 2015)

While my journal entry suggests that a degree of spontaneity characterizes the process of collaboration, in fact, every time that I visited Rob in studio he had iTunes open on his iMac with some of the latest popular music at hand, including Elevation Worship. That way, he maintained a constant link to the field, always ready to adapt. Significantly, his technological mediation with the current state of the art reveals a self-transformative strategy that at once mediates Rob's biography and the wider field. In other words, the ongoing work of reclamation-proclamation. However, I did not acquire such a revelation until a later point in which I was conducting a post-production interview with Rob. Here, Rob confessed that at the time of our collaboration, he had been dealing with writer's block stemming from an existential struggle with self-doubt. Rob elaborates:

RW: There was this part of me that felt like I'm not relevant no more as Fresh I.E. These fears came up. There was a season before YFC when I had all these fears: I would lay in bed just, it'd be four or five in the morning, my wife sleeping and I'm laying there [thinking], 'I'm not going to be able to be a provider no more; I'm not going to be able to rap no more; I can't get a regular job because I didn't graduate - how am I going to provide for my wife? She won't even want to be with me no more. I'm not going to be nobody' - all these things came to me 'I'm just going to be one of these dudes that had this story: 'Ya, I had all this success, but now I'm here in this back alley just in this garbage bin.' Y'know, these weird fears of failure and relevancy.

So I began to search, 'Who am I outside of me? Is there life after this?' But it was in me searching that I found that life isn't over; this is not even close to being over.

So, finding my identity. I think the foundation for transformation is finding out who you are. Like, to be self-transformed is different from being transformed. Self-transformation is you trying to transform yourself into something, but when you're transformed, you just become who you're meant to be. Y'know what I mean, you find your destiny, your purpose. And all those things that tell you you're dying, bows to destiny. So death, meaning fears and all those things that are working against your confidence, your self-esteem, or whoever you are, it bows down to your destiny. 
AK: But your destiny still comes from somewhere.

RW: What I'm saying is that destiny is a destination; there's somewhere you're getting to. Sometimes we feel like when we start to mold ourselves to a way, we feel like we've arrived to that destination, we try to mold ourselves to something.

AK: We think we have control over that something.

RW: Ya. But when we actually start to become transformed we realize we actually haven't reached our destiny yet. I'm not over, it's not over yet, there's still more road to drive. I'm pressing toward the mark of the prize and the high calling of Christ [Phillipians 3:14] - Our high calling of God in Christ Jesus. So, I'm pressing towards that mark. And that's the reason that I was able to snap out of the whole writer's block and say, 'Ok this is not over; I can still do another album; It's still in me; I'm gonna do it, I'm gonna do it,' y'know? (Interview March 24, 2015)

It's interesting to consider the songs on Collide relative to the struggle that Rob was going through in the early stages of production, in addition to his suicide attempt just four years prior. Perhaps intuitively, Rob differentiates between self-directed transformation and the kind of transformation that I am exploring in this dissertation, having to do with struggle, with external and internal forces, time and space, silence and sound, stillness and rhythm. Having achieved Grammy recognition early in his career, his struggle with relevance, now, seems to have more to do with aging, for instance his relation as a fortysomething year old husband and professional rapper to the changing state of the Christian and popular music fields around him, than with his musical practice. On the one hand, as discussed above, Rob overcame his fears by rising to the challenge of the changing field, drawing on his ethic and practice of musical self-transformation, enlisting the help of collaborators, producers and engineers to produce an album that represents the cutting edge of his field at that time. Collide received eight nominations and three Canadian Gospel Music Awards, including Collaboration of the Year for Collide, Rap Song of the Year for "Broken Veil," and perhaps most significantly, Fresh I.E. was awarded Artist of the Year, becoming the first black artist to do so in Canada. If not for his ethic and 
practice of musical self-transformation, in this case Rob would have remained based in his home-studio, performing his back catalogue of tunes on the basis of his past achievements alone, and perhaps succumbing to his self-doubt, reducing his music making to modes, for instance, to listening only.

On the other hand, Collide also represents Rob's rising to the challenge of existential precariousness represented by his fears. In returning to Christian scripture, for instance, Rob employed a self-transformative technique to overcome self-doubt by "pressing toward the mark," trusting that his self-worth was at once attained through his faith in Jesus, contemporaneously with the projection of sound. The musical mediation of such religious practices is often underestimated in the literature. In this case, Rob proclaims his "calling" through his musical practice, describing it in the interview above as though he is suspended and sustained by the sense of purpose that calling provides, somewhere between having arrived and yet to arrive at a destination. ${ }^{128}$ Arguably, Rob's musical self-transformative technique of studio recording constitutes resistance against internalized fears rooted in his biography and the changing character of the music industry. Such emotions are overlooked in DeNora and Hennion's respective sociologies of music. Rob's overcoming of his fears through music making entails a reclamation of his past self rooted in his formative and educational years, and their ongoing musical selftransformation through proclamation or projection into the unknown future. Moreover, the complex subjectivity of Rob's sense of injustice - "'I'm not going to be able to be a

\footnotetext{
128 "Purpose" as it relates to the self is a major sustaining force against fear and death, popularized recently by Christian theologian Rick Warren in The Purpose Driven Life: What on earth am I here for? (2002). Max Weber defines "calling" as "an obligation which the individual is supposed to feel and does feel towards the content of his professional activity, no matter in what it consists, in particular no matter whether it appears on the surface as a utilization of his personal powers, or only of his material possessions (as capital)" (1958: 54). While space does not permit its pursuit here, it would be interesting to explore the specific ways in which Rob's "calling" infuses his musical self-practice and ethic of self-transformation.
} 
provider no more; I'm not going to be able to rap no more; I can't get a regular job because I didn't graduate - how am I going to provide for my wife? She won't even want to be with me no more. I'm not going to be nobody" - are intimately tied to his emotions which in turn are reconstituted along with his musical self through his ethic and gradual practice of self-transformation, supported in this case by his morals. In other words, if not for the musical mediation of Rob's, in this case, self-sustaining moral of "pressing toward the mark," he would have had to resist his self-doubt by other means, perhaps succumbing to the precariousness of his situation.

\section{6-Appendix: Contradictions of collective interest in musical self-}

\section{transformation}

This chapter began with a socio-analysis of Rob "Fresh I.E." Wilson's musical selftransformation, sudden and gradual. The complex subjectivity of his biography is made up of formative, educational and professional aspects, and musically mediates various planes, from immediate experience to institutions. Arguably, Rob's present musical practice and ethic of musical self-transformation is influenced by inequalities rooted in his complex subjectivity and the changing music industry, while at the same time being incentivized by music's capacity to sustain him in the face of such precariousness. Yet his musical self also speaks to a relational dynamic between the outward force and emanating power of his practice, and its recognition or reception. Indeed there is an ongoing vitality that is mediated through live performance, the omission of which, here, as an aspect of Rob's musical self-transformation would be to risk falling into a solipsistic rendering of his musical self and a teleological understanding of music, overlooking a significant, indeed defining aspect of the local scene around him, that being 
the potential for collective transformation. In other words, the significance of Rob's musical self-practice is found not only in the intentions of his production, but also in the "interests" that he shares with his audiences. ${ }^{129}$ Such interests are multiplicative, but for the most part related to hope in the face of fear, and redemption in the face of self-doubt. Why else does he insist on leaving the comfort of his home studio? However, such hope, when it becomes the sole collective interest, "hope for hope-sake," tends to obscure contradictions that otherwise get in the way of achieving real change. Importantly, Rob's performances raise ethical concerns, for instance around the question of music's objectification (Christian hip-hop) and its institutional mediation (CCM) as already discussed. In terms of collective musical-transformation, his performances also raise concerns around the way in which the institutional church mediates that practice, on the one hand, and the way in which his musical practice mediates Canada's Indigenous peoples, on the other hand. To address such concerns, here, I trace the "meaning" or specificity of Rob's music making to the articulations of his peers and audiences, to the forms that his live performances take, and by extension, to their various contexts. As such we can better understand and explain the ethic and practice of collective musical self-transformation as a combined problematization and response to shared inequalities. Yet with a more comprehensive understanding of collective musical self-transformation in Rob's case, we are better prepared to collaborate in ethical musical self-transformation.

\footnotetext{
${ }^{129}$ According to the sociologist, Pierre Bourdieu, an agent's actions are influenced by their "interests" but neither in a utilitarian sense of being rationally calculated nor in terms of Marx' class interest (1991: 10811). Rather, as they are wrapped up in the habitus-field relation, specific forms of "interest" are produced and called forth by fields. As such, involvement in a specific practice is distinguished by one's investment in the stakes in the field or game. As such, there are as many interests as there are games. I use Bourdieu's "interest" as it reminds of the economic logic behind otherwise "disinterested" acts, thus allowing for a critical assessment, here, of musical self-practice and collective transformation.
} 
- Diagram 2 (Shared Interests)

The three main interests in Rob's musical practice that he and his audience and various peers share are commercial, identity based, and issue specific (See Diagram 2). The way in which these interests are negotiated, in turn, affects the form that Rob's live performances take, whether concerts or working partnerships, and in turn the duration of his involvement with his audience. For instance, at the Collide album release party ${ }^{130}$ on April 11, 2015, at New Beginnings Pentecostal church in Winnipeg, Fresh assembled a live band and supporting acts, including the Winnipeg Gospel Choir, Flood the Stone, One8Tea and other KMF members, and Paul Brandt, who altogether attracted about two hundred mainly country and hip-hop fans, and who also shared a common faith in Christ. North End based Aboriginal activist, Michael Champagne, emceed the evening, welcoming all to Treaty 1 territory. Audience ages ranged from childhood to middle age,

\footnotetext{
${ }^{130}$ In this youtube.com clip, Fresh performs Collide live with backing band, over backing tracks, and with various collaborators. I positioned my camera at the sound booth in such a way as to capture images of the entire stage, the first few rows of the audience, and aspects of the church structure and ornamentation (e.g. stage lighting and national flags hanging from rafters).
} 
while background appeared to be middle class and racially diverse. While the atmosphere was electric both in terms of my own experience and audience members' enthusiasm expressed throughout, the show's significance is also gauged by the discourse articulated around it. ${ }^{131}$ For instance, a survey of concert footage and related interviews includes country performer Paul Brandt, who although describing the making of his collaboration with Fresh as, "a strange left turn in his career," enthusiastically supports his participation in the concert. Up and coming guitarist, Brandon Blume, states in a post-show interview that, "it was a blast" ("Collide CD release party"). The show was perhaps most significant for eleven year old back up singer, Bernadine, who told me two months after the fact, "I still cry when I sing my solo; I still cry when I sing "Beautiful" because it's like I'm singing for God and it's like God is singing to me, 'I'm beautiful;' but not that I want to sing 'I am beautiful' but that everyone is beautiful" (Interview May 22, 2015). Economically, the release party generated enough funds through ticket and merchandise sales to cover the cost of recording the album. Overhead was minimized by the rent-free use of the church and in-house audio-visual personnel, combined with the volunteer labour of amateur musicians and Brandt's pro bono contribution. The show was promoted via Fresh's Facebook page, on local Christian FM radio (CHVN), and Brandt did a promotional interview on mainstream country station, QX104. ${ }^{132}$

\footnotetext{
${ }^{131}$ In posting my video recording on youtube.com I had hoped to attract just such responses, but alas, I was unsuccessful, and for a variety of reasons, my camera skills not being least. However, the aforementioned videos published by Mike Blume (n.60), including interviews with musicians suggests general excitement among said musicians, mainly around involvement in the spectacle, and genre related boundary crossing in the case of star, Paul Brandt.

${ }^{132}$ Additional funds for recording the album were channeled through online campaigns like gofundme.com and a few of Fresh's personal backers, some of whom have supported him since his Grammy nominations, such as former Winnipeg Mayor Sam Katz, while others lacked previous communications. Some funders support Fresh based on common religious beliefs, while all share secular aspirations for positive social change through his hip-hop.
} 
However, Rob's live performances are also tempered by market-based constraints. In Winnipeg's comparatively small Christian hip-hop scene, concerts like the Red Letterz 13 and Collide release parties are simply unsustainable on a regularly occurring basis, at least as they are in this case separated by one year. Because of the precarity of the "indie" market and his refusal to return to the mainstream touring circuit, then, Rob has organized his musical practice around touring First Nations and Inuit communities and youth mentorship programs hosted by local churches. In turn, a shared interest in selfidentity and self-transformation emerges in his musical self strategy of touring and in live performances. In fact, I found his performances to Indigenous peoples most intriguing but also problematic as I prepared to work with him. For instance, I found on his website (freshmusic.ca, since taken down) a list of statistics stating that by 2014, Fresh I.E. had toured over two hundred reservations, including in the U.S. and Canada, and that he had witnessed hundreds of commitments to Christ. In light of the summary findings of the Truth and Reconciliation Commission of Canada (Final Report of the TRC released June 2015) in which chair, Justice Murray Sinclair, states that the legacy of the Residential Schools and its educators in forcibly separating generations of indigenous children from their parents, and thus cultural ancestry, through forced indoctrination, "amounted to nothing short of "cultural genocide"' (Schwartz 2015), ${ }^{133}$ such statistics appear to fly

\footnotetext{
${ }^{133}$ Adapted from Lemkin's development of the term, genocide, after the Second World War, "cultural genocide" involves the annihilation of a group of people by non-physical means, including detachment from any moral, spiritual, or cultural aspects. The residential schools were sponsored by the Canadian government and mainline churches to assimilate indigenous First Nations, Inuit and Métis people to EuroCanadian culture from 1883 when the federal government sanctioned the first three schools for First Nations children in Western Canada, until the final school was closed in 1996 (Final Report of the TRC 2015: 37-134). It is estimated that at least 150,000 First Nation, Métis, and Inuit children passed through the system (TRC Vol.6 2015: 3).
} 
provocatively in the face of Canada's redress movement. ${ }^{134}$ Indeed, I became indignant to understand how Rob reconciled the evangelistic side of his faith with the history of the schools, as assimilation through forced conversion remains anathema in my own system of ethics - and as Carleton University's ethics board proscribes it. Conclusively, I discovered it is also so both with Rob and with his wife, Grand Chief MKO Sheila North. But how is this relationship between Rob and the First Nations and Inuit reserves that he tours justified? ${ }^{135}$ Is it justifiable? And how can we evaluate this relationship?

In these politically contentious times, this ethnography of Rob's tours provides insight into the form that that relationship takes, providing a basis for evaluation of that relationship and possible areas for improvement. For instance, in working with Rob, I found that he received several offers to perform, including at Peter Ballantyne Cree Nation at Deschambault Lake, Saskatchewan. The specific interest and feasibility of touring the reserve increased for several reasons in 2015. At about the time of the Collide CD release party, when Rob's old friend and music coordinator at New Beginnings Church, Deval Dryden, set up a promotional tour from June 5-12, that was intended to include up to six stops between Deschambault, and Thunderbay, Ontario. Like a practice run, a function of the tour was to build the musicians' appreciation for the work that went into the songs, and to sharpen the band's live performance before playing major markets where stakes were higher - including a highly anticipated but ultimately canceled gig in Brooklyn, New York. However, a number of determining factors influenced the make up

\footnotetext{
${ }^{134}$ The movement to redress the "trauma trails" of widespread social injustices experienced through the Residential Schools, such as racism, isolationism, physical and sexual abuse, began in the 1980s as Settlement churches began to take responsibility for their contribution to nation-wide detrimental effects, including disproportional representation in the criminal justice and prosecution system. The movement culminated with the Indian Residential Schools Settlement Agreement in 2007, with Prime Minister Stephen Harper offering a formal public apology in 2008, and TRC findings released in 2015 (TRC 2015). ${ }^{135}$ Such freedom of choice I consider a hallmark of liberal democracy worth preserving in Canada for future birth cohorts, and which in light of recent populist movements appears to be strained.
} 
of the tour, and the specific nature of the Deschambault gig. Financially, like many Canadian indie bands, Rob drew on modest "Recording Artist Touring Support" from the regionally focused and provincially funded, Manitoba Film \& Sound, in order to hit the road. But despite funding, Rob's finances were still limited, constraining his capacity to manage all that went into the tour, in this case contributing to a series of delays, including replacing a trailer with a broken leaf spring and flat tire, renting lights and a smoke machine, and renting an RV through kijiji.ca. We finally set out on the $904 \mathrm{~km}$ journey from Winnipeg at 9:00pm on Thursday June 4, 2015, after initially wanting to leave at 9:00am. We arrived the next afternoon after a short stop to sleep at a gas station in the Manitoba Interlake region. The geographical isolation of Deschambault, in this case relative to Rob's home base in Winnipeg, is a conditioning factor of his live performance, raising the stakes involved, both in terms of recompense and band-audience rapport. As such, Deschambault strategically became the "anchor gig" of the tour, organized to span a weekend as a "worship conference," replete with speaker, David Seida, an itinerant preacher of sorts who ministers on First Nations reserves. The billing of Deschambault as a "worship conference" brings into relief the relation between Rob's interests with the interests of his audience, in this case, suffering a rash of suicide and what Justice Sinclair identifies as a "growing crisis among Indigenous youth" (Schwartz 2015).

On Friday afternoon, June 4, 2015, about thirty kilometers north of the nearest two-lane highway, we rolled into a community that looked for all intents and purposes to be devastated: ready-to-move houses (RTM), several of which, if not burned to the footings, were missing siding and doors, while many windows were broken and boarded up (see Image 1); the elementary and high schools were both vandalized, inside and out; 
and a single convenience store stood at the middle of the reserve where frozen pizzas could be bought for about $\$ 9$ each. Not to be hyperbolic, Deschambault's schools were each constructed in the last ten years, and the reserve population of 1,400 is serviced by regularly rotating educators who live in brand new, fully furnished RTM's. Health care workers are similarly installed in the local clinic. Yet despite being set in the beauty of the Canadian Shield, Deschambault Lake appears to have recently experienced war, and in a sense it had; like many First Nations in Canada and Northern Saskatchewan, suicide has hit disproportionally high rates, five times the national average for ages $1-19$, at up to 30 per 100,000 for males, and 25.5 per 100,000 for females (Statscan 2016). In January 2015, a man was discovered in the high school parking lot, frozen to death, with alcohol a contributing factor (CBC 2015); and just over one year after Fresh's gig, a ten year old girl, the fourth of at least six in a month in the wider region, committed suicide (CBC 2016). Indeed, suicide was the main reason for Rob's invitation to Deschambault, its resistance being the interest shared by both Rob and his hosts on the reserve. 
Deschambault Lake "ready-to-move" house - Image 1

Rob's worship conference at Deschambault Lake consisted of Friday and Saturday night services, and a concluding Sunday morning service and baptism, in which Fresh and his band performed songs before and after Dave Seida's messages. Such events spanned over three hours each, taking place in the Kistapiskaw elementary school gym, with about 40-50 local attendees coming and going throughout, ranging in age from infant to sixty-something, mostly kids and their parents or guardians. The Friday night service coincided with the high school graduation, which I discovered the next day while exploring the setting of the reserve. It was then that I was shocked to come across an RTM full of infants whose murmurs were audible from outside. Presently, the babies were cared for by a relative while their parents slept off the previous night of partying. During the same downtime on Saturday Rob's band split three ways, some getting much needed rest, others joining a fishing party out on the lake, and some like myself, visiting 
with a group of curious local kids who seemed to welcome us as a distraction from the mundane. We reconvened in front of the elementary school for a BBQ, the band and about twenty kids, before taking the stage that night. Field notes of my participatoryobservation provide insight into the way in which conversion, or "commitment to Christ," occurs:

Tentative plans for [Sunday] were for us to conclude our worship conference at the elementary school and head down to the lake for baptisms. The night before, Fresh had asked me to prepare to lead worship with the band. Again, probably due to reduced sleep, I was reluctant; but in the end I led [the songs], "Deep Cries Out" and "Amazing Grace." The first song seemed to flow as Sa'ad, Brandon, Noel and I had performed it often during Tha City, but I had to bring up the lyrics for "Amazing Grace" - it felt a little awkward reading off of my phone. I remember the mood of the service, thankfully, settling in to a peaceful state, particularly, as I used the time between songs to reflect on God's faithfulness - to "enter his gates with thanksgiving, his courts with praise" [a reference to Psalm 100:4]. In a sense it precluded Dave, the speaker, from trying to whip the service into frenzy as in the night before, although an undercurrent of urgency occasionally rose up in his delivery. Fresh and the band followed Dave with a short set of songs, but the energy level of the band and audience was much more subdued compared to the previous night - [local] kids came and went throughout. Finally, after finishing an hour or so later than planned, we all headed across the reserve to the lake to baptize a few of the young faithful, some of whom indicated their interest beforehand, others at the lakeside. Dave, a one-time drug dealer in Moosejaw - for an infamous biker gang no less - turned itinerant preacher to First Nations, presided. (Field notes June 7, 2015)

Shortly after the baptisms, we packed up and left, only to discover that Rob's suitcase, with laptop and cash from the weekend's proceeds inside, had been stolen. ${ }^{136}$ To add insult to injury, our motorhome blew a tire on our way back to the highway.

Coincidently, we changed the tire less than 100 kilometers proximal to a forest fire that apocalyptically illuminated the sky with an orange hue and rained down ashes upon us.

We arrived home the next day exhausted, broke, and humiliated - at least I did. But at least I had the option of licking my wounds.

Based on the above description, the relationship between Rob and Peter Ballantyne Cree Nation is in some ways gravely concerning. Despite a few hopeful

\footnotetext{
${ }^{136}$ Rob's suitcase was eventually found and returned, including his laptop with tracks from Collide, but not the cash.
} 
moments and interactions in our brief visit, we apparently left Deschambault in the same materially wretched conditions that we found it. This and the curious revocation of Rob's website on which his evangelism statistics were posted gives cause to wonder whether his interest in the reserve is coldly instrumental: to gain personally both from private funders who support his practice based on his conversion statistics, and from public funders such as Manitoba Film and Sound whose agents may be oblivious to such fleecing. If this worst-case scenario is true, Rob's intentions at Deschambault arguably count as unethical, his actions culturally colonial. Indeed, as discussed in the first example of live performance above, economic rationalism plays into Rob's musical practice. However, also as noted above, when asked about it directly, Rob insists that he has been invited to every reserve at which he has performed. How can this be? Who is doing the inviting, then, and how can they not recognize the apparent futility of this musical exercise? Is music futile here? How can we evaluate this complicated relationship?

There is an historical answer, for one, which allows us to account for the interests of Wilson's interlocutors. Although a complicated set of relationships, it has been reported that two-thirds of Canadian Aboriginals continue to practice Christianity despite the history of the residential schools (cf. CBC 2016). ${ }^{137}$ The prevalence of Christianity among Aboriginals is explained by the difference between the Church as institution, and "the church" as a network of believers. Historically, many Aboriginals recognized the support of Christian educators and other agents as supporting traditional beliefs and languages despite the negligence of the government and sponsored authorities in the

\footnotetext{
${ }^{137}$ According to the National Household Survey (NHS) profile of 2011, of 32,852,320 Canadians, 64,935 self-identify with Traditional (Aboriginal) Spirituality. In 2011, there were 1,836,035 of North American Aboriginal origins in Canada (NHS 2011). More details on religion are to be restored to the long-form census in 2021.
} 
Church. Yet, the religious profile of Aboriginal youth is distinguished by acceptance of both Christianity and traditional spirituality, suggesting openness and perhaps syncretism. Sociologists of religion, Bibby et al., trace a "rebirth of Aboriginal spirituality," noting that 4 out of 10 youth in Band schools in Alberta identify both Christianity and Aboriginal spirituality as important; another 4 out of 10 identifying just Aboriginal spirituality as important; 1 out of 10 viewing Christianity only as important; and the remainder viewing no spirituality as important (2010: 36-40). Comparatively, the authors note that spirituality among Indigenous peoples is higher than average across Canada. This is likely due in part, to lower rates of post-secondary education, but also because of a distrust of secularity in general, and government in particular (cf. Pinsky and Brown in Robbins 2004: 150-8) ${ }^{138}$ Yet while a preexisting, locally based, Christian group invited Rob to Deschambault, he is also invited to perform on reserves for specifically secular reasons. For instance, on 18 November, 2015, I accompanied Rob and some KMF members to a gig at Fisher River Cree Nation for "addictions awareness week." As at Deschambault, he was contracted because of his "positive message" and the attraction of his beats for youth (Interview with event coordinator, 18 Nov, 2015). However, while positivity infused his message to the youth in attendance, he refrained from inviting said youth to commit to Jesus.

The Truth and Reconciliation Commission of Canada (TRC) chaired by Justice, now Senator, Murray Sinclair, issued its final report in 2015, including an evaluative model for dignifying those traumatized in and through the Residential Schools by reclaiming their lawful rights and freedoms, and significantly for this analysis, 94 calls to

\footnotetext{
${ }^{138}$ In explaining recent rises in global conflict due to religion, both authors distinguish between recent turns to orthodoxy and fundamentalism. The former is considered a response to religion's loss of pietism, while the latter, a response to a loss of power.
} 
action as a means of reconciliation, establishing a conciliatory relationship between all Canadians. The final report lays bare the colonial history and horrific legacy of the Residential Schools in Canada (TRC 2015). The truth of this legacy is articulated in the multiple stories of forced separation of children from their parents, and the experience of physical and sexual abuse at the hands of government endorsed, clergy and non-clergy teachers. That entire generations of Canada's indigenous peoples lost their culturally specific skills and knowledge for healthful reproduction, only to be replaced with self effacement or worse, is tantamount to "cultural genocide," even if the federal government refuses to acknowledge it as such. Yet where apology is the first important step, the final report also insists on reconciliation as a means of reestablishing trust, defining it as:

.... an ongoing process of establishing and maintaining respectful relationships. A critical part of this process involves repairing damaged trust by making apologies, providing individual and collective reparations, and following through with concrete actions that demonstrate real societal change... It is important that all Canadians understand how traditional First Nations, Inuit, and Métis approaches to resolving conflict, repairing harm, and restoring relationships can inform the reconciliation process. $(2015: 16-17)$

According to the final report, three of the four settlement churches, Anglican, United, and Presbyterian, began to recognize and accept responsibility for their abuses beginning in 1985, when representatives from the highest ranks made the first genuine apologies, and in the 1990s, when all four settlement churches began allocating funds specifically for healing and reconciliation in community.

According to political scientist Matt James, a genuine political apology is recorded officially in writing, names the wrongs in question, accepts responsibility, states regret, promises non-repetition, does not demand forgiveness, is not hypocritical or arbitrary, and undertakes - through measures of publicity, ceremony, and concrete 
reparation - both to engage morally those in whose name the apology is made and to assure the wronged group that the apology is sincere (TRC 2015: 84). Prime Minister Stephen Harper apologized on behalf of the federal government and Canadian people, June 11, 2008, known as the "Day of the Apology." He acknowledged that it was wrong for the government to take the children away from their parents for the purpose of "killing the Indian," finally stating, "we are sorry." While those words needed to be heard, as in the apologies made by the settlement church representatives, and in many cases were accepted, forgiveness in still other cases remains pending. This is because trust was so badly betrayed. The TRC final report states:

The Treaty, constitutional, and human rights violations that occurred in and around the residential school system confirm the dangers that exist for Aboriginal peoples when their right to self-determination is ignored or limited by the state, which purports to act 'in their best interests.' Historically, whenever Aboriginal peoples have been targeted as a specific group that is deemed by government to be in need of protective legislation and policies, the results have been culturally and ethnically destructive. For Aboriginal peoples in Canada, the protection and exercise of their right to self-determination are the strongest antidote for further violation of their rights (2015: 87).

While acknowledgement and apologies are important steps on the road to healing, it is understandable why in the historical context of the residential schools, government representatives and Christians are held at arms length, and self-determination has became an important factor moving forward. The TRC proposes 94 calls to action in the interest of reconciliation and accountability, including number 57 , which calls for educating public servants on the history of Aboriginal peoples, and skills-based training in intercultural competency, conflict resolution, human rights, and anti-racism (2015: 94-5).

As a call to conciliatory action and method of evaluating Wilson's relationship with reserves, Volume 6 of the TRC final report discusses church healing and 
reconciliation projects, and provides a definition of spiritual violence (2015: 110-16).

The four settlement churches that began funding such projects in the 1990s have followed three primary purposes: "healing," including reaching out to Aboriginal people on the streets, in hospitals, and jails, and education about culture and tradition toward reconciliation; "language and culture revitalization," including reconnecting Aboriginal youth to their homelands and cultures; and "education and relationship building," including anti-racist initiatives between Anglican and Catholic Aboriginals. Beyond the settlement churches, the TRC final report calls peoples of all faith communities and those interested in social justice to incorporate these themes. For instance, Anabaptist Church leaders who represent in part the heritage of my own faith, issued statements to the TRC at the Saskatchewan and Alberta National Events in 2014:

We acknowledge that we are all treaty people and that we are meeting on Treaty 6 territory, on land that is part of an historic agreement between First Nations people and newcomers, an agreement involving mutuality and respect... We are humbled to witness this [TRC] event... As we have listened to your stories, we've added our tears to the countless tears that you have shed. We acknowledge that there was, and is, much hurt and much suffering. We have learned much and we have much to learn... We recognize that being part of a dominant culture, our attitudes and perspectives made the Residential School experience possible and that these attitudes and perspectives became entrenched in our relationships and in our culture. We regret our part in the assimilation practice... We regret that, at times, the Christian faith was used, wrongly, as an instrument of power... that some leaders within the Church abused their power... As leaders of Mennonite and Brethren in Christ church communities, we acknowledge that we have work to do in addressing paternalism and racism... We repent of our denominational encounters with Indigenous peoples that at times may have been motivated more by cultural biases than by the unconditional love of Jesus Christ. We repent of our failure to advocate for marginalized Indigenous peoples as our faith would instruct us to... We hope to build relationships with First Nations communities so that we can continue this learning journey and walk this path together. We are followers of Jesus Christ, the great reconciler. We are aware that words without actions are not only ineffective but may also be harmful... We commit ourselves to walk with you, listening and learning together as we journey to a healthier and more just tomorrow. (2015: 393-5) 
With all sincerity, I too am sorry. My hope is that both my collaboration with Rob and this dissertation, count as reconciliatory.

As a final measure of conciliatory action, I should like to evaluate my collaboration with Wilson by the definition of "spiritual violence" provided in the final report. The way in which Residential School teachers and clergy traumatized Aboriginal children was by removing them from their families and villages, to reject the spiritual ways of their ancestors in favour of settler Christianity. As such Aboriginal children were treated as inferior, a stark contrast with the teachings of Jesus. Moreover, federal laws and policies amplified such traumatic experience by banning traditional spiritual practices in home communities for much of the Residential School era. Although no reference is given as to the source, according to the final report, "spiritual violence" occurs when: a person is not permitted to follow her or his preferred spiritual or religious tradition; a different spiritual or religious path or practice is forced on a person; a person's spiritual or religious tradition, beliefs, or practices are demeaned or belittled; or, a person is made to feel shame for practicing his or her traditional or family beliefs (TRC 2015). By this definition, spiritual violence was indeed common throughout the Residential School system. Unequivocally, by the same definition then, spiritual violence did not occur during my collaboration with Rob. Yet arguably, we have failed to reach our potential for establishing sustainable conciliatory relationships with reserve based people.

Indeed, Wilson's tours appear to leave desperate conditions intact, but no less than the Rock bands that performed the same night as we were at Deschambault Lake. In fact to his credit, comparatively, Rob's message was "positive," and materially, he used 
the tour to deliver dozens of bags of used clothes on behalf of his then home base church, New Beginnings. As a group of musicians with little to no previous contact with reserves and few skills to offer, all bands that tour reserves would stand to benefit from the TRC call to action that includes familiarizing ourselves with the history of the residential schools in order to effect positive change. Beyond the TRC, groups like Rob's would benefit from establishing ongoing relationships with reserves in order to prepare to meet reserve specific material needs, yet within the capacity of the group. For instance, Rob's case reveals a complex dynamic that tends to be overlooked in the TRC final report. Like many Aboriginal people in Canada, his mixed roots in a racialized space complicate his musical self. As in his biography discussed above, this led to Rob anchoring his identity variously in violent behaviour and misogyny, as opposed to a legitimate job. The way in which he was rejected by his parents and raised by his aunts and adoptive family in a time prior to the redress movement, explains his early non-exposure to Aboriginal spirituality. And the epiphanal way in which Rob came to Christ contributed to a deep-seated faith and conviction that Jesus' model of redemption is valuable. As such, Rob offers a story of deliverance and redemption that many Canadian Indigenous people relate to and indeed desire themselves. For instance, many in the KMF and EDIFY organizations of Rob's scene, with minoritized identities, share his transformative practice of reclamation and proclamation. Similarly, those inviting Rob to the reserves share an interest in the current and future well being of their young people. Victoria Ballantyne, a Deschambault Lake event organizer, expresses that interest as follows:

AK: What was it about the concert this weekend? VB: You know what surprisingly? The older people - it was very emotional for a lot of us. We maybe just, finally are realizing that hey, this is a way we can reach our own kids; what these guys are doing. 
AK: So do you think that this could transform Deschambault?

VB: Yes, especially the gang activity. [For] kids that have come together to protect each other, hip-hop is what they listen to. And through Fresh I.E. and what I've seen this weekend, I can't wait to tell the kids what I have seen. I volunteer with youth groups too, and we're going to be talking about this for a long time. (Interview: June 2015)

Yet while the interest in social change is shared by Rob and by his audiences on reserves, intersecting on "youth crisis" issues such as alienation, suicide and mental illness, the TRC calls to action could be expanded to consider cultural workers such as Rob. The major difficulty faced by workers like Rob, is in establishing and sustaining meaningful relationships in which interests are mutually beneficial. With self-determination and mutual respect being standard ethical interests, the reconciliation of all Canadians and Aboriginals would stand to benefit for instance, from increased mobility between reserves, rural spaces and urban centers. Simply and optimistically, mobility increases the possibility for reconciliation. ${ }^{139}$ And as music making has the potential for building trust in a non-adversarial, collaborative way, as compared to sports, its practice further encourages reconciliation. To be clear, conversion to Christianity is not my intention here. Although I hold a personal commitment to Christ myself, my interest in Christianity for this project is in the self-transformative power that is modeled in the example of Christ, specifically in terms of hope and redemption; transformation, as in the case of Rob Wilson, that harks back to one's formative years in order to reclaim injustices, through proclamation, for the sake of sustainable, shared interests with others; and hope, which is rarely achieved in materialist approaches. Arguably, musical self-

\footnotetext{
${ }^{139}$ Freedom of mobility is protected under the Canadian Charter of Rights and Freedoms as are individual rights protected under the Canadian Criminal Code.
} 
practice holds remarkable power for such reconciliatory transformation, regardless of faith or non-faith.

The second form that Wilson's musical self-practice takes tends to be focused by a collective interest in mentorship. As a complement to concert touring, mentorship allows Rob to base his operations in one place for long terms, helping to sustain both his studio production, and the peer and fan-based relationships making up his scene. Ideally, mentorship also attends to the problem of sustainability in conciliatory relationships, precluded for instance by concert forms. However, varying interests between Rob and his partners affect the form that his youth work takes. The first example is Tha City, a mentorship program that was briefly hosted at the Youth for Christ (YFC) "youth excellence centre" strategically located in the Winnipeg inner-city core, at Main and Higgins. ${ }^{140}$ While for over ten years YFC ran a skate park just a few blocks from the new centre, apparently without controversy, public funding added accountability and opposition. For instance, in May 2014, YFC drew the ire of critics for failing to achieve the very goals that garnered public support in the first place, including supporting local at risk youth through accessible activities (CBC 2014). Tha City was meant to address that shortcoming: for one, occurring regularly on Wednesday nights; for another, being free;

\footnotetext{
${ }^{140}$ The area is infamous as an underworld of prostitutes, gangs, and impoverished substance abusers, many of whom are ethnic minorities, and migrants from northern reserves. Indeed, construction of the centre was not without controversy, supported by federal and municipal funding, and hastily pushed through under Mayor, Sam Katz, yet opposed by aboriginal and advocacy groups who saw the project as a regressive step back to residential schools. According to Free Press journalist, Dan Lett, the small window of time between the federal government approving funding and city councilors' requirement to arrange endorsement through municipal corporation, Centre Venture, contributed to the perception that Christians were pitted against aboriginal groups (Lett 2010). According to retired University of Winnipeg Political Scientist, Christopher Leo, the emergence of joint-venture projects like YFC's centre is part of a neo-liberal shift since the 1980s on the part of the federal government, to relinquish local "governance" to companies, community or religious organizations (Leo 2010).
} 
for yet another, addressing the sorely missing element of music to a mix of able- and gender normative programs like a dance studio, indoor skate park, climbing wall, weight room and gym. Rob asked me to form and lead the house band at Tha City for the duration of the program's existence at YFC, from October 2014-April 2015. Below, I describe a Wednesday night in the depths of winter, noting a growing camaraderie among the band and regular attendees, though shrinking in number:

Due to a smaller crowd of people and two missing members from my band, tonight was a little more laid back than last week, but I was glad - I didn't get a lot of sleep this week... Similarly, [backup singer] J-M has been kept awake thinking about her son who has been in Child and Family Service care, and Fresh, because of financial pressure. In fact he had to shut his phone off because of surmounting bills. In any case, the schedule for tonight followed an opening game, sermonette, small-group discussion around identity rooted in character traits found in the Bible, another game, and then worship. At the same time that I hit the stage, the kids were dismissed to snack on apples and play games such as pool, mini-hockey, or climb the adjacent climbing walls. I certainly felt less pressure to perform. We played the same set as last week, starting with "Deep Cries Out" reggae style... It seems like people respond to "Deep Cries Out," but then again, I like to scan the crowd for those people most engaged. That guy is usually Fresh, [positioned] beside the soundboard, dancing to the rhythm, waving his hands or singing along. (Dissertation journal: Wednesday, January 28, 2015)

Tha City was typically attended by youth from age ten to nineteen, participating in games and consuming snacks, and addressed in sermonettes by Rob and guests, including professional athletes such as football players from the Winnipeg Blue Bombers. Musical guests came from across North America, often including KMF artists and performing songs with or without Rob. As the above description suggests, an intention of Tha City was to create a space in which members and newcomers could gain solidarity through integration. As per Rob and YFC's shared interest, common themes centered on identity and redemption, such as anti-bullying and anti-suicide, and according to Christian ethics.

Curiously, despite being enthusiastically attended by 65 on opening night, and being free to attend, Tha City rarely attracted more than twenty regulars. Rather than a matter of quality, say, of Rob's musical self-practice, YFC's institutional mediation of 
that practice reveals a number of contradictory interests that led to the unceremonious cancelation of the program on April 22, 2015. Summarily, YFC director John Courtney simply stated, "Fresh didn’t fit with the centre vision," (Interview April 15, 2015) that being "to help young people make good choices and establish a solid foundation for principled living" (yfcwinnipeg.com, consulted February 2017). ${ }^{141}$ Arguably, there is very little difference in Rob and YFC's interest in mentoring youth. However, the nature of their partnership, YFC's public image and relationship to the institutional church, and the background of attendees influenced Tha City's inability to grow and subsequent cancellation. For instance, YFC's mentorship approach is geared to adolescent suburban youth, as evidenced in the middle class Anglo-Saxon protestant makeup of those who frequented the skate park, climbing wall and dance studio, as with the volunteers whose relationship with those youth are characterized by non-invasiveness. Normally, while new volunteers sign forms in which they agree to adhere to Christian morals, including abstaining from public alcohol consumption, Christianity is only discussed if attendees initiate the conversation. As such, volunteers can be taken as disinterested, the attraction to the center being in the programming. In contrast, Rob's overt focus on identity related themes of redemption and perseverance in the face of adversity, ironically clashed with YFC's program. Given the background that generally characterizes Tha City's core area attendees, including racialized violence, addictions, and drug and sexual abuse, Rob's approach emphasizes techniques that fall under the category of sudden, as opposed to gradual, self-transformation, which stem from his own biographical experience and

\footnotetext{
${ }^{141}$ Rob was so disappointed that he nearly canceled the final meeting. He felt betrayed, that he wasn't given a fair shot. Yet, with encouragement, he delivered his final sermonette for the sake of the kids, in an informal gathering - no stage or lights, just an acoustic guitar - where he implored everyone to "never give up, even when facing a wall.” (Dissertation journal notes, April 22, 2015)
} 
Christian hip-hop "politics of conversion" discussed in the previous chapter. Again, when commitments to Christ occurred, it was by open invitation.

Regardless of their respective approaches to mentoring youth, Tha City was doomed to redundancy in part because of Rob's limited term of less than seven months, and that, during the winter months when it is especially hard to attract walk in traffic. In comparison, his early career work at inner city youth missions occurred where institutional relationships were long established both in terms of location and programming. Moreover, Rob's musical performances at Tha City were supplanted by his organizing and delivering sermonettes and informal games following a format much like a church, yet scheduled during evenings and mid-week. As such, Tha City was inclusive for youth, in this case older children and young adolescents, but not for young adults, parents or guardians. Relatedly, overtly Christian themes limited interested parties to the already faithful narrowed further by the overarching presence of Rob's personality and his reputation as an award-winning Christian hip-hop artist. As such, YFC's partnership with Rob failed to harness the potential of his greatest strength, his practice of hip-hop. As discussed above, hip-hop is best conceived as a scene in which participants are empowered in and through their musical self-practice of music making, the means by which significance is allowed to emerge as a "technology of articulation." While Rob was provided separate studio space and meeting space for Tha City, there was limited overlap between either. Importantly, it is imperative that such interactions are given enough time for meaningfulness to sediment in order to establish its significance, and turn such spaces into places (Connell and Gibson 2003: 19-44). This is where their collective interests diverged: Rob's interest in sudden self-transformation wrapped up in 
the "politics of conversion" was cut short by YFC's narrower concept of gradual transformation.

Despite his short tenure at YFC, Wilson found support elsewhere; in March 2015, he was invited to base his studio and EDIFY program in the basement of New Beginnings Pentecostal Church in St. Vital. The transition was eased by the fact that many of his volunteers from Tha City were already attending the church, including Refuge and Bernadine, and the church board and members agreed to host the Collide release party. As at YFC, the church pastors' interests in hosting Fresh include, "staying current with the youth," or more accurately, offering programs that kept both youth and their parents "happy" (Interview May 1, 2015). Nonetheless, by April 11, 2016, the first cohort of students had completed EDIFY training. In an informational event, students showcased their acquisition of song writing and production skills. Following individual song performances, in the ensuing Q\&A, students told of the hardest lessons learned, technical skills such as "mixing," whereby students such as Phoenix learned to listen to sounds critically. Most students described song writing as their most challenging yet rewarding musical self-practice. Like Wilson, many of the students derive from working class and minority backgrounds characterized by struggle. Relatedly, students were asked, "Does the program help you to encourage others in your school as opposed to bullying?" To which a student responded, "Definitely. It has also allowed us to heal from our own personal problems so that we can help others." When asked, "In what way has the program helped your personal lives?" respondents said that their confidence went up, evident in their interpersonal communication. While onstage with his students, taking questions, Fresh jumped in to relay the importance of "stage presence," to "engage the 
audience directly when you do your songs... convince them of your story, let them feel your story when they look in your eyes" (Field notes April 11, 2016). In terms of ethics, Fresh maintains that he feels called to Canada, to encourage men and women to be mothers and fathers that support each other, and where men protect their women. In fact he opines that women are going missing because men have failed to provide protection. Finally, Rob explains his interest in mentorship and what it looks like on an everyday level:

RW: And that's what mentorship is, men or women touring each other's lives... No matter how wrong or how right you're doing, I'm going to walk with you for the rest of your life, that's what it's about. It's not about, if you're really good, you can be in my program. I don't want to program peoples' minds to be a certain way. I want them to discover something that's already in them - it's called, 'greatness.' I want to help them discover what's inside of them because I never had anyone help me discover what's inside of me until God and some great people came into my life sharing the truth, and then greatness came out. (EDIFY info night, April 11, 2016).

\section{7 - Conclusion: The precariousness of musical self-transformation}

In this chapter, I have outlined the practices and processes making up Rob "Fresh I.E." Wilson's musical self-transformations, linking those transformations to topics discussed in previous chapters, for instance, theorizing musical-self-transformation and the methods of their tracing, their history in African-American religious musical practice, and the institutional organization of the Christian music industry around Christian hip-hop. It was found that in the formative years of his biography, Rob's musical self was musically mediated in ways that amounted to significant experiences for his biography, specifically, through the sounds of Prince's “Free" and Michael Jackson's Thriller. In the former, "Free" provided a "technology of articulation" that afforded Rob the means of problematizing and coming to terms with his complex subjectivity, specifically, the sense of difference, rejection, and abuse that stemmed from his parents' own inculcation 
through the "trauma trails" of post-colonialism. Comparable to the block parties of the Bronx, Rob's formative conditions in Winnipeg's North End also afforded him with the space of possibility to exercise his complex subjectivity through his body in dance. In the local conditions of the public housing in which he grew up, Rob developed a feel for the game relative to his neighbours not only overcoming his self-doubts but also anticipating the ways in which he could use performance as a technique of musical selftransformation. The practice of such techniques and strategies continued into his educational years, conditioned by Winnipeg's first hip-hop scene. Here, endorsement by members of the established scene and technological mediation afforded by the emergent DJs in the house parties and clubs making up that scene, Rob was afforded the space of possibility to musically self-transform from b-boy to MC "Freshie." If not for the successful use of such strategies of endorsement and tactics of posturing, Rob might not have secured his education in hip-hop, or his early ethic of self-transformation that played into his transition from dancer to rapper. Still, despite helping to establish the local and national hip-hop scene, to Rob, that scene would not reciprocate due to its precarity; the symbolic currency of masculine prowess and fresh styles was found to better translate into pimping, drugs and alcohol, that is, until the precarity of the gangsta lifestyle proved to be unsustainable.

Rob secured his sudden musical self-transformation after 1998 through his conversion to Christianity and the musical self-practice of what was yet to be called Christian hip-hop. Such transformation was traced across various musical mediations, including with the biography of his musical self, the local Christian music scene, wider sociological imaginaries, and the institutional church and Christian music industry. Key 
relationships or "collaborators" in his transformation include his wife, local musicians, and international industry representatives, which altogether allowed him to reclaim aspects of his past and self-proclaim his redemption through his objectivation of "Fresh I.E." However, the politics of his conversion are not so cut-and-dried. Despite influencing the transnational recognition of musical self-practices called Christian hiphop, the institutional objectification and subsequent normalization of its sounds and practice reflected back on Rob's musical self, creating in this case, an unbearable selfdissonance that precipitated his suicidal ideation.

Finally, in light of his contemplation of suicide, the ethnography of Rob's present musical self-practice found a variety of techniques and strategies making up his gradual transformation. In terms of the four planes of musical mediation, the immediate experience of Rob's present music-making practices, from studio production to mentorship, mediates self-doubt rooted in his biography. Techniques of reclaiming his past and projecting ideals were found throughout. Restructuring his musical self-practice away from the transnational Christian music industry to a local indie scene affords Rob continued gradual self-transformation. However, in the mediation of his present practice with the institutional church and First Nations reserves, various struggles and contradictions emerge. Namely, the church's apparent reluctance to accept Christian hiphop as a legitimate form of worship, as discussed in the previous chapter, along with Rob and his audiences' shared interest in sudden transformative techniques, results in Rob's constant practice of self-legitimation. Such practices, for instance include his referencing his Grammy-nominations in order to secure a working relationship with local churches and attract youth to his mentorship program. At the same time, the collective interest in 
musical self-transformative practices that he shares with the "crisis of youth" affecting First Nations and Inuit communities, combined with the precariousness of his indie practice appears to affect Rob's live music-making practices. With consideration of the historical context of such collective musical self-transformation, including my own collaboration in that practice, I recommend more collaborative music making, indeed, albeit with greater awareness training toward reconciliation and increased mobility between all Canadian peoples. In the next and final chapter, I discuss these findings and recommendations further. 
252 


\section{Chapter Six}

\section{Conclusion: De-marginalizing the Musical Self}

\section{1 - Dissertation findings}

Having determined, at the start, that this dissertation stems from my interests both in the musically "lived problems" of everyday life, including those issues related to my own successes and limitations as a semi-professional musician during the early $2000 \mathrm{~s}$, and the (limited) ways in which "musical uses" are conceived in the music sociology literature, it then became relevant to ask how music contributes to self-transformation in the particular case of a practicing music maker. As a formerly semi-professional musician, I am interested in the ways in which music is performed and discursively constituted and how it contributes to or detracts from one's wellbeing, hence my consideration of studies that foreground musical performance or music making. Yet for various reasons, it was found that much of the latest music sociology and its literature tend to focus singularly on either music's consumption or production, and as such, is interpretive, heavily weighted toward active self-identity construction (Hennion 2012; De Nora 2000). Such studies frame music-making activities as boundlessly positive or good and the self as in control of its own musical mediation. Moreover, the subjects of such research seemed to be invariably white, of a narrow age range, and middle class in background. Having experienced the regular inconsistencies of music making during my upbringing and across my own career, it became apparent that more was at play than the simple difference between production and consumption. And having grown up in the prairie city of Winnipeg, made infamous over the course of this dissertation for being the "racist capital of Canada" (MacDonald 
2015), it became apparent that the musical mediation of social inequalities such as racism ought to be considered here.

Having taken the case of Rob "Fresh I.E." Wilson, two-time Grammy nominated Christian hip-hop artist, born in 1973 to his Trinidadian mother while not knowing his father of First Nations heritage, raised by his adoptive aunts in the segregated and racialized space of Winnipeg's North End, I began pursuing answers to the question, "How does music contribute to self-transformation?" It seemed obvious that music positively contributed to Rob's self-transformation from former drug dealer and pimp to mentor for inner-city young people, by unrestrainedly opening doors of opportunity or spaces of possibility. However, in the course of 26 months of fieldwork with Rob, from April 2014 to May 2016, I was struck by his sudden confession that he struggled with suicidal ideation in 2010. With such information, I reflexively reconsidered my theorymethod of music and self-transformation. This reconsideration led to four main findings.

The first of my main findings suggests that music does not simply contribute to self-transformation rather because it is self-transformation. In the first chapter of this dissertation, I reviewed the literature on music and self-transformation in order to understand and explain its mediation, process, and practice in Rob's case. Importantly, the question of "music's" contribution to "self-transformation" misleadingly suggests that music is some "thing" separate from the self. And yet, it was precisely "music's" objectification as such, both in terms of the music industry's categorization of sounds for capitalist purposes and in terms of Rob's self-objectivation as "Fresh I.E.," including all that he invested in his public persona apart from his real felt needs, that led to Rob's selfdoubt and subsequent suicidal thoughts. 
As Shepherd and Devine trace (2015: 1-22), the idea that music is an object with a life of its own, meaningful in and of itself, is rooted in disciplinary perspectives such as musicology and industrialization-related processes of recording technology and commercial distribution. However, while the shortcomings of the musicological perspective may be obvious now, it was found that the social constructionist critique of music's objectification is just as unsatisfactory, tending to explain away music's "meaning" or significance as arbitrarily assigned, for instance by the network of members making up an "art world" (Becker 1982). ${ }^{142}$ Even more recent sociologies of music that attribute music's significance to the "collective representation" of its performers (McCormick 2006: 121-44), despite valuably considering the realm of music making, are unable to explain both how "the social" gets into music, becoming significant to the self across the life cycle, and how its performance is affected by its institutional mediation, including historically.

In reconsidering the relations of music and the self, I began with Shepherd and Wicke's Music and Cultural Theory (1997), in which the authors compare music to language in that its sounds are variably significant to the self, yet distinctly nondenotative in its experience. They theorize a "semiological moment" in which music becomes inextricably one with the self(1997: 159-68). Importantly, this moment marks a distinct level of primary signification, where music's sounds become intertwined with the self and provide a "technology of articulation" (Shepherd and Wicke 1997: 117-24; also Shepherd 2016: 9). It is only at the fleeting moment of its binding with the self that the organized sounds of music as "music" distinguish the level of secondary signification -

\footnotetext{
${ }^{142}$ Following Peterson's more nuanced approach, this is also called the production of culture perspective (with Anand 2004).
} 
when those sounds enter the symbolic realm. Thus, music's power to leverage the self valuably allows for us to theorize the ways in which music became significant for Rob Wilson. However, it also became necessary to expand consideration beyond the theoretical sonic constitution of the self to the ways in which musical self-transformation occurs as a negotiation of that negotiated constitution between the "specificity of music as a cultural form" and the "processes through which musical experiences or 'music' arises" (Shepherd 2016: 11). In other words, I needed to link the semiological moment to the empirical conditions of music's experience.

"Mediation" is a key concept for understanding and explaining musical selftransformation. It was found that De Nora, a leading figure in music sociology, added valuable knowledge in her field methods-based consideration of the "everyday life" realm of music's practice $(1999 ; 2000)$, including her conceptualization of the "musical event" in which music becomes significant to its participants through its mediation of those participants and the context of their musical experience (2003: 49). Not that participants are taken at their word, De Nora couples her method with music's theorization as sound mediating the emotions of the self as a resource "affording" self-ordering behaviours such as the "entrainment" of bodily movement toward dance, for instance. She states:

Music, as it moves through time and changes over time, provides a device with which subject-bodies orient to and configure themselves within the environments within which music plays. In this respect, music is a powerful means for reconfiguring ambience, and for doing so in ways that have the power to shift subjective orientation in real time. And to the extent that this is so, music may serve as a device of social ordering and social control. (De Nora 2003: 138-9)

However, while I do not doubt music's potential to "shift subjective orientation in real time," De Nora hastily jumps to the conclusion that music is a "technology of the self," gesturing to Foucault's term here to suggest that music is freely used by the self for self 
purposes. Problematically, her singular focus on its consumption tends to underestimate music's power across the life cycle of the self, most importantly, to reproduce social inequalities having to do with difference, racism, and social class. Further, despite considering music's technological mediation as affording possibilities, she also underestimates the role of institutions in mediating musical self-transformation. While establishing that the self is musically constituted through its mediation with both the sounds of music during the "semiological moment" and the context of a "musical event" in which those sounds are experienced, it follows that a change in music's mediation with the self constitutes self-transformation, even to the slightest degree. And yet critically for understanding and explaining Rob's case, it was necessary to expand our consideration beyond immediate experience and context.

Music's mediation of the self throughout life and with social and economic institutions as a principle aspect of self-transformation demands our conceptualization of the modern "musical self." This is the second of the main findings here. Born's "four planes of musical sociality" (2012: 202-11) allow us to trace the specificity of music's significance - for the self - according to four mediations that are irreducible to each other. On the first plane, the musical self mediates the immediate experience of sound (the semiological moment). Second, the musical self mediates a local context or scene in which "affective alliances" emerge. Third, it mediates a wider "imagined community," in Rob's case having to do with African-American musical practices such as hip-hop and its history. Fourth the musical self is mediated by the organization of music's institutional means of production and distribution. Thus in Wilson's case, changes in his musical mediation with respect to each plane coincided with his musical self-transformation. 
To distinguish significant transformations throughout the life of his musical self I drew on the three spatial-temporal durations that Bourdieu identifies in his "sketch for a self-analysis" having to do with formative, educational and professional years (2004: 94114; 2008). For instance, I considered the significant moments in Rob's formative and educational years in which his musical self was conditioned by a "space of possibilities" and social inequalities making up a field of positions, resulting in a durable or selfsustaining set of dispositions making up his habitus (Bourdieu 1993: 64). Using biographical methods of interviews and focus groups, I found that two significant musical experiences occurred early on, co-mediating his experiences of sexual and physical abuse, and racialized difference as a child. Prince's "Free" afforded a sense that he could be liberated from such injustice while Michael Jackson's Thriller afforded Rob with a double sense of power over his body through dance and upon his conditions through the apparent influence of his dance on his audience in the projects. This self-confidence and musical skillset led to his participation in Winnipeg's first hip-hop house party scene in the late-1980s where he learned to trade in the "symbolic capital" of masculine posturing. Using primary historical methods I confirmed the existence of the scene and its institutional mediation with the first major label act to perform in the city in 1990. While Rob's musical antics helped to establish the city's club scene, they also set him on an exponentially precarious trajectory involving gangs, drugs, and pimping.

Wilson's most significant musical self-transformations have to do with his professional practice in which he is mediated by the institutional organization of the Christian music industry and the church. In the first "sudden" transformation following his conversion to Christianity, Rob employed a set of techniques that "reclaim," 
"project," and "proclaim" aspects of his self. These techniques are the third main finding of this dissertation. For instance, it was found that Rob uses his lyrics to redeem his sense of injustice rooted in his past, in this case, according to the moral system of Christianity and the example of Jesus' forgiveness of sins. The sonic transcription of those injustices count as both a reclamation and as a projection in that they recall the various and varying "semiological moments" found in the formative and educational years that mediate his experiences of injustice, while at the same time projecting them in new conditions. As a final step, the translation of injustices into text, in this case "rap," counts as a proclamation. Rob's many proclamations, for instance, involve a denouncing of his former behaviours having to do with drugs and pimping, violence and womanizing. Altogether, Rob uses these techniques of musical self-transformation in order to secure his transformation. However, his mediation with the local Christian music scene and transnational contemporary Christian music industry, especially as it led to his Grammy nominations, worked to objectivate his musical self-practice according to expectations wrapped up in the category "Christian hip-hop." Ostensibly, his institutional musical mediation was positive or good, affording new avenues of influence over his conditions. However, the objectification of "Fresh I.E." the performer, in an otherwise unstable capitalist free market, proved to be a dissonant, therefore unsustainable, experience. As a strategy of self-transformation, Rob used suicide to break free of his institutionalized musical-self.

The fourth main finding made in this dissertation has to do with the ethic of musical-self-transformation. Rob's transformations are explainable not only according to his successful employment of transformative techniques, nor to broad matters of morality 
stemming from his conversion, but to a collection of historical processes and practices making up an ethos or strategy of diagnosis, prognosis, and motivation. It was found that the ethic of musical self-transformation itself is founded in the historical processes of the Axial Age (Shulman and Stroumsa 2002: 3-16) that gave rise to the "care of the self" practices of the Greco-Roman world combined with the early Christian revelation of the soul as an unchangeable aspect of the self (Foucault 1986: 37-68). From these processes and practices, "types of self-transformation" (Silva 2010) emerged, including the distinction between "sudden" and "gradual" types. Drawing on Koopman's reading of Foucault's genealogical method, for instance as problematization, and his concern for the ethic of self-care as a "practice of freedom," for instance as response, I argued that selftransformation is itself a modern ethic. However, Rob's case and the conditions of the African-American experience demand further consideration.

As it relates to Rob's case, I combined my understanding and explanation of the ethic of musical self-transformation with Miller's concept of "complex subjectivity" (2013: 97-122). Complex subjectivity allows for consideration of the conditions of subjectification as wrapped up as much with social inequalities having to do with race, difference, and rejection, as it is with affording musical "self-care." Miler's concept is instructive in allowing us to move beyond phenomenological perspectives that base the self in a self-contained state of sui generis, for instance, between "terror and fixity." Instead, the precariousness of terror and fixity are considered varying characteristics of the musical self and can be related to biographically rooted subjectivities, such as Rob's sense of rejection, and commercially related processes, such as his self-doubt. 
To begin chapter three, linking Rob to the history of African-American religious musical practice, it was found that the modern musical self-transformational ethic first emerged as a distinct mode aboard the slave ships of the middle passage to the New World. Here, music lost part of its anthropological function of reproducing tribal culture; instead musical self-practice was objectivated for various strategies having to do with self-sustenance and commercial purposes. This event forms the basis for our critical consideration of Rob's mediation with the institutional church and the music industry. My critical explanation of the techniques and strategies making up the ethic of musical self-transformation draws on Bourdieu and Miller. In his concept of habitusfield, Bourdieu valuably overcomes the subject-object dichotomy, allowing for our understanding and explanation of the dispositions, techniques and strategies making up the ethic of musical self-transformation as having to do with the emergence of the modern musical self as a viable process and practice for collective interests having to do with self-care and self-sustenance, and anti-commercialism and anti-materialism (Bourdieu 1993: 64). Miller's "complex subjectivity" and Bourdieu's habitus-field valuably allow for a critical explanation of musical self-transformation as strategic, having to do with the conditions of possibility in which Rob was subjectivated during his formative and educational years, his prognosis or problematization of those conditions and his present self diagnosis or objectivation as it also relates to the commercial realm of his professional practice.

Summarily, the four main findings in this dissertation supported by Rob "Fresh I.E." Wilson's case are, first, that music is self-transformation by virtue of its multiple and multiply varying mediations with the self. Second, that music's inextricable binding 
with the complex subjectivity of the self across the life cycle and with the potential for mediating the process and practice of self-transformation necessitates the concept of the "musical self." Third, that musical self-transformation can be initiated and practiced by the self as a set of techniques of reclamation, projection and proclamation. And fourth, the strategic practice of musical self-transformation counts as an ethic.

\section{2 - Recommendations for future research}

Rob Wilson's case raises several questions from which we can derive recommendations for further research. Certainly, music has be significant for Rob in terms of processing social inequalities in his complex subjectivity but is this the case for other music makers like him, and in what ways? While plenty of hagiographic biographies exist, there is little critical research of the "average" musical self, including consideration of how that self is conditioned during formative and educational years, how that self uses music across the life cycle as an ethic of self-transformation. Relatedly, how has musical selftransformation panned out for other music makers across the life cycle? There was an instance during my field work with Rob in which his peer, Deval, had proposed collaborating with other hip-hop artists that had had distinguished popular careers but who were now suffering from the sort of separation anxiety that precipitated Rob's suicidal ideation. Music and aging is a growing area of study (Shepherd and Devine 2015: 14-15), however, such research stands to benefit from the consideration of a variety of music making practices that mediate the music industry, including from "indie" to label-supported professional practice. Such research would move us from the objectification of music makers as "aging stars," for instance, to their consideration as implicated through various and varying musical mediations. This is not to diminish their 
accomplishments either, but to address the way in which music making can be objectified, thus devalued, in Western culture through processes of commodification, leading us to discard aging artists as irrelevant.

Relatedly, as I discuss in the appendix of chapter five, there seems to be vitality to music making in situ having to do with the "collective interest" of performers and participants. Regardless of the degree to which the music maker mediates the music and culture industry, the four findings of this dissertation remind that musical selftransformation is potentially a practice of freedom. A recommendation for further study, then, is for the evaluative research of music making. In this dissertation I encountered points of conflict between Wilson's musical practice and the reluctance of the church to accept those practices despite his same faith, and between his touring practice and reserves that stand to benefit from music making but are denied that potential because of brevity. Although I offer a brief evaluation, in chapter five, of my own musical making collaboration with Rob and the Christians at Deschambault Lake according to the terms of reconciliation laid out in the TRC Final Report (2015), such consideration ought to be expanded to include other collaborative performances with Canada's Indigenous peoples.

Further, Rob's ethic of musical self-transformation and its practice is one of few found that is shared with minority youth and with such potential for positive change. ${ }^{143}$ That he has committed to redeeming the injustices rooted in his complex subjectivity through mentoring youth with similar experiences is commendable in the senses that, for

\footnotetext{
${ }^{143}$ Mark and Madura report urban music education as a perennial area of concern for music education in the U.S. because of high rates of minorities and low rates of funding (2014:167). Unfortunately, Canadian governments have been divesting in music education for quite some time. According to a recent report released by the non-profit agency, People for Education, for instance, just $41 \%$ of Ontario elementary students have a "specialist music teacher," down from $49 \%$ ten years ago, and close to $60 \%$ twenty years ago (CBC 2017).
} 
one, it is rare in its practice (see note 143), while for another, he offers his mentorship without standing to gain as much as if he were, for instance, to return to a professional performance practice such as touring. With rising concerns about the "crisis of youth," including increasing rates of suicide, opioid abuse, anxiety, and depression, musical mentorship is an area that offers to deepen our understanding of music's potential for transformative change across and between birth cohorts.

Overall, Rob's case of musical self-transformation, sudden and gradual, begs the question, why music and why now? There are three areas that could benefit from further research that would broaden and deepen our understanding and explanation of musical self-transformation. First, in terms of historical research, it seems as though I barely scratched the surface in my analysis of the emergence of the modern musical self in the complex subjectivity of modern slavery. While the musical self has been increasingly mediated since that time in Western countries, what of other cultures and regions? How have modern processes having to do with industrialization, secularization, and the nationstate affected a variety of complex musical subjectivities? Much historical work is to be done here. Second, disciplinarily, aside from a few outliers sociologists have generally been reluctant to consider music, and to do so with some conventionalism (Shepherd and Devine 2015: 1-4). I am not implying some sort of orthodoxy, however, consistent disciplinary support in the way of academic conferences and departmental bases, and increased communications in the way of journal publications, would help to provide moral support and de-marginalizing exposure for music sociologists. Finally, an increase in musical scholarship has undoubtedly occurred in the last twenty years (Shepherd and Devine 2015: 14). To understand and explain this shift, it would be valuable to study 
these scholars themselves, whether in terms of interviews and focus groups, or in terms of reflexive "auto"-biographies and ethnographies.

\section{3 - Why the musical self matters: Personal opinion, accepted limitations, and}

an answer

Rob's “sudden" transformation following his transnational music industry recognition was not all good. The industry's objectification of his "music" according to the category “Christian hip-hop,” despite de-marginalizing his musical practice and its condition through its exposure to a broad potential support base of fans, creates a contradictory and untenable state. At once, Rob was contracted to produce and perform on a recurring basis, while at the same time being expected to reproduce his musical "genius," objectified for his apparent ability to relate to a broad audience. As a result, he felt an implicit demand to stay relevant and explicit demand to hit the road. These demands are rooted in the music industry's capitalist supply-demand logic and are exerted on contracted performers like Rob irrespective of their biography and present circumstances. However, as the "musical self" reveals, such music making cannot be separated from the self without consternation. Arguably, Rob was suffering from "alienation"144 from his own musical self through the commodification of "Fresh I.E.," and equally, his separation from those that mattered most to him, namely his wife Sheila North, suggesting that his professional music making contributed to his sense of "anomie"145 or loneliness.

Comparatively, Rob’s “gradual” self-transformation since contemplating suicide in 2010 is the result of his strategically altering his multiple musical mediations with his

\footnotetext{
${ }^{144}$ It is assumed that Marx' term is well known, having to do with the mode of mass production and the separation anxiety that commodification affects upon its labourers.

${ }^{145}$ It is also assumed that Durkheim's term is well known, having to do with one's integration with others and the sense of solidarity or belonging.
} 
self, scene, broad imagined community with which he considers himself a member, and the institutional church and Christian music industry. And yet, this transformation has been no less contradictory. Part and parcel of his "sinner-to-saint" moral trajectory, Rob is reluctant to perform in the potentially lucrative yet secular realm of the popular music industry. This reluctance influences his decision to variously collaborate with the institutional church, tour, and run his youth mentorship program. However, his "street" style precludes him from full participation in the church which itself is hesitant to incorporate hip-hop into worship. In terms of touring, Rob's musical self-practice offers a transformative model with potential to bring positive change to reserves suffering from suicide, hopelessness, and loneliness due to relative isolation. However, the temporary structure of his tours limits the extent to which change can be realized. Nonetheless, Rob's youth mentorship program, EDIFY, offers the greatest potential for musical selftransformation and collective change.

It is my suggestion that musical self-transformation achieves its full potential not simply in performance, that being either production or consumption, but when it is mediated by a collective interest and the presence of an audience of at least one. The most significant relationship in Rob's musical self-practice, arguably, is his wife Sheila North-Wilson. Having believed in him early on, North-Wilson's interest encouraged Rob to take the first step of writing music that de-marginalized Christian hip-hop and continues to guard him against precariousness. She was also Rob's point person when he contemplated suicide. Their relationship represents an under studied area of musical selfpractice having to do not only with gender but also with their various shared interests, including their commitment to each other. By extension, Rob's musical mentorship of 
young people encourages a transformative ethic that youth can take with them throughout life. Something about music's shared experience affords a powerful guard against existential and market-related forces by creating a space of possibility in which one's deepest held beliefs and values, including hurts and fears, are transformed. Such freedom is hard to buy, try as we may. According to Nielson's latest tracking, "Music consumption is at an all-time high," propped up by its ease of accessibility and low cost:

Overall volume is up 3\% over 2016 [ 723.7 million songs downloaded; 442.4 million digital albums and track equivalent albums, and on-demand streaming equivalent albums], fuelled by a $76 \%$ increase in on-demand audio streams, enough to offset declines in sales and return a positive year for the business. Nearly 650 solo artists, groups and collaborators appeared on the Top 200 Song Consumption chart in 2016, representing over 1,200 different songs.... (Nielson 2017)

While it is perhaps simplistic to criticize such consumption as an objectification of "music," the more poignant aspect, with musical self-transformation and youth mentorship in mind, is that it represents a cohort defining mediation or collective musical-self transformation. Considering its mediation of the complex subjectivities of 650 solo artists, groups and collaborators, and millions of listeners, last year alone, there is tremendous potential here to introduce musical self-transformation techniques to the next birth cohort. ${ }^{146}$ True, one of the unique aspects of musical self-transformation is in distinguishing the one's self from one's progeny, for instance, affording strategic potential. However, in focusing on transformative techniques, the unique potential of the model of Rob's musical mentorship is in mediating a variety of differences, including birth cohort differences and fear. Young people facing existential fears at a fragile time in their lives would instead be encouraged to harness music's transformative power for

\footnotetext{
${ }^{146}$ I am using "birth cohort" as opposed to "generations" as it is defined less in terms of collective values and beliefs and more, generally, in terms of a range of years in which one is born.
} 
themselves. Although this dissertation and my opinion here is limited by the methodological individualism of Wilson's case, against all odds, Rob's case has proven resilient throughout his life, and offers a model worth pondering, indeed, researching further.

Finally, music certainly contributes to self-transformation as self-transformation, but the potential for self-harm in the way of precariousness or fear threatens to outweigh the potential for freedom through the objectification of its practice. In other words, the least objectifiable musical self-practice there is, is the one that is given away. 


\section{Appendix: Interview Guide}

Name or Pseudonym:

Age:

Performer or audience member:

Sex:

Nationality:

Faith:

\section{Occupation:}

\section{Interview Guide}

1. How did you become a hip-hop performer/fan? How long?

2. What are your top three favourite artists or songs, and what is it that makes them favourites? How has this changed recently, if at all?

3. Do you think that music like hip-hop can transform society, including yourself? How? Is this something you imagine while performing/listening? How?

4. What do you think about Fresh IE's hip-hop? Compared to others?

5. Describe a concert, perhaps a favourite concert with Fresh. How did you prepare for the concert?

Describe a highlight of the concert. What do you think it is about that moment that stands out to you?

How did you feel after the concert?

6. Do you think that Fresh's music has affected you?

7. Do you think that Fresh's music is affecting the community? Whose community? How?

8. Do you listen to Fresh's music regularly? When and where? What sort of things are you doing while listening to his music? What sort of things do you think about while listening to Fresh's music?

9. How do you get ready to listen to hip-hop? Has this changed recently?

10. Has hip-hop changed since you've become a performer/fan? Do you see hip-hop changing in the future? How? 


\section{Bibliography}

All scriptural references: 1984. The Holy Bible: New International Version. Grand Rapids, MI: Zondervan.

Adamana, Janet. 2010. "7 Things to Do." in Winnipeg Free Press.

Adorno, Theodor W. 2001. The Culture Industry: Selected Essays on Mass Culture. New York: Routledge.

. Adorno, Theodor, Walter Benjamin, Ernst Bloch, Bertolt Brecht, and Georg Lukács. 2007. Aesthetics and Politics. New York: Verso

Alexander, Jeffrey. 2004. Cultural Trauma and Collective Identity. Berkeley: University of California Press.

Anderson, Benedict. 2006. Imagined Communities: Reflections on the Origin and Spread of Nationalism. New York: Verso.

Baade, Christina. 2014, January 14. "What Are We Fighting For: Jazz, Race and Democracy at The Wartime BBC." Paper presented at the Music department conference, Carleton University.

Baraka, Amiri [Leroi Jones]. 1963. Blues People: Negro Music in White America. New York: William Morrow.

Barnes, Sandra L. 2008. "Religion and Rap Music: An Analysis of Black Church Usage." Review of Religious Research 49(3):319-38.

Becker, Howard S. 2008 [1982]. Art Worlds. Berkeley: University of California Press.

Benjamin, Walter. 1968. "The work of art in the age of mechanical reproduction." Pp. 217-52. In Illuminations: Essays and reflections

Berger, Peter and Anton Zijderveld. 2010. In Praise of Doubt: How to Have Convictions without Becoming a Fanatic. New York: Harper One.

Bibby, Reginald W. 2010. "Alberta's Emerging Millenials: A National Survey Reading of Alberta Teens and Other Teens." Lethbridge, AB: Project Canada. Retrieved.

Bohlman, Philip V. 1999. "Ontologies of Music." Pp. 17-34 in Rethinking Music, edited by N. Cook and M. Everist. Oxford: Oxford University Press.

- 2012. "Music and Culture: Historiographies of Disjuncture, Ethnographies of Displacement." Pp. 28-39 in The Cultural Study of Music: A Critical Introduction, edited by M. Clayton, T. Herbert and R. Middleton. New York: Routledge.

Born, Georgina. 1993. "Against negation, for a politics of cultural production: Adorno, aesthetics, the social." Screen, 34(3): 223-42 1995. Rationalizing Culture: IRCAM, Boulez, and the Institutionalization of the Musical Avant-Garde. Berkeley: University of California Press . 2000. "Introduction: On Difference, Representation, and Appropriation in Music." in Western Music and Its Others: Difference, Representation, and Appropriation in Music, edited by G. a. D. H. Born. Berkeley, CA: University of California Press. . 2005. "On Musical Mediation: Ontology, Technology and Creativity", Twentieth Century Music 2(1): 1-30.

. 2011. "Music and the Materialization of Identities." Journal of Material Culture. 16(4):376-88. . 2012. "Music and the Social." Pp. 202-11 in The Cultural Study of Music, edited by R. Middleton, T. Herbert and M. Clayton. New York: Routledge.

Bourdieu, Pierre. 1977. Outline of a Theory of Practice. New York: Cambridge University Press. 
1987. "Legitimation and Structured Interests in Weber's Sociology of Religion." Pp. 119-36 in Max Weber: Rationality and Modernity, edited by S. Whimster and S. Lash. London: Allen \& Unwin.

1990. In Other Words: Essays Towards a Reflexive Sociology. Stanford, CA: Stanford University Press.

- 1991. Language \& Symbolic Power. Cambridge, MA: Harvard University Press.

Bourdieu, Pierre and Loïc Wacquant. 1992. An Invitation to Reflexive Sociology. Malden, MA: Polity.

Bourdieu, Pierre. 1993. "The Field of Cultural Production, Or: The Economic World Reversed." Pp. 29-73 in The Field of Cultural Production, edited by R. Johnson. New York: Columbia University Press.

- 1998. "The New Capital." in Practical Reason. Stanford: Stanford University Press.

- 2004. Science of Science and Reflexivity. Chicago: University of Chicago Press.

- 2008. Sketch for a Self-Analysis. Chicago: The University of Chicago Press.

- 2010 [1984]. Distinction: A Social Critique of the Judgement of Taste. New York: Routledge.

Brown, Timothy A. 2004 [1999]. "Does Religion Promote--or Subvert--Civil Society?" Pp. 1548 in Talking Points on Global Issues: A Reader, edited by R. H. Robbins. Toronto: Pearson.

Brubaker, Rogers and Frederick Cooper. 2000. "Beyond "Identity"." Theory and Society 29(1):147.

Burke, Peter. 1978. Popular Culture in Early Modern Europe. London: Temple Smith.

Canada, Health. 2016. National Aboriginal Youth Suicide Prevention Strategy (Naysps)Congress, (http://www.hc-sc.gc.ca/fniah-spnia/pubs/promotion/_suicide/strat-prev-youth-jeuneseng.php\#fnb3).

CBC. 2015. "Northern Sask. Man, 18, Found Frozen to Death in School Parking Lot." in $C B C$. cbc.ca.

- 2017. "Some Ontario schools go silent as music programs are defunded." In $C B C$. cbc.ca

Chang, Jeff. 2005. Can't Stop, Won't Stop: A History of the Hip-Hop Generation. New York: Picador.

Clayton, Martin, Trevor Herbert and Richard Middleton. 2012. The Cultural Study of Music: A Critical Introduction. London: Routledge.

CMG, Capitol. 2016, "About Capitol Christian Distribution". Retrieved April 5, 2016, (http://<span lang="EN-US" style="font-size:12.0pt)(mso-bidi-language:AR-

SA">http://www.capitolchristiandistribution.com/about/about_us.aspx\#faq $<$ span lang="EN-US" style="font-size:10.0pt).

Comack, Elizabeth, Lawrence Deane, Jim Silver and Larry Morrissette. 2013. "Indians Wear Red": Colonialism, Resistance, and Aboriginal Street Gangs. Winnipeg: Fernwood Publishing.

Connell, John and Chris Gibson. 2003. Sound Tracks: Popular Music, Identity and Place. New York: Routledge.

Corcoran, Michael. 2012. "He Is My Story: The Sanctified Soul of Arizona Dranes." San Francisco: Tompkins Square.

CTV. 2013, "Bio: Sheila North Wilson", ctv.ca. Retrieved January 28, 2017, (http://winnipeg.ctvnews.ca/sheila-north-wilson-1.1658746). 
Curtis, Bruce. 2014. "Data Provenance, Metadata, and Reflexivity: Comments on Method." Encounters on Education 15:43-61.

2015. "How much and how not to explain: Gestural referencing and conceptual misappropriations." Canadian Journal of Sociology. 40(2): 223-39 . 2017. Personal correspondence. July 17, 2017

Cusic, Don. 2002. "The Development of Gospel Music." Pp. 44-60 in The Cambridge Companion to Blues and Gospel Music, edited by A. Moore. New York: Cambridge University Press.

- 2012 [2002]. Saved by Song: A History of Gospel and Christian Music. Jackson: University of Mississippi Press.

Darden, Robert. 2004. People Get Ready! A New History of Black Gospel Music. New York: Continuum.

Davis, Angela Y. 1998. Blues Legacies and Black Feminism: Gertrude [Sic] "Ma" Rainey, Bessie Smith, and Billie Holiday. New York: Pantheon Books.

DeNora, Tia. 1999. "Music as a Technology of the Self." Poetics 27(1):31-56.

- 2003. After Adorno: Rethinking Music Sociology. Cambridge: Cambridge U Press. . 2004. "Historical Perspectives in Music Sociology." Poetics 32(3):211-21 2010. "Emotion as Social Emergence: Perspectives from Music Sociology." Pp. 159-86 in Handbook of Music and Emotion: Theory, Research, Applications, edited by P. N. Juslin and J. Sloboda. New York: Oxford University Press.

- 2000. Music and Everyday Life. New York: Cambridge U Press. 2014. Making Sense of Reality: Culture and Perception in Everyday Life. Thousand Oaks, CA: Sage.

Denzin, Norman K. and Yvonna S. Lincoln. 2008. "Introduction: Critical Methodologies and Indigenous Inquiry." Pp. 1-20 in Handbook of Critical and Indigenous Methodologies, edited by N. K. Lincoln, Y. S. Lincoln and L. T. Smith. Los Angeles: Sage.

di Giacomo, Michael. 2009. "Pentecostal and Charismatic Christianity in Canada : Its Origins, Development, and Distinct Culture." Pp. 15-38 in Canadian Pentecostalism: Transition and Transformation, edited by M. Wilkinson. Montréal: McGill-Queen's U Press.

Dimitriadis, Greg. 2004. "Hip-Hop: From Live Performance to Mediated Narrative." in That's the Joint: The Hip-Hop Studies Reader, edited by M. Forman and M. A. Neal. New York: Routledge.

DuBois, W.E.B. 2009 [1903]. The Souls of Black Folk. Toronto: Simon \& Schuster Paperbacks. Durkheim, Émile. 1965 [1915]. The Elementary Forms of Religious Life. New York: Free Press.

Dyson, Michael Eric. 2004. "The Culture of Hip-Hop." in The Michael Eric Dyson Reader, edited by M. E. Dyson. New York: Basic Civitas Books.

Einarson, John. 2005. Made in Manitoba: A Musical Legacy. Winnipeg: Great Plains Publications.

Elias, Norbert. 1993. Mozart: Portrait of a Genius. Berkeley, CA: U of California Press.

Epstein, Dena J. 1977. Sinful Tunes and Spirituals: Black Folk Music to the Civil War Urbana: University of Illinois Press.

Eyerman, Ron and Andrew Jamison. 1998. Music and Social Movements: Mobilizing Traditions in the Twentieth Century. New York: Cambridge University Press.

Eyerman, Ron. 2002. Cultural Trauma: Slavery and the Formation of African-American Identity. New York: Cambridge University Press. 2006. "Toward a Meaningful Sociology of the Arts." in Myth, Meaning, and 
Performance: Toward a Cultural Sociology of the Arts, edited by R. Eyerman and L. McCormick. Boulder: Paradigm Publishers.

Faulkner, Robert R. and Howard S. Becker. 2008. "Studying Something You Are a Part Of: The View from the Bandstand." Ethnologie Française 38(1):15-21.

Feld, Stephen and Donald Brenneis. 2004. "Doing Anthropology in Sound." American Ethnologist 31(4):461-74.

Forman, Murray and Mark Anthony Neal. 2004. That's the Joint!: The Hip-Hop Studies Reader. New York: Routledge.

Foucault, Michel. 1977. Discipline and Punish: The Birth of the Prison. New York: Vintage. - 1978. The History of Sexuality: Vol. 1. New York: Vintage. . 1985. The History of Sexuality, Vol. 2: The Use of Pleasure. New York: Vintage 1986. The History of Sexuality, Vol. 3: The Care of the Self. New York: vintage . 1988. "Technologies of the Self." Pp. 16-49 in Technologies of the Self: A Seminar with Michel Foucault., edited by L. H. Martin, H. Gutman and P. H. Hutton. Amherst: The University of Massachusetts Press.

. 1991. "The Ethic of Care for the Self as a Practice of Freedom: An Interview Translated by J.D. Gauthier." in The Final Foucault, edited by J. Bernauer, and David Rasmussen. Cambridge: The MIT Press.

Franklin, Kirk. 2010. The Blueprint: A Plan for Living above Lifes Storms. Toronto: Penguin Books.

2015. "Kirk Franklin Interview at the Breakfast Club Power 105.1 (11/13/2015)." in The Breakfast Club.

Friesen, Renée Joette. 2007. "Fresh I.E. Battles High Suicide Rate: Local Hip-Hop Artist Brings Message of Hope to First Nations Reserves." in Christian Week.

Frith, Simon. 1981. Sound Effects: Youth, Leisure, and the Politics of Rock'n'roll. New York: Pantheon Books. 1989. World Music, Politics, and Social Change: Papers from the International Association for the Study of Popular Music. Manchester: Manchester University Press. . 1996. "Music and Identity." in Questions of Cultural Identity, edited by S. Hall and P. duGay. Thousand Oaks, CA: Sage.

Gates Jr., Henry Louis. 1988 The Signifying Monkey: A Theory of Afro-American Literary Criticism. New York: Oxford University Press.

Gault, Erika. 2013a. "'No Matter What They Think of Me:" Religious Beliefs and Practices of Gospel Rappers in Buffalo, Ny." PhD, American Studies, State University of New York, Buffalo.

. 2013b. "My Soul Knows How to Flow: A Critical Analysis of the History of Urban Black Christian-Themed Rap." in Urban God Talk: Constructing a Hip Hop Spirituality, edited by A. E. Johnson. Lanham, MD: Lexington Books.

George, Nelson. 2004. "Hip-Hop's Founding Fathers Speak the Truth." Pp. 50-63 in The HipHop Studies Reader, edited by M. Forman and M. A. Neal. New York: Routledge. . 1989. "The Death of Rhythm \& Blues.". New York: E.P. Dutton.

Gilroy, Paul. 1993. The Black Atlantic: Modernity and Double Consciousness. Cambridge, MA:: Harvard University Press.

Goffman, Erving. 1961. Asylums: Essays on the Social Situation of Mental Patients and Other Inmates. Garden City, N.Y.: Anchor Books. - 1986. Frame Analysis: An Essay on the Organization of Experience. Boston: 
Northeastern University Press.

1959. The Presentation of Self in Everyday Life. Toronto: Random House.

Goodman, Steve. 2010. Sonic Warfare: Sound, Affect, and the Ecology of Fear. Cambridge, Mass: MIT Press.

Gosa, Travis L. 2015. "The Fifth Element: Knowledge." in The Cambridge Companion to HipHop, edited by J. A. Williams. Cambridge: Cambridge University Press.

Graham, Rod. 2004. "From Prison to Praise." in Calgary Street Talk.

Gray, Ann. 2003. Research Practice for Cultural Studies: Ethnographic Methods and Lived Cultures. Thousand Oaks: Sage.

Gray, Herman. 2005. Cultural Moves: African-Americans and the Politics of Representation. Berkeley: University of California Press.

Grazian, David. 2004. "Opportunities for Ethnography in the Sociology of Music." Poetics 32(34):197-210. 2005. Blue Chicago: The Search for Authenticity in Urban Blues Clubs. Chicago: University of Chicago Press.

Hall, Stuart. 1996 [1993]. "What Is This 'Black' in Black Popular Culture?" Pp. 465-75 in Stuart Hall: Critical Dialogues in Cultural Studies, edited by S. Hall, D. Morley and K.-H. Chan. New York: Routledge.

_. 2002 [1980]. "Race, Articulation, and Societies Structured in Dominance." in Race Critical Theories: Text and Context, edited by P. Essed and D. T. Goldberg. Malden, MA: Blackwell.

Hall, Stuart and Tony Jefferson. 2006 [1976]. Resistance through Rituals: Youth Subcultures in Post-War Britain. New York: Routledge.

Hansen, Kjetil Falkenberg. 2015. "Djs and Turntablism." in The Cambridge Companion to HipHop, edited by J. A. Williams. Cambridge: Cambridge University Press.

Harris, Michael W. 1992. Rise of the Gospel Blues: The Music of Thomas Andrew Dorsey in the Urban Church. Oxford: Oxford University Press.

Hebdige, Dick. 1979. Subculture: The Meaning of Style. New York: Routledge.

Heinich, Nathalie. 2009. "The Sociology of Vocational Prizes: Recognition as Esteem." Theory, Culture \& Society 26(5):85-107.

2012. "Mapping Intermediaries in Contemporary Art According to Pragmatic Sociology.". European Journal of Cultural Studies 15(6):695-702.

Hennion, Antoine. 2007. "Those Things That Hold Us Together: Taste and Sociology." Cultural Sociology 1(1):97-114.

- 2012. "Music and Mediation: Toward a New Sociology of Music " in The Cultural Study of Music: A Critical Introduction, Vol. 2nd, edited by M. Clayton, T. Herbert and R. Middleton. New York: Routledge.

Henoux, Devin. 2016. "Northern Saskatchewan Communities in Shock as 4th Girl Takes Own Life." in $C B C$. cbc.ca.

Hesmondhalgh, David. 2008. "Towards a Critical Understanding of Music, Emotion, and SelfIdentity." Consumption, Markets \& Culture 11(4):329-43.

Hibbett, Ryan. 2005. "What Is Indie Rock?". Popular Music \& Society. 28(1):55-77.

Howard, Jay R. and John M. Streck. 1999. Apostles of Rock: The Splintered World of Contemporary Christian Music. Lexington: University Press of Kentucky.

Insanul, Ahmed. 2014. "24 Rappers Who Have 4 Fewer Grammys Than Macklemore." Complex. Jasen, Paul. 2016. Low End Theory: Bass, Bodies and the Materiality of Sonic Experience. New 
York: Bloomsbury Academic.

Joas, Hans. 2005. "Cultural Trauma?: On the Most Recent Turn in Jeffrey Alexander's Cultural Sociology." European Journal of Social Theory 8(3):365-74.

Johnson, Andre E. 2013. Urban God Talk: Constructing a Hip-Hop Spirituality. Lanham, MD: Lexington Books.

Johnson, Imani Kai. 2015. "Hip-Hop Dance." in The Cambridge Companion to Hip-Hop, edited by J. A. Williams. Cambridge: Cambridge University Press.

Jones, Keith. 2005. "Music in Factories: A Twentieth-Century Technique for Control of the Productive Self." Social \& Cultural Geography 6(5):723-44.

Jones [Baraka, Amiri], Leroi. 1963. Blues People: Negro Music in America. Toronto: HarperPerennial.

Jonna, Jamil R. and John Bellamy Foster. 2016. "Marx's Theory of Working-Class Precariousness: Its Relevance Today." Monthly Review 67(11):1-19.

Ju, Shirley. 2014. "The Five Percent Nation: A Brief History Lesson." Retrieved: May 11, 2016 (http://www.hotnewhiphop.com/the-five-percent-nation-a-brief-history-lessonnews.11319.html?).

Keyes, Cheryl L. 2002. Rap Music and Street Consciousness.: Urbana: University of Illinois Press.

Khabeer, Su'ad Abdul. 2016. Muslim Cool: Race, Religion, and Hip Hop in the United States. New York: NYU Press.

King, Martin Luther. ed. 1963. Martin Luther King Jr. Delivers His "I Have a Dream" Speech Ca. 1963. Films on Demand: The WPL Film Library.

Kirk-Duggan, Cheryl A. and Marlon Hall. 2011. Wake Up!: Hip-Hop, Christianity, and the Black Church. Nashville: Abingdon Press.

Kives, Bartley. 2004. "The Faith and the Fury: After Leaving a Life of Crime, Reborn Christian Rapper Fresh I.E. Says His Grammy Nomination Is a Gift from God." in Winnipeg Free Press.

Klassen, Aaron J. 2012. "Notating Indie Culture: Aesthetics of Authenticity." M.A., Sociology, University of Manitoba, Winnipeg.

Koopman, Colin. 2013. "Foucault's Reconstruction of Modern Moralities: An ethics of selftransformation." In Genealogy as Critique: Foucault and the problems of modernity. Bloomington: Indiana University Press

Kot, Greg. 2014. I'll Take You There: Mavis Staples, the Staple Singers, and the March up Freedom's Highway. Toronto: Scribner.

Krahn, Leona [Director] K. C. Absurd Machine Films [Producer]. 2009. Beyond the Beat.

Kumanyika, Chenjerai and C. Michael Elavsky. 2013. "Microphone Czech, Keepin' It Real: Politics of Creative Strategy in Cross-Cultural Music Production." Popular Communication 11(3): 257-71.

Lamont, Michele, and Virag Molnar. 2002. "The study of boundaries in the social sciences". Annual Review of Sociology 28 : 167-95.

Laslett, Barbara. 1991. "Biography as Historical Sociology: The Case of William Fielding Ogburn." Theory and Society 20(4): 511-38.

Leo, Christopher. 2010. "Should Youth for Christ Be Involved in Governance? How About the United Church or New Life Ministries?". Research-based analysis and commentary. Retrieved 2017 (https://christopherleo.com/2010/06/21/should-youth-for-christ-beinvolved-in-governance-how-about-the-united-church-or-new-life-ministries/). 
Lett, Dan. 2010. "Controversy Opened Old Wounds: Political Process Pitted Christians against Aboriginals." in Winnipeg Free Press. Winnipeg.

Levasseur, Joanne. 2014. "Youth for Christ Broke Promises, Not Supporting Community, Advocates Say." in $C B C$ News. cbc.ca.

Lewis, George. 1996. "Improvised Music after 1950: Afrological and Eurological Perspectives." Black Music Research Journal 16(1):91-122.

Lewis, Harold MacLean. 1963. Planning the Modern City., Vol. One. New York: John Wiley \& Sons, Inc.

Lockhart, Teresa. 2004. "Fresh Faith Raps It Up." in Ring light news.

Lott, Eric. 1993. Love \& Theft: Blackface Minstrelsy and the American Working Class. New York: Oxford University Press.

Marley, Karin. 2016. "Majority of Indigenous Canadians Remain Christians Despite Residential Schools." in The Current. cbc.ca.

Martin, Rux. 1988. "Truth, Power, Self: An Interview with Michel Foucault." Pp. 9-15 in Technologies of the Self: A Seminar with Michel Foucault. Amherst: The University of Massachusetts Press.

McCormick, Lisa. 2006. "Music and Social Performance." Pp. 121-44 in Myth, Meaning, and Performance: Toward a Cultural Sociology of the Arts, edited by R. Eyerman and L. McCormick. Boulder, CO: Paradigm Publishers.

McRobbie, Angela and Jenny Garber. 2006. "Girls and Subcultures." Pp. 177-88 in Resistance through Rituals, edited by S. Hall and A. Jefferson. New York: Routledge.

Merleau-Ponty, Maurice. 2012 [1945]. Phenomenology of Perception. New York: Routledge. Miller, Monica R. 2013. Religion and Hip-Hop. New York Routledge.

Moore, Allan, ed. 2002. The Cambridge Companion to Blues and Gospel Music. New York: Cambridge University Press.

Moore, Lecrae. 2014. "Good, Bad, Ugly." in Anomaly: Reach Records.

- July 2014. "Rapper Lecrae on Racism, Homosexuality, and America's Culture." Retrieved April 4, 2016 (https://www.youtube.com/watch?v=Yli3tY8gdhM).

Moran, Ry. 2016. "Truth and Reconciliation Commission." The Canadian Encyclopedia. (http://www.thecanadianencyclopedia.ca/en/article/truth-and-reconciliationcommission/).

Neal, Mark Anthony. 1999. What the Music Said: Black Popular Music and Black Popular Culture. New York: Routledge.

Negus, Keith. 2004. "The Business of Rap: Between the Street and the Executive Suite." in That's the Joint: The Hip-Hop Studies Reader, edited by M. Forman and M. A. Neal. New York: Routledge.

Newman, Michael Z. 2009. "Indie Culture: In Pursuit of the Authentic Autonomous Alternative.". Cinema Journal. 48(3):16-34.

Nielson. 2017. "2016 U.S. Music Year-End Report." Retrieved: February 1, 2017 (http://www.nielsen.com/us/en/insights/reports/2017/2016-music-us-yearendreport.html).

Northup, Solomon. 2012 [1853]. Twenty Years a Slave. Toronto: Penguin Books.

Oliver, Paul, Max Harrison and William Bolcom. 1986. "Gospel, Blues and Jazz with Spirituals and Ragtime." in The New Grove. New York: W.W. Norton \& Company.

One, KRS. 2017. "The Temple of Hip Hop." Retrieved June 20, 2017 (https://thetempleofhiphop.wordpress.com). 
Ostick, Stephen. 1990.-a. "Rap Superstars Kill Stereotypes: 3000 Fans Welcome Duo’s Childlike Act." in Winnipeg Free Press.

1990.-b. "Rap: Anomaly of the Music Business Has Been around the City for Years." in Winnipeg Free Press.

Perkinson, James W. 2013. "Somewhere Underneath the Mc's Wit and the Evangelical Word: Toward a Christian Ethical Evaluation of Hip Hop Polemic." Pp. 1-18 in Urban God Talk: Constructing a Hip Hop Spirituality, edited by A. Johnson. Toronto: Lexington Books.

Peterson, Richard A. and Roger M. Kern. 1996. "Changing Highbrow Taste: From Snob to Omnivore." American Sociological Review 61(5):900-7.

Peterson, Richard A. 1999 Creating Country Music: Fabricating Authenticity. Chicago: University of Chicago Press.

. 2005. "In Search of Authenticity." Journal of Management Studies 42:1083-98.

Pinn, Anthony B. 2003. Noise and Spirit: The Religious and Spiritual Sensibilities of Rap Music. New York: NYU Press.

Pinsky, Mark I. 2004 [1997]. "On a String and a Prayer: In Nation after Nation Religion Has Taken on a Role as the Primary Force for Political Change." Pp. 151-3 in Talking Points on Global Issues: A Reader, edited by R. H. Robbins. Toronto: Pearson.

Prior, Nick. 2011. "Critique and Renewal in the Sociology of Music: Bourdieu and Beyond." Cultural Sociology 5(1):121-38.

Radano, Ronald. 2012. "Music, Race, and the Fields of Public Culture." Pp. 308-16 in The Cultural Study of Music, edited by M. Clayton, T. Herbert and R. Middleton. New York: Routledge.

Reconciliation, Canada's residential schools : the final report of the Truth and Reconciliation Commission of Canada : Volume 6 :. 2015. "Canada's Residential Schools: Vol. 6: Reconciliation." Vol. Kingston, ON: McGill-Queen's UP.

Reiff, Corbin. 2015. "These Are the Breaks: 10 of the Most Sampled Drum Beats in Music History." (http://www.avclub.com/article/these-are-breaks-10-most-sampled-drum-beatsmusic--222885).

Rose, Tricia. 1994. Black Noise: Rap Music and Black Culture in Contemporary America. Hanover, NH: Wesleyan University Press.

Roy, William G. 2004. ""Race Records" And "Hillbilly Music": Institutional Origins of Racial Categories in the American Commercial Recording Industry." Poetics 32:265-79.

Roy, William G. and Timothy J. Dowd. 2010. "What Is Sociological About Music?". Annual Review of Sociology 36(1):183-203.

Schwartz, Daniel. 2015a. "Truth and Reconciliation Commission: By the Numbers." in $C B C$. cbc.com.

. 2015b. "Cultural Genocide Label for Residential Schools Has No Legal Implications, Expert Says." in $C B C$. cbc.ca.

- 2015. "Truth and Reconciliation Commission: By the Numbers." in $C B C$. cbc.ca.

Shellnut, Kate. 2015. "Why Grammy Winner Lecrae Will Never Dominate the Gospel Charts Again." Christianity Today. Retrieved: April 5, 2016

(http://www.christianitytoday.com/gleanings/2015/february/why-grammy-nominatedlecrae-never-dominate-gospel-charts.html).

Shepherd, John and Peter. Wicke. 1997. Music \& Cultural Theory. Malden, MA: Polity. Shepherd, John. 2012. "Music and Social Categories." Pp. 239-48 in The Cultural Study of 
Music: A Critical Introduction, edited by M. Clayton, T. Herbert and R. Middleton. New York: Routledge.

. 1993. "Value and Power in Music: An English Canadian Perspective." Pp. 171-206 in Relocating Cultural Studies: Developments in Theory and Research, edited by V. Blundell, J. Shepherd and I. Taylor. New York: Routledge.

Shepherd, John and Kyle Devine. 2015. "Introduction: Music and the Sociological Imagination Pasts and Prospects." Pp. 1-22. In The Routledge Reader on the Sociology of Music. New York: Routledge

. 2016. "Beyond Text and Context: The material power of music." Paper presented at Humboldt University, Berlin. February 7, 2016

Shulman, David and Guy G. Stroumsa. 2002. "Introduction: Persons, Passages, and Shifting Cultural Space." Pp. 3-18. In Self and Self-Transformation in the History of Religion. Oxford: Oxford University Press.

Silva, José. 2010. "Music as a vehicle for self-transformation: An organic inquiry into the experience of Rita Lee's songs." Phd. Dissertation. California Institute of Integral Studies, San Francisco

Silver, Jim. 2006. "North End Winnipeg's Lord Selkirk Housing Development: History, Comparative Context, Prospects." Vol. Winnipeg: Canadian Centre for Policy Alternatives, Manitoba Office.

Small, Christopher. 1998. Musicking: The Meanings of Performing and Listening. Hanover, NH: University Press of New England.

Snape, Dawn and Liz Spencer. 2003. "The Foundations of Qualitative Research." Pp. 1-23 in Qualitative Research Practice: A Guide for Social Science Students and Researchers. Los Angeles: Sage.

Southern, Eileen. 1971. The Music of Black Americans: A History. New York: W.W. Norton.

Statscan. 2011. National Household Survey: Data Tables -- Profile - Immigration and Ethnocultural Diversity, and Aboriginal PeoplesCongress, (http://www12.statcan.gc.ca/nhs-enm/2011/dp-pd/dt-td/Rpeng.cfm?APATH $=3 \& D E T A I L=0 \& D I M=0 \& F L=A \& F R E E=0 \& \mathrm{GC}=0 \& \mathrm{GID}=0 \& \mathrm{GK}=0 \&$ $\mathrm{GRP}=0 \& \mathrm{LANG}=\mathrm{E} \& \mathrm{PID}=105540 \& \mathrm{PRID}=0 \& \mathrm{PTYPE}=105276 \& \mathrm{~S}=0 \& \mathrm{SHOWALL}=0 \& \mathrm{~S}$ $\mathrm{UB}=0 \& \mathrm{THEME}=95 \& \mathrm{Temporal}=2013 \& \mathrm{VID}=0 \& \mathrm{VNAMEE}=\& \mathrm{VNAMEF}=)$.

- 2016. Lifetime Suicidal Thoughts among First Nations Living Off Reserve, Métis and Inuit Aged 26 to 59: Prevalence and Associated CharacteristicsCongress. Aboriginal Peoples survey 2012 (http://www.statcan.gc.ca/pub/89-653-x/89-653-x2016008eng.htm).

Sterne, Jonathan. 1997. "Sounds Like the Mall of America: Programmed Music and the Architectonics of Commercial Space." Ethnomusicology 41(1):22-50. . 2012. Mp3: The Meaning of a Format. Durham: Duke University Press.

Stowe, David W. 2011. No Sympathy for the Devil: Christian Pop Music and the Transformation of American Evangelicalism. Chapel Hill: University of North Carolina.

Straw, Will. 2010. "Cultural Production and the Generative Matrix: A Response to Georgina Born." Cultural Sociology 4(2). 1991. "Systems of Articulation, Logics of Change: Communities and Scenes in Popular Music." Cultural Studies 5(3):368-88.

Sumrall, Lester. 1995. Pioneers of Faith. Tulsa, OK: Harrison House.

Szakolczai, Arpad. 1998. "Reflexive Historical Sociology." European Journal of Social Theory 
1(2):209-27.

2000. Reflexive Historical Sociology. New York: Routledge.

Taylor, Charles. 1991. The Malaise of Modernity. Toronto: Anansi.

Tharpe, Sister Rosetta. 1941. "Rock Me." edited by T. A. Dorsey.

Thornton, Sarah. 1996. Club Cultures: Music, Media, and Subcultural Capital. Hanover: University Press of New England.

Tomaselli, Keyan G., Lauren Dyll and Michael Francis. 2008. "Autoethnography Is Queer." Pp. 347-72 in Handbook of Critical and Indigenous Methodologies, edited by N. K. Denzin, Y. Lincoln and L. T. Smith. Los Angeles: Sage.

Toop, David. 1984. The Rap Attack: African Jive to New York Hip-Hop. Boston: South End Press.

Tracy, Steve. 2002. "'Black Twice": Performance Conditions for Blues and Gospel Artists." Pp. 89-101 in The Cambridge Companion to Blues and Gospel Music, edited by A. Moore. New York: Cambridge University Press.

Turner, Ralph. 1976 "The Real Self: From Institution to Impulse." The American Journal of Sociology 81:989-1016.

Wacquant, Loïc. 2004. Body \& Soul: Notebooks of an Apprentice Boxer. Oxford: Oxford U Press.

Wald, Gayle. F. 2007. Shout, Sister, Shout! The Untold Story of Rock-and-Roll Trailblazer Sister Rosetta Tharpe. Boston: Beacon Press.

Walton, Jonathan L. 2010. "The Preachers' Blues: Religious Race Records and Claims of Authority on Wax." Religion and American Culture: A Journal of Interpretation 20(2):205-32.

Warren, Rick. 2002. The Purpose Driven Life: What on Earth Am I Here For? Grand Rapids, MI: Zondervan.

Weber, Max, Hans Gerth and C. Wright Mills. 1946. From Max Weber: Essays in Sociology. New York: Oxford University Press.

Weber, Max. 1976. The Protestant Ethic and the Spirit of Capitalism. New York: George Allen \& Unwin Ltd. 1993. The Sociology of Religion. Boston: Beacon Press

Weekes, Melinda E. 2005. "This House, This Music: Exploring the Interdependent Interpretive Relationship between the Contemporary Black Church and Contemporary Gospel Music." Black Music Research Journal 25(1/2):43-72.

Weis, Gary [Director]. Year. 80 Blocks from Tiffany's.

Western, Jenny. 2003. "Rapper Ministers from the Heart." in CC Manitoba.

Whitaker, Lang. 2014. "Christian Rapper Lecrae on Hip-Hop's 'Inconsistency' and Ferguson ". (http://www.billboard.com/articles/news/6251372/christian-rapper-lecrae).

Williams, Justin A. 2015. "Introduction: The Interdisciplinary World of Hip-Hop Studies." Pp. 110 in The Cambridge Companion to Hip-Hop, edited by J. A. Williams. Cambridge: Cambridge University Press.

Williams, Rob. 2003. "Soul Power: Spreading the Gospel Leas to Grammy Nod for Hip-Hopper Fresh I.E." in Winnipeg Sun. 2006. "Grammy Faith-Off." in Winnipeg Free Press.

Yanovich, David. 2008. "Address Racial Profiling: Suspicion, Stereotyping Tend to Foster More of the Same." in Winnipeg Free Press.

Zanfagna, Christina. 2010. "Holy Hip Hop in the City of Angels: Music, Urban Space, and the 
Politics of Conversion." PhD, Ethnomusicology, UCLA, Los Angeles. . 2012. "Kingdom Business: Holy Hip Hop's Evangelical Hustle." Journal of Popular Music Studies 24(2):196-216.

- 2015. "Hip-Hop and Religion: From the Mosque to the Church." in The Cambridge Companion to Hip-Hop, edited by J. A. Williams. Cambridge: Cambridge University Press.

\section{Select Discography}

2Pac. 1995. "So Many Tears." in Me Against the World: BMI.

Delirious? 1995. "I found Jesus". In Cutting Edge: Furious?

Elevation Worship. 2014. "The King is Among Us." In Wake up the Wonder.: Sony Music. Franklin, Kirk. 2015. "Losing My Religion." in Losing my Religion.: Fo Yo Soul Recordings; RCA

Fresh I.E. 1999. In Resurrection: Return of the living dead. Winnipeg: Independent.

- 2000. "Free". In 28:3. Winnipeg: Verb Records.

- 2003. Red Letterz.: Red Sea.

- 2005. Truth is Fallin' in Tha Streetz: Red Sea.

- 2012. City of Worship: Independent.

—. 2014. Red Letterz 13 Live. DVD. Winnipeg: www.fresh-ie.ca. 2015. Collide: City of Worship 2: Convurgent Records.

Grandmaster Flash \& The Furious Five. 1983. "The Message.” Sugarhill Records.

Jackson, Michael. 1983. Thriller.: Sony Music.

Johnson, Gord. 2012. "Everything We Need." in City of Worship., Vol. 1. Winnipeg.

Moore, Lecrae. 2014. Good, Bad, Ugly. In Anomaly: Reach Records.

Prince. 1982. "Free". In 1999. Warner Bros.

The Sugarhill Gang. 1979. Rapper's Delight. New York: Sugarhill Records.

Tharpe, Sister Rosetta. 1941. "Rock Me.” Decca Records.

Wiley, Stephen. 1985. "Bible Break." Brentwood Contemporary. 